UNIVERSIDADE DE SÃO PAULO

ESCOLA DE ENGENHARIA DE SÃO CARLOS

DEPARTAMENTO DE ENGENHARIA DE ESTRUTURAS

\title{
ANÁLISE DO PROJETO DE ESTRUTURAS METÁLICAS ESPACIAIS: ÊNFASE EM COBERTURAS
}

ARNALDO NASCIMENTO DE SOUZA

Dissertação apresentada à Escola de Engenharia de São Carlos da Universidade de São Paulo, como parte dos requisitos para obtenção do Título de Mestre em Engenharia de Estruturas.

ORIENTADOR: Prof. Dr. Maximiliano Malite 
Aos meus pais, Arnaldo e Berenice.

À minha esposa, Mônica. 


\section{AGRADECIMENTOS}

Ao Professor Maximiliano Malite, pela orientação, amizade e incentivo desde o período da graduação.

Aos professores Roberto Martins Gonçalves e José Jairo de Sáles pela atenção e amizade.

Aos demais professores e funcionários do Departamento de Estruturas, pela presteza demonstrada nos momentos de necessidade.

Aos engenheiros Francisco Salum e Sérgio Teruya, pelos ensinamentos passados sobre as treliças espaciais. 


\section{SUMÁRIO}

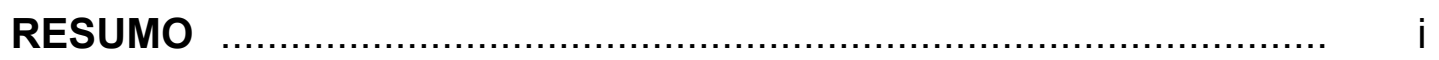

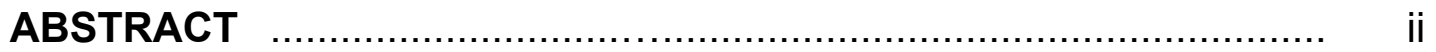

DEFINIÇÕES ……........................................................... ii

LISTA DE FIGURAS …........................................................... iv

LISTA DE TABELAS

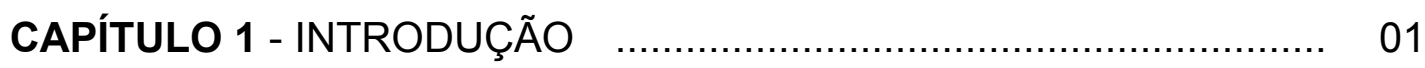

CAPÍTULO 2 - REVISÃO BIBLIOGRÁFICA ….................................. 05

2.1. Generalidade e história ….............................................. 05

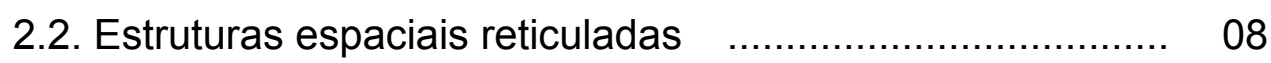

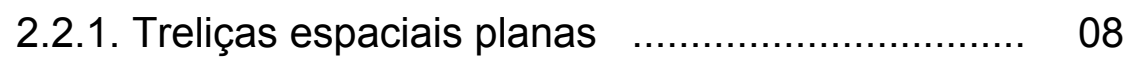

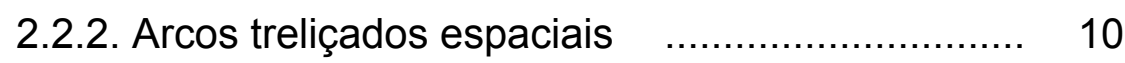

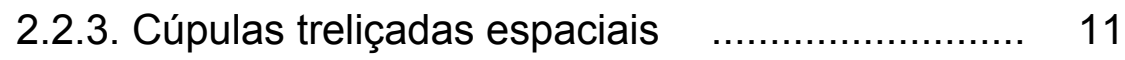

2.3. Sistemas de treliças espaciais ...................................... 12

2.3.1. Sistemas utilizados no Brasil ........................ 18

2.4. Análise estrutural de treliças espaciais …..................... 26

2.5. Comportamento estrutural de treliças espaciais $\quad . . . . . . . . . . . . \quad 30$

2.5.1. Comprimento de flambagem das barras $\quad \ldots \quad 30$

2.5.2. Comportamento dos elementos e do conjunto .. 31

2.5.3. Ruína estrutural …….................................... 33

2.6. Aspectos relativos ao projeto de treliças espaciais ......... 36

2.6.1. Apoios ................................................... 36

2.6.2. Arranjo geométrico ………............................ 39

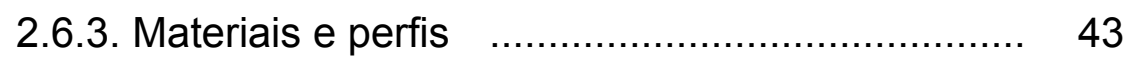

2.6.4. Conexões ...................................................... 44

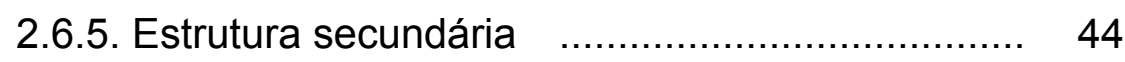

2.6.6. Elementos de vedação ..................................... 48

2.7. Ações consideradas no projeto …….............................. 50

2.7.1. Ações permanentes ...................................... 50 
2.7.2. Ações variáveis $\quad$.............................................. 51

2.8. Normas aplicáveis $\quad$..................................................... 59

2.9. Descrição de algumas obras .......................................... 60

2.9.1. Centro de Exposições Anhembi $\quad$...................... $\quad 60$

2.9.2. Cobertura Estádio Mané Garrincha ….............. 62

2.9.3. Complexo Industrial de Jacarepaguá $\quad$.............. 63

2.9.4. Hangar de Manutenção - Índia $\quad$........................ 64

2.9.5. Hangar de Manutenção - China $\quad$...................... 66

2.9.6. Centro de Convenções Associação Árvore da Vida ............................................... 68

\section{CAPÍTULO 3 - ANÁLISE NUMÉRICA DOS ARRANJOS}

ESTRUTURAIS PROPOSTOS …............................ 69

3.1. Esquema geral das edificações analisadas $\quad$..................... 69

3.2. Determinação das ações $\quad$............................................. 72

3.2.1. Ações permanentes ...................................... 72

3.2.2. Ações variáveis ............................................. 72

3.3. Arranjos estruturais propostos …................................... 76

3.3.1. Arranjos estruturais com planta quadrada $\quad$........ 76

3.3.2. Arranjos estruturais com planta retangular $\quad$...... 94

3.4. Processamento das estruturas ….............................. 101

3.4.1. Combinações de ações ….............................. 101

3.4.2. Perfis utilizados …....................................... 102

3.4.3. Procedimentos ............................................... 103

CAPÍTULO 4 - RESULTADOS E DISCUSSÕES …............................. 105

4.1. Quantidade de nós e barras …...................................... 105

4.2. Consumo de material ….............................................. 108

4.3. Deslocamentos ............................................................... 115

4.4. Reações de apoio .......................................................... 120

4.5. Esforços internos …....................................................... 123 
CAPÍTULO 5 - COMENTÁRIOS E CONCLUSÕES

REFERÊNCIAS BIBLIOGRÁFICAS 


\section{RESUMO}

SOUZA, A.N. Análise do projeto de estruturas metálicas espaciais: ênfase em coberturas. São Carlos, 2002. Dissertação (Mestrado) - Escola de Engenharia de São Carlos, Universidade de São Paulo.

As estruturas metálicas espaciais de cobertura apresentam aspectos diferenciados de projeto. Existem diversos arranjos geométricos possíveis para estas estruturas, cuja escolha está associada, entre outros fatores, às formas e dimensões do contorno, aos pontos de apoio e aos sistemas de conexões empregados. Neste trabalho foi analisado o projeto destas estruturas, abordando os aspectos históricos, os sistemas de ligação, o comportamento estrutural, as particularidades de projeto, e realizando uma análise numérica de diferentes arranjos geométricos. Foram analisados 27 arranjos geométricos quadrados $(66 \mathrm{~m} \times 66 \mathrm{~m})$ e 6 arranjos geométricos retangulares $(186 \mathrm{~m} \times 66 \mathrm{~m})$, todos com vãos centrais de $60 \mathrm{~m}$, e com variações na quantidade e posicionamento dos apoios, na disposição das barras do reticulado, na altura e nas dimensões dos módulos. Adotou-se o modelo de treliça ideal em análise elástica linear (teoria de primeira ordem). Com os resultados dos processamentos realizou-se uma comparação entre os modelos, abrangendo os seguintes aspectos: quantidade de nós e barras, consumo de material, deslocamentos máximos, reações de apoio máximas e esforços internos máximos. O fator que causou maior influência no comportamento dos arranjos analisados foi a disposição dos apoios.

Palavras-chave: estruturas metálicas, estruturas espaciais, treliças espaciais, arranjos tridimensionais, projeto de coberturas. 


\section{ABSTRACT}

SOUZA, A.N. Analysis of design of space steel structures: emphasis in roofs. São Carlos, 2002. Dissertação (Mestrado) - Escola de Engenharia de São Carlos, Universidade de São Paulo.

The roofing space steel structures have differentiated aspects of design. There are many types of arrangements to these structures, and the choice is associate, among other factors, with the shapes e dimensions of the boundary, with the points of support and with the connection systems employed. In this work was analysed the design of these structures, including the historical aspects, the connection systems, the structural behaviour, the particulars aspects of the design, and a numerical analysis of differents arrangements. Twenty seven square structures $(66 \mathrm{~m} \times 66 \mathrm{~m})$ and six rectangular structures $(186 \mathrm{~m} \times 66 \mathrm{~m})$ were analysed, all them with $60 \mathrm{~m}$ span, and variations in the amount and position of supports, in the member arrangement, in the depth and in the node spacing. These structures were analysed adopting the ideal truss model with elastic linear behaviour. With the results were made a comparison between the arrangements that reports these aspects: amount of nodes and members, material consumption, displacements, support reactions and internal forces. The factor that caused the biggest influence in the behaviour of the space structures analysed was the amount and position of supports.

Keywords: metal structures, space structures, space trusses, threedimensional arrangement, design of roofs. 


\section{LISTA DE DEFINIÇÕES}

1. Reticulado tridimensional: estrutura linear cujas barras estão dispostas em planos diversos.

2. Treliça espacial: reticulado tridimensional formado por um ou mais reticulados dispostos em camadas, chamados de banzos, que são interligados por outras barras, chamadas diagonais, não caracterizando um plano principal para as barras que compõem a estrutura.

3. Treliça espacial plana: treliça espacial formada por duas ou mais camadas planas e paralelas de banzos.

4. Arco treliçado espacial: treliça espacial formada por uma ou mais camadas de banzos em forma de abóbada (casca de curvatura simples).

5. Cúpula treliçada espacial: treliça espacial formada por uma ou mais camadas de banzos em forma de cúpula (casca de dupla curvatura). 


\section{LISTA DE FIGURAS}

Figura 2.1 - Estrutura espacial reticulada de Alexander Graham Bell................................................................. 06

Figura 2.2 - Sistema desenvolvido pela MERO.................................... 06

Figura 2.3 - Deslocamentos ao longo da seção BB da estrutura com planta quadrada.

08

Figura 2.4 - Modelos de reticulados com uma camada ........................ 09

Figura 2.5 - Modelos de reticulados com duas camadas de banzos..... 10

Figura 2.6 - Estruturas com reticulados quadrado sobre quadrado........ 10

Figura 2.7 - Cobertura em arco treliçado espacial................................. 11

Figura 2.8 - Cobertura em cúpula treliçada espacial............................. 11

Figura 2.9 - Sistema OMNI-HUB ................................................... 13

Figura 2.10 - Sistema GEO-HUB.................................................... 13

Figura 2.11 - Sistema TRIODETIC ............................................... 14

Figura 2.12 - Sistema MERO.......................................................... 14

Figura 2.13 - Sistema NODUS................................................... 15

Figura 2.14 - Sistema UNISTRUT................................................... 15

Figura 2.15 - Sistema OKTAPLATTE........................................... 16

Figura 2.16 - Sistema UNIBAT.................................................... 16

Figura 2.17 - Sistema VESTRUT..................................................... 17

Figura 2.18 - Sistema CATRUS....................................................... 17

Figura 2.19 - Sistema de nó típico ou nó "amassado".......................... 18

Figura 2.20 - Protótipo com nó típico................................................. 19

Figura 2.21 - Ruína do protótipo com nós típicos................................. 20

Figura 2.22 - Análise numérica tridimensional dos nós típicos............... 21

Figura 2.23 - Sistema de nó típico com chapa de banzo....................... 22

Figura 2.24 - Sistema de nó típico com chapa de diagonal.................... 22

Figura 2.25 - Sistemas de nó de aço................................................ 23

Figura 2.26 - Ruína do protótipo com nós de aço.................................. 24

Figura 2.27 - Sistemas de nós de aço com barras com ponteiras......... $\quad 25$

Figura 2.28 - Deslocamentos verticais dos protótipos ensaiados.......... 26 
Figura 2.29 - Relação Tensão x Deformação................................. 29

Figura 2.30 - Treliça espacial plana apoiada nos quatro vértices.......... 34

Figura 2.31 - Formação de um mecanismo de ruína na treliça............. 34

Figura 2.32 - Apoio no banzo inferior...................................... 37

Figura 2.33 - Apoio no banzo superior................................... 38

Figura 2.34 - Apoio do tipo "pé-de-galinha" ................................... 38

Figura 2.35 - Apoio do tipo "engaste" ......................................... 39

Figura 2.36 - Arranjo quadrado sobre quadrado............................ 41

Figura 2.37 - Arranjo quadrado diagonal sobre quadrado diagonal....... 41

Figura 2.38 - Arranjo quadrado sobre quadrado diagonal.................. 42

Figura 2.39 - Elementos da estrutura secundária para suporte das telhas de cobertura e fechamento.............................. 45

Figura 2.40 - Elementos da estrutura secundária para captação das águas pluviais - calha no alinhamento do banzo superior

Figura 2.41 - Elementos da estrutura secundária para captação das águas pluviais - calha fora do alinhamento do banzo superior

Figura 2.42 - Telhas Metálicas - Perfis Ondulados e Trapezoidais....... 48

Figura 2.43 - Isolamentos térmicos com espuma de poliuretano e lã de vidro/rocha.

Figura 2.44 - Fixações com parafuso, gancho e suporte móvel.

Figura 2.45 - Coeficientes de pressão e de forma, externos, para telhados múltiplos, simétricos, de tramos iguais, com $h \leq a^{\prime}$

Figura 2.46 - Coeficientes de pressão e de forma, externos, para paredes de edificações de planta retangular

Figura 2.47 - Coeficientes de pressão e de forma, externos, para balanços e marquises.

Figura 2.48 - Esquema geral da cobertura analisada em túnel de vento.

Figura 2.49 - Coeficientes de forma do modelo - vento longitudinal 
Figura 2.50 - Coeficientes de forma do modelo - vento transversal....... 58

Figura 2.51 - Vista Externa- Centro de Exposições Anhembi............... 60

Figura 2.52 - Planta dos apoios - Centro de Exposições Anhembi...... 61

Figura 2.53 - Vista dos apoios e da treliça - Centro de Exposições

Anhembi........................................................... 61

Figura 2.54 - Cobertura Estádio Mané Garrincha.......................... 63

Figura 2.55 - Vistas Externa e Interna - Complexo Industrial de Jacarepaguá...................................................... 64

Figura 2.56 - Hangar de Manutenção - Mumbai / Índia....................... 65

Figura 2.57 - Planta baixa e corte - Hangar de Manutenção Mumbai / Índia..................................................... 65

Figura 2.58 - Hangar de manutenção - Beijing / China...................... 67

Figura 2.59 - Planta baixa e corte - Hangar de manutenção Beijing / China...................................................... 67

Figura 2.60 - Centro de Convenções Associação Árvore da Vida......... 68

Figura 2.61 - Modelo tridimensional da estrutura - Centro de

Convenções Associação Árvore da Vida. 68

Figura 3.1 - Galpão com planta quadrada e pilares a cada 60 m......... 70

Figura 3.2 - Galpão com planta quadrada e pilares a cada 30 m......... 70

Figura 3.3 - Galpão com planta retangular e pilares a cada 60 m......... 71

Figura 3.4 - Galpão com planta retangular e pilares a cada 30 m......... 71

Figura 3.5 - Coeficientes de forma externos (Ce) - Galpões com planta quadrada.

Figura 3.6 - Coeficientes de forma externos (Ce) - Galpões com planta retangular.

Figura 3.7 - Arranjo estrutural 1A............................................ 77

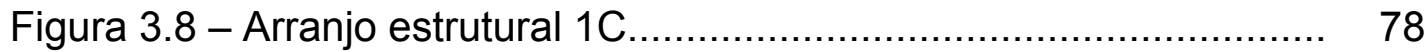

Figura 3.9 - Arranjo estrutural 1D ................................................. 79

Figura 3.10 - Arranjo estrutural 2A........................................ 80

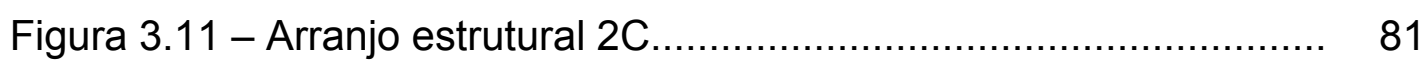

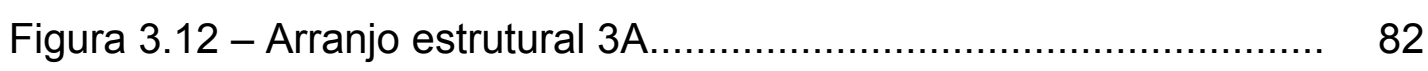

Figura 3.13 - Arranjo estrutural 3 C........................................... 83 
Figura 3.14 - Arranjo estrutural 4A........................................ 84

Figura 3.15 - Arranjo estrutural 4 C........................................ 85

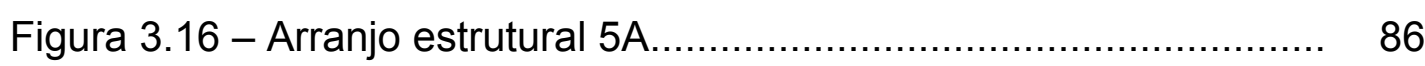

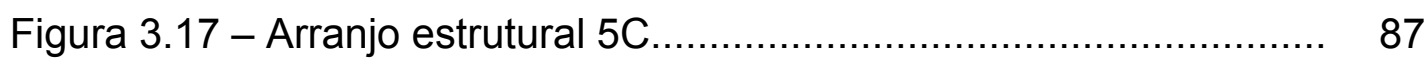

Figura 3.18 - Arranjo estrutural 6 A ........................................... 88

Figura 3.19 - Arranjo estrutural 6 C............................................. 89

Figura 3.20 - Arranjo estrutural 7A.......................................... 90

Figura 3.21 - Arranjo estrutural 7C - Apoio do tipo "engaste".............. 91

Figura 3.22 - Arranjo estrutural 8 A........................................... 93

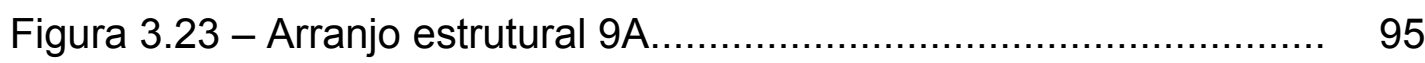

Figura 3.24 - Arranjo estrutural 9 C.......................................... 96

Figura 3.25 - Arranjo estrutural 10A..................................... 97

Figura 4.1 - Consumo de material por unidade de área -

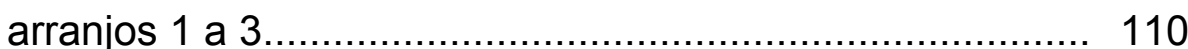

Figura 4.2 - Consumo de material por unidade de área arranjos 4, 5 e 6 .

Figura 4.3 - Consumo de material por unidade de área arranjos $1,7,8$ e 9

Figura 4.4 - Consumo de material por unidade de área arranjos 4 e 10.

Figura 4.5 - Deslocamento vertical - arranjos 1, 2 e 3....................... 116

Figura 4.6 - Deslocamento vertical - arranjos 4, 5 e $6 \ldots \ldots \ldots \ldots \ldots \ldots \ldots \ldots 117$

Figura 4.7 - Deslocamento vertical - arranjos 1, 7, 8 e $9 \ldots \ldots \ldots \ldots \ldots \ldots \ldots . \ldots 118$

Figura 4.8 - Configurações deslocadas - arranjos 1B, 4B, 7B, 8C, 9B e 10B.................................. 119

Figura 4.9 - Máximas reações de apoio verticais - R-FZ .................... 122

Figura 4.10 - Máximas reações de apoio de momentos

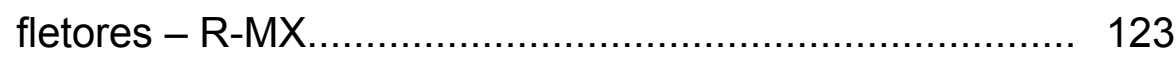

Figura 4.11 - Diagramas de esforços normais - Arranjo 1B............... 127

Figura 4.12 - Diagramas de esforços normais - Arranjo 2B............... 128

Figura 4.13 - Diagramas de esforços normais - Arranjo 3B............... 129

Figura 4.14 - Diagramas de esforços normais - Arranjo 4B............... 129 
Figura 4.15 - Diagramas de esforços normais - Arranjo 5B................ 130

Figura 4.16 - Diagramas de esforços normais - Arranjo 6B............... 131

Figura 4.17 - Diagramas de esforços normais - Arranjo 7D................. 132

Figura 4.18 - Diagramas de esforços normais - Arranjo 9B............... 133 


\section{LISTA DE TABELAS}

Tabela 3.1 - Resumo dos arranjos estruturais propostos.................... 98

Tabela 4.1 - Quantidade de nós e barras - arranjos 1 a $6 \ldots \ldots \ldots \ldots \ldots \ldots . . \ldots 106$

Tabela 4.2 - Quantidade de nós e barras - arranjos 7...................... 106

Tabela 4.3 - Quantidade de nós e barras - arranjos 8..................... 107

Tabela 4.4 - Quantidade de nós e barras - arranjos 9 e 10................ 107

Tabela 4.5 - Consumo de material - arranjos 1 a $6 \ldots \ldots \ldots \ldots \ldots \ldots \ldots \ldots . . . . . . . . . .109$

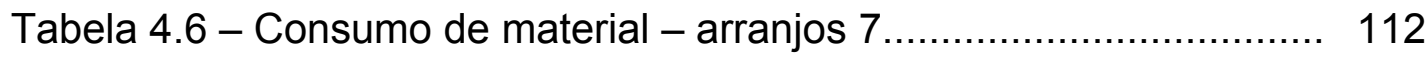

Tabela 4.7 - Consumo de material - arranjos 8............................. 112

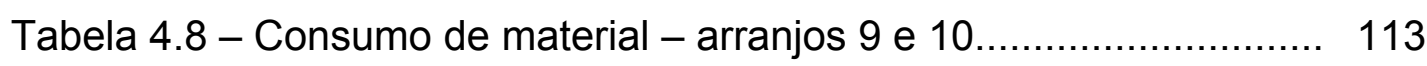

Tabela 4.9 - Deslocamentos máximos - arranjos 1 a $6 \ldots \ldots \ldots \ldots \ldots \ldots \ldots . . . \ldots 115$

Tabela 4.10 - Deslocamentos máximos - arranjos $7 \ldots \ldots \ldots \ldots \ldots \ldots \ldots \ldots \ldots 117$

Tabela 4.11 - Deslocamentos máximos - arranjos 8...................... 117

Tabela 4.12 - Deslocamentos máximos - arranjos 9 e 10.................. 118

Tabela 4.13 - Reações de apoio máximas.................................... 120

Tabela 4.14 - Esforços máximos - banzo inferior........................... 124

Tabela 4.15 - Esforços máximos - banzo superior......................... 124

Tabela 4.16 - Esforços máximos - diagonais............................... 125

Tabela 4.17 - Esforços máximos - Arranjos 7 .............................. 126

Tabela 4.18 - Esforços máximos - Arranjos 8............................. 127 


\section{INTRODUÇÃO}

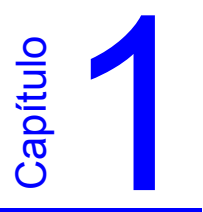

As estruturas reticuladas tridimensionais, mais conhecidas simplesmente por estruturas espaciais ou treliças espaciais, são amplamente utilizadas em coberturas de edificações que necessitem grandes áreas livres, tais como ginásios, hangares, centros de exposição e edifícios industriais. Alguns dos fatores que favorecem o uso deste tipo de estrutura em relação às estruturas planas convencionais são:

- grande rigidez, sendo possível a realização de obras de grandes vãos;

- facilidade de fixação de instalações, devido à grande quantidade de nós nos quais podem ser fixados suportes;

- liberdade arquitetônica na locação de apoios;

- beleza arquitetônica, permitindo explorar as mais diversas formas;

- possibilidade de ampliação, e fácil montagem e desmontagem para estruturas não permanentes;

- menor peso e menor custo para grandes vãos (acima de 40 m);

As estruturas espaciais são formadas em sua grande maioria por perfis de seção transversal tubular circular, que dispensam a verificação de flambagem por torção ou por flexo-torção. O uso de outros tipos de perfis é restrito a sistemas específicos de determinados fabricantes ou a obras 
especiais em que os perfis de seção transversal tubular circular não atendem aos requisitos de resistência ou forma geométrica.

As barras das estruturas espaciais são conectadas por dispositivos denominados nós. Existem diversos tipos de nós, desde os mais simples, formados pelo amassamento das extremidades dos perfis e um único parafuso de conexão, até os mais requintados, nos quais os nós são peças esféricas moldadas e as barras da estrutura apresentam as extremidades usinadas na forma de pinos que se encaixam nos nós. Porém, muitas vezes estas conexões não correspondem ao modelo teórico adotado e apresentam problemas de instabilidade. Vários estudos teóricos e experimentais vêm sendo conduzidos para analisar o comportamento local e global da estrutura para determinados tipos de sistemas de conexão.

A partir de 1995, o Departamento de Engenharia de Estruturas da Escola de Engenharia de São Carlos (EESC-USP) passou a ser solicitado a participar de trabalhos técnicos e assessorias envolvendo treliças metálicas espaciais, quase sempre relacionadas com o colapso total ou parcial destas estruturas. Estes trabalhos, na sua maioria, deram ênfase aos sistemas de ligação mais utilizados no Brasil.

A configuração geométrica de uma estrutura espacial é definida, em princípio, em função da arquitetura da edificação. Por meio da arquitetura tem-se os requisitos básicos necessários para o início da determinação das características geométricas da estrutura, entre eles, a disposição dos apoios e os contornos da estrutura. A disposição dos apoios define os vãos livres e os balanços da estrutura. Os contornos são compostos por superfícies planas e curvas que delimitam a estrutura, determinando a extensão e a forma externa da estrutura.

Com a determinação dos pontos de apoio e do gabarito externo da estrutura, e analisando-se as ações, as limitações de deslocamentos máximos e as condições e tecnologias de fabricação, montagem e içamento, podem ser definidos outros aspectos específicos das estruturas espaciais, tais como as dimensões e orientações dos módulos, quantidades de camadas e altura da estrutura. 
Diversos trabalhos vêm sendo publicados em vários países abordando a concepção geométrica das treliças espaciais, verificando os fatores que mais influenciam e as formas geométricas de melhor desempenho. Porém, muitas vezes estes estudos não se enquadram na realidade brasileira de arquitetura e de ações.

Este trabalho tem como objetivo fornecer subsídios para a concepção de projetos de treliças metálicas espaciais planas de cobertura, buscandose características geométricas, tais como disposição das barras, modulação, altura do módulo, quantidades de camadas e tipos de apoio, que apresentem o melhor desempenho diante de determinadas condições existentes em obras correntes no Brasil. Estas condições referem-se à disposição e quantidade de apoios, vãos, ações, limitações de flecha entre outras.

Para atingir tal objetivo foram analisados alguns arranjos estruturais de treliças metálicas espaciais de cobertura, adotando-se o modelo de treliça ideal em análise elástica linear (teoria de primeira ordem), buscando representar a maneira como os projetos são normalmente executados nos escritórios de cálculo. Os arranjos estruturais foram processados no programa SAP $2000^{\circledR}$ e a análise foi feita via Método dos Elementos Finitos. Os nós foram adotados articulados e sem excentricidades, e as ações aplicadas exclusivamente nos nós da estrutura.

Como ponto de partida para o desenvolvimento deste trabalho, o segundo capítulo apresenta a revisão bibliográfica sobre o assunto, abordando alguns aspectos históricos, tipos mais utilizados, sistemas de ligação, análise e comportamento estrutural, e aspectos de projeto de treliças espaciais, além da descrição de algumas obras relevantes realizadas com este tipo de estrutura.

No terceiro capítulo são apresentados os arranjos estruturais analisados, abordando as ações, as configurações geométricas e os procedimentos de cálculo. 
No quarto capítulo são apresentados os resultados obtidos dos processamentos dos arranjos estruturais, sendo discutidos e comparados os seguintes itens:

- Quantidade de barras e nós;

- Consumo de material;

- Deslocamentos;

- Reações de apoio;

- Esforços internos.

No quinto capítulo são apresentadas as conclusões do trabalho e sugestões para sua continuidade. 


\section{REVISÃO BIBLIOGRÁFICA}

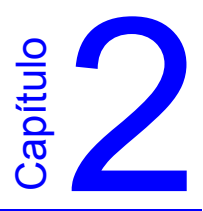

\subsection{GENERALIDADES E HISTÓRIA}

O termo "estrutura espacial" é empregado de maneira geral para designar um sistema estrutural em que não há subsistemas planos definidos. Pode-se perceber que o termo estrutura espacial é bastante abrangente, envolvendo estruturas reticuladas, constituídas por elementos de barra, estruturas contínuas, constituídas por placas, membranas ou cascas, e estruturas mistas, constituídas pela combinação de elementos discretos e contínuos (MAKOWSKI 1987).

As treliças espaciais planas, os arcos treliçados espaciais e as cúpulas treliçadas espaciais são os principais tipos de estruturas espaciais reticuladas. Estas estruturas surgiram por volta do século XVIII. Em 1907, Alexander Graham Bell desenvolveu um reticulado espacial constituído por barras de mesma dimensão conectadas por um único tipo de nó, formando elementos modulares tetraédricos (Figura 2.1). Mostrava-se, assim, a alta capacidade de padronização e a conseqüente facilidade de industrialização deste tipo de estrutura (DU CHATEAU 1984).

No início dos anos 30, a TOMOE Corporation, no Japão, desenvolveu o sistema "treliça diamante" devido à demanda crescente por estruturas de cobertura para hangares que abrigassem as aeronaves que começavam a surgir. Um pequeno triângulo foi adotado como unidade básica. A combinação desses triângulos, gerava uma estrutura "rígida" e de elevada 
capacidade de carga que lembrava a forma de um diamante. Porém, o grande avanço na difusão dos reticulados espaciais foi o surgimento da MERO, na Alemanha em 1943, que desenvolveu um sistema pré-fabricado de estrutura espacial que consiste na combinação de dois elementos básicos: nós esféricos e barras de seção tubular circular (Figura 2.2). Outros sistemas pré-fabricados surgiram na seqüência, entre eles os que se destacaram foram o UNIBAT da França, o TRIODETIC do Canadá, o MODUSPAN UNISTRUT dos Estados Unidos e o NODUS da Inglaterra (IFFLAND 1982). O impacto da industrialização na pré-fabricação de estruturas espaciais foi muito significativo, pois permitiu uma padronização econômica dos elementos. (MAKOWSKI 1984).

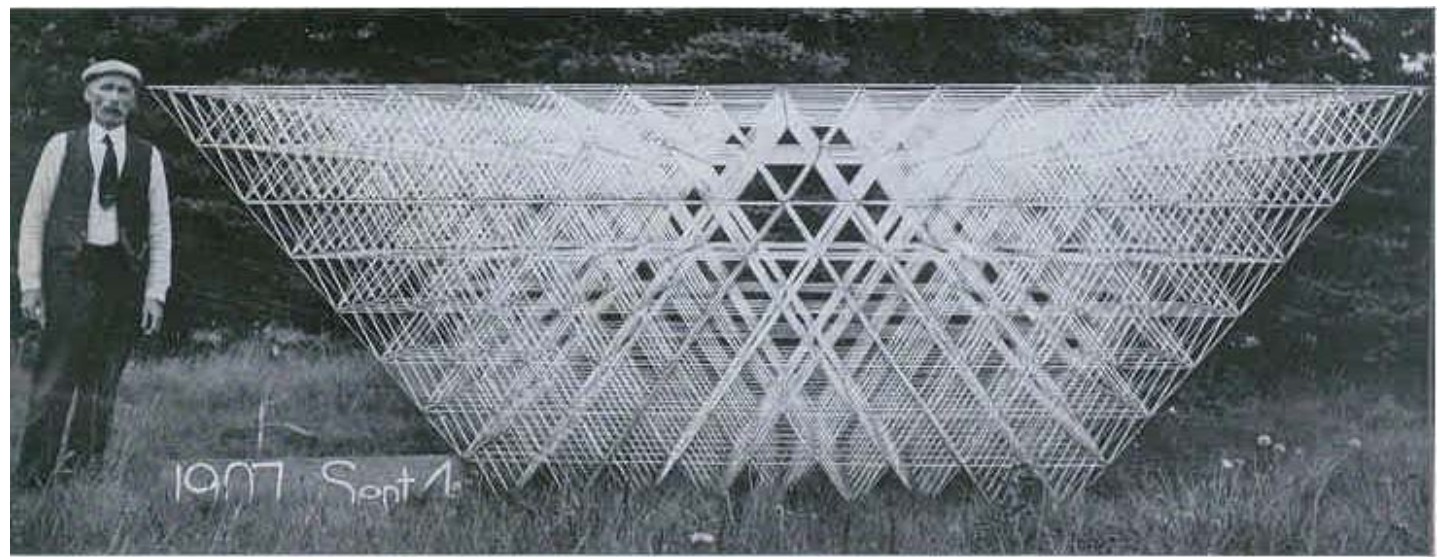

Figura 2.1 - Estrutura espacial reticulada de Alexander Graham Bell Fonte: DU CHATEAU (1984)
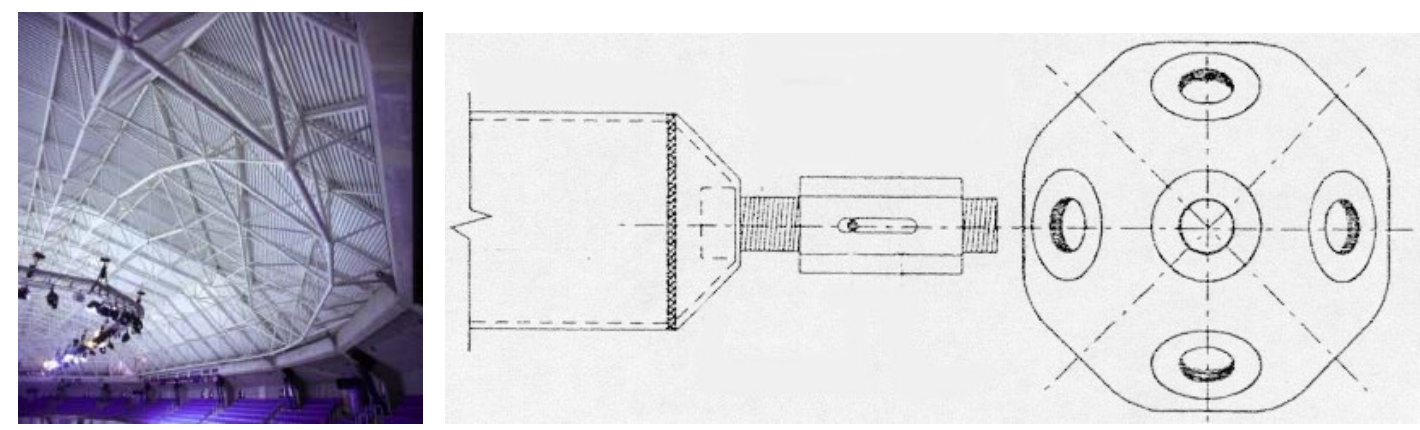

Figura 2.2 - Sistema desenvolvido pela MERO -

Fontes: www.mero.com e EL-SHEIKH (1996) 
Em 1966 foi realizada em Londres a primeira conferência sobre estruturas espaciais, marcando o início da integração e do aprofundamento das pesquisas sobre estas estruturas. No ano seguinte foi criado pelo ASCE nos Estados Unidos um comitê específico para o estudo destas estruturas.

No início, a análise estrutural destes reticulados espaciais demandava muito tempo e muitas vezes utilizavam-se processos aproximados, tal como o de analogia de placas. Isso limitava muito a liberdade de criação de engenheiros e arquitetos, pois se buscavam formas padronizadas que diminuíssem o trabalho de cálculo. FLOWER \& SCHMIDT (1971) apresentam um método simplificado para o cálculo de treliças espaciais por meio de analogia de placa.

MAGALHÃES (1996) apresenta uma comparação de resultados de esforços, deslocamentos e reações de apoio, obtidos por meio de uma análise utilizando analogia de placa, com os obtidos em estruturas discretizadas em barras. Foram analisadas duas estruturas, uma quadrada, com dimensões $50 \mathrm{~m} \times 50 \mathrm{~m}$ e vãos entre apoios de $40 \mathrm{~m}$, e outra retangular, com dimensões $50 \mathrm{~m} \times 130 \mathrm{~m}$ e vãos entre apoios também de $40 \mathrm{~m}$. Adotouse uma ação uniformemente distribuída de $0,6 \mathrm{kN} / \mathrm{m}^{2}$ e barras com seção $\varnothing$ $63,5 \times 3,0 \mathrm{~mm}$. A altura adotada para treliça foi $2 \mathrm{~m}$ e a espessura da placa equivalente $17,62 \mathrm{~cm}$, obtida considerando-se compatibilidade de rigidez à flexão. Na Figura 2.3 são mostrados os deslocamentos da treliça espacial e da placa equivalente na seção BB, que corresponde a um corte tranversal passando pelo centro da estrutura com planta quadrada.

A partir da década de 70, com o advento dos computadores eletrônicos, houve uma grande revolução no desenvolvimento das estruturas espaciais. Com o aparecimento de novas técnicas computacionais foi possível buscar concepções geométricas de melhor desempenho estrutural e que mais atendiam aos anseios arquitetônicos (MAKOWSKI 1993).

Segundo MAKOWSZI (1984), outros fatores que provocaram um grande desenvolvimento na utilização destas estruturas foram 0 desenvolvimento de sistemas padronizados eficientes de conexão e as pesquisas científicas sobre o comportamento elástico e não-elástico das 
estruturas espaciais e sobre os modos de falha das mesmas quando sujeitas a carregamento excessivo.

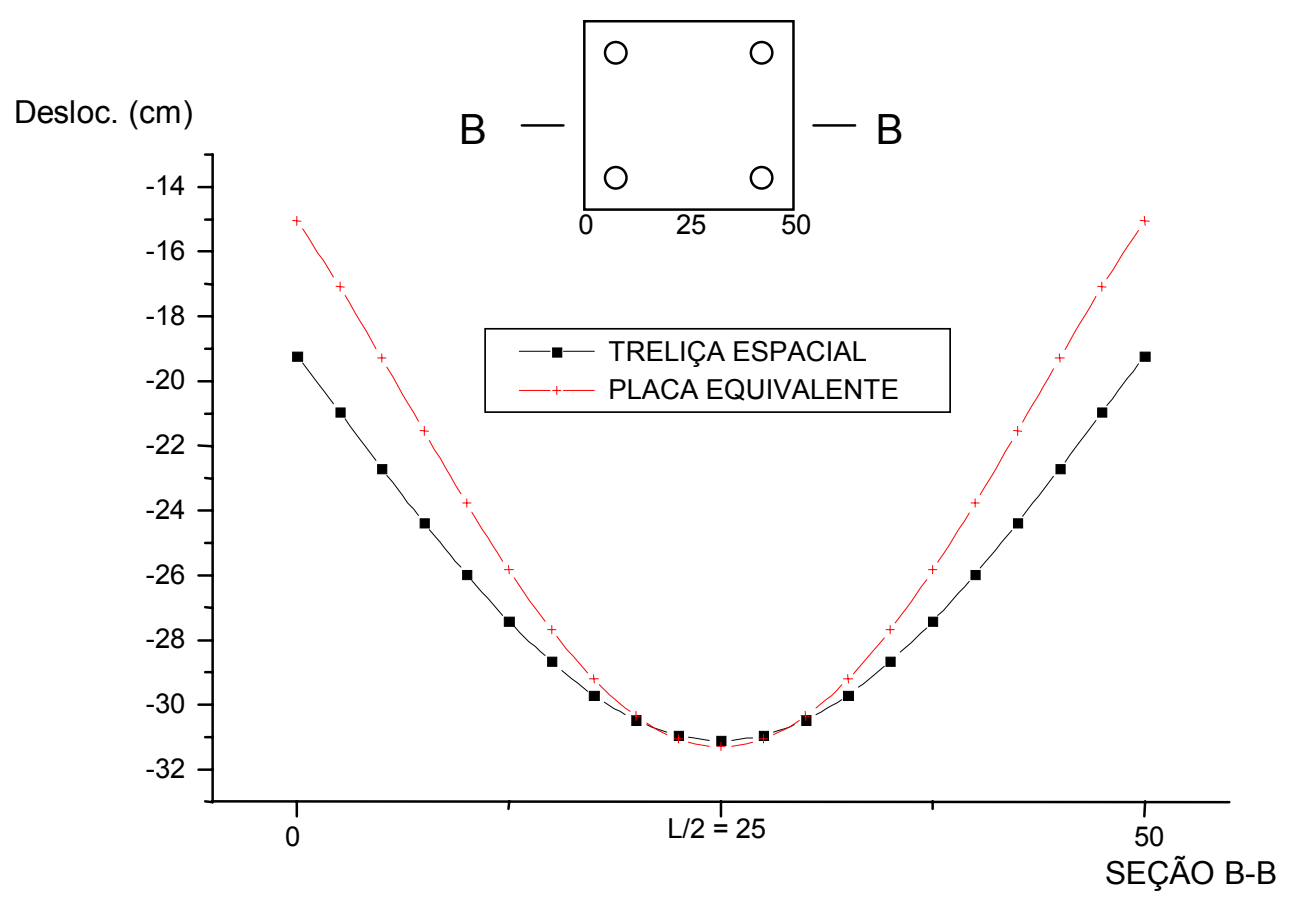

Figura 2.3 - Deslocamentos ao longo da seção BB da estrutura com planta quadrada - Fonte: MAGALHÃES (1996)

\subsection{ESTRUTURAS ESPACIAIS RETICULADAS}

\subsubsection{TRELIÇAS ESPACIAIS PLANAS}

São formadas por uma ou mais camadas planas de barras. Estas camadas são denominadas banzos, e as barras responsáveis pela ligação entre os diversos planos são denominadas diagonais. Os pontos de encontro entre banzos e diagonais são denominados "nós" e neles são realizadas as conexões.

Quando formadas por um único nível de banzos, constituem grelhas, portanto os nós da treliça devem ser rígidos, ou seja, os banzos estão sujeitos a momentos fletores, momentos de torção e forças cortantes, a fim 
de manter a estabilidade do conjunto. Porém, estas estruturas apresentam grandes limitações de uso, pois os deslocamentos são muito elevados e muito sensíveis ao aumento do vão. Alguns tipos de composição de reticulados são mostrados na Figura 2.4.

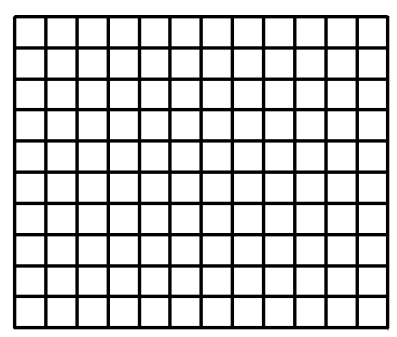

MALHA QUADRADA

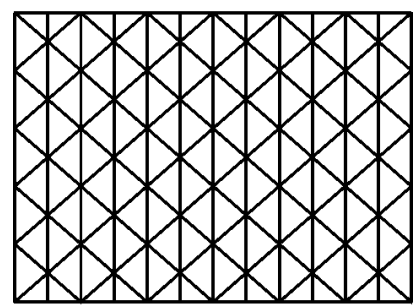

MALHA TRÊS-DIREÇÕES

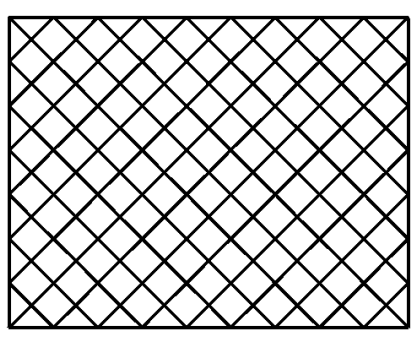

MALHA DIAGONAL

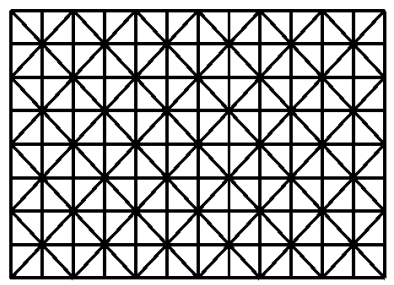

MALHA QUATRO-DIREÇÕES

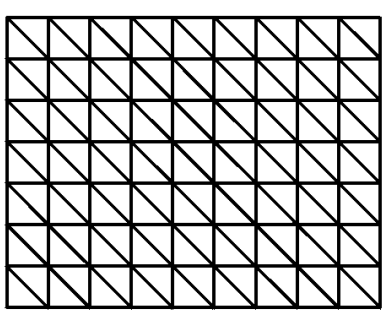

MALHA TRÊS-DIREÇÕES

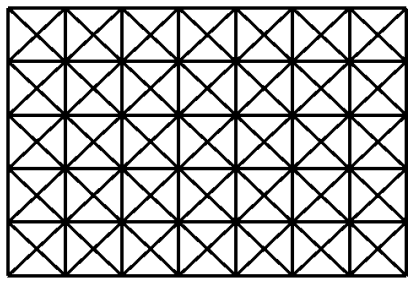

MALHA QUATRO-DIREÇÕES

Figura 2.4 - Modelos de reticulados com uma camada -

Fonte: www.surrey.ac.uk

Nos reticulados formados por duas ou mais camadas paralelas, o principal esforço interno é a força axial, porém dependendo das características do nó podem surgir momentos fletores, momentos de torção e forças cortantes. A opção por mais de duas camadas de banzos, normalmente decorre da necessidade de se vencer grandes vãos e limitar os deslocamentos máximos da estrutura. $\mathrm{O}$ aumento na quantidade de camadas de banzo provoca aumento de rigidez da estrutura.

Quanto ao arranjo geométrico das camadas, existem diversas soluções possíveis. A opção por determinado arranjo depende de alguns fatores, tais como a forma e a dimensão do contorno, os pontos de apoio, os carregamentos, os materiais utilizados e a maneira como a estrutura será montada. Algumas configurações são mostradas nas Figuras 2.5 e 2.6. 


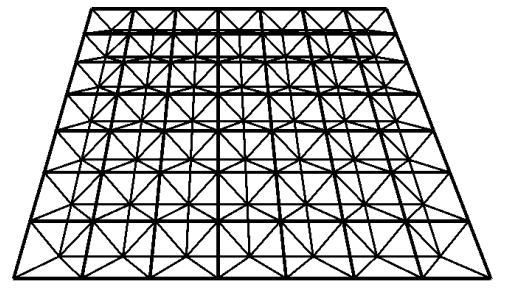

MALHA QUADRADO SOBRE QUADRADO

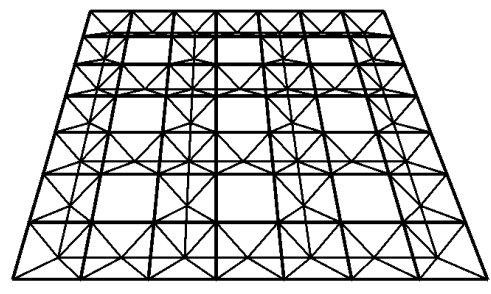

MALHA QUADRADO SOBRE QUADRADO REDUZIDA

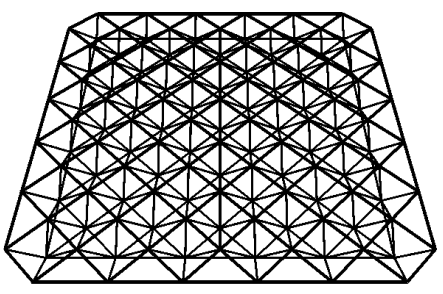

MALHA DIAGONAL SOBRE DIAGONAL

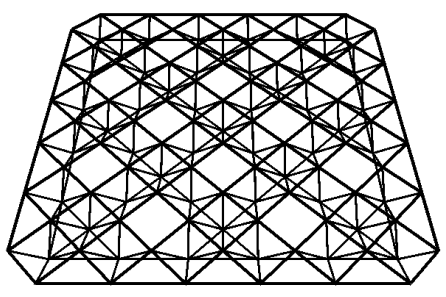

MALHA DIAGONAL SOBRE DIAGONAL REDUZIDA

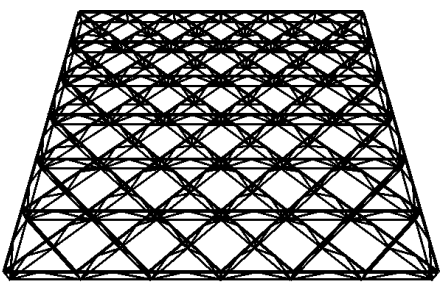

MALHA DIAGONAL SOBRE DIAGONAL - TRÊS DIREÇÕES

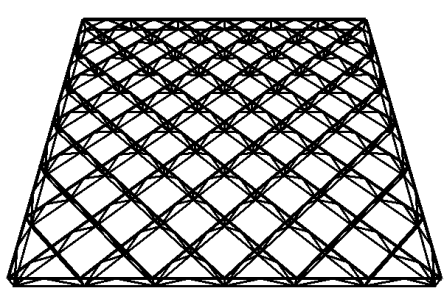

MALHA DIAGONAL SOBRE DIAGONAL

Figura 2.5 - Modelos de reticulados com duas camadas de banzos -

Fonte: www.surrey.ac.uk
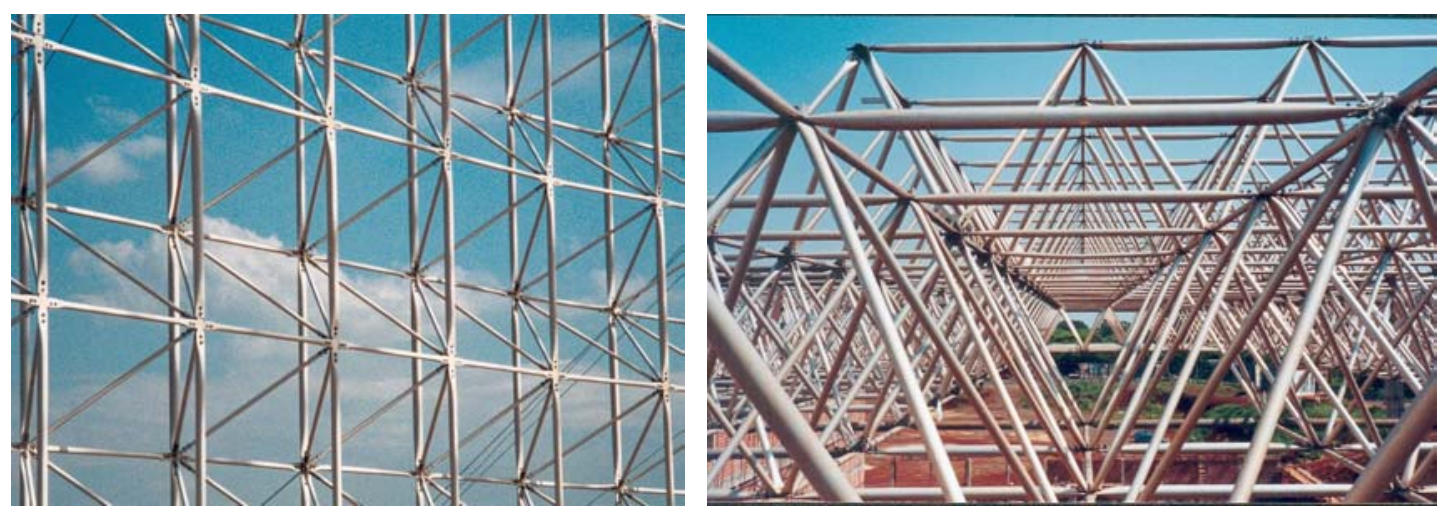

Figura 2.6 - Estruturas com reticulados quadrado sobre quadrado

\subsubsection{ARCOS TRELIÇADOS ESPACIAIS}

São obtidos pelo arqueamento da treliça espacial plana ao longo de uma direção. O resultado é uma forma cilíndrica que pode ser constituída por uma ou mais camadas de banzo (Figura 2.7).

DEHDASHTI \& SCHMIDT (1995) descrevem um processo de formação de arcos espaciais por meio da protensão do banzo inferior. A grande vantagem deste processo é a facilitação da montagem, pois a estrutura pode ser montada com os banzos contidos em superfícies planas, sendo os mesmos arqueados depois pela protensão do banzo inferior. 


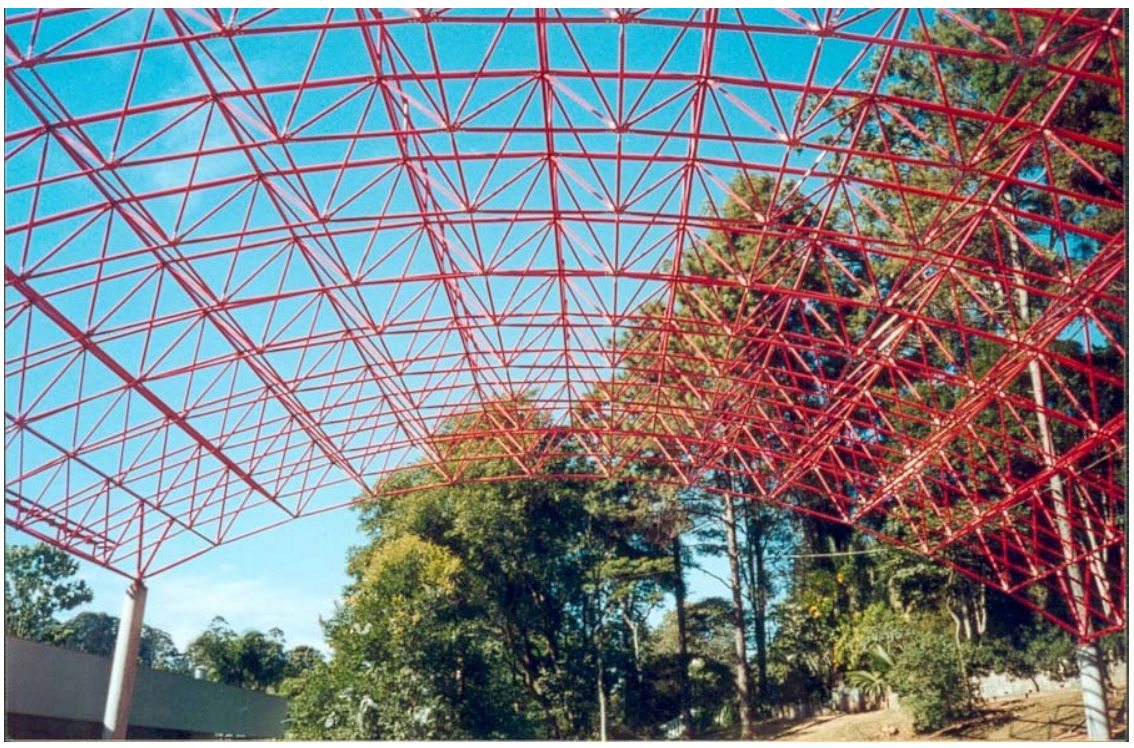

Figura 2.7 - Cobertura em arco treliçado espacial

\subsubsection{CÚPULAS TRELIÇADAS ESPACIAIS}

São treliças espaciais formada por uma ou mais camadas de banzos em forma de cúpula (Figura 2.8). A superfície de uma cúpula normalmente é parte de uma superfície única tal como uma esfera ou um parabolóide.

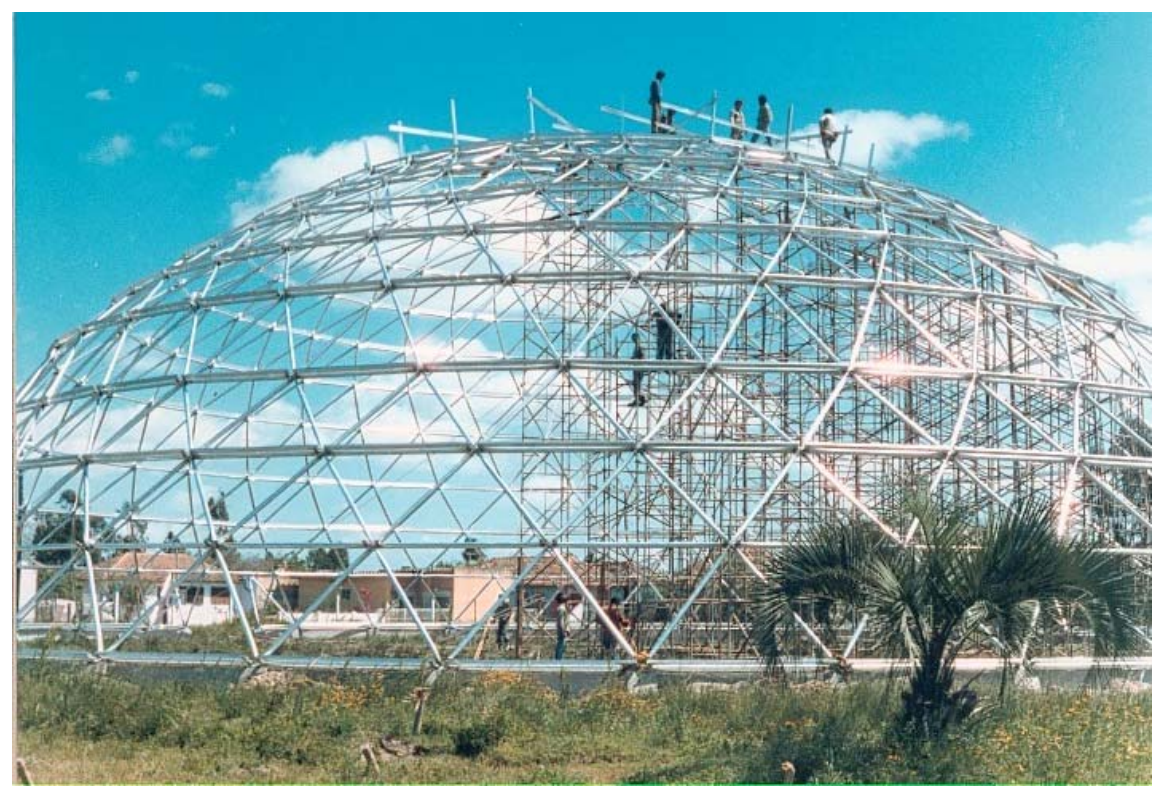

Figura 2.8 - Cobertura em cúpula treliçada espacial Fonte: catálogo ALUSUD 
Segundo SHU-T'IEN LI (1962) as cúpulas apresentam uma série de vantagens, sendo um dos tipos de estrutura espacial mais econômicos. Isto explica o fato deste sistema estrutural criado na antiguidade ser ainda muito utilizado.

VENDRAME (1999) apresenta um estudo sobre as cúpulas treliçadas espaciais, abordando aspectos referentes ao comportamento e ao projeto e execução.

\subsection{SISTEMAS DE TRELIÇAS ESPACIAIS}

Para um sistema de treliça espacial ser competitivo, ele deve atender às seguintes características:

- deve ser leve, fácil de fabricar e transportar os componentes, e de rápida montagem;

- deve ser esteticamente agradável;

- deve ter baixo custo para construir e manter.

As ligações entre as barras de um reticulado espacial são um dos fatores que tem a maior influência na confiabilidade, no comportamento e no custo final de um sistema. A definição do sistema de ligação está diretamente ligada ao perfil, à quantidade e à disposição das barras que incidem no nó. Além disso, o nó deve representar da maneira mais fiel possível as hipóteses de cálculo adotadas. A maioria dos sistemas apresentam ligações parafusadas, pois as ligações soldadas possuem custo elevado e são de difícil execução em obra, podendo muitas vezes comprometer a eficiência da ligação.

As barras podem ser diversos tipos de perfis, tais como perfis de seção tranversal tubular circular e retangular, "I" soldados e laminados, cantoneiras, entre outros. A escolha do perfil está ligada ao nível de solicitação da barra, ao sistema de conexão, à concepção arquitetônica, à 
finalidade da estrutura ou a alguma função que o perfil deverá exercer, por exemplo, suporte para fixação de telhas.

Quanto ao material, os mais utilizados são o aço e o alumínio, sendo que o uso do alumínio vem caindo acentuadamente nos últimos anos devido ao elevado custo.

IFFLAND (1982) descreve alguns sistemas patenteados utilizados, entre eles:

- OMNI-HUB (Estados Unidos): o nó é uma esfera sólida na qual são conectadas as barras por meio de um parafuso. As barras são de seção tranversal tubular circular (Figura 2.9);
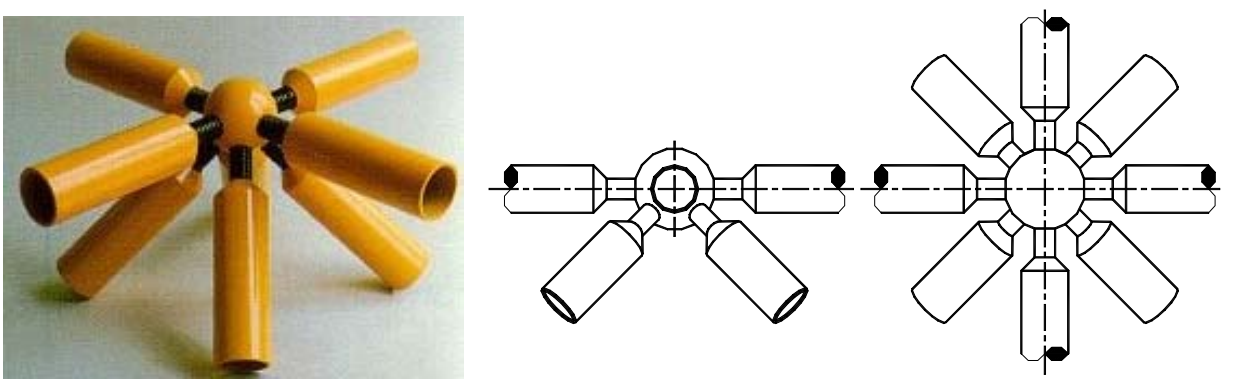

Figura 2.9 - Sistema OMNI-HUB - Fonte: www.starnetint.com

- GEO-HUB (Estados Unidos): o sistema é similar ao anterior. A diferença é a utilização de barras de seção tranversal tubular quadrada no lugar das circulares, resultando em conexões mais complicadas. As barras são conectadas por parafusos e há um parafuso central que atravessa todo nó (Figura 2.10);
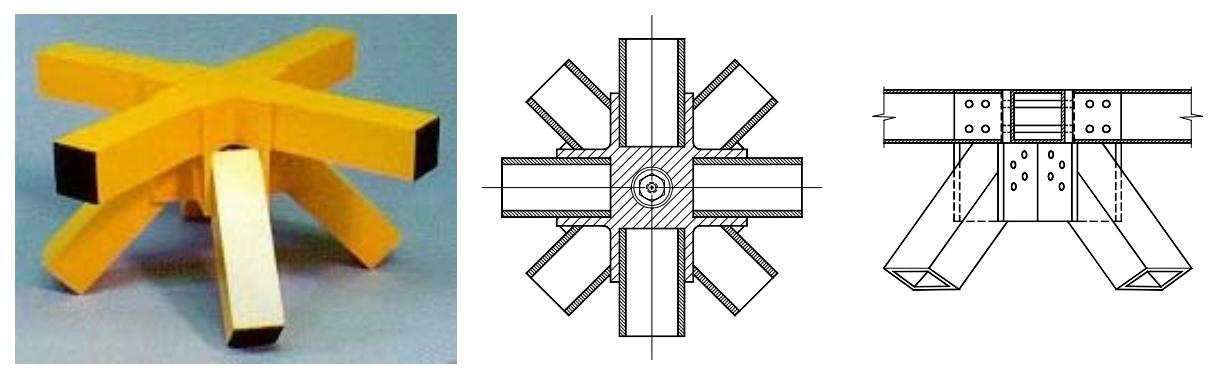

Figura 2.10 - Sistema GEO-HUB - Fonte: www.starnetint.com 
- TRIODETIC (Canadá): o nó é um cilindro com seis a nove fendas ranhuradas. A barras são perfis de seção tranversal tubular circular com as extremidades estampadas de tal maneira que se encaixam nas fendas existentes no cilindro (Figura 2.11);

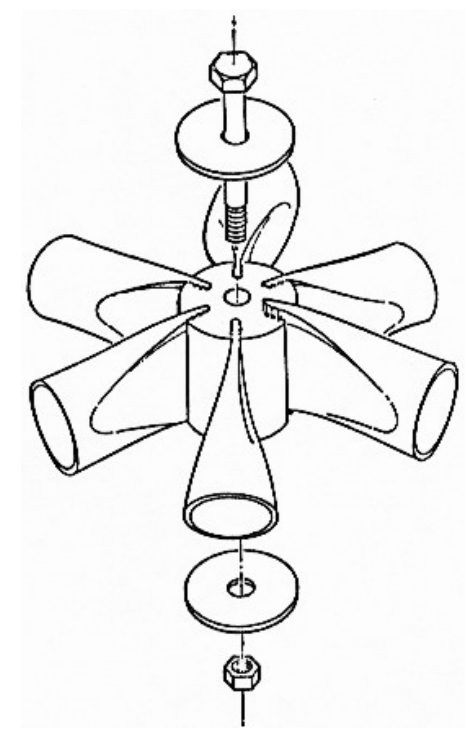

Figura 2.11 - Sistema TRIODETIC - Fonte: CROOKER (1970)

- MERO (Alemanha): é o nó mais conhecido e de uso mais difundido em todo mundo. Consiste em barras de seção tranversal tubular circular de aço com parafusos nas extremidades que são conectados a nós esféricos. Cada nó pode receber até 18 conexões (Figura 2.12);

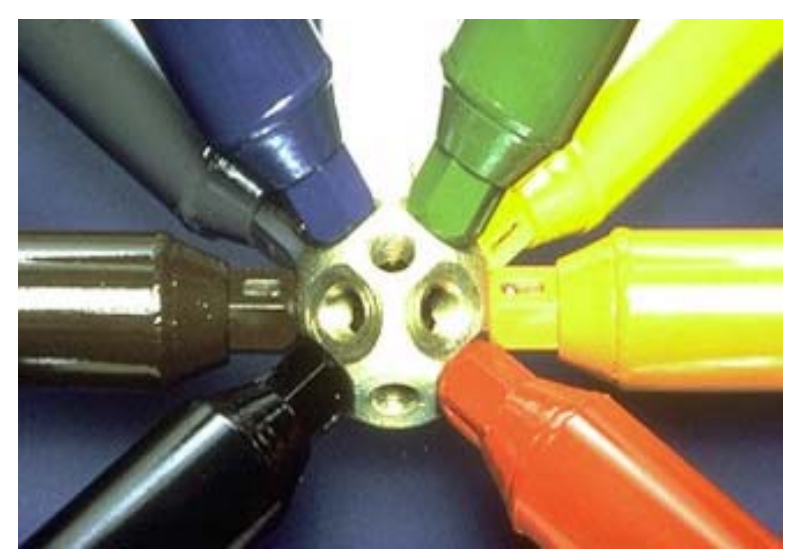

Figura 2.12 - Sistema MERO - Fonte: www.mero.de 
- NODUS (Inglaterra): o nó é formado for duas calotas moldadas para receberem as barras, e todas são parafusados. Oito barras podem ser conectadas no nó, podendo ser de seção tranversal tubular circular ou retangular (Figura 2.13);

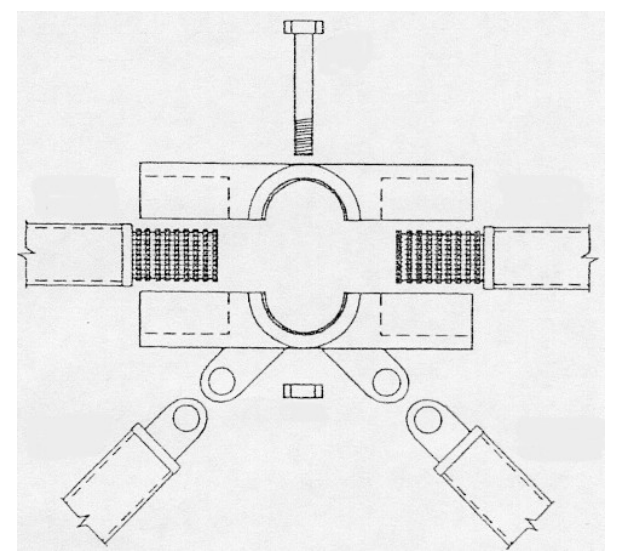

Figura 2.13 - Sistema NODUS - Fonte: EL-SHEIKH (1996)

- MODUSPAN UNISTRUT (Estados Unidos): o nó é formado por uma chapa estampada de tal forma que permita as conexões das barras. As barras são perfis do tipo "U” (Figura 2.14);

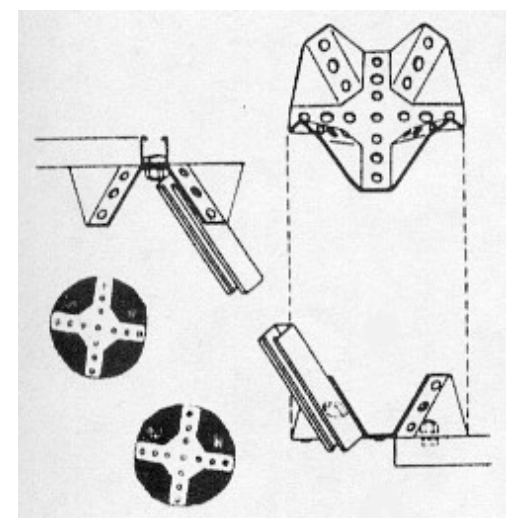

Figura 2.14 - Sistema UNISTRUT - Fonte: IFFLAND (1982)

- OKTAPLATTE (Alemanha): este sistema utiliza esferas de aço ocas e barras de seção tranversal tubular circular que são conectadas por soldas de filete (Figura 2.15); 


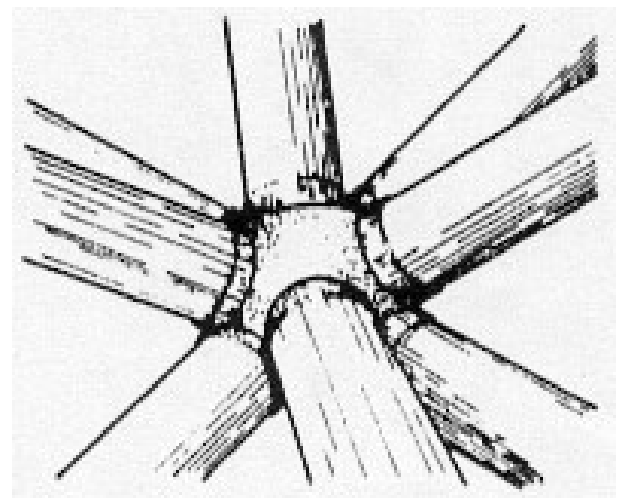

Figura 2.15 - Sistema OKTAPLATTE- Fonte: IFFLAND (1982)

- UNIBAT (França): o sistema é formado por módulos piramidais pré-fabricados que são parafusados uns aos outros. As barras do banzo superior são perfis do tipo "I", as do banzo inferior são seção tranversal tubular circular e as diagonais são do tipo seção tranversal tubular retangular (Figura 2.16);

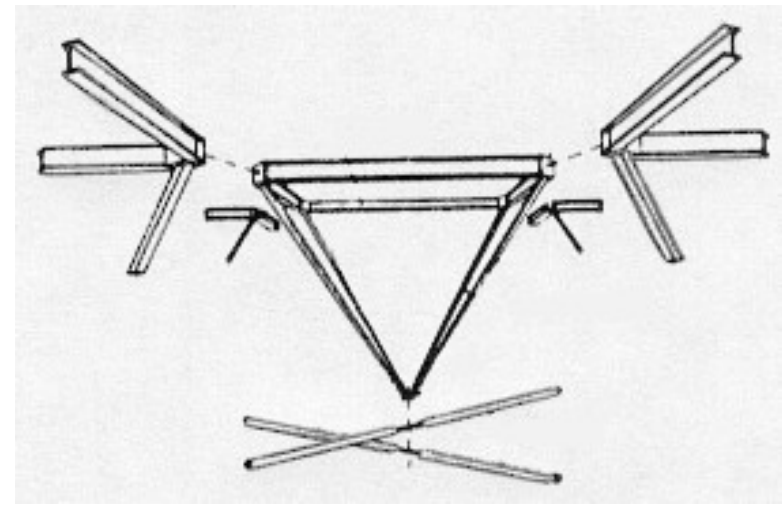

Figura 2.16 - Sistema UNIBAT- Fonte: IFFLAND (1982)

LANDOLFO \& MAZZOLANI (1993) realizaram ensaios para caracterizar o sistema italiano VESTRUT. Neste sistema, o nó é formado por três elementos circulares, sendo duas calotas e um disco central fechandoas, todos unidos por um único parafuso. As barras são de seção tranversal tubular circular, e a conexão entre o nó e a barra é feita por um terminal formado por um vergalhão (Figura 2.17). 

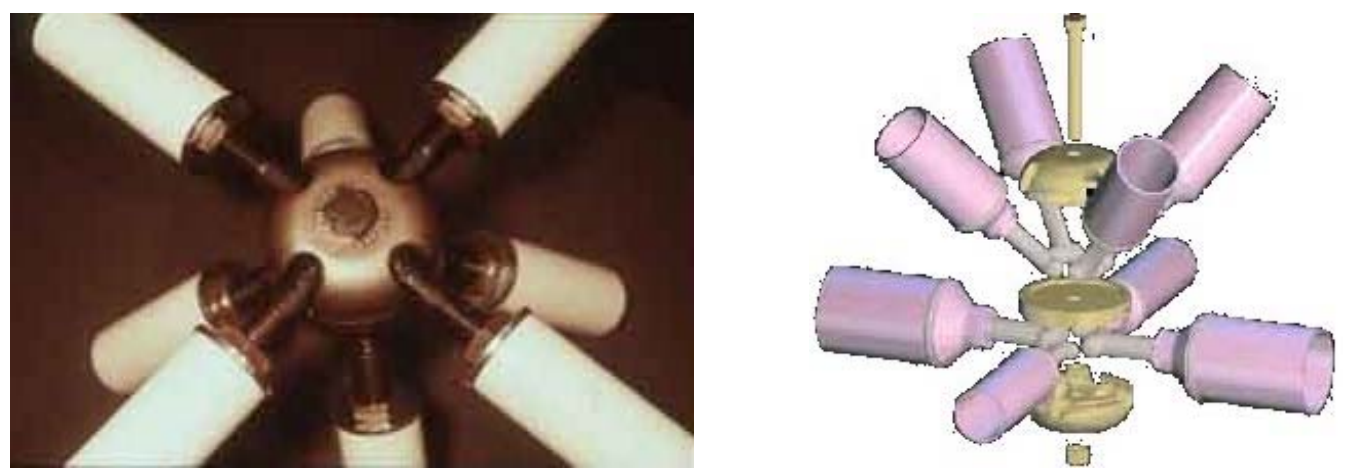

Figura 2.17 - Sistema VESTRUT - Fonte: www.vestrut.com

EL-SHEIKH \& EL-BAKRY (1996) apresentam o sistema CATRUS. Neste sistema as barras são conectadas por meio de um único parafuso no nó. Os banzos são contínuos, sem interrupção nos nós. Os banzos superiores são perfis tubulares retangulares e os inferiores barras chatas. As diagonais são de seção tranversal tubular circular com as extremidades estampadas. Como pode ser observado na Figura 2.18, o sistema tem a vantagem de apresentar o banzo superior contínuo, porém existem excentricidades nas ligações, e o banzo inferior, sendo em barra chata, apresenta bom desempenho apenas quando está tracionado, ou seja, apenas para carregamentos devidos à ação da gravidade. Para situações em que ocorre inversão de esforços, como por exemplo, a ação de sucção do vento, o banzo inferior estará comprimido, e o sistema perde a eficiência.
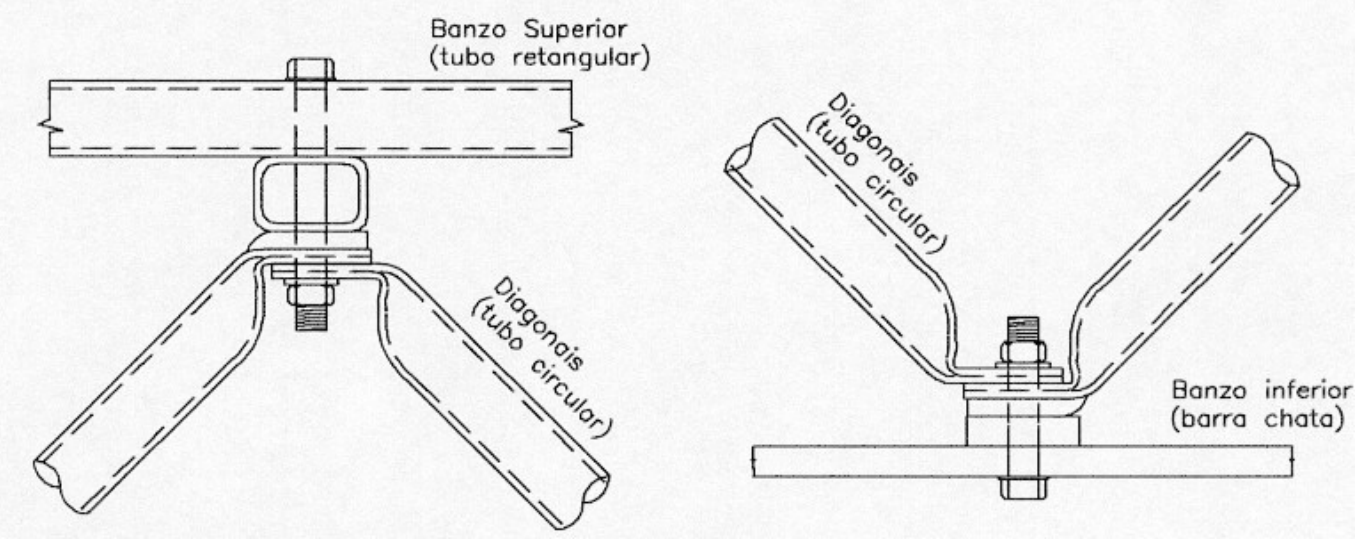

Figura 2.18 - Sistema CATRUS - Fonte: EL-SHEIKH (1996) 


\subsubsection{SISTEMAS UTILIZADOS NO BRASIL}

No Brasil existe uma variedade de sistemas empregados. Estes sistemas variam de acordo com o fabricante, mas de maneira geral nenhum deles é patenteado, com exceção de algumas obras executadas pela MERO. Na maioria dos casos, estes sistemas foram criados a partir da própria experiência do fabricante ou da cópia de outros sistemas, e não foram submetidos a análises experimentais que comprovassem sua segurança, confiabilidade e adequação ao modelo teórico.

A seguir são descritos alguns tipos de sistemas de ligação para estruturas espaciais encontrados no Brasil. A nomenclatura aqui utilizada para descrever os sistemas não é padrão para todos os fabricantes, porém procurou-se utilizar as denominações mais utilizadas no mercado.

\subsubsection{NÓ TÍPICO OU NÓ "AMASSADO"}

Neste sistema o nó é formado pela sobreposição das extremidades estampadas das barras unidas por um único parafuso e duas arruelas quadradas que confinam o conjunto (Figura 2.19). Este tipo é o mais empregado no país, devido ao baixo custo de fabricação e montagem.

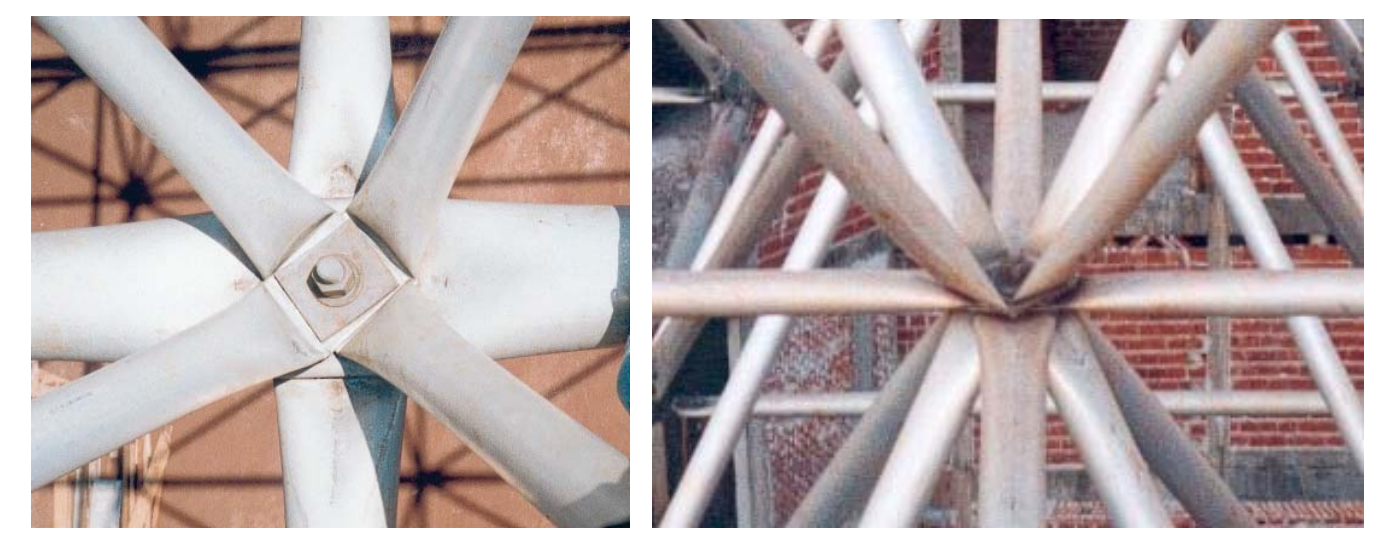

Figura 2.19 - Sistema de nó típico ou nó "amassado" 
Este nó vem sendo alvo de uma série de pesquisas teóricas e experimentais na EESC-USP, motivadas por acidentes ocorridos em obras que utilizavam este sistema.

MAIOLA (1999) realizou uma análise teórica e experimental com protótipos de treliças espaciais planas que utilizavam este sistema. Foram ensaiados dois protótipos com dimensões em planta 7,5m x 7,5m, modulação 2,5m x 2,5m e altura 1,5m (Figura 2.20).

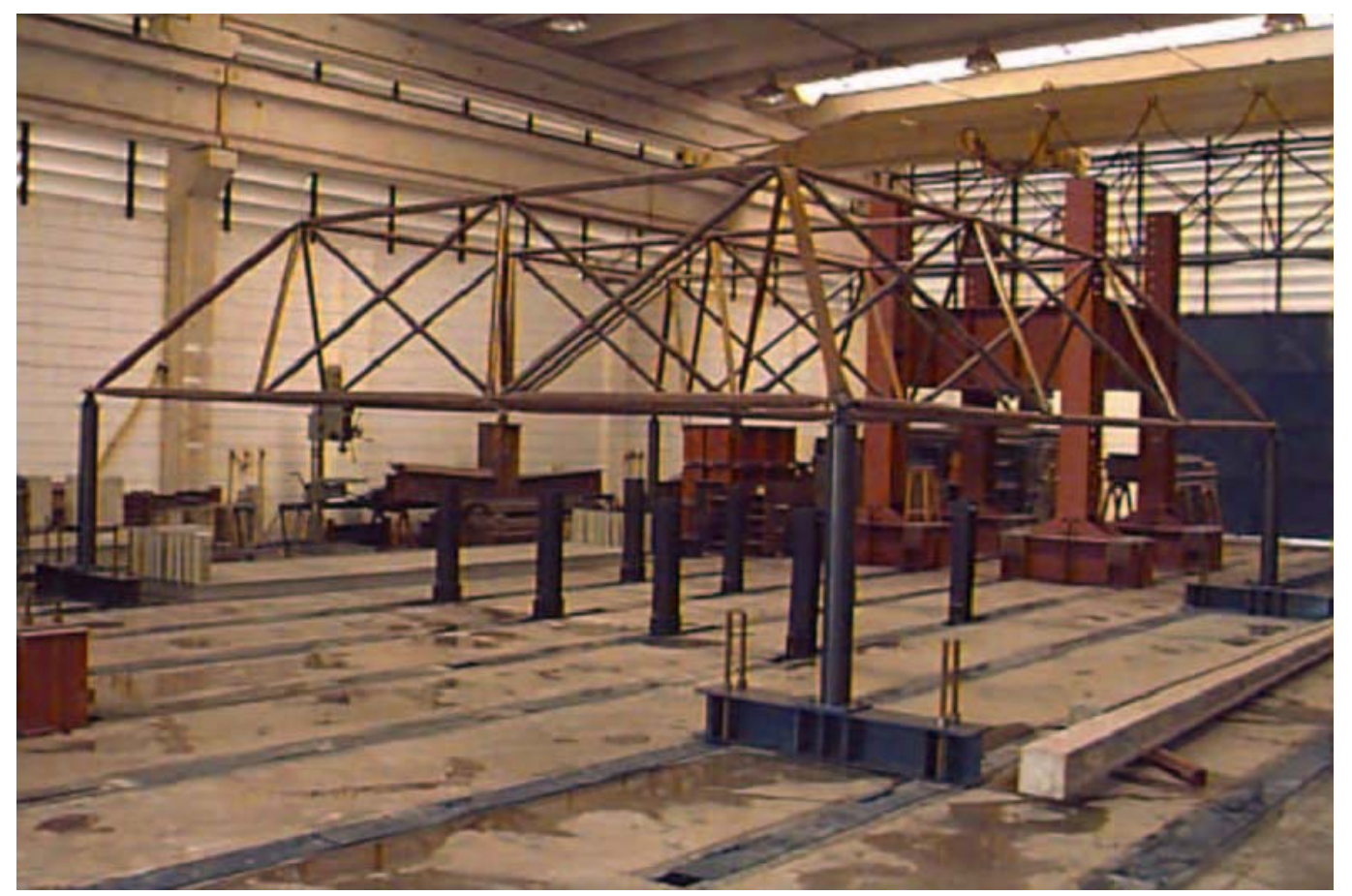

Figura 2.20 - Protótipo com nó típico - Fonte: MAIOLA (1999)

Os protótipos ensaiados por MAIOLA apresentaram uma carga última de cerca de $60 \%$ do valor teórico calculado por análise elástica linear. A falha foi caracterizada pela ruína do nó. Foi observada a plastificação das extremidades das barras, rotações excessivas dos nós e parafusos, separação e escorregamento entre barras (Figura 2.21). Os protótipos também apresentaram deslocamentos cerca de três vezes maiores que o previsto teoricamente pela análise elástica de primeira ordem. Vale salientar que os protótipos possuíam elevada relação altura/vão (1:5), ou seja, havia grande influência da força cortante. Segundo MAIOLA, o nó típico constitui- 
se num detalhe limitado do ponto de vista estrutural, não explorando a capacidade das barras e induzindo à uma baixa rigidez da estrutura, tomando-se como parâmetro de comparação a treliça ideal em análise elástica de primeira ordem.
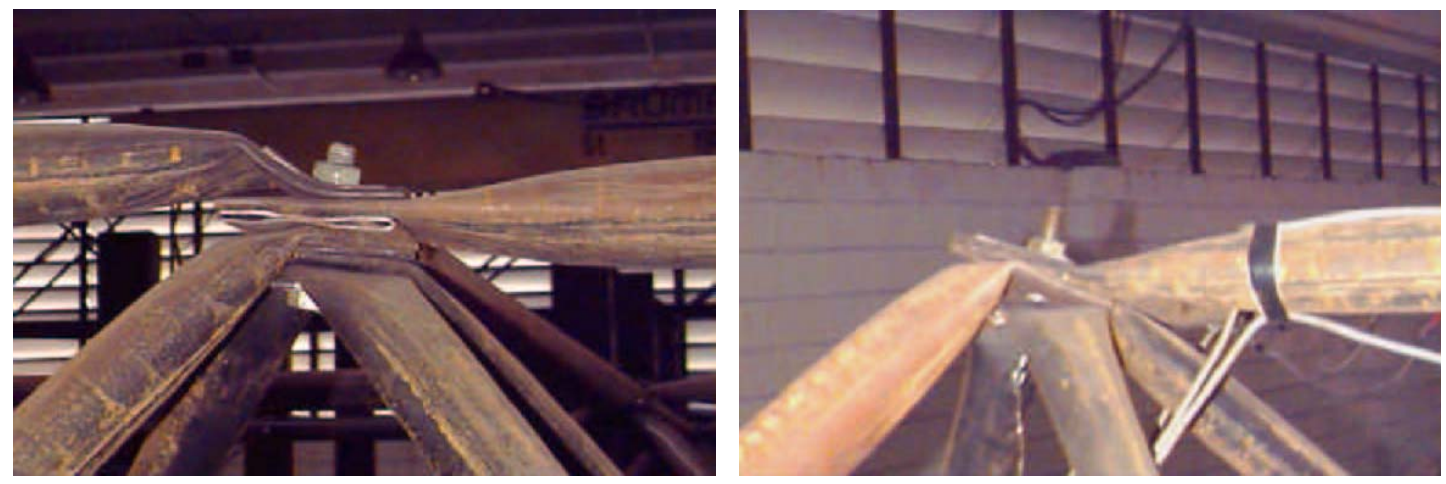

Figura 2.21 - Ruína do protótipo com nós típicos - Fonte: MAIOLA (1999)

Conforme citado por VENDRAME (1999), este nó apresenta alguns problemas, entre eles:

- Redução de inércia nas extremidades das barras,

- As barras estão ligadas por um único parafuso, contrariando as recomendações correntes de se utilizar no mínimo dois parafusos;

- Excentricidade na ligação, o que provoca o surgimento de momentos fletores nas barras, que pode acarretar em plastificação precoce nas extremidades das barras, sobretudo nas diagonais que além de amassadas são dobradas na extremidade;

- Escorregamento relativo e abertura excessiva entre as extremidades das barras, ocasionando um aumento nos deslocamentos verticais.

VENDRAME (1999) realizou uma análise numérica tridimensional do nó típico do protótipo ensaiado por MAIOLA (1999), utilizando elementos de casca (Figura 2.22). Através dessa análise, concluiu que a rigidez do nó tem influência fundamental na distribuição dos esforços nos elementos e que os 
modelos teóricos convencionais não são capazes de reproduzir o modo de ruína, caracterizado pela rotação excessiva dos nós e plastificação na região estampada dos tubos.
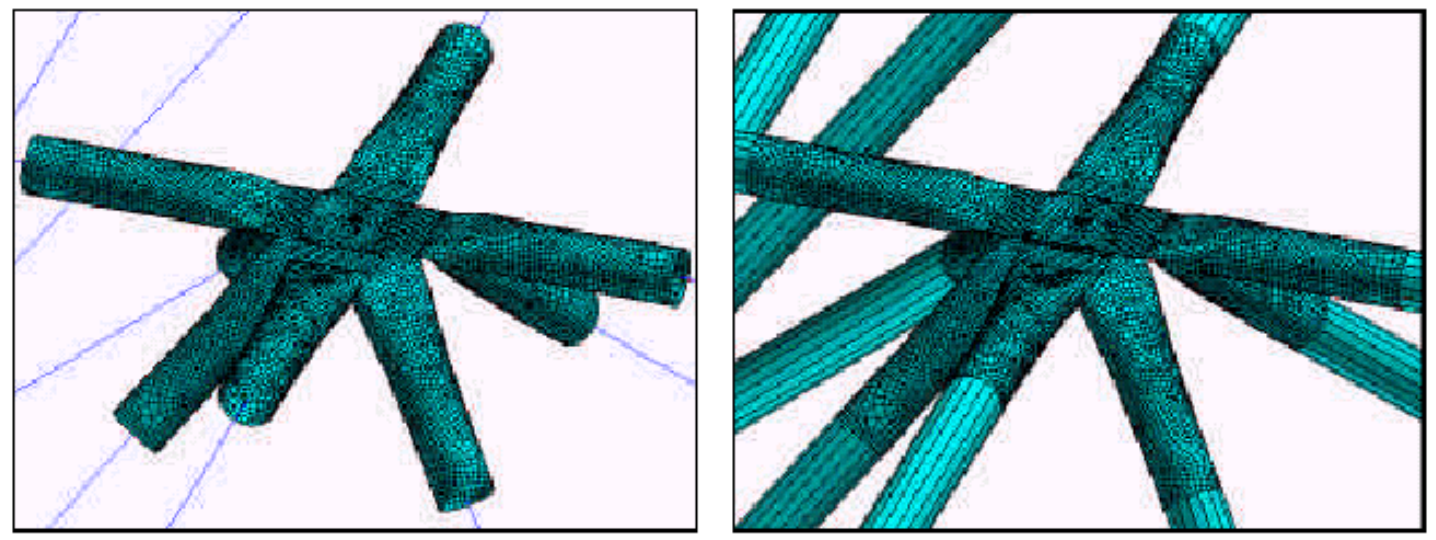

Figura 2.22 - Análise numérica tridimensional dos nós típicos Fonte: VENDRAME (1999)

Outro ponto a ser levantado é a dimensão das regiões estampadas. Muitos projetistas e fabricantes, a fim de diminuir o número de peças diferentes na obra e facilitar o detalhamento, a fabricação e a montagem da estrutura, padronizam para toda obra estampos de grandes dimensões que resolvem de maneira geral os problemas de interferência entre as barras. Estas regiões amassadas de grandes dimensões diminuem ainda mais a rigidez da região nodal e provocam o agravamento dos problemas relatados anteriormente.

\subsubsection{NÓ TÍPICO COM CHAPA DE BANZO}

Este sistema é uma variação do nó típico, com a interrupção dos banzos antes da chegada ao nó e a colocação de uma chapa para ligação (Figura 2.23). Este sistema é empregado quando os esforços nos banzos são muito elevados e podem provocar o cisalhamento do parafuso central ou o esmagamento da borda do furo, esta última situação mais comum para 
estruturas de alumínio. A chapa de ligação permite a colocação dos parafusos necessários e é responsável pela "continuidade" entre os banzos.
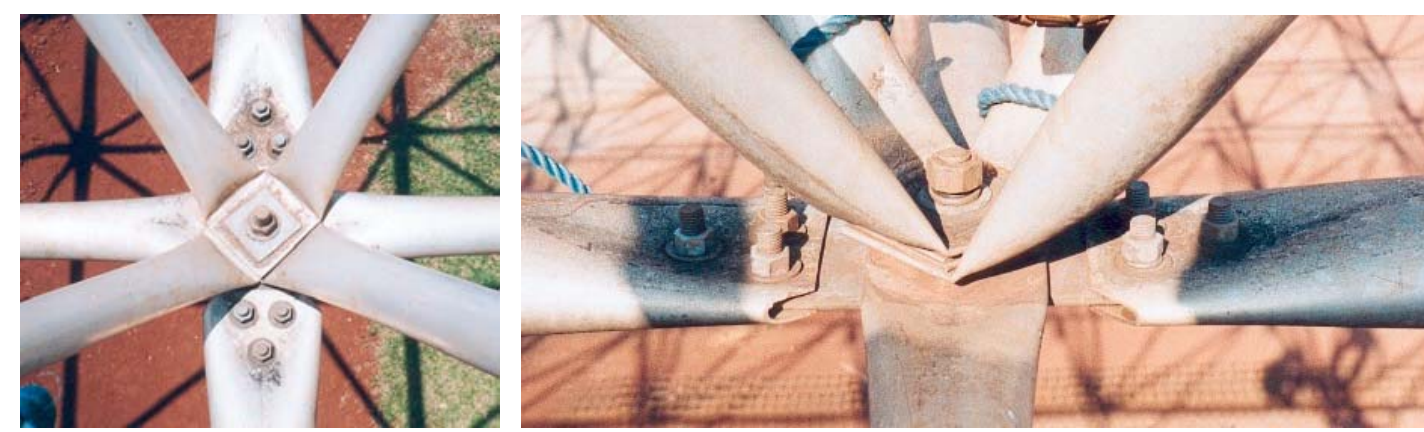

Figura 2.23 - Sistema de nó típico com chapa de banzo

Para banzos comprimidos este sistema apresenta um problema adicional em relação ao nó típico, pois a pequena rigidez à flexão da chapa pode comprometer o desempenho estrutural do nó.

\subsubsection{NÓ TÍPICO COM CHAPA DE DIAGONAL}

Este sistema também é uma variação do nó típico, com a utilização de um perfil dobrado em chapa grossa no formato de "U" para realizar as ligações das diagonais com os banzos (Figura 2.24). Este sistema apresenta uma vantagem em relação ao nó típico, pois as extremidades das diagonais não precisam ser dobradas para a ligação, porém podem surgir instabilidades na chapa do perfil "U" caso a espessura não seja suficiente. $O$ problema das excentricidades das diagonais permanece.
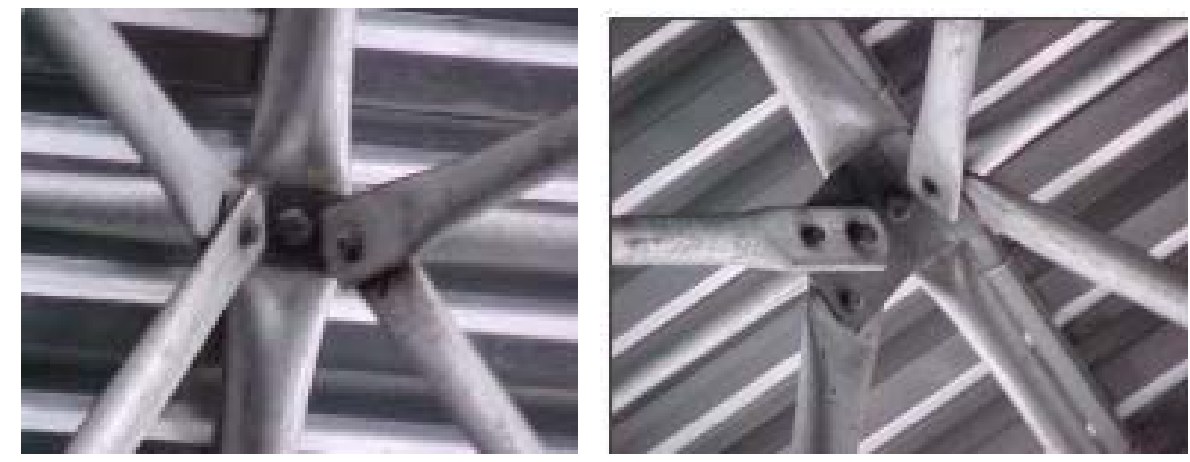

Figura 2.24 - Sistema de nó típico com chapa de diagonal 
D'ESTE (1998) realizou ensaios de protótipos de treliça com este tipo de nó. Em todos os protótipos o carregamento último experimental resultou muito inferior ao previsto teoricamente. O modo de ruína típico foi a instabilidade do perfil "U" ou a plastificação das extremidades das barras estampadas.

\subsubsection{NÓ DE AÇO}

Neste sistema as barras são conectadas por parafusos a um nó composto por chapas soldadas, sendo teoricamente possível eliminar as excentricidades (Figura 2.25). Estes nós apresentam um comportamento estrutural melhor que os anteriores, mas o custo de produção é muito superior.

Existem vários tipos de nós de aço, cuja escolha está relacionada a diversos fatores, entre eles: geometria da estrutura, níveis de esforços e padrões do fabricante.
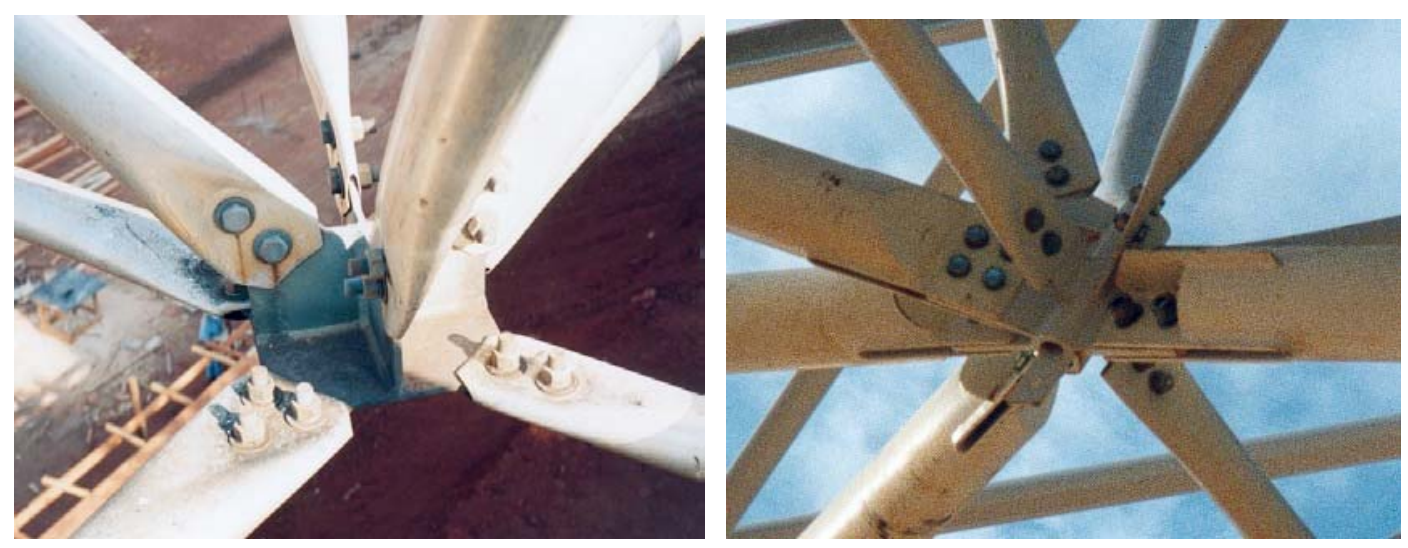

Figura 2.25 - Sistemas de nó de aço - o primeiro mais utilizado em treliças espaciais planas, e o segundo em arcos e cúpulas espaciais

MAIOLA (1999) ensaiou um protótipo que apresentava este sistema de ligação, com dimensões em planta 7,5m x 7,5m, modulação 2,5m x 2,5m e altura $1,5 \mathrm{~m}$. O protótipo ensaiado apresentou uma carga última próxima ao do valor teórico. O modo de falha foi a flambagem das barras comprimidas, evidenciando a eficiência do nó (Figura 2.26). Comparando-se os 
deslocamentos teóricos com os experimentais, em serviço, o modelo teórico de treliça ideal em análise elástica de primeira ordem foi satisfatório para este sistema. Segundo MAIOLA, o sistema de nó de aço quando comparado ao sistema de nó típico, apresentou uma maior eficiência estrutural, conduzindo a uma maior eficiência e rigidez da estrutura.

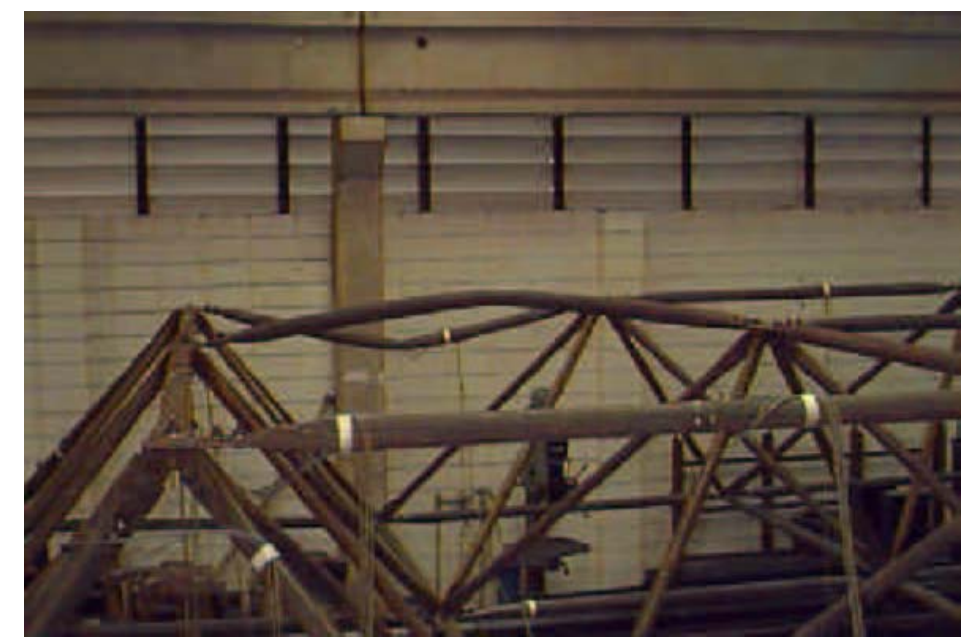

Figura 2.26 - Ruína do protótipo com nós de aço - Fonte: MAIOLA (1999)

Vale salientar que caso a distância entre o centro da ligação da barra e o centro no nó seja muito grande, podem ocorrer problemas de instabilidade nas chapas que compõem o nó, visto que as mesmas apresentam baixa rigidez à flexão fora de seu plano.

Nos sistemas de nó típico e de nó típico com chapa de diagonal, as barras utilizadas são perfis de seção tranversal tubular circular com as extremidades estampadas. No sistema de nó típico com chapa de banzo, as barras ligadas à chapa podem apresentar as extremidades estampadas ou na forma de uma ponteira constituída por chapas soldadas, porém as demais barras conectadas ao nó apresentam as extremidades estampadas. No sistema de nó de aço todas as barras podem apresentar as extremidades estampadas ou na forma de ponteira. A escolha pelo tipo de extremidade, na maioria das vezes, está ligada ao diâmetro e à espessura do tubo a ser conectado. Tubos de diâmetro e espessura elevados são difíceis de serem 
estampados, por isso opta-se pela execução de ponteiras, que constituem um detalhe de melhor desempenho estrutural. Salienta-se, que alguns fabricantes utilizam ponteiras para todos os diâmetros, não utilizando tubos estampados.

As barras com ponteiras formadas por chapas muito esbeltas podem apresentar reduções na capacidade devido a problemas de instabilidade. Para minorar os efeitos deste problema, algumas ponteiras apresentam chapas enrijecedoras soldadas perpendicularmente ao plano principal da ligação. Normalmente, as ponteiras são formadas por duas chapas que se encaixam na aleta (chapa) do nó, ou o inverso, uma chapa na ponteira e duas no nó, realizando uma ligação na qual os parafusos trabalham a corte duplo e a barra fica centralizada na ligação (Figura 2.27). Existem detalhes de ponteira que utilizam uma chapa única, a qual é ligada na aleta do nó que também é uma chapa única. Isto faz com que as ligações funcionem a corte simples e apresentem desalinhamento entre o eixo da barra e o eixo do nó, prejudicando o desempenho da ligação.

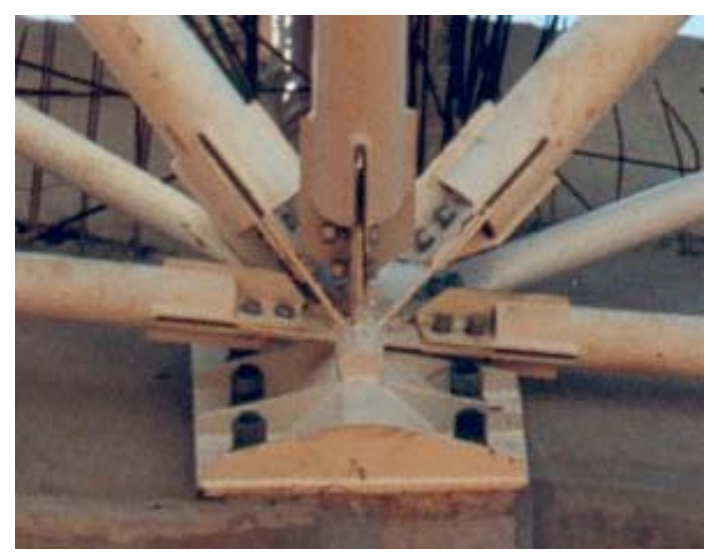

Figura 2.27 - Sistema de nó de aço com barras com ponteiras

Os sistemas descritos anteriormente podem ser utilizados de maneira combinada, assim, é muito comum existirem na mesma estrutura nós típicos e nós de aço, sendo estes últimos utilizados nas regiões de maiores esforços. Esse sistema "misto", ensaiado por MAIOLA (1999), apresentou valores de rigidez e resistência intermediários aos dos sistema de nó típico e nó de aço, podendo representar uma solução interessante em alguns casos, 
embora necessite de mais estudos, tendo em vista a limitação estrutural observada no nó típico. Na Figura 2.28 apresenta-se graficamente, o comportamento força aplicada $\mathrm{x}$ deslocamento vertical do nó central para os protótipos com nó típico (PROT 1), nó de aço (PROT 3) e "misto" (PROT 4) ensaiados por MAIOLA (1999).

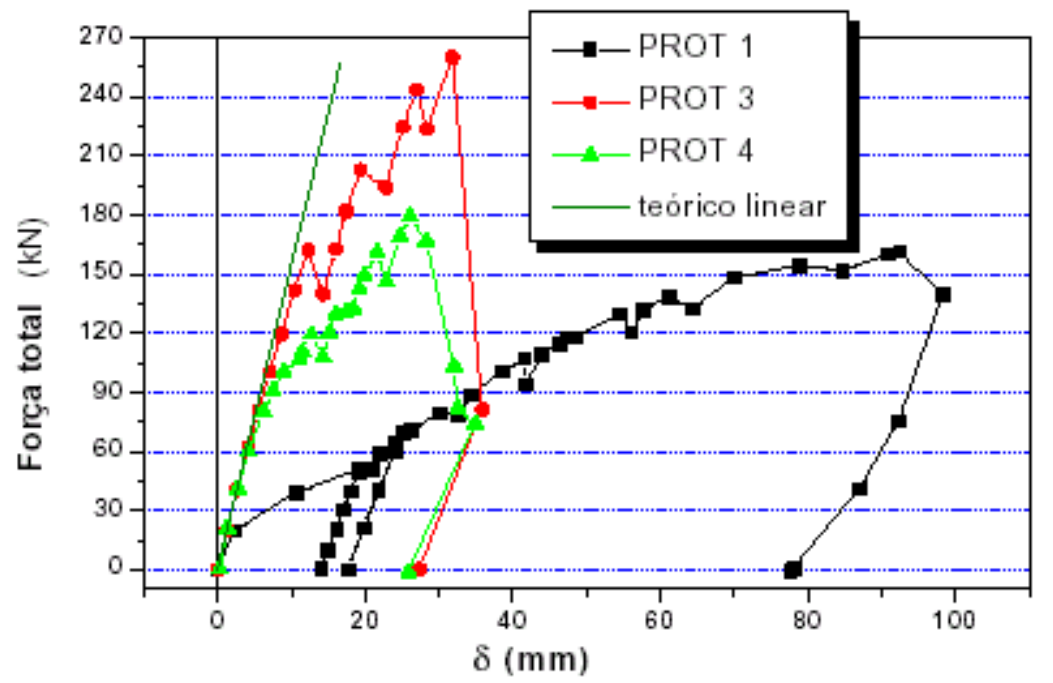

Figura 2.28 - Deslocamentos verticais dos protótipos ensaiados Fonte: MAIOLA (1999)

Pode-se perceber que os sistemas utilizados no Brasil nem sempre condizem com os modelos teóricos empregados comumente na análise estrutural, o de treliça ideal em análise linear elástica. Por esse motivo, vários trabalhos teóricos e experimentais vêm sendo desenvolvidos na EESC-USP com o objetivo de avaliar o real comportamento destes sistemas de ligação.

\subsection{ANÁLISE ESTRUTURAL DE TRELIÇAS ESPACIAIS}

Algumas características fazem as estruturas espaciais reticuladas terem uma análise estrutural diferenciada, entre elas, a tridimensionalidade, 
a grande quantidade de elementos estruturais e o alto grau de hiperestaticidade.

Sendo a estrutura espacial reticulada um conjunto de barras interconectadas em um número finito de pontos, é natural esperar que um modelo discreto forneça uma melhor simulação do comportamento real do que um modelo contínuo. Porém, a confiabilidade do método discreto pode apresentar dois pontos de incerteza de difícil avaliação em modelos discretos: imperfeições geométricas e eficiência dos nós.

Outra análise importante diz respeito ao comportamento linear ou não linear das estruturas espaciais.

Segundo MALLA \& SERRETTE (1996b), para pequenos deslocamentos e baixos valores de carregamento (condições de serviço), o material exibirá um comportamento elástico linear. Para estes casos, uma análise elástica linear é suficiente para prever o comportamento da estrutura.

A análise elástica linear de sistemas hiperestáticos assume barras perfeitas e uma resposta linear à força normal. Segundo MARSH (2000), devido à redundância natural de uma estrutura espacial reticulada, imperfeições geométricas podem levar a uma distribuição de forças entre as diversas barras que difere da ideal, com a possibilidade de algumas barras receberem esforços superiores aos previstos na análise teórica, podendo levar a uma falha prematura. Para levar em conta esta possibilidade, imperfeições devem ser introduzidas no modelo elástico analisado, e suas conseqüências estabelecidas.

HILL et al. (1989) sugerem um comportamento linear apenas para estruturas com pequenos deslocamentos e solicitações de serviço, desde que a região nodal represente corretamente esta condição. Para as demais estruturas, o comportamento apenas pode ser adequadamente avaliado considerando as não linearidades física e geométrica. Para as treliças espaciais, devem ser consideradas as não linearidades tanto nas barras como nos nós. 
Para análise não linear, podem ser considerados dois tipos de não linearidade:

- geométrica: relacionada ao equilíbrio de um sistema estrutural na posição deslocada. A consideração da não lineridade geométrica é necessária quando a configuração deslocada da estrutura é significativamente diferente da configuração original;

- física: relacionada ao comportamento não linear da relação tensão x deformação do material;

Para as treliças espaciais é interessante a análise das não lineridades geométricas, pois alguns de seus efeitos, tais como grandes deslocamentos e rotações, podem alterar significativamente o equilíbrio da estrutura. Imperfeições geométricas tais como falta de linearidade das barras e excentricidades de carregamento tendem a amplificar o comportamento não linear.

Para se realizar uma análise não linear física, é necessário idealizar um modelo constituivo (tensão $x$ deformação) para o material. Conforme citado por SOUZA (1998), para as barras tracionados o diagrama tensão $x$ deformação é facilmente obtido por meio de um ensaio de tração. Porém, para barras comprimidas é mais complicado estabelecer o comportamento tensão $\mathrm{x}$ deformação, pois se deve considerar o efeito da flambagem. $\mathrm{A}$ flambagem destas barras depende, além das características do material, da esbeltez e das condições de vinculação.

MADI \& EL-TAYEM (1993) idealizam uma relação tensão $x$ deformação composta por quatro trechos distintos (Figura 2.29):

1. trecho correspondente a fase elástica do material, na tração e na compressão;

2. patamar de escoamento, referente à fase de plastificação do material tracionado;

3. trecho correspondente ao decréscimo da resistência após ser atingida uma tensão limite na compressão; 
4. patamar referente à resistência residual do material na compressão.

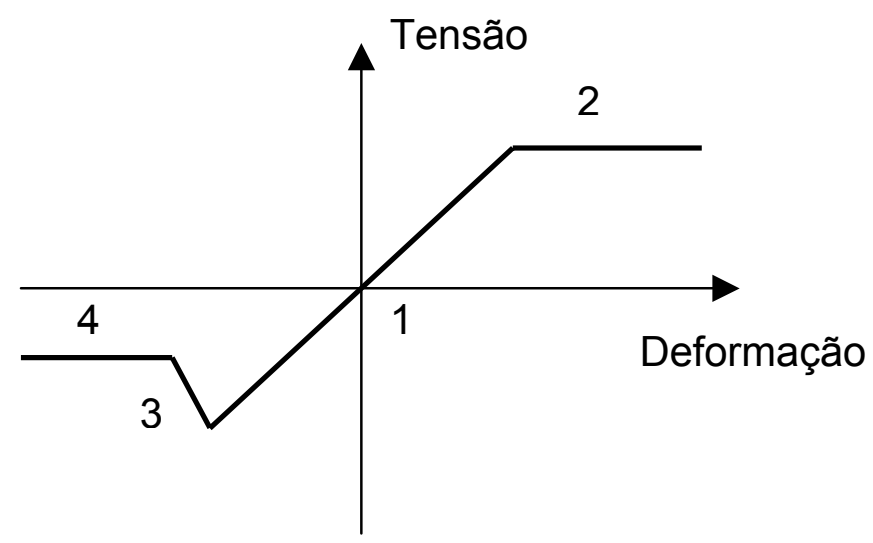

Figura 2.29 - Relação Tensão x Deformação Fonte: MADI \& EL-TAYEM (1993)

MURTHA-SMITH (1994) descreve alguns métodos de análise de elementos comprimidos para o uso na análise não linear de estruturas espaciais, e alerta que o aumento do nível de sofisticação e acuracidade dos modelos implica num maior esforço computacional.

Na prática corrente, os projetistas e fabricantes utilizam o método dos elementos finitos e uma análise linear elástica (teoria de primeira ordem), considerando a treliça com nós rotulados.

Segundo MAKOWSKI (1987), a rigidez das conexões em treliças espaciais planas tem pouco efeito nas magnitudes das forças normais (de 10 a 15\%), e por isso, durante a análise computacional, as treliças espaciais são idealizadas com ligações rotuladas e com todas as ações externas aplicadas aos nós. SAKA \& HEKI (1984) concordam que as forças normais obtidas supondo todos os nós rotulados são uma boa aproximação para uso prático, até mesmo se existirem restrições de rotações nos nós. Porém, a resistência da treliça espacial como um todo não é sempre a mesma daquela correspondente à treliça com todos os nós rotulados. Não somente a própria resistência do nó, mas também a rigidez da ligação afeta a resistência da treliça. 
A seqüência da análise estrutural normalmente empregada é a seguinte:

1. Assume-se um perfil único para cada um dos grupos (banzos e diagonais) e procede-se a análise linear elástica (teoria de primeira ordem), por computador, para os carregamentos de projeto;

2. Altera-se à seção das barras buscando-se aquelas que resistam, de acordo com os padrões da norma adotada, aos níveis de tensões encontrados. Realiza-se também uma uniformização de perfis por regiões visando limitar o número de perfis diferentes na obra;

3. Processa-se um novo ciclo de análises. Caso alguma força na barra tenha se alterado e o perfil anteriormente adotado seja insuficiente, altera-se novamente o perfil. Este item 3 é repetido a quantidade de vezes necessárias até que não haja mais nenhuma alteração.

\subsection{COMPORTAMENTO ESTRUTURAL DE TRELIÇAS ESPACIAIS}

\subsubsection{COMPRIMENTO DE FLAMBAGEM DAS BARRAS}

Usualmente, as barras comprimidas têm seu comprimento de flambagem tomado igual à distância de centro a centro dos nós. Segundo MARSH (2000), o comprimento de flambagem de uma barra comprimida é função da orientação das barras que se conectam ao nó, das suas rigidezes à torção, das forças atuantes e do modo de conexão ao nó. Se todas as barras que se conectam ao nó estiverem com seus valores máximos de compressão, como pode ocorrer na região central de uma estrutura de cobertura, não haverá restrição a nenhuma das barras e o comprimento de flambagem dos banzos e diagonais será a distância de centro à centro dos nós, para flambagem em torno de quaisquer eixos. Se os banzos e as 
diagonais estiverem pouco solicitados em relação a suas capacidades máximas, o parâmetro efetivo de flambagem (K) para os banzos comprimidos pode chegar a 0,7. Por outro lado, a instabilidade no nó pode reduzir a capacidade para um valor abaixo do valor de uma rótula simples, resultando $\mathrm{K}>1$.

MADI \& EL-TAYEM (1991) sugerem os seguintes valores de K para uso em uma análise elástica :

- Barras com seção completa na extremidade (barras com as extremidades soldadas, por exemplo, sistema OKTAPLATTE - Figura 2.15): $\mathrm{K}=0,70$;

- Barras com seção reduzida nas extremidades (barras com as extremidades tronco-cônicas, por exemplo, sistema MERO - Figura 2.12): $\mathrm{K}=0,90$;

- Barras com extremidades estampadas (por exemplo, sistema de nó típico - Figura 2.19): $\mathrm{K}=0,95$.

Vale salientar que os valores citados por MADI \& EL-TAYEM (1991) são contra a segurança. Por exemplo, para o caso de barras com extremidades estampadas (nó típico), devido as deficiências deste tipo de ligação, o valor de $\mathrm{K}$ pode ser superior a 1. Na prática, os projetistas, no Brasil, utilizam $\mathrm{K}$ igual a 1.

\subsubsection{COMPORTAMENTO DOS ELEMENTOS E DO CONJUNTO}

Segundo SCHMIDT (2000), a resposta global de uma treliça espacial será, geralmente, muito dependente das características de resistência das barras comprimidas. Como a maioria das barras em uma treliça espacial tem esbeltez elevada, as respostas das barras comprimidas e da treliça ao carregamento último apresentam um comportamento instável. Conseqüentemente, até mesmo o valor teórico referente ao limite do comportamento elástico pode não ser alcançado devido ao comportamento instável das barras, as quais são particularmente sensíveis às imperfeições, tais como curvatura inicial e excentricidades da força normal. 
Os esforços atuantes nas barras podem variar consideravelmente em relação aos obtidos na análise teórica, por causa das imperfeições nas linhas de ação das forças, tolerâncias nos comprimentos das barras e a existência de estados pré-tensionados que interagem com estes fatores. A montagem de centenas, se não milhares, de barras com alto grau de interação na treliça espacial, significa que forças iniciais podem ser geradas durante a montagem, que não são levadas em conta durante o cálculo.

BALUT \& GIONCU (2000) discutem os efeitos das imperfeições das barras, tais como curvaturas, tensões residuais e diferenças de comprimento, mostrando as reduções que estas imperfeições podem causar na capacidade de barras comprimidas e no comportamento global da estrutura.

Segundo MURTHA-SMITH (1994), existe continuidade entre as barras em muitas treliças espaciais devido ao sistema de conexão empregado. $\mathrm{O}$ efeito da continuidade é o aumento do nível de carregamento requerido para causar a instabilidade da primeira barra, contudo, não necessariamente aumenta o carregamento requerido para levar à ruína.

A maioria das pesquisas recentes sobre o comportamento das treliças espaciais foi focada nos aspectos relativos ao comportamento dos banzos, incluindo os efeitos de falhas locais, imperfeições geométricas e super ou sub-dimensionamento. Porém, poucas pesquisas foram apresentadas sobre o comportamento das diagonais e seus efeitos na estrutura. EL-SHEIKH (1999) apresenta um trabalho sobre a influência das diagonais no comportamento das treliças espaciais, mostrando o quão críticas estas barras podem ser.

Segundo HANAOR \& MARSH (1989), a ductilidade e a distribuição de esforços entre as barras da treliça espacial, influenciam diretamente o seu comportamento. Uma maneira de se aumentar a ductilidade é o subdimensionamento dos banzos tracionados e super-dimensionamento dos banzos comprimidos. Assim, provoca-se um escoamento inicial nas barras tracionadas e retarda-se a flambagem das barras comprimidas. 
MARSH (1986) descreve como, pela remoção de algumas diagonais selecionadas, pode-se aumentar a capacidade de treliças que apresentam banzos uniformes.

Conforme citado por MAIOLA (1999), a instabilidade rotacional das conexões pode influenciar o comportamento da estrutura. Esta instabilidade pode ser causada pela redução de rigidez das barras nas extremidades, ações de forças excêntricas, forças desbalanceadas no nó ou pela própria flexibilidade da conexão.

\subsubsection{RUÍNA ESTRUTURAL}

Segundo MARSH (2000), o início da ruína pode se dar devido a qualquer um dos seguintes estados limites:

- Falha por falta de resistência à tração;

- Falha por falta de resistência à compressão;

- Falha por falta de resistência da conexão;

- Instabilidade da região nodal.

Se a falha de uma barra conduz à ruína ou à redistribuição de esforços entre as barras com maior resistência, depende da posição da barra. Por exemplo, as diagonais, exceto aquelas ligadas aos apoios, não são usualmente críticas, e muitas podem falhar antes que a ruína ocorra.

Geralmente assume-se que uma boa concepção estrutural requeira que um razoável grau de hiperestaticidade seja estabelecido na estrutura. Assim, se ocorrer a falha de uma ou várias barras, a estrutura irá se deformar de uma maneira dúctil, e não numa maneira catastrófica. No dimensionamento de estruturas espaciais é necessário que seja dada atenção especial a esta situação, pois nem sempre alto grau de hiperestaticidade indica alta reserva de resistência (SCHIMDT 2000).

AFFAN \& CALLADINE (1986) analisam o caso de uma treliça espacial plana apoiada nos quatro vértices, conforme mostrado na Figura 2.30, que pode apresentar ruína quando submetida a um aumento regular de ação vertical. 


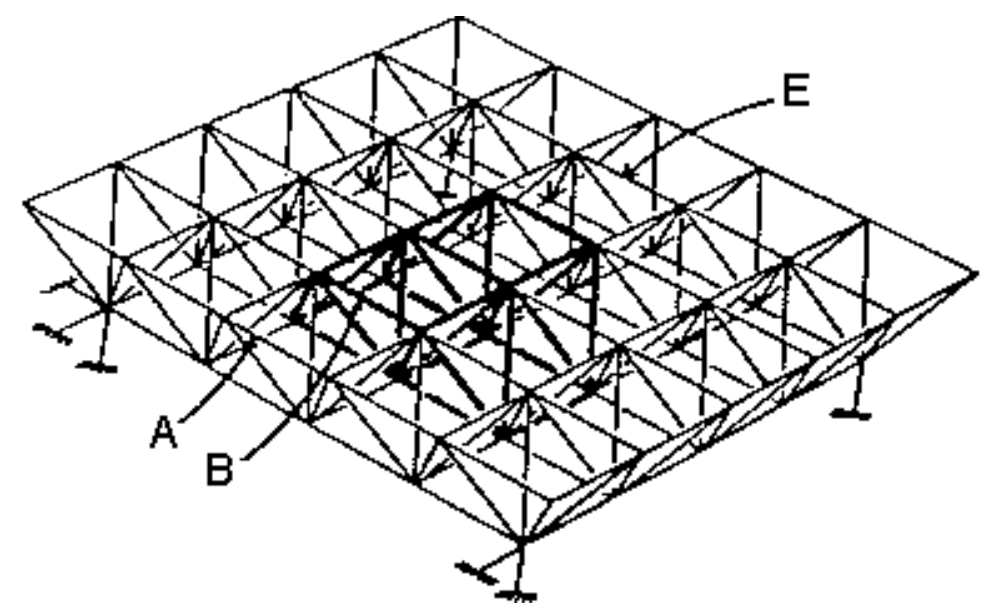

Figura 2.30 - Treliça espacial plana apoiada nos quatro vértices Fonte: AFFAN \& CALLADINE (1986)

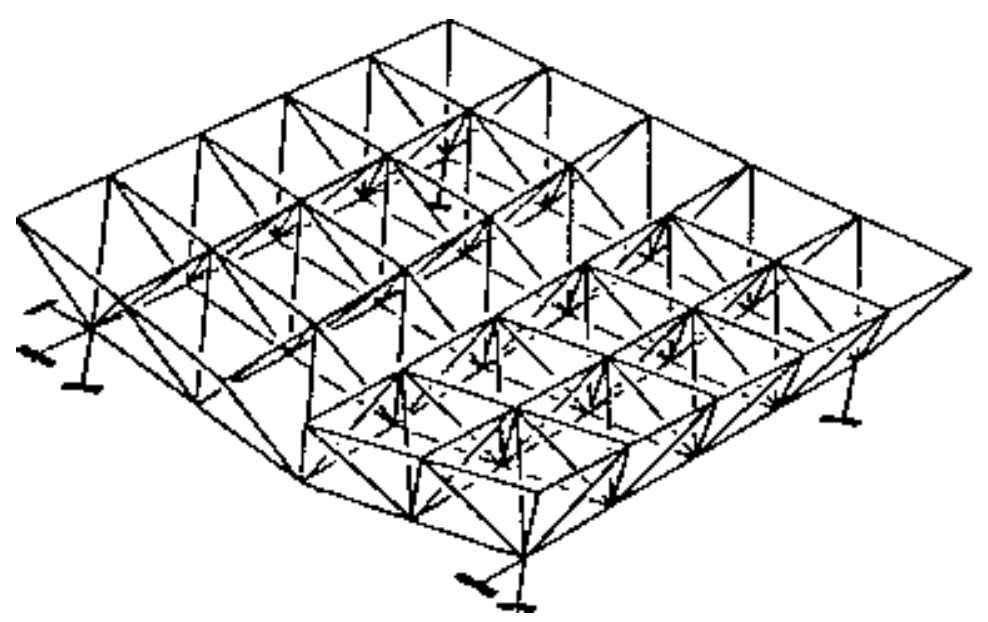

Figura 2.31 - Formação de um mecanismo de ruína na treliça Fonte: AFFAN \& CALLADINE (1986)

Se as barras da estrutura mostrada na Figura 2.30 têm igual resistência, e o carregamento vertical é uniforme, as barras de borda na posição "A" apresentam a maior força normal de compressão, e quando uma delas falha por flambagem, as barras "B", ..., "E" ficam sujeitas a acréscimos de solicitação, o que leva rapidamente à formação de um mecanismo de ruína conforme mostrado na Figura 2.31. Existem duas causas principais neste tipo de falha. Primeiro, as barras são esbeltas e possuem pequena resistência pós-flambagem. Segundo, a falha de uma barra leva a uma 
propagação instável da falha ao longo da estrutura. Há pouco que se possa fazer com relação ao primeiro fator, mas pode ser bem possível criar maneiras de se alterar o modo de propagação da falha da barra ao longo da estrutura. Por exemplo, as condições de contorno podem fazer muita diferença. Se os pontos de apoio estivessem em toda borda e não apenas nos vértices, o comportamento de ruína seria muito menos instável.

Segundo MALLA \& SERRETTE (1996b), várias situações, tais como vibração excessiva, imperfeições geométricas, impactos, acidentes, defeitos em materiais e conexões, e fenômenos de flambagem, podem causar danos, ou grandes deformações, ou aumento de tensão em uma barra ou em parte da estrutura. Apesar de um dano em uma barra afetar inicialmente uma pequena porção da estrutura, ele tem potencial para se propagar para outras partes da estrutura e pode até causar a ruína da estrutura, conforme já mostrado no estudo realizado por AFFAN \& CALLADINE (1986). Este tipo de mecanismo de falha é conhecido por "colapso progressivo".

O "colapso progressivo" resulta da redistribuição de esforços quando uma barra falha, causando conseqüentemente, um aumento de solicitação em outra barra. Os dois métodos práticos mais utilizados para se analisar o "colapso progressivo" são o método da remoção de barras, que se baseia na retirada da barra que tenha atingido sua capacidade, e o método da resistência residual da barra, que consiste em se limitar o valor da resistência da barra que tenha atingido sua capacidade.

MURTHA-SMITH (1988) analisa a vulnerabilidade das treliças espaciais ao "colapso progressivo". Para isso, ele utiliza um método alternativo, no qual somente uma barra é removida e a estrutura é analisada para determinar-se o efeito. Usando uma análise linear, os fatores de segurança de todas as barras são determinados para cada treliça danificada analisada, para as ações de serviço. Usando uma análise não linear, o carregamento de ruína para estrutura danificada pode ser determinado, e um coeficiente de segurança global pode ser estabelecido para o sistema. As análises lineares mostram que algumas barras são mais críticas que outras para iniciarem o "colapso progressivo". A análise não linear mostra que há 
alguma correlação entre os resultados da análise linear e da não linear, mas somente a análise não linear pode determinar se haverá a ruína da estrutura devido a um dano local. $O$ estudo demonstrou que as treliças analisadas, que foram dimensionadas de uma maneira convencional, eram vulneráveis ao "colapso progressivo" para todas as ações de dimensionamento. $\mathrm{O}$ autor sugere que os banzos comprimidos e diagonais ao longo e nas proximidades das linhas de apoio sejam super-dimensionados, particularmente no meio do vão do alinhamento dos apoios.

MURTHA-SMITH \& LEARY (1993) utilizando o mesmo método da remoção de uma barra para análise do "colapso progressivo", analisaram a influência dos seguintes parâmetros: quantidade e localização dos apoios, relação vão / dimensão do módulo, relação altura / vão e relação maior vão / menor vão. O parâmetro de maior influência no comportamento foi a localização dos apoios, tendo como pior situação aquela com apoios apenas nos quatro vértices.

MALLA \& SERRETTE (1996b) alertam que a falha ou ruptura de uma barra que comanda o início do "colapso progressivo" é um processo que causa efeitos dinâmicos na estrutura que devem ser avaliados.

\subsection{ASPECTOS RELATIVOS AO PROJETO DE TRELIÇAS ESPACIAIS}

\subsubsection{APOIOS}

A quantidade e a disposição dos apoios exercem grande influência no comportamento das treliças espaciais, pois determinam os vãos livres e balanços.

As restrições impostas, quanto às translações e às rotações, nos pontos de apoio também influenciam muito no comportamento. Geralmente, os apoios apresentam restrições às translações verticais e horizontais. As restrições podem ser totais ou parciais, neste caso são substituídas por coeficientes de mola que representam as rigidezes dos pontos de apoio. 
Normalmente, as treliças espaciais apresentam elevadas reações horizontais, causadas tanto pela variação de temperatura, como pela ação do vento nos fechamentos das treliças. Quando existem limitações quanto à máxima reação horizontal, seja pela resistência do pilar ou da fundação, os apoios podem ser do tipo móvel, com translações livres em uma ou mais direções horizontais. Os apoios do tipo móvel eliminam as reações horizontais, porém aumentam os deslocamentos.

Existem diversas formas e tipos de apoio, algumas utilizadas são:

- Apoios no banzo inferior: são os mais utilizados, pois tornam os apoios mais simples e evitam as interferências (Figura 2.32);

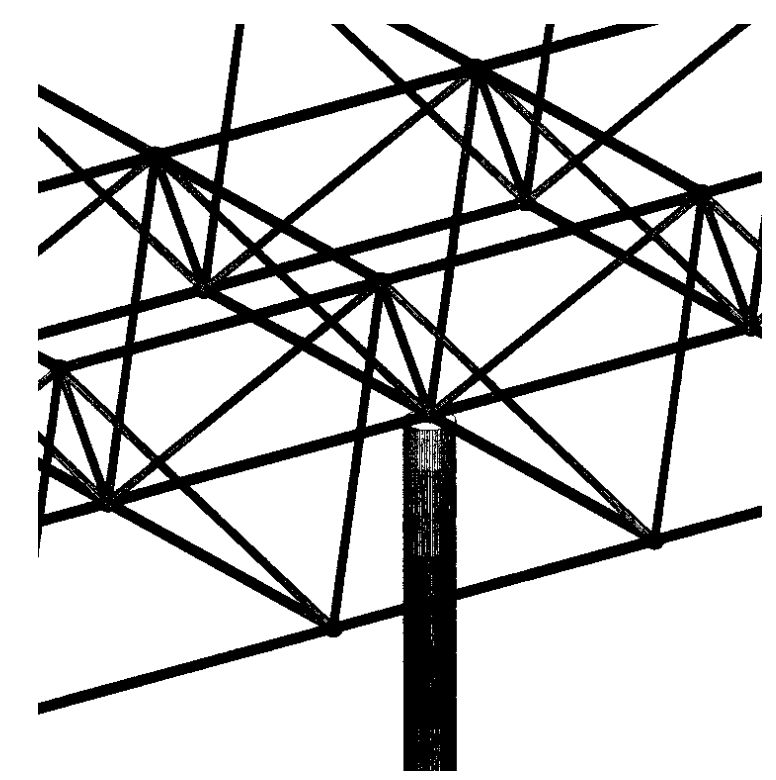

Figura 2.32 - Apoio no banzo inferior

- Apoios no banzo superior: são menos utilizados, pois podem ocorrer interferências entre as diagonais da treliça e a seção do pilar, dependendo das dimensões e dos ângulos envolvidos. Normalmente ocorrem quando a modulação do banzo superior coincide com o ponto em que deve estar o pilar pelo projeto arquitetônico (Figura 2.33); 


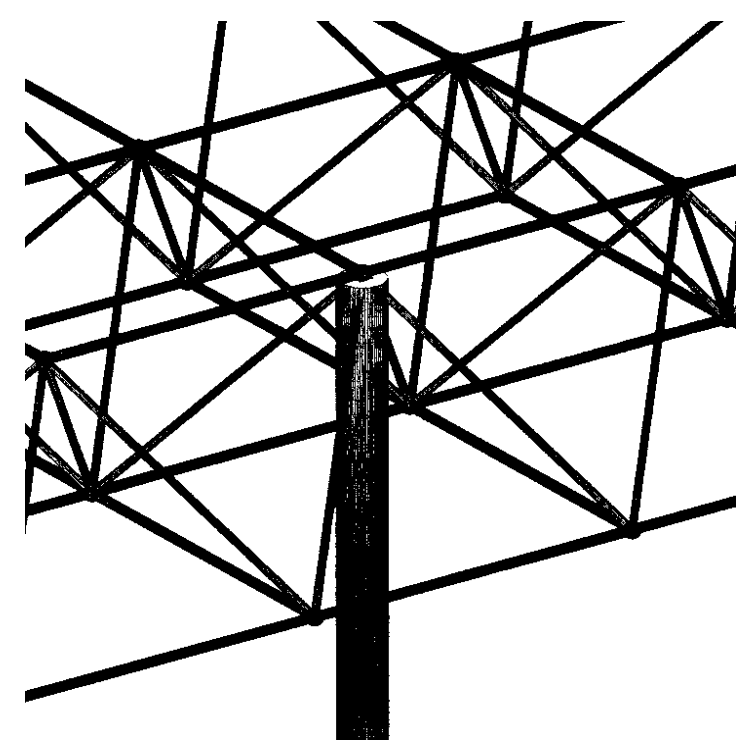

Figura 2.33 - Apoio no banzo superior

- Apoios do tipo "pé-de-galinha": o ponto de apoio está abaixo do nível do banzo inferior, sendo a ligação da estrutura ao ponto de apoio feita por meio de diagonais auxiliares. Estes apoios geralmente são escolhidos para atender a um destes três fatores: projeto arquitetônico, falta de coincidência da modulação do banzo inferior com o ponto de apoio ou tentativa de diminuição do vão livre entre apoios (Figura 2.34);

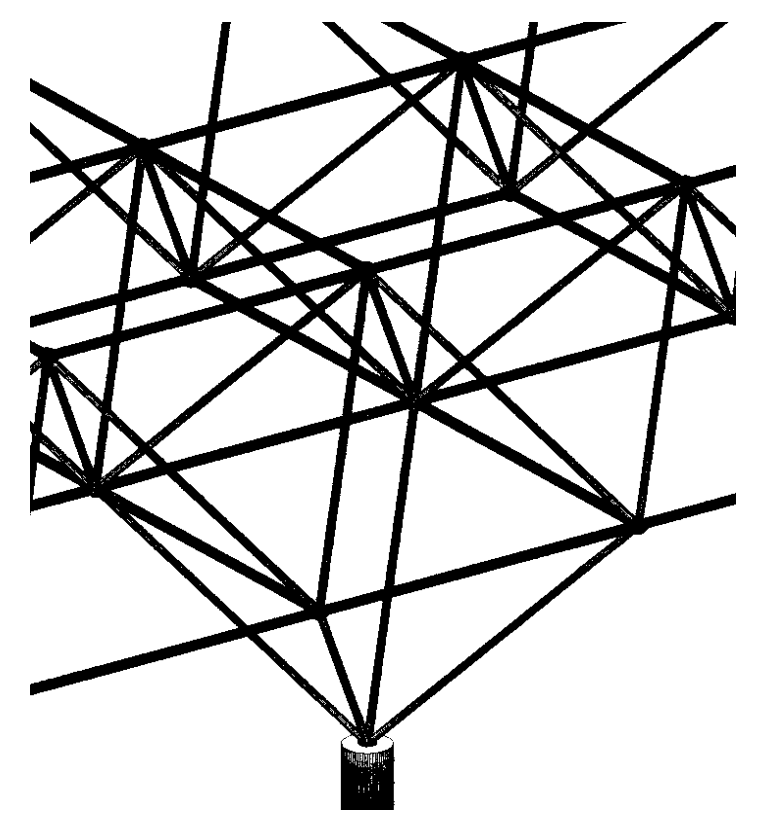

Figura 2.34 - Apoio do tipo "pé-de-galinha" 
- Apoios do tipo "engaste": as barras da treliça apóiam-se em mais de um nível do pilar. Utilizados em treliças espaciais com mais de duas camadas de banzo, em que existam limitações de deslocamentos ou de reações de apoio. São de difícil execução pois implicam em interferências entre as barras e o pilar (Figura 2.35);

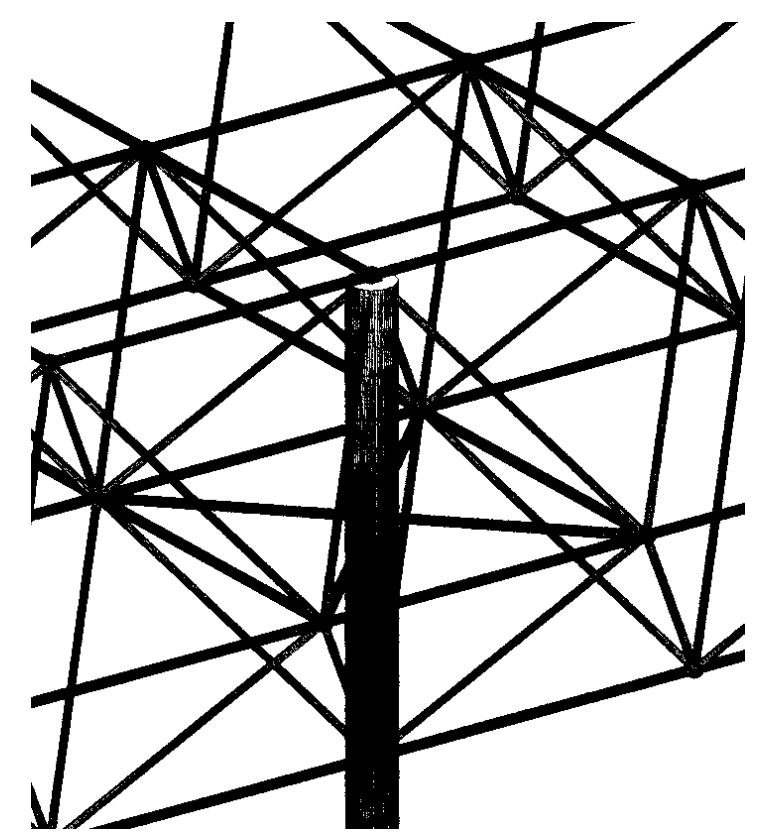

Figura 2.35 - Apoio do tipo "engaste"

O posicionamento dos apoios define os balanços laterais da estrutura. A principal vantagem da utilização dos balanços é a redução dos momentos fletores no meio dos vãos internos da estrutura, levando a uma treliça de dimensionamento mais econômico. Porém, em situações em que a força de sucção do vento seja muito elevada, estes balanços, dependendo de suas dimensões, podem apresentar um dimensionamento antieconômico.

\subsubsection{ARRANJO GEOMÉTRICO}

Conforme já foi discutido no item 2.2, existem diversos arranjos geométricos possíveis, que levam a diferentes distribuições de tensões. Formas geométricas ótimas geralmente apresentam tensões distribuídas 
uniformemente. Alguns fatores importantes na determinação do arranjo geométrico mais apropriado são a quantidade e a posição dos apoios, o layout em planta da edificação, o custo dos nós e as técnicas de montagem e içamento a serem utilizadas.

Segundo AGERSKOV (1986), a determinação do arranjo geométrico ótimo não deve estar associada apenas às soluções de mínimo peso, devem ser levados em conta outros fatores, tais como, número de nós ( $25 \%$ a $75 \%$ do custo da treliça - IFFLAND 1982) e número de barras. A densidade de barras na estrutura deve ser baixa, pois além de reduzir o consumo de material diminui o número de nós e o custo da montagem. A estrutura deve apresentar barras tracionadas longas e barras comprimidas curtas.

Várias formas têm sido utilizadas ao longo dos anos. Os tipos de unidades básicas construtivas mais utilizados são a tetraédrica, a cúbica e a octaédrica, por apresentarem melhor adequação às treliças espaciais planas. No uso destas formas, naturalmente tem se tentado otimizar a disposição das barras nos arranjos, de tal forma que a resistência da treliça seja aumentada. Alguns dos arranjos geométricos mais utilizados nas obras correntes e também mais analisados nas pesquisas teóricas e experimentais são:

- Arranjo quadrado sobre quadrado com defasagem de meio módulo: este é sem dúvida o tipo de disposição de barras mais utilizado e mais estudado, tem como unidade básica um tetraedro de forma piramidal que se repete ao longo de toda estrutura (Figura 2.36);

- Arranjo quadrado diagonal sobre quadrado diagonal com defasagem de meio módulo: este tipo é uma variação do arranjo anterior, com inclinação dos banzos de $45^{\circ}$ (Figura 2.37). Segundo alguns autores (SHUTUN 1999), este tipo de disposição de barras apresenta uma melhor distribuição de esforços, diminuindo as deformações e os esforços internos. Uma das desvantagens deste sistema é que o banzo superior em diagonal dificulta o detalhamento de fabricação, e aumenta 
a dimensão, dos elementos da estrutura secundária de cobertura (terças, travessas, etc.) ;
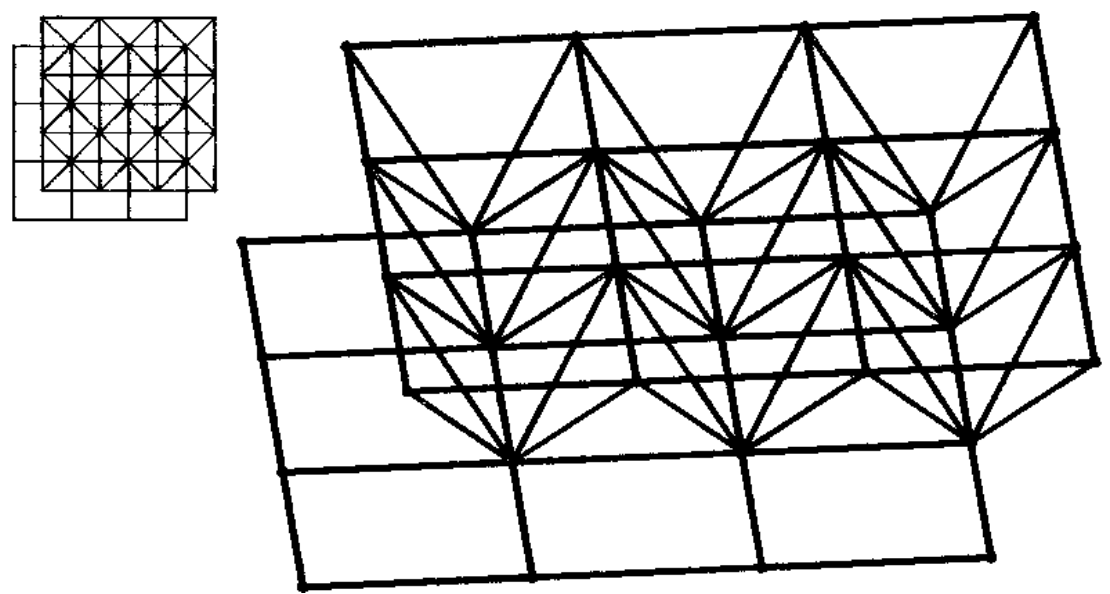

Figura 2.36 - Arranjo quadrado sobre quadrado
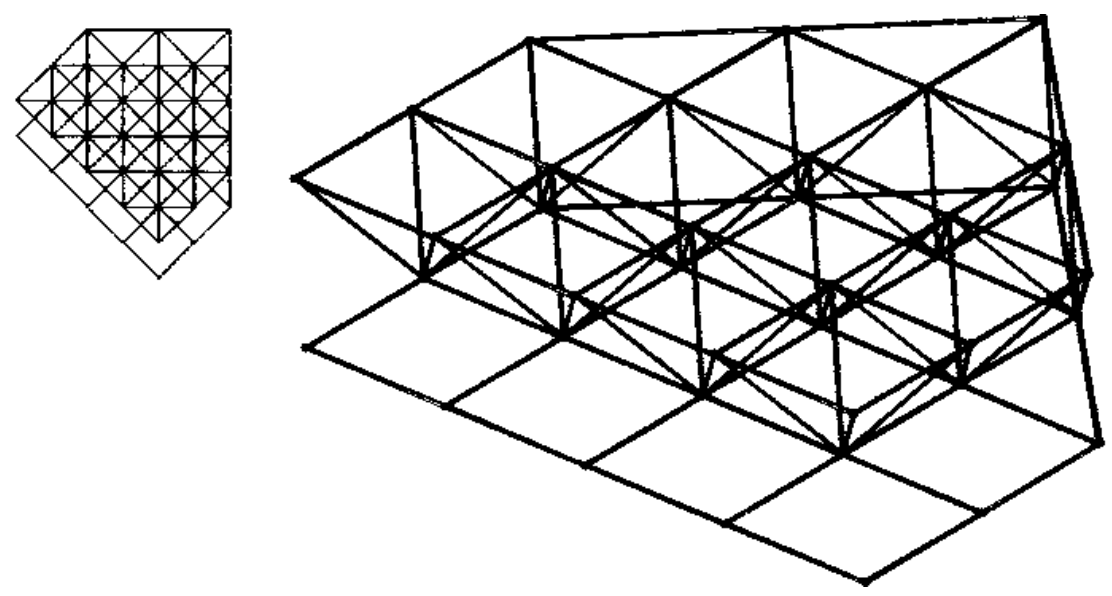

Figura 2.37 - Arranjo quadrado diagonal sobre quadrado diagonal

- Arranjo quadrado sobre quadrado diagonal: corresponde a uma combinação dos dois tipos anteriores, que tem sido muito utilizada em outros países. Neste arranjo geométrico, as barras do banzo inferior em diagonal apresentam a mesma dimensão da diagonal do quadrado do banzo superior (Figura 2.38). Este sistema é interessante para situações de sobrecarga elevada, 
pois o banzo inferior tracionado apresenta dimensões maiores que o banzo superior comprimido, seguindo a recomendação de alguns autores.

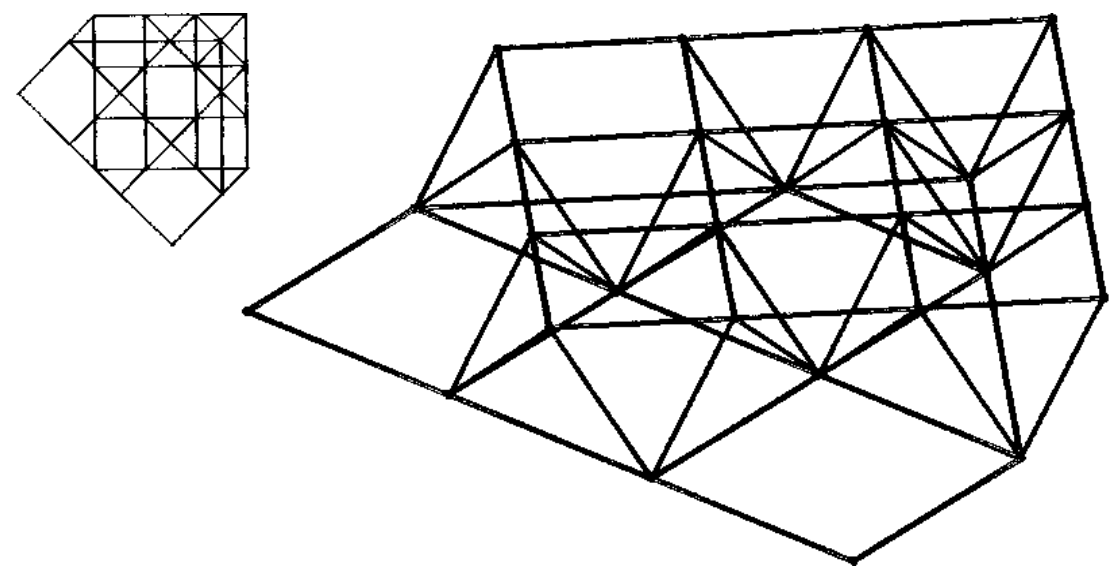

Figura 2.38 - Arranjo quadrado sobre quadrado diagonal

Segundo LAN \& QIAN (1986), os principais fatores que influenciam no peso e no custo de uma treliça espacial são as dimensões do módulo e a altura da estrutura. Utilizando estes dois fatores como variáveis principais para otimização, eles analisaram diversas treliças com vãos variando de $24 \mathrm{~m}$ a $72 \mathrm{~m}$, apoiadas em todo perímetro, e desenvolveram formulações para dimensões do módulo e altura da estrutura em função do vão. Estas formulações resultaram em alturas entre vão/11 e vão/15.

IFFLAND (1982) recomenda variações de altura da ordem de vão/20 até vão/60, dependendo do sistema utilizado. Já MARSH (2000) recomenda alturas de vão/10 até vão/20 e espaçamentos de nós variando de 1 a 2 vezes a altura da treliça.

AGERSKOV (1986) recomenda alturas da ordem de vão/15 até vão/20, e a dimensão do módulo deve ser tal que o ângulo da diagonal com os planos horizontais esteja em torno de $45^{\circ}$. Estas recomendações de AGERSKOV se aproximam dos valores adotados por fabricantes e projetistas no Brasil. 


\subsubsection{MATERIAIS E PERFIS}

Os elementos das treliças espaciais podem ser dos mais diversos materiais, incluindo madeira, concreto, aço, entre outros. Porém, a maior aplicação comercial se dá com materiais metálicos, mais especificamente com o aço e com alumínio.

O alumínio apresenta algumas vantagens em relação ao aço, tais como, baixa necessidade de manutenção, pois o material não está sujeito ao fenômeno da corrosão, e diminuição do peso próprio da estrutura, facilitando a montagem e o içamento. No Brasil foram realizadas várias obras com este material, principalmente na década de 80 , porém o elevado custo do mesmo tem feito o seu uso decrescer ao longo dos últimos anos. A maioria destas obras é formada por perfis de seção tranversal tubular circular extrudados na liga estrutural ASTM 6351-T6. As conexões são normalmente realizadas pelos sistemas de nós típicos ou de nós de aço, sendo que parafusos e chapas soldadas são em aço galvanizado ou aço-inox. Os perfis tubulares de alumínio com as extremidades estampadas são extrudados na têmpera T4, a qual é mais maleável e permite a estampagem. Após a usinagem, estes perfis retornam aos fornos onde sofrem um processo de "envelhecimento" e atingem a têmpera final T6. MARSH (2000) alerta sobre a possibilidade de ocorrerem trincas nos perfis tubulares de alumínio devido ao processo de estampagem, além dos problemas já relacionados de falha prematura deste sistema de conexão.

O aço sem dúvida é o material mais utilizado e o maior alvo das pesquisas na atualidade. O desenvolvimento de ligas de alta resistência à corrosão incrementou o uso deste material. Diversos tipos de perfis podem ser utilizados, dependendo do sistema escolhido e das características da obra.

No Brasil, o tipo de perfil mais utilizado é o tubular circular. Estes perfis podem ser conformados a frio recebendo posteriormente uma solda de costura, ou serem laminados. Normalmente os diâmetros até 152,4mm são conformados a frio e apresentam espessura máxima de $4,75 \mathrm{~mm}$, e a partir 
deste diâmetro são laminados. Entre os perfis de seção tranversal tubular circular comerciais mais utilizados nas estruturas correntes, podemos destacar os seguintes (diâmetro [mm] x espessura [mm]): $\varnothing 50,8 \times 2,00 ; \varnothing$ $60,3 \times 2,00 ; \varnothing 63,5 \times 2,00 ; \varnothing 76,2 \times 2,00 ; \varnothing 88,9 \times 2,65 ; \varnothing 88,9 \times 3,00 ; \varnothing$ $101,6 \times 2,65 ; \varnothing 101,6 \times 3,00 ; \varnothing 114,3 \times 3,00 ; \varnothing 127,0 \times 3,00 ; \varnothing 127,0 \times 3,75$; $\varnothing 152,4$ x 4,75; Ø 168,3 x 6,35; Ø 168,3 x 7,11; Ø 219,0 x 6,35.

SCHIMDT (2000) recomenda o uso de aços estruturais dúcteis para construção de estruturas espaciais. Para medida de ductilidade ele adota como parâmetro a razão entre a tensão última e a tensão de escoamento. 0 desejável é que este parâmetro seja da ordem de 1,25 ou superior.

\subsubsection{CONEXÕES}

O projeto de estruturas espaciais requer que muita atenção seja dada ao sistema de conexão utilizado, conforme já discutido anteriormente.

A maioria dos sistemas apresenta ligações parafusadas. No Brasil, os tipos de parafusos mais utilizados em treliças espaciais são:

- Estruturas de alumínio: parafusos em aço na liga ASTM A307 ou em aço-inox na liga AISI 304;

- Estruturas de aço: parafusos em aço na liga ASTM A325;

A explicação para utilização de parafusos de menor resistência para as estruturas de alumínio, é porque geralmente o estado limite atingido na ligação é o esmagamento da borda do furo do perfil, e não o cisalhamento do parafuso.

\subsubsection{ESTRUTURA SECUNDÁRIA}

A estrutura secundária é conectada à treliça espacial, considerada a estrutura principal, e é responsável pela sustentação dos elementos de vedação da cobertura e do fechamento, além da distribuição dos esforços provenientes destas vedações diretamente para os nós da treliça espacial. No Brasil, os elementos secundários geralmente são perfis formados a frio 
(cantoneiras, perfis "U" e perfis "Z"), ou perfis extrudados de alumínio (cantoneiras e perfis "U”).

Os principais elementos da estrutura secundária para suporte de telhas de cobertura e fechamento são (Figura 2.39):

- terças: servem como elementos de sustentação para fixação das telhas ou outras vedações da cobertura;

- montantes: são os apoios das terças, e são responsáveis pela inclinação da cobertura, quando esta não é dada pela própria estrutura;

- longarinas: servem como elementos de sustentação para fixação das telhas ou outras vedações do fechamento;

- suportes: possuem funções de interligação entre os elementos da estrutura secundária e entre estes e a estrutura principal.

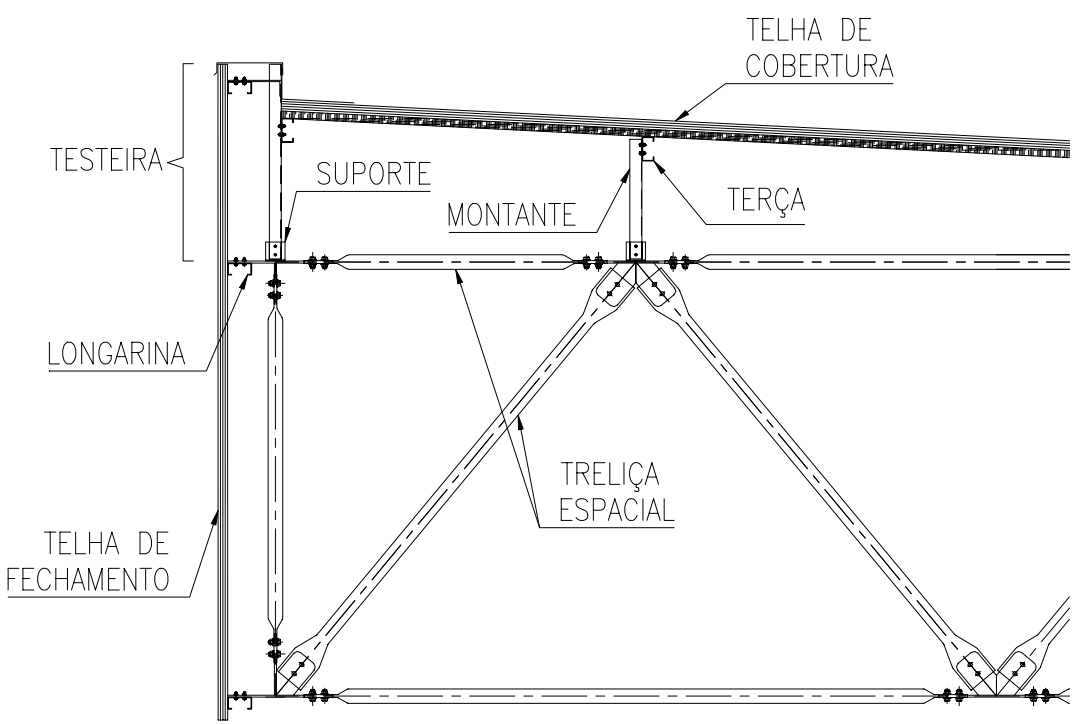

Figura 2.39 - Elementos da estrutura secundária para suporte das telhas de cobertura e fechamento

Os principais elementos da estrutura secundária para a captação das águas pluviais retidas pelas telhas de cobertura são (Figuras 2.40 e 2.41):

- travessas de calha: servem como elementos de sustentação para fixação dos montantes de calha. O alinhamento da calha pode ou não coincidir com a linha dos banzos superiores. No 
caso de coincidir, a travessa tem aproximadamente o tamanho da calha e transmite os esforços para o nó do banzo superior do alinhamento (Figura 2.40). No caso de não coincidir, a travessa tem o tamanho do módulo do banzo superior e transmite os esforços para os nós do banzo superior adjacentes ao alinhamento (Figura 2.41).

- montantes de calha: são os apoios das terças de calha;

- terças de calha: servem como elementos de sustentação para fixação das telhas e dos ganchos de calha;

- ganchos de calha: são os responsáveis pela conexão entre os berços e as terças de calha. Por meio deles regula-se a inclinação da calhas.

- berços de calha: servem de suporte para as calhas;

- calhas: responsáveis pela captação das águas pluviais retidas pelas telhas. Normalmente, apresentam largura mínima de $500 \mathrm{~mm}$ para facilitar a manutenção, altura mínima de $100 \mathrm{~mm}$ para evitar que respingos entrem dentro da edificação, e apresentam declividade variando de 0,5 a 2,0\%. As calhas são dimensionadas levando-se em conta o índice pluviométrico do local e as áreas de contribuição da cobertura.

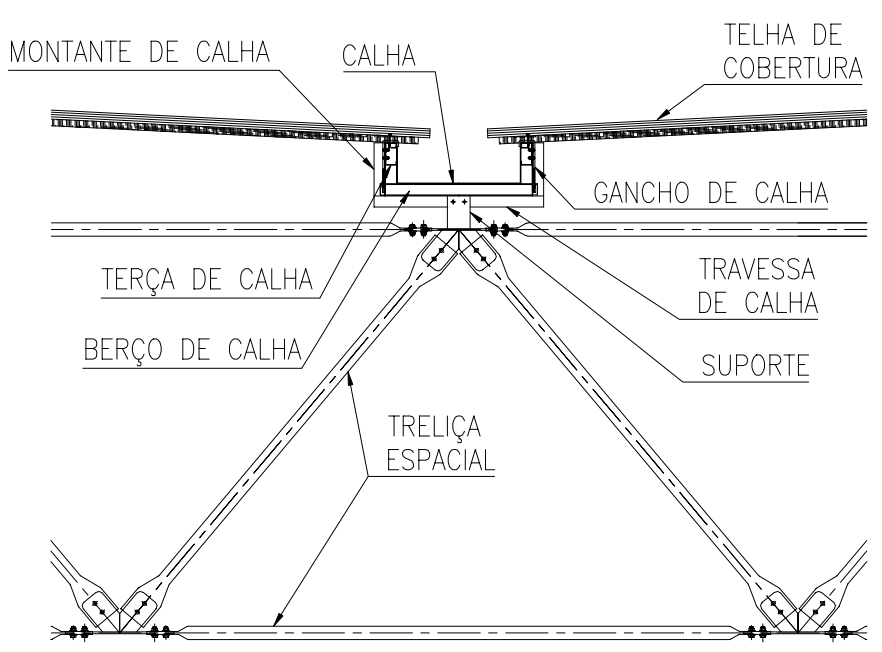

Figura 2.40 - Elementos da estrutura secundária para captação das águas pluviais - calha no alinhamento do banzo superior 


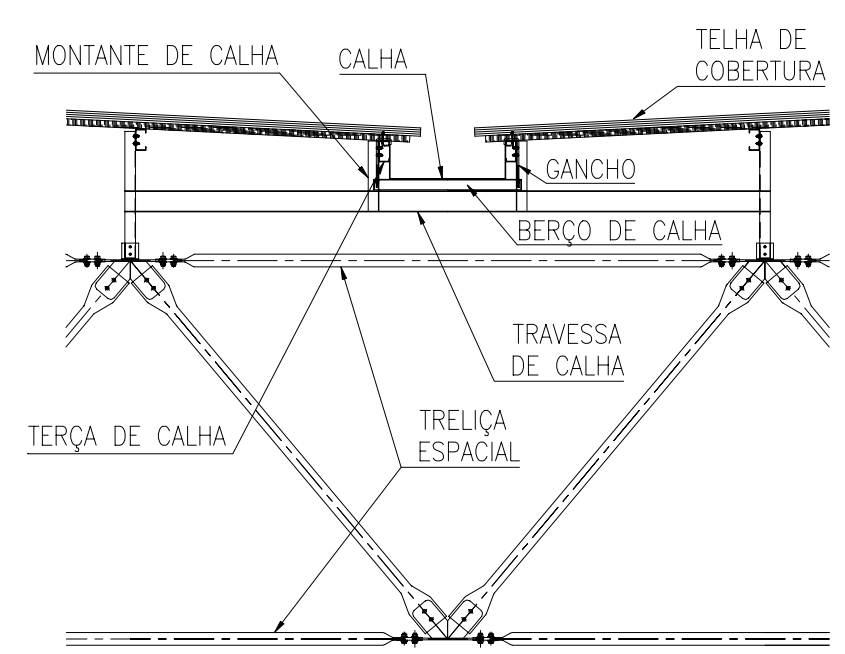

Figura 2.41 - Elementos da estrutura secundária para captação das águas pluviais - calha fora do alinhamento do banzo superior

Os modelos de cálculo empregados para o dimensionamento dos montantes de cobertura da estrutura secundária, na maioria das vezes, supõem que este elementos estejam engastados nos nós do banzo superior da treliça espacial. Estes modelos de cálculo são incompatíveis com o modelo de treliça ideal, com todos os nós articulados, utilizado para o cálculo da estrutura principal.

Algumas treliças espaciais de cobertura não apresentam a estrutura secundária e conseqüentemente os elementos de vedação são fixados diretamente sobre a estrutura principal. Isto faz com que as barras da treliça, recebam ações não apenas nos nós, mas também ao longo das barras, diminuindo a resistência das mesmas devido ao esforço de flexão que se soma ao esforço normal existente.

A estrutura secundária é responsável pela declividade da cobertura. Normalmente esta declividade varia de $2 \%$ a $5 \%$. Esta baixa inclinação pode gerar alguns problemas, tais como:

- retorno ou infiltração de água pelas emendas longitudinais e transversais dos elementos de vedação (telhas);

- empoçamento de água, caso os deslocamentos da estrutura anulem ou alterem a declividade da cobertura, diminuindo a velocidade de escoamento das águas pluviais; 
O primeiro problema, normalmente é solucionado aumentando-se o traspasse entre telhas, utilizando-se fitas de vedação ou conformando-se telhas de grande comprimento, no local da obra, evitando as emendas.

O segundo problema é mais grave, pois pode gerar uma sobrecarga de grande magnitude, que normalmente não é prevista no cálculo. Assim, a utilização dessas baixas declividades implica num controle rigoroso dos deslocamentos da estrutura, prevendo-se contra-flechas, ou na consideração das sobrecargas devidas ao empoçamento de águas pluviais na cobertura.

\subsubsection{ELEMENTOS DE VEDAÇÃO}

Os elementos de vedação, tais como as telhas de cobertura e fechamento, são os responsáveis pelo fechamento externo da treliça espacial.

As telhas metálicas são fabricadas tanto em aço como em alumínio, e apresentam perfis ondulados, com altura de $17 \mathrm{~mm}$, ou trapezoidais, com altura variando de 25 a 100mm (Figura 2.42).
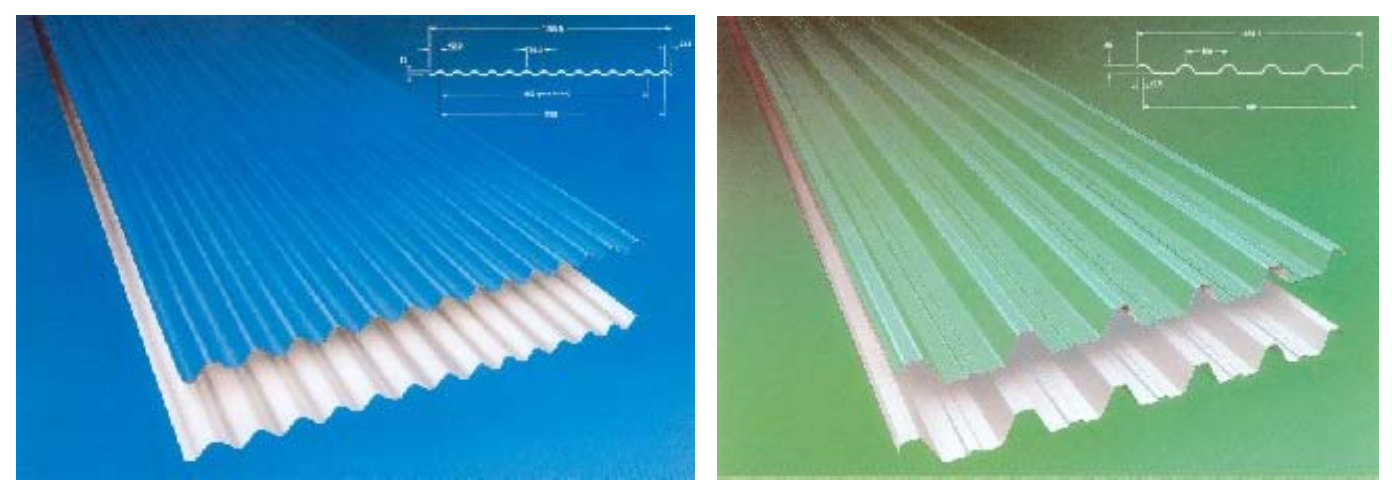

Figura 2.42 - Telhas Metálicas - Perfis Ondulados e Trapezoidais

Os elementos de vedação podem apresentar isolantes térmicos tais como espuma de poliuretano, poliestireno expandido, lã de fibra de vidro ou lã de rocha (Figura 2.43). Estes isolantes podem ser aplicados diretamente na face superior ou inferior da telha, ou estarem confinados entre duas telhas formando um painel composto. A aplicação diretamente sobre a face 
superior pode provocar o empoçamento de águas pluviais na cobertura caso haja algum descolamento parcial entre o isolante e a telha, e acumule água nesta interface. Esta sobrecarga adicional pode provocar a ruína da estrutura, caso seja superior à considerada no dimensionamento.
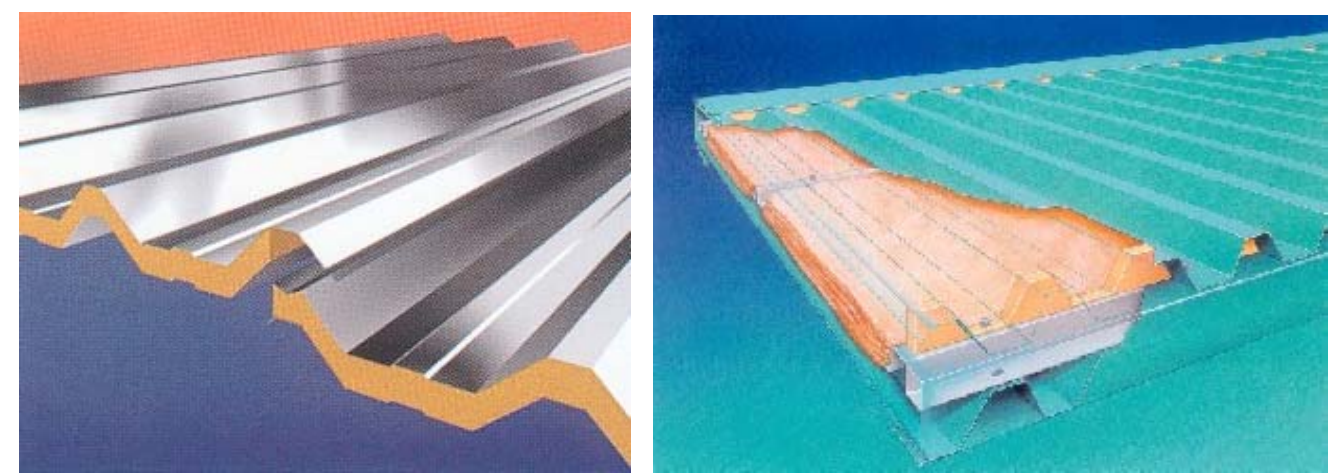

Figura 2.43 - Isolamentos térmicos com espuma de poliuretano e lã de vidro/rocha

A fixação das telhas pode ser "rígida", por meio de parafusos e ganchos, ou "móvel", por meio de suportes que permitem a movimentação das telhas no seu plano (Figura 2.44). A fixação por parafusos fornece um certo grau de contraventamento à mesa superior das terças de cobertura, porém apresenta o problema da perfuração das telhas, que compromete a estanqueidade da cobertura. A fixação por suportes móveis, típica dos sistemas de "telhas zipadas", minora os efeitos de contração e dilatação térmica que as telhas apresentam, e melhora a estanqueidade da cobertura, pois não são necessárias perfurações nas telhas.
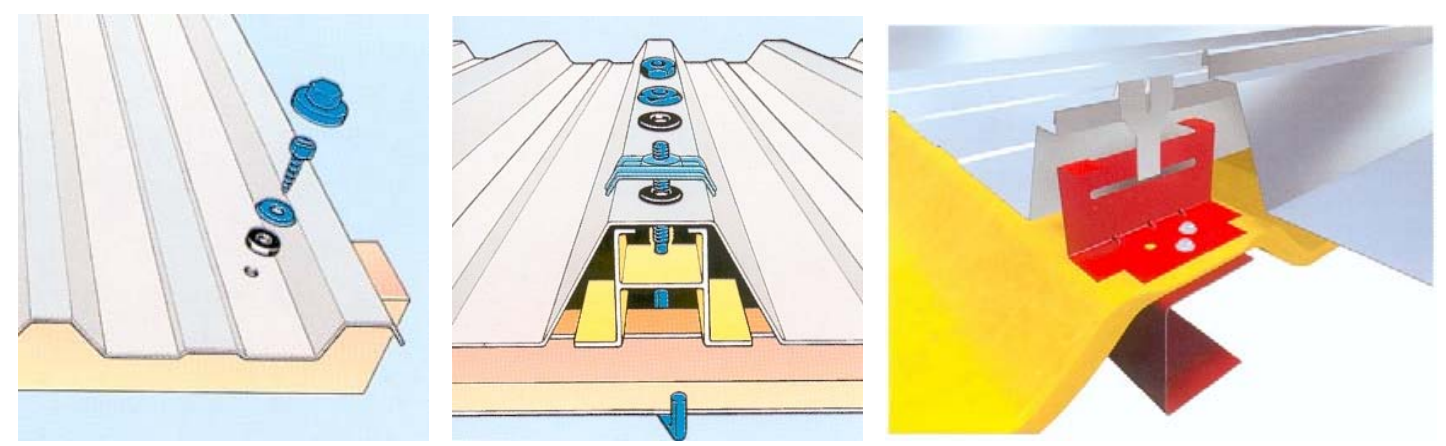

Figura 2.44 - Fixações com parafuso, gancho e suporte móvel 


\subsection{AÇÕES CONSIDERADAS NO PROJETO}

\subsubsection{AÇÕES PERMANENTES}

As ações permanentes consistem de:

- peso próprio dos elementos da estrutura principal, incluindo os banzos, diagonais, nós e parafusos. Este peso, para estruturas em aço, normalmente varia de $0,10 \mathrm{kN} / \mathrm{m}^{2}$ (para estruturas com vãos em torno de $20 \mathrm{~m}$ ) até $0,30 \mathrm{kN} / \mathrm{m}^{2}$ (para estruturas com vãos em torno de $60 \mathrm{~m}$ ). Estes valores podem sofrer alterações dependendo das ações variáveis atuantes;

- peso próprio dos elementos da estrutura secundária, incluindo os perfis das terças, montantes, longarinas, suportes, travessas, entre outros. Este peso, para estruturas em aço, normalmente varia de $0,03 \mathrm{kN} / \mathrm{m}^{2}$ (para estruturas com módulos em torno de $3 \mathrm{~m}$ ) até $0,08 \mathrm{kN} / \mathrm{m}^{2}$ (para estruturas com módulos maiores que $4 \mathrm{~m}$, que necessitem de terças intermediárias entre as linhas de banzo, visto que as telhas utilizadas normalmente não vencem vãos superiores a $3 \mathrm{~m}$ );

- peso próprio dos elementos de vedação, incluindo as telhas de cobertura, fechamento e forros. Este peso normalmente varia de $0,02 \mathrm{kN} / \mathrm{m}^{2}$ (para telhas de alumínio simples) até $0,15 \mathrm{kN} / \mathrm{m}^{2}$ (para telhas de aço duplas com isolante térmico).

- peso próprio dos elementos de passarelas e escadas de manutenção;

- pesos de instalações, acessórios e equipamentos permanentes, tais como tubulações de água, esgoto, águas pluviais, gás, dutos e cabos elétricos, que estejam fixados na cobertura;

- quaisquer outras ações, que estejam atuando na cobertura, de caráter praticamente permanente ao longo da vida da estrutura; 


\subsubsection{AÇÕES VARIÁVEIS}

As ações variáveis nas coberturas são aquelas que resultam do uso ou ocupação da edificação, tais como: sobrecargas em escadas e passarelas de manutenção, sobrecargas de instalações não permanentes, sobrecargas de equipamentos industriais e pontes rolantes. São também consideradas ações variáveis o vento, a variação de temperatura e as sobrecargas devidas ao empoçamento de águas pluviais na cobertura.

\subsubsection{SOBRECARGAS}

\section{SOBRECARGA DE TELHADO}

A NBR 8800 (1986) recomenda que nas coberturas comuns, não sujeitas a acúmulos de quaisquer materiais, e na ausência de especificações em contrário, deve ser prevista uma sobrecarga nominal mínima de 0,25 $\mathrm{kN} / \mathrm{m}^{2}$, em projeção horizontal.

\section{SOBRECARGA DE EQUIPAMENTO (AÇÕES TECNOLÓGICAS)}

Para levar em conta o impacto, caso o equipamento provoque, o peso de equipamentos e cargas móveis que atuam na cobertura devem ser majorados. A NBR 8800 (1986) recomenda os seguintes coeficientes de majoração, caso não haja especificação em contrário:

- equipamentos leves cujo funcionamento é caracterizado fundamentalmente por movimentos rotativos; talhas $\Rightarrow \varnothing=1,2$;

- equipamentos cujo funcionamento é caracterizado fundamentalmente por movimentos alternativos $\Rightarrow \varnothing=1,5$.

As estruturas de cobertura que suportam pontes rolantes devem ser dimensionadas para o efeito das ações de projeto, majoradas para levar em conta o impacto, se este for desfavorável, e considerando forças horizontais. 
A NBR 8800 (1986) recomenda os seguintes coeficientes de majoração, caso não haja especificação em contrário:

- $\quad$ majoração das ações verticais das rodas $\Rightarrow \varnothing=1,25$;

- a força transversal ao caminho de rolamento, a ser aplicada no topo do trilho, de cada lado, deve ser igual ao maior dos seguintes valores:

- $10 \%$ da soma da carga içada com o peso do trole e dos dispositivos de içamento;

- $5 \%$ da soma da carga içada com o peso total da ponte incluindo trole e dispositivos de içamento;

- uma porcentagem da carga içada, variável de acordo com o tipo e finalidade da ponte.

- A força longitudinal ao caminho de rolamento, a ser aplicada no topo do trilho, integralmente de cada lado, quando não determinada de forma mais precisa, deve ser igual a $20 \%$ da soma das cargas máximas das rodas motoras e/ou providas de freio;

- A força devida ao choque da ponte rolante com o batente deve ser determinada pela teoria do choque

Vale salientar que as pontes rolantes fabricadas atualmente apresentam uma série de dispositivos eletrônicos de segurança e controle que minoram as forças e os coeficientes de impacto recomendados pela norma.

\section{SOBRECARGA DEVIDA AO EMPOÇAMENTO DE ÁGUAS PLUVIAIS NA COBERTURA}

A baixa declividade ( $2 \%$ a $5 \%$ ) das coberturas das treliças espaciais pode acarretar numa sobrecarga adicional de empoçamento de águas pluviais. O empoçamento pode ser causado tanto pela demora no escoamento das águas pluviais em coberturas muito extensas, como pela 
anulação da declividade da cobertura causada pelos delocamentos da treliça espacial em condições de serviço.

O item 8.3.3 da NBR 8800 (1986) recomenda que as estruturas de cobertura devam ser analisadas de forma que seja garantida sua estabilidade, quando sujeitas às cargas de empoçamento de água, a não ser que haja suficiente inclinação para pontos de drenagem ou número adequado de drenos individuais, de forma a impedir o acúmulo de água de chuva. Para considerar o sistema de cobertura estável, não necessitando de outras verificações, este item da norma estabelece duas condições a serem verificadas, baseadas numa análise da rigidez do sistema de cobertura. Porém, as expressões das condições a serem verificadas são para estruturas convencionais, onde existem subsistemas planos definidos (vigas principais e secundárias).

\subsubsection{VENTO}

O peso próprio de uma cobertura em treliça espacial pode ser substancialmente menor que as forças de sucção do vento. Em alguns casos, as ações do vento podem ser superiores a $1,0 \mathrm{kN} / \mathrm{m}^{2}$, enquanto que 0 peso próprio da estrutura pode estar em torno de $0,2 \mathrm{kN} / \mathrm{m}^{2}$. As ações do vento estão normatizadas pela NBR 6123 (1988).

Por se tratarem de estruturas com grandes vãos, e muitas vezes de geometria incomum, não previstas na norma, devem ser realizados ensaios em túneis de vento para avaliação dos reais coeficientes de pressão e de forma. Muitas vezes, a simples extrapolação dos casos previstos na norma não condizem com a situação real, levando a um sub ou superdimensionamento da estrutura.

$\mathrm{Na}$ maioria dos casos, devido às coberturas em treliça espacial apresentarem fechamento lateral de paredes (coberturas não isoladas) e telhados de múltiplas águas, adota-se para as coberturas os coeficientes de pressão e de forma, externos, previstos na Tabela 7 da norma (Figura 2.45). 


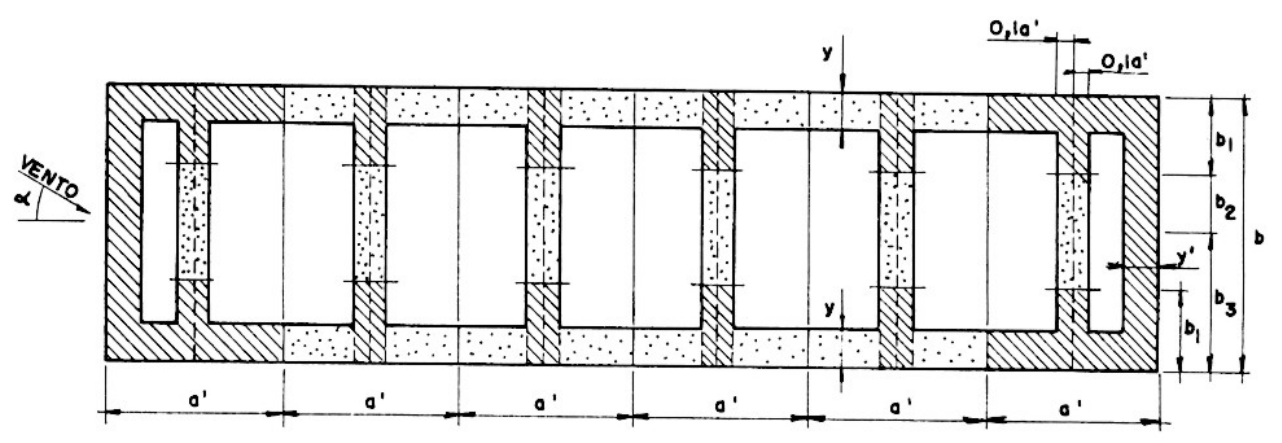

$\mathrm{y}=\mathrm{h}$ ou $0,1 \mathrm{~b}$ (tomar o menor dos dois valores)

$y^{\prime}=h$ ou 0,1 b ou 0,25 a' (tomar o menor dos três valores)

$b_{1}=b_{2}=h$

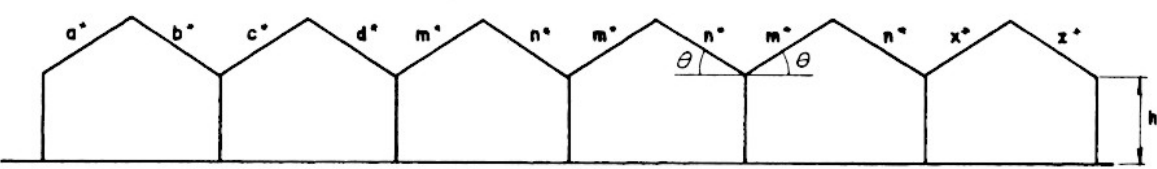

\begin{tabular}{|c|c|c|c|c|c|c|c|c|c|c|c|}
\hline \multirow{3}{*}{$\begin{array}{c}\text { Inclinação } \\
\text { do } \\
\text { telhado } \\
\Theta\end{array}$} & \multirow{3}{*}{$\begin{array}{l}\text { Ângulo } \\
\text { de inci- } \\
\text { dência do } \\
\text { vento } \\
\alpha\end{array}$} & \multicolumn{8}{|c|}{$c_{e}$} & \multirow{2}{*}{\multicolumn{2}{|c|}{$\mathrm{C}_{\text {pe }}$ médio }} \\
\hline & & \multicolumn{2}{|c|}{$\begin{array}{c}\text { Primeiro } \\
\text { tramo }\end{array}$} & \multicolumn{2}{|c|}{$\begin{array}{l}\text { Primeiro } \\
\text { tramo } \\
\text { interme- } \\
\text { diário }\end{array}$} & \multicolumn{2}{|c|}{$\begin{array}{c}\text { Demais } \\
\text { tramos } \\
\text { interme- } \\
\text { diários }\end{array}$} & \multicolumn{2}{|c|}{$\begin{array}{l}\text { Último } \\
\text { tramo }\end{array}$} & & \\
\hline & & $a^{\star}$ & $b^{\star}$ & $c^{\star}$ & $d^{*}$ & $\mathrm{~m}^{\star}$ & $n^{\star}$ & $x^{*}$ & $\mathbf{z}^{*}$ & & $\because$ \\
\hline $5^{\circ}$ & $0^{\circ}$ & $-0,9$ & $-0,6$ & $-0,4$ & $-0,3$ & $-0,3$ & $-0,3$ & $-0,3$ & $-0,3$ & & \\
\hline $10^{\circ}$ & $0^{\circ}$ & $-1,1$ & $-0,6$ & $-0,4$ & $-0,3$ & $-0,3$ & $-0,3$ & $-0,3$ & $-0,4$ & $\int$ & \\
\hline $15^{\circ}$ & $0^{\circ}$ & $-0,9$ & $-0,6$ & $-0,4$ & $-0,3$ & $-0,3$ & $-0,3$ & $-0,3$ & $-0,5$ & $\{-2,0$ & $-1,5$ \\
\hline $20^{\circ}$ & $0^{\circ}$ & $-0,7$ & $-0,6$ & $-0,4$ & $-0,3$ & $-0,3$ & $-0,3$ & $-0,3$ & $-0,5$ & l & \\
\hline $30^{\circ}$ & $0^{\circ}$ & $-0,2$ & $-0,6$ & $-0,4$ & $-0,3$ & $-0,2$ & $-0,3$ & $-0,2$ & $-0,5$ & & \\
\hline $45^{\circ}$ & $0^{\circ}$ & $+0,3$ & $-0,6$ & $-0,6$ & $-0,4$ & $-0,2$ & $-0,4$ & -02 & $-0,5$ & & \\
\hline
\end{tabular}

\begin{tabular}{|c|c|c|c|c|}
\hline \multirow{2}{*}{$\begin{array}{c}\text { Inclinação } \\
\text { do telhado }\end{array}$} & \multicolumn{2}{|c|}{$\begin{array}{c}\text { Ângulo de } \\
\text { incidência } \\
\text { do vento }\end{array}$} & $\mathrm{c}_{\mathrm{e}}$ na distância: \\
& $\boldsymbol{\alpha}$ & $\mathrm{b}_{1}$ & $\mathrm{~b}_{2}$ & $\mathbf{b}_{3}$ \\
\hline$\leq 45^{\circ}$ & $90^{\circ}$ & $-0,8$ & $-0,6$ & $-0,2$ \\
\hline
\end{tabular}

Figura 2.45 - Coeficientes de pressão e de forma, externos, para telhados múltiplos, simétricos, de tramos iguais, com $\mathrm{h} \leq \mathrm{a}$

Normalmente, as coberturas em treliça espacial apresentam grandes fechamentos laterais em telha, com altura igual a altura da treliça somada à altura da testeira (Figura 2.39). A testeira é o trecho de telha localizado acima do banzo superior cuja função é fechar o espaço existente entre as telhas de cobertura e o banzo superior, proporcionando um acabamento uniforme em todo perímetro da cobertura. Nesses fechamentos laterais 
atuam ações de vento que podem provocar elevados esforços horizontais na estrutura espacial e conseqüentemente nos pilares. Para estas regiões, tratando-se de edificações de planta retangular, adota-se os coeficientes de pressão e de forma, externos, para paredes previstos na Tabela 4 da norma (Figura 2.46).

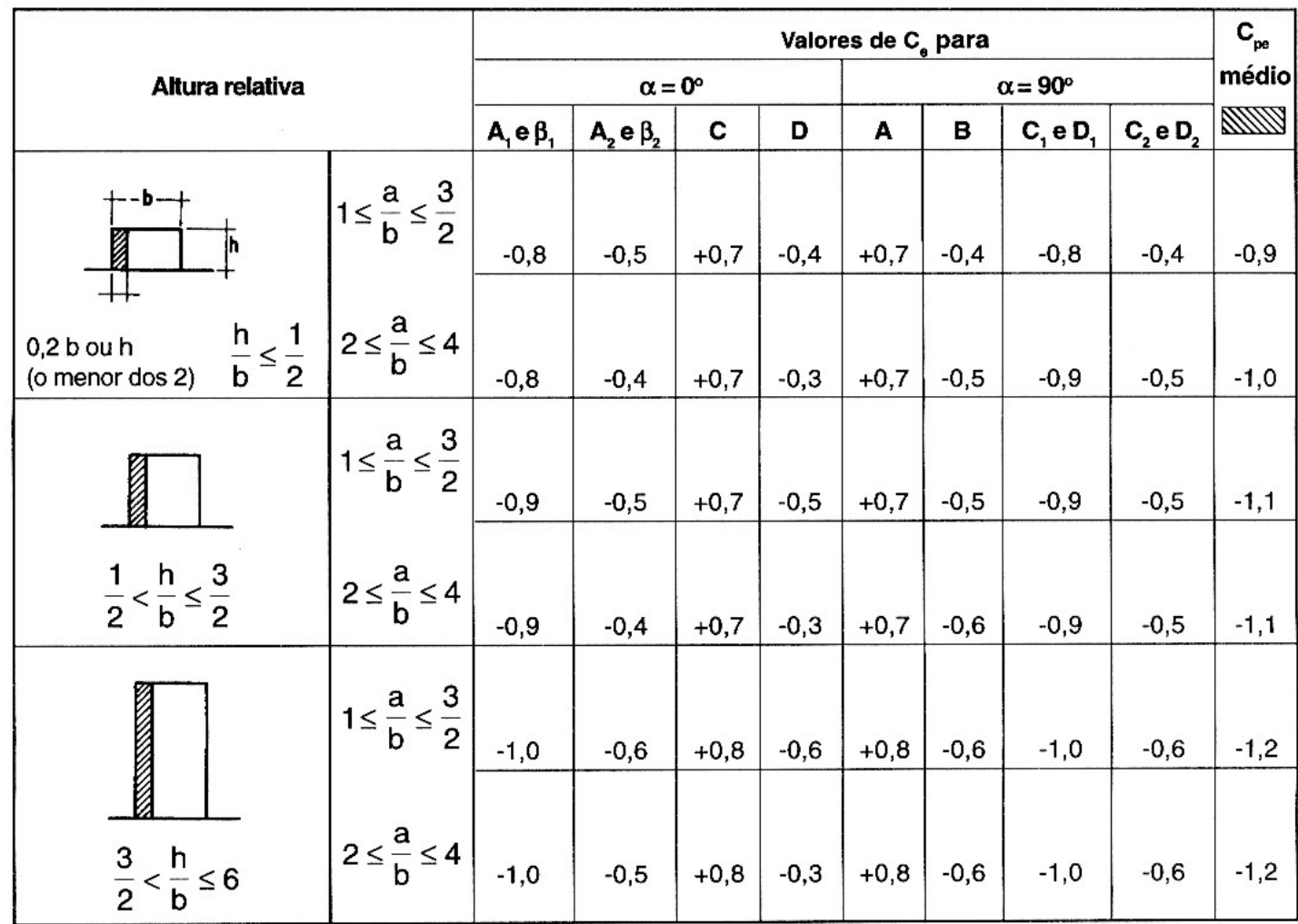
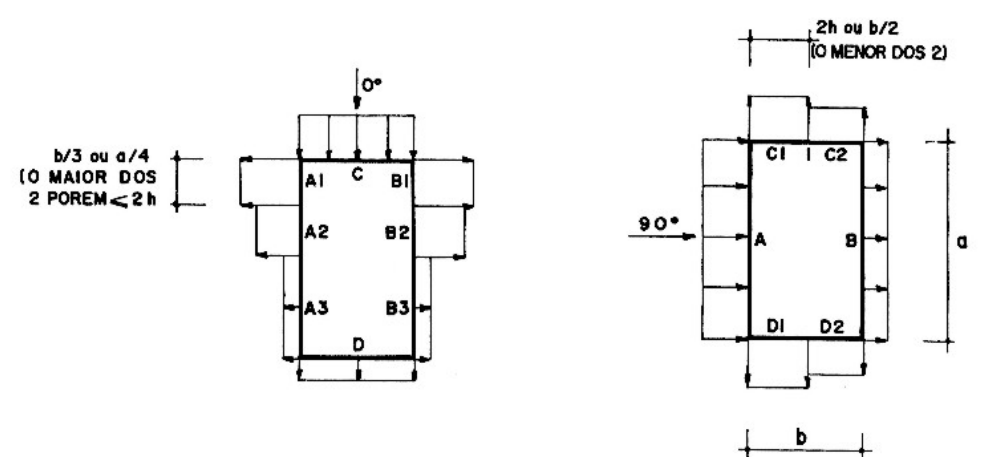

Figura 2.46 - Coeficientes de pressão e de forma, externos, para paredes de edificações de planta retangular

Os balanços laterais e as marquises em estrutura espacial podem apresentar dimensões elevadas, superiores a $10 \mathrm{~m}$, sendo portanto, muito 
sensíveis à ação de sucção do vento. Os coeficientes finais de forma da cobertura nestas regiões, são obtidos, normalmente, pela soma dos coeficientes de forma das paredes com os da cobertura (Figura 2.47).

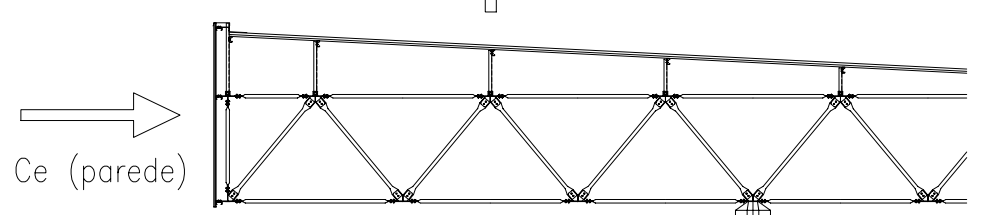

Figura 2.47 - Coeficientes de pressão e de forma, externos, para balanços e marquises

A NBR 6123 (1988) aborda com certa restrição as coberturas isoladas. Os coeficientes de pressão das Tabelas 17 e 18 desta norma são aplicáveis somente se $h \geq 0,5 . I_{2}$ (onde "h": altura livre entre o piso e o nível da aresta horizontal mais baixa da cobertura e " $\mathrm{l}_{2}$ ": profundidade da cobertura). Normalmente as coberturas espaciais possuem "h" inferior a este limite. Para estes casos, ou para os casos em que obstruções possam ser colocadas sob ou junto à cobertura, a norma recomenda o cálculo da ação do vento assumindo a edificação como fechada e de mesma cobertura, com aplicação de coeficientes de pressão internos $\mathrm{Cpi}=+0,8$ para obstruções na borda de sotavento e $\mathrm{Cpi}=-0,3$ para obstruções na borda de barlavento. Estes valores de coeficientes de pressão internos, recomendados pela norma, se aplicados a toda a cobertura resultam em uma condição de carregamento muito conservadora. 
Conforme citado por MAGALHÃES (1996), o estudo em túnel de vento de um modelo reduzido para uma cobertura isolada, com o esquema geral apresentado na Figura 2.48, revelam o grau de conservadorismo dos coeficientes propostos pela NBR-6123 (1988). Os coeficientes de forma são mostrados nas Figuras 2.49 e 2.50 .

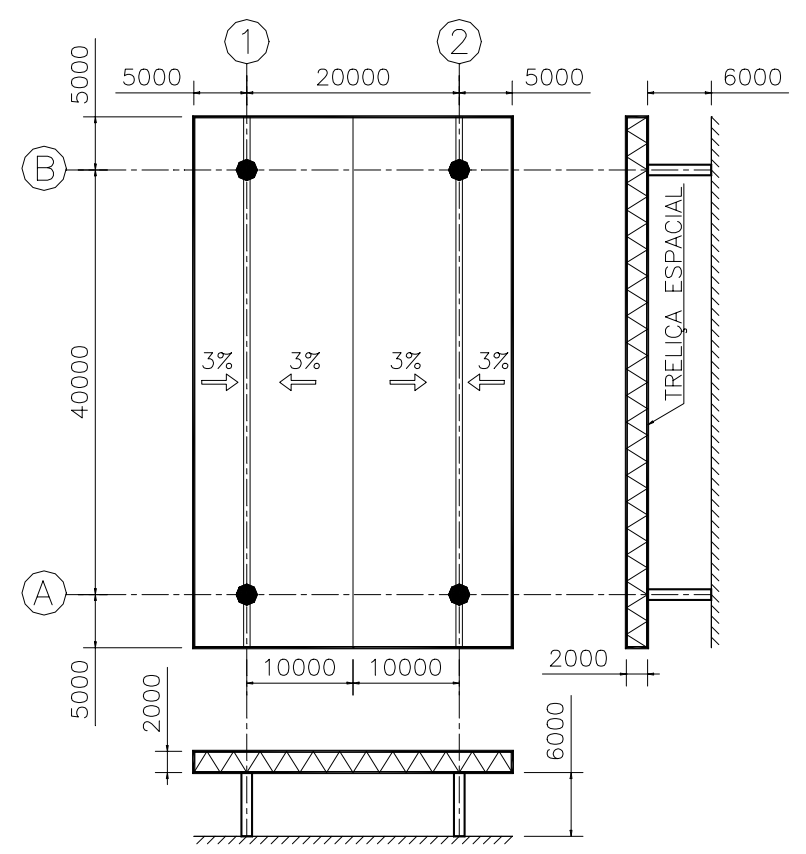

Figura 2.48 - Esquema geral da cobertura analisada em túnel de vento

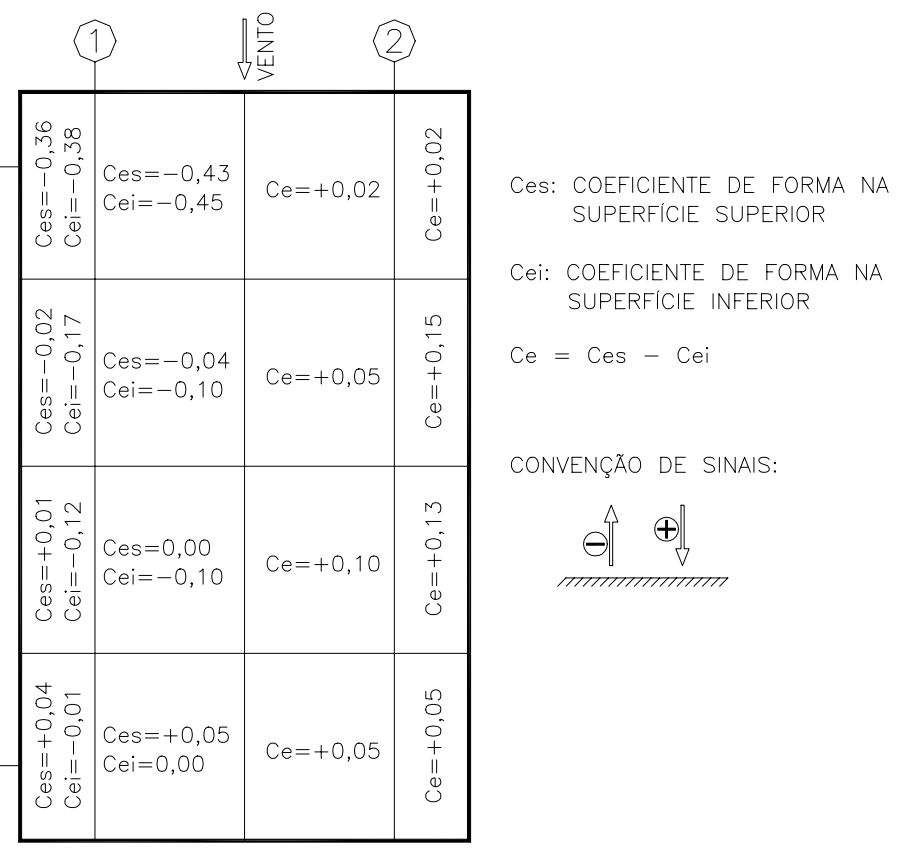

Figura 2.49 - Coeficientes de forma do modelo - vento longitudinal 


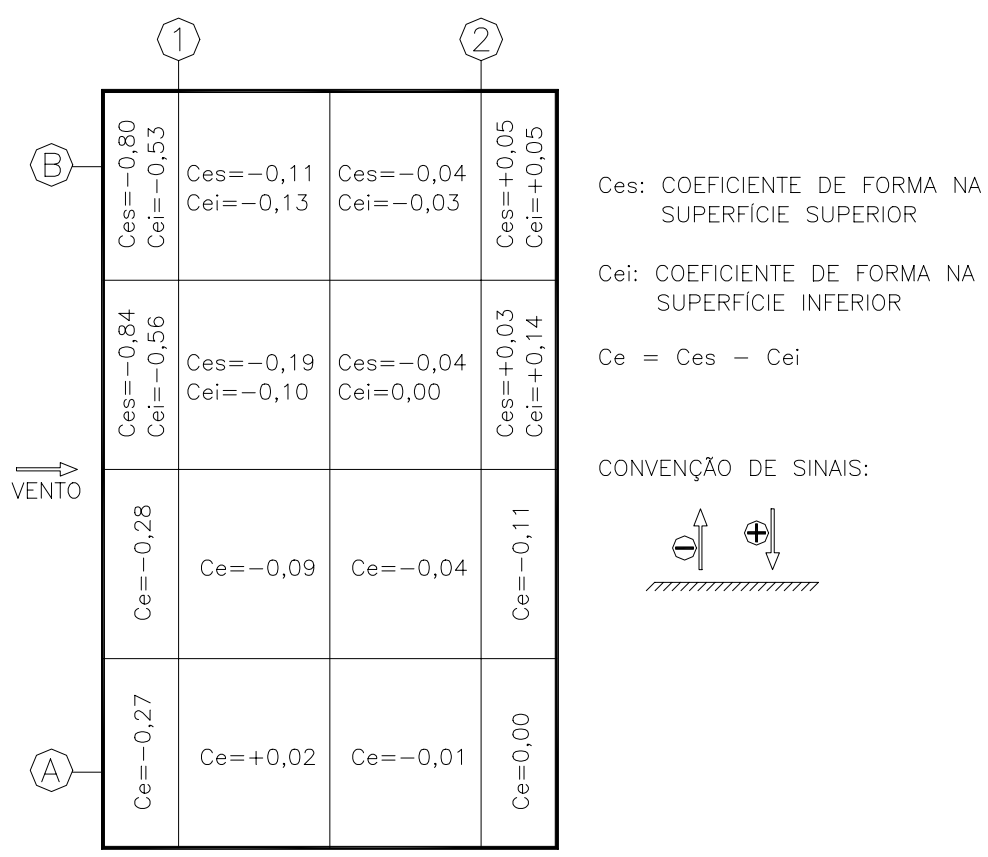

Figura 2.50 - Coeficientes de forma do modelo - vento transversal

\subsubsection{VARIAÇÃO DE TEMPERATURA}

De maneira geral, em treliças espaciais, protegidas ou não, supõe-se, para o cálculo, que as variações de temperatura sejam uniformes ao longo da estrutura, salvo em casos de construções sujeitas a diferenças simultâneas de temperatura em pontos diversos. As normas em geral prevêem uma variação de temperatura da atmosfera, para serem levadas em consideração nos cálculos, de $\pm 15^{\circ} \mathrm{C}$ para estruturas protegidas e de $\pm 30^{\circ} \mathrm{C}$ para estruturas que não são protegidas dos raios solares. $O$ coeficiente de dilatação do aço é considerado igual a $12 \times 10^{-6}$ por ${ }^{\circ} \mathrm{C}$.

Geralmente, as coberturas em treliça espacial são contínuas e de grandes dimensões, sem juntas de dilatação. Devido ao alto grau de hiperestaticidade do sistema, a contração e a dilatação térmica das barras provocam elevados esforços internos e elevadas reações de apoio. Para minorar estes esforços devidos à variação de temperatura, adotam-se apoios móveis, com translações livres em uma ou mais direções horizontais. 


\subsection{NORMAS APLICÁVEIS}

As principais normas brasileiras utilizadas na determinação das ações na estrutura são:

- NBR-6120 (1980) - Cargas para o cálculo de estruturas de edificações;

- NBR-8681 (1984) - Ações e segurança nas estruturas;

- NBR-6123 (1988) - Forças devidas ao vento em edificações;

Não existe norma específica para o dimensionamento de treliças metálicas espaciais. As principais normas brasileiras utilizadas no dimensionamento destas estruturas são:

- NBR-8800 (1986) - Projeto e execução de estruturas de aço de edifícios (método dos estados limites): baseada no método dos estados limites e utilizada para o dimensionamento dos elementos e ligações da estrutura principal;

- NBR-14762 (2001) - Dimensionamento de estruturas de aço constituídas por perfis formados a frio - Procedimento: baseada no método dos estados limites e utilizada para o dimensionamento dos perfis formados a frio e das ligações desses perfis;

As normas americanas de dimensionamento também são bastante utilizadas, principalmente pelo fato da maioria dos softwares de pósprocessamento utilizarem estas normas para o dimensionamento da estrutura. As principais normas utilizadas são:

- AMERICAN INSTITUTE OF STEEL CONSTRUCTION (1989): $A S D$ - Allowable Stress Design (Ninth Edition): baseada no método das tensões admissíveis e utilizada para o dimensionamento dos elementos e ligações da estrutura principal;

- AMERICAN INSTITUTE OF STEEL CONSTRUCTION (1999). LRFD - Load and Resistance Factor Design (Third Edition): baseada no método dos estados limites e utilizada para o 
dimensionamento dos elementos e ligações da estrutura principal;

- AMERICAN IRON AND STEEL INSTITUTE (1996). LRFD Load and resistance factor design specification for cold-formed steel manual: baseada no método dos estados limites e utilizada para o dimensionamento dos perfis formados a frio e das ligações desses perfis;

\subsection{DESCRIÇÃO DE ALGUMAS OBRAS}

\subsubsection{CENTRO DE EXPOSIÇÕES ANHEMBI - SÃO PAULO / SP}

A estrutura de cobertura do Centro de Exposições Anhembi foi construída no final da década de 60 e representa um marco nas estruturas espaciais construídas no Brasil. Trata-se da maior estrutura em alumínio tubular do mundo (Figura 2.51).

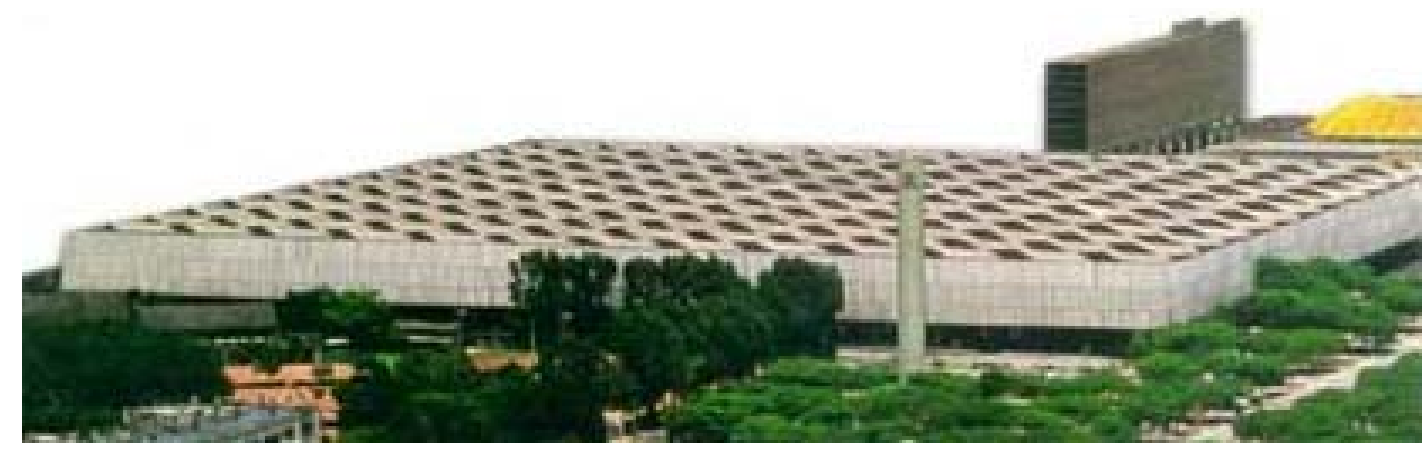

Figura 2.51 - Vista Externa - Centro de Exposições Anhembi Fonte: www.anhembi.com.br

A estrutura espacial em alumínio cobre uma área de $260 \mathrm{~m} \times 260 \mathrm{~m}$, e está apoiada em 25 pilares que formam vãos de 53,33m e 60m. Cada pilar possui 2 pernas de aço articuladas nas bases, que vencem altura de 5,36m. Da junção articulada das extremidades superiores das pernas partem 4 braços de aço que alcançam a altura de $8,64 \mathrm{~m}$, perfazendo um pé direito de 
$14 \mathrm{~m}$ (Figuras 2.52 e 2.53). Estas articulações permitem deslocamentos radiais, diminuindo os esforços horizontais provocados por efeitos de variação de temperatura.

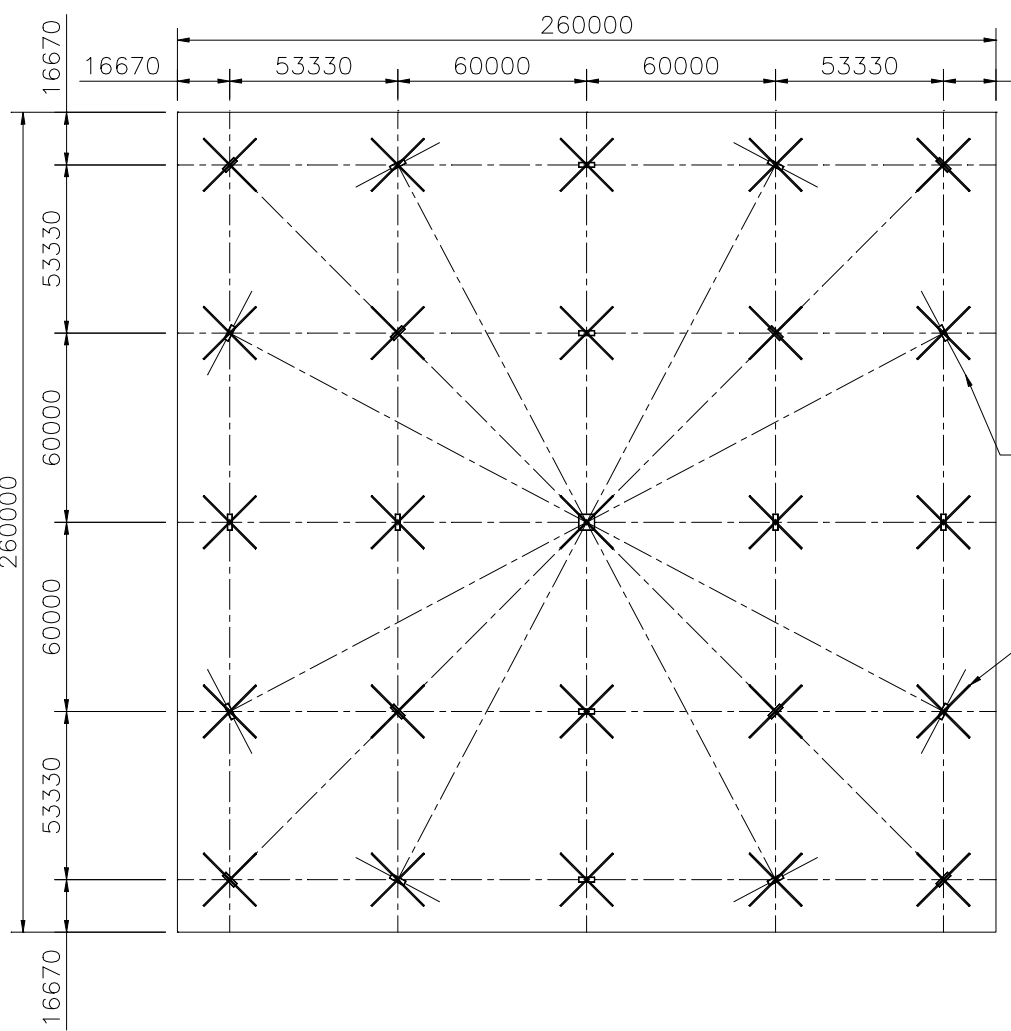

Figura 2.52 - Planta dos apoios - Centro de Exposições Anhembi Fonte: OLIVEIRA (1969)

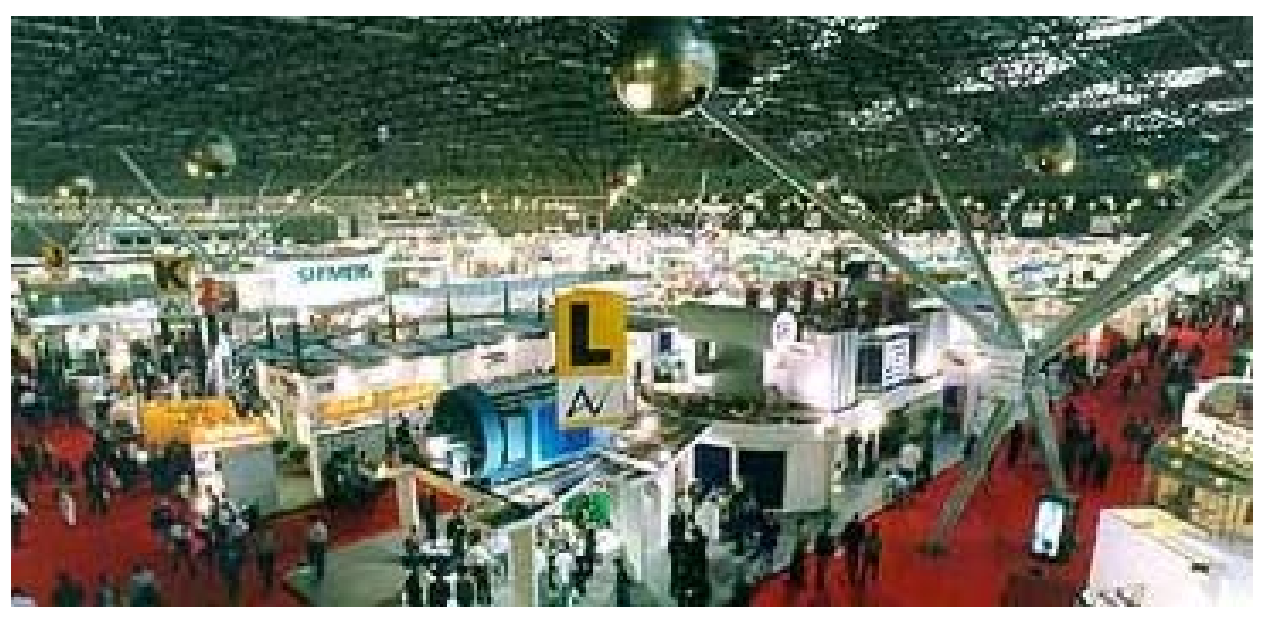

Figura 2.53 - Vista dos apoios e da treliça - Centro de Exposições Anhembi - Fonte: www.anhembi.com.br 
Nas extremidades superiores dos braços está ligada a treliça espacial, por meio de conexões articuladas. A treliça é formada por um arranjo geométrico do tipo quadrado sobre quadrado. A modulação é $3,333 \mathrm{~m} x$ $3,333 \mathrm{~m}$ com altura de $2,357 \mathrm{~m}$, e conseqüentemente as diagonais também possuem um comprimento teórico de 3,333m. Existe ainda uma estrutura espacial adicional, no perímetro da estrutura principal de cobertura, responsável pela sustentação do fechamento vertical da platibanda. As estruturas principal e secundária apresentam um total de cerca de 60 mil barras de seção tranversal tubular circular e um peso total de cerca de 360 toneladas.

As conexões das barras tubulares são realizadas por meio de nós, formados por chapas soldadas de aço galvanizado, nos quais se encaixam as extremidades estampadas das barras. A conexão é realizada com parafusos de aço de alta resistência.

A estrutura secundária de cobertura também é em alumínio, com montantes de seção tranversal tubular circular e terças com perfil "U", formando múltiplos "sheds" quadrados, de $14,14 \mathrm{~m}$ x 14,14m, com declividade de $12,5 \%$ no sentido diagonal.

\subsubsection{COBERTURA ESTÁDIO MANÉ GARRINCHA - BRASÍLIA / DF}

Esta cobertura em perfil tubular de alumínio construída em 1983, destaca-se pelo balanço, cerca de $31,5 \mathrm{~m}$, o maior já executado no país com este tipo de estrutura até aquela data (Figura 2.54).

A estrutura com cerca de $170 \mathrm{~m}$ de extensão está apoiada em 21 pórticos de concreto, com três aparelhos de apoio de aço em cada um. $\mathrm{O}$ arranjo geométrico do reticulado é do tipo quadrado sobre quadrado. $\mathrm{O}$ módulo na parte reta da estrutura tem dimensões de $3,50 \mathrm{~m} \times 3,50 \mathrm{~m}$ e altura variável de $3,50 \mathrm{~m}$ a $2,00 \mathrm{~m}$. O sistema de ligação é do tipo nó de aço com as extremidades dos perfis tubulares de alumínio estampadas. Os perfis de seção tranversal tubular circular variam de $\varnothing 90,0 \mathrm{~mm} \times 2,00 \mathrm{~mm}$ até $\varnothing 170,0$ $x 8,00 \mathrm{~mm}$. A cobertura é formada por domos translúcidos de fibra de vidro. 
Para avaliação da ação do vento foram realizados ensaios aerodinâmicos em túnel de vento.

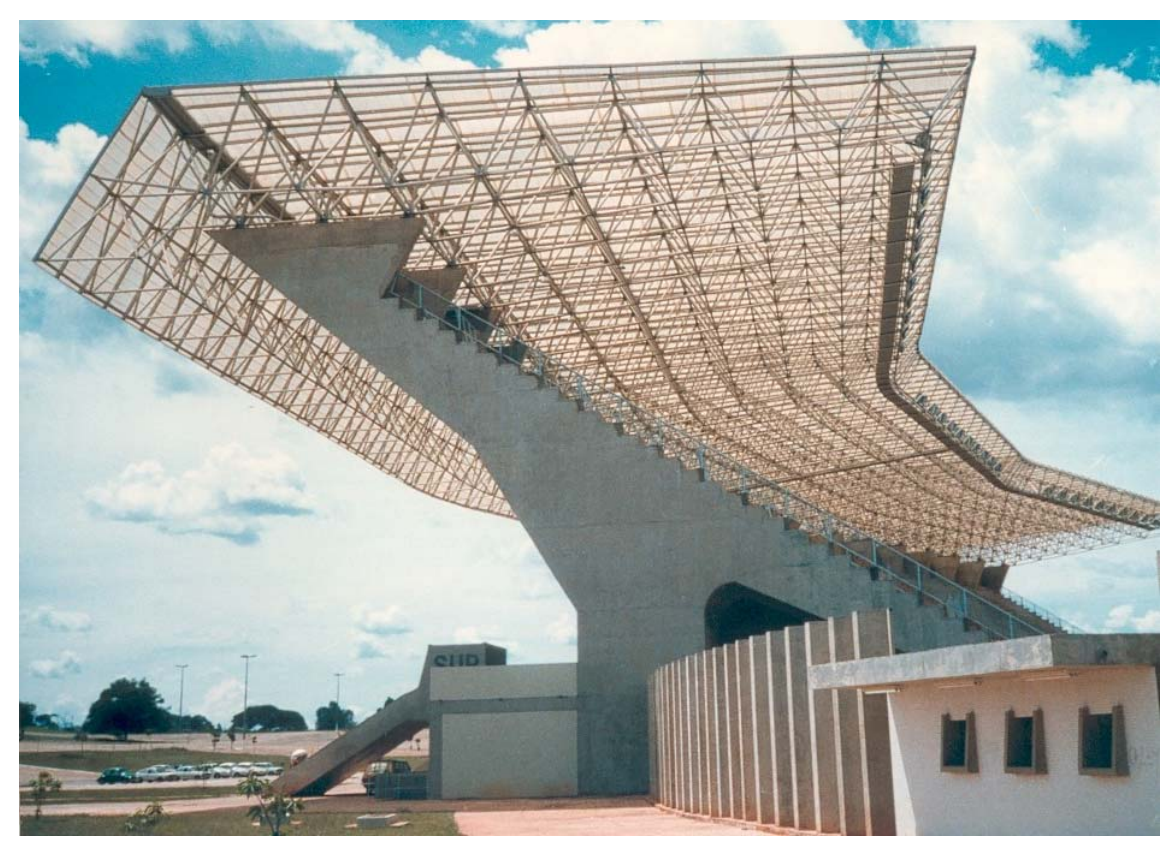

Figura 2.54 - Cobertura Estádio Mané Garrincha Fonte: catálogo ALUSUD

\subsubsection{COMPLEXO INDUSTRIAL DE JACAREPAGUÁ - BRAHMA - RIO DE JANEIRO / RJ}

Esta obra trata-se da maior área contínua coberta em treliça espacial de aço do mundo (Figura 2.55).

O complexo industrial, construído em 1995, é formado por vários prédios, porém dois deles são interligados, perfazendo uma área contínua de $114.351 \mathrm{~m}^{2}$. Os vãos máximos variam entre $30 \mathrm{~m}$ e $60 \mathrm{~m}$. A modulação é $3,75 \mathrm{~m} \times 3,75 \mathrm{~m}$, com alturas de treliça de $2,10 \mathrm{~m}$, para vãos de $30 \mathrm{~m}$, e de $2,80 \mathrm{~m}$, para os vãos de $60 \mathrm{~m}$. O sistema de ligação é do tipo nó de aço com as extremidades dos perfis tubulares de aço estampadas ou na forma de ponteiras de chapas soldadas. 


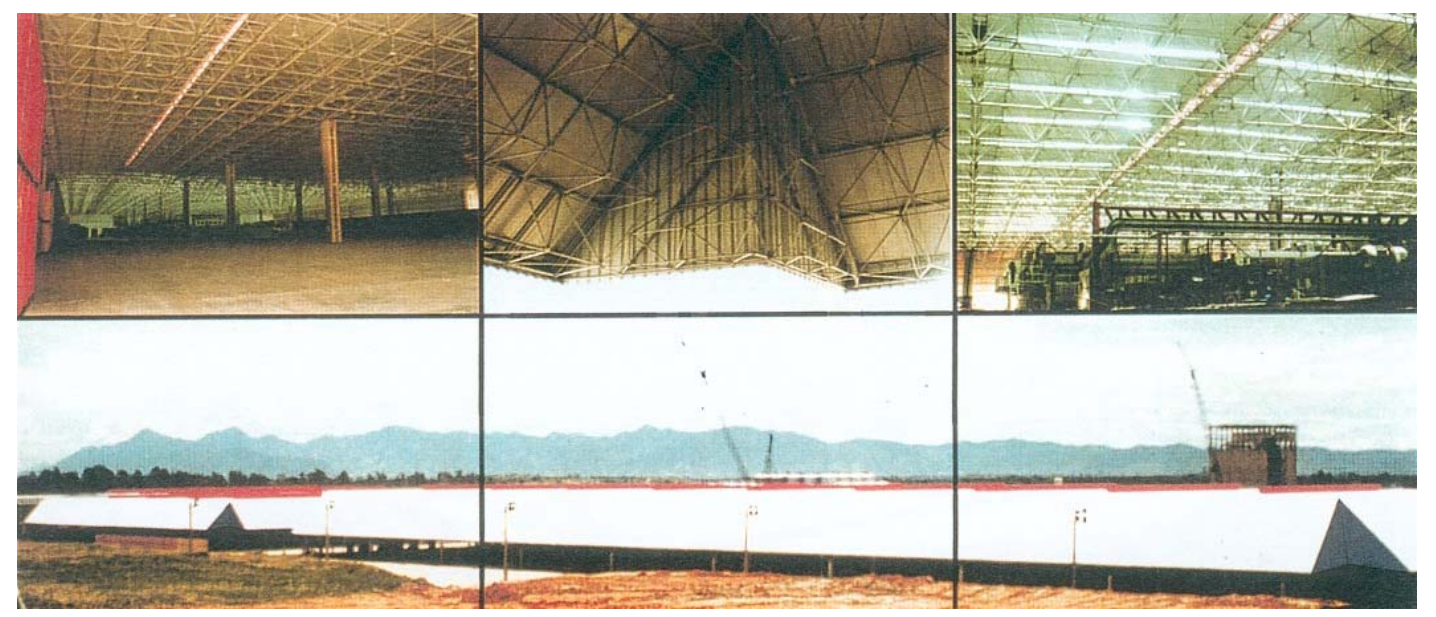

Figura 2.55 - Vistas Externa e Interna Complexo Industrial de Jacarepaguá - Fonte: catálogo ALUSUD

\subsubsection{HANGAR DE MANUTENÇÃO - MUMBAI / ÍNDIA}

Construído em 1994, o hangar apresenta um vão livre 129m e um pé direito de 23m, com capacidade para manutenção de até 2 aviões B747-400. O hangar é equipado com 2 pontes rolantes de 10 ton e 3 pontes de 3 ton fixadas na treliça espacial de cobertura (Figuras 2.56 e 2.57).

Segundo JOGLEKAR et al. (1999), a estrutura de cobertura do hangar compreende as seguintes partes:

- Viga de borda frontal com vão livre de $129,384 m$ e largura de $8,444 \mathrm{~m}$ apoiada nas extremidades em pilares de aço de $25 \mathrm{~m}$ de altura para funcionar como um portal. Esta viga frontal é uma treliça espacial formada por cinco camadas de banzos com ligações rígidas e altura de 8,683 m;

- Viga interna com vão livre de $129,384 m$ e largura de $12,667 m$, contínua sobre dois pilares de concreto intermediários, e apoiada nas extremidades em pilares de concreto. Esta viga apresenta a mesma altura da treliça principal, porém as ligações são rígidas;

- Treliça principal com três camadas de banzo e altura de $4,871 \mathrm{~m}$. As camadas superior e inferior apresentam arranjo quadrado com orientação diagonal em relação ao contorno. A 
camada intermediária apresenta arranjo quadrado com orientação ortogonal em relação ao contorno;

A maior parte da estrutura espacial principal considerada com nós articulados para fins de análise, é composta de perfis tubulares com conectores esféricos ocos de diâmetros 135,0mm, 162,5mm e 200,0mm. Na camada intermediária, os nós esféricos são maciços. Os perfis tubulares utilizados apresentam tensão de escoamento de $220 \mathrm{MPa}$ e suas seções variam de $\varnothing 60,3 \mathrm{~mm} \times 3,65 \mathrm{~mm}$ até $\varnothing 328,9 \times 6,30 \mathrm{~mm}$ e $\varnothing 273,0 \mathrm{~mm}$ x $9,50 \mathrm{~mm}$. A conexão da barra ao nó se dá por meio de um único parafuso. Adotou-se no cálculo um parâmetro de comprimento de flambagem $\mathrm{K}=0,95$.

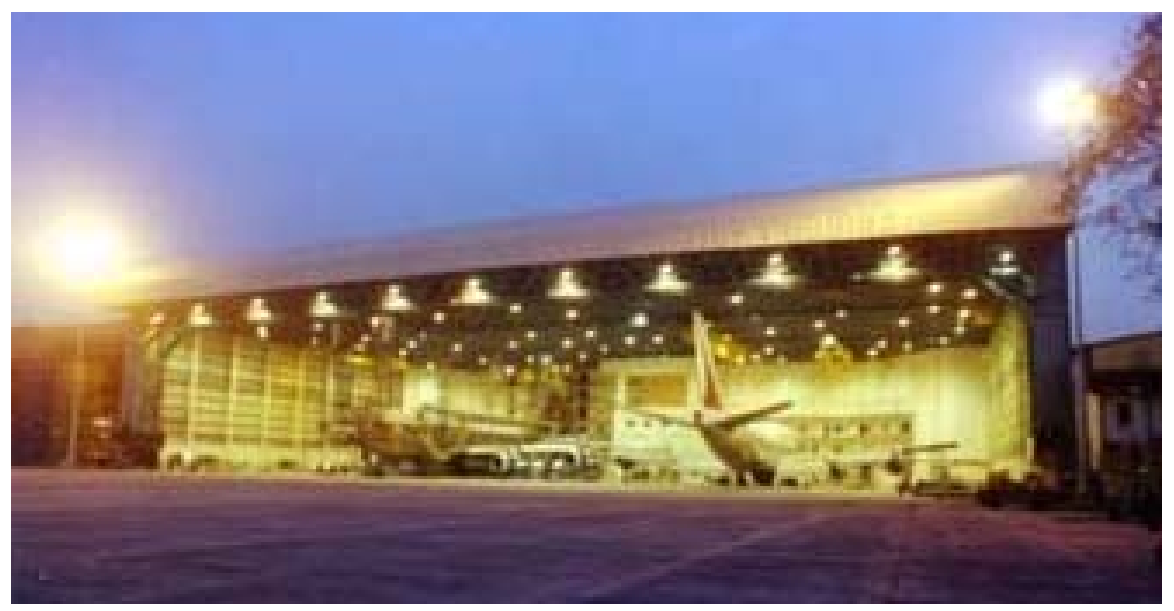

Figura 2.56 - Hangar de Manutenção - Mumbai / Índia

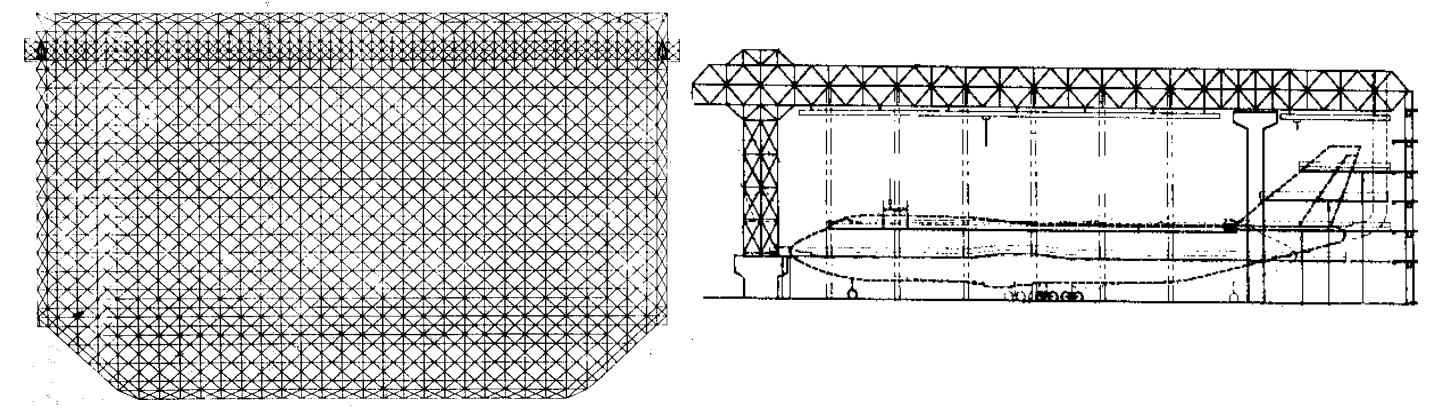

Figura 2.57 - Planta baixa e corte - Hangar de Manutenção Mumbai / Índia - Fonte: JOGLEKAR et al. (1999) 


\subsubsection{HANGAR DE MANUTENÇÃO - BEIJING / CHINA}

Este hangar, construído em 1995, apresenta dois vãos livres de $153 \mathrm{~m}$, e é considerado um dos maiores hangares do mundo, com capacidade para manutenção de até 4 aviões B747-400 (Figuras 2.58 e 2.59).

O hangar apresenta pontes rolantes fixadas na cobertura e está localizado numa região sujeita a abalos sísmicos de alta intensidade.

Segundo SHUTUN (1999), a cobertura é formada por uma treliça espacial com três camadas de banzo e $6,00 \mathrm{~m}$ de altura. As camadas superior e inferior apresentam arranjo quadrado com orientação diagonal em relação ao contorno, com dimensão de módulo de 4,22m x 4,22m. A camada intermediária apresenta arranjo quadrado com orientação ortogonal em relação ao contorno, com dimensão de módulo de $6,00 \mathrm{~m} \times 6,00 \mathrm{~m}$. Todos as barras de seção tranversal tubular circular são conectadas por solda a nós esféricos, totalizando 16.800 perfis tubulares e 4.000 nós esféricos. Os perfis tubulares apresentam seções que variam de $\varnothing 102 \mathrm{~mm} \times 5 \mathrm{~mm}$ até $\varnothing 273 \times$ $16 \mathrm{~mm}$, sendo que o aço possui tensão de escoamento de $400 \mathrm{MPa}$ e tensão última de $540 \mathrm{MPa}$. Os nós esféricos são ocos e variam de $\varnothing 500 \mathrm{~mm} \times 6 \mathrm{~mm}$ até $\varnothing 800 \mathrm{~mm} \times 22 \mathrm{~mm}$. $O$ fato das conexões serem soldadas exigiu um elevado controle de qualidade e exames de ultrasom em todas as conexões. O arranjo com três camadas de banzo foi selecionado porque, para este vão, a rigidez do arranjo com duas camadas é muito baixa, não satisfazendo as exigências quanto aos deslocamentos. Comparada com o arranjo de duas camadas, a altura do arranjo com três camadas pode ser reduzida em $0,80 \mathrm{~m}$, as forças internas em $27 \%$, a deformação em $15 \%$ e o consumo de aço em $27 \%$. A definição da viga de borda para estrutura espacial sobre os portões principais foi um problema difícil, pois a mesma deveria satisfazer uma série de exigências para a correta operação dos portões. Além disso, por suportar toda treliça espacial principal, ela deveria ter rigidez suficiente para garantir uma distribuição racional de forças ao longo da malha. A 
solução encontrada foi a composição de treliças com alturas variando de $6 \mathrm{~m}$ a $15 \mathrm{~m}$, cujas barras eram perfis soldados do tipo duplo "l".

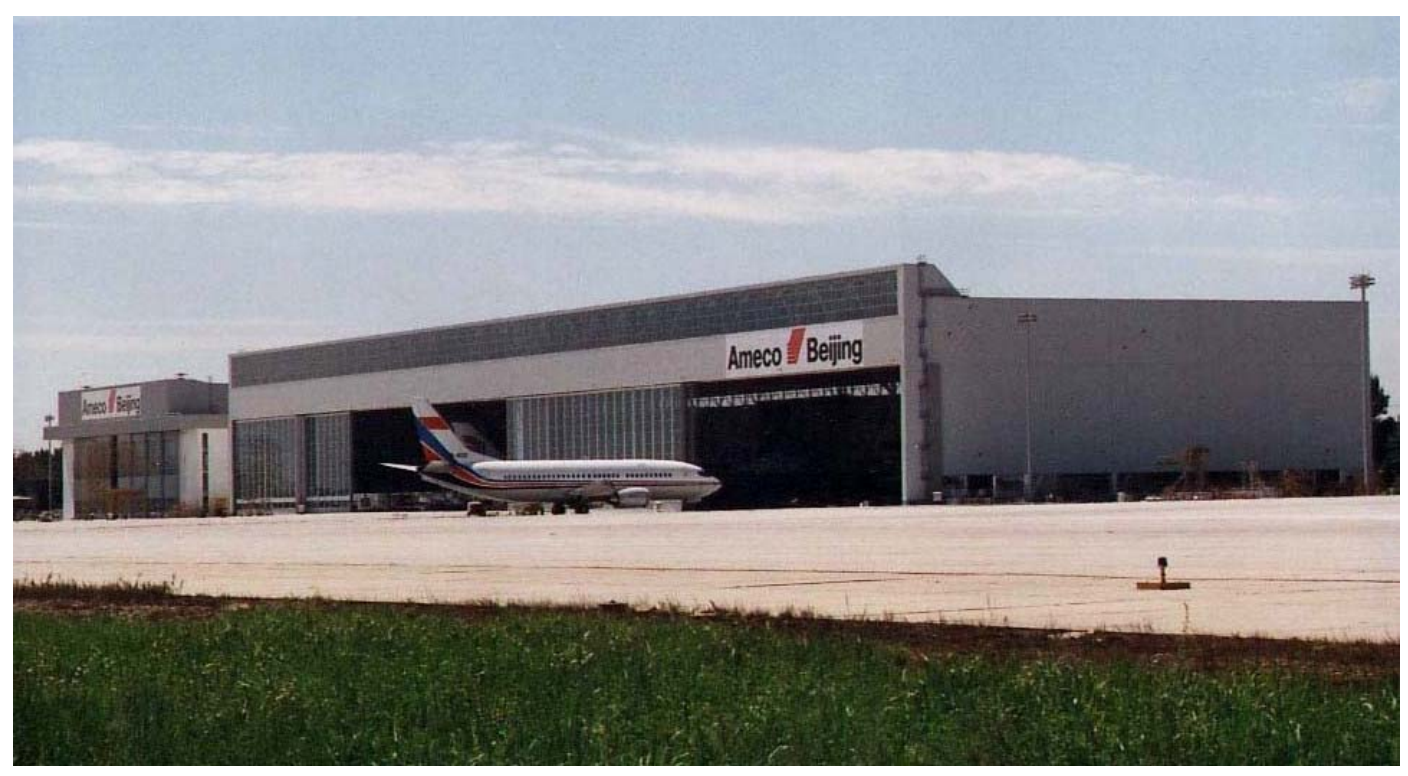

Figura 2.58 - Hangar de manutenção - Beijing / China
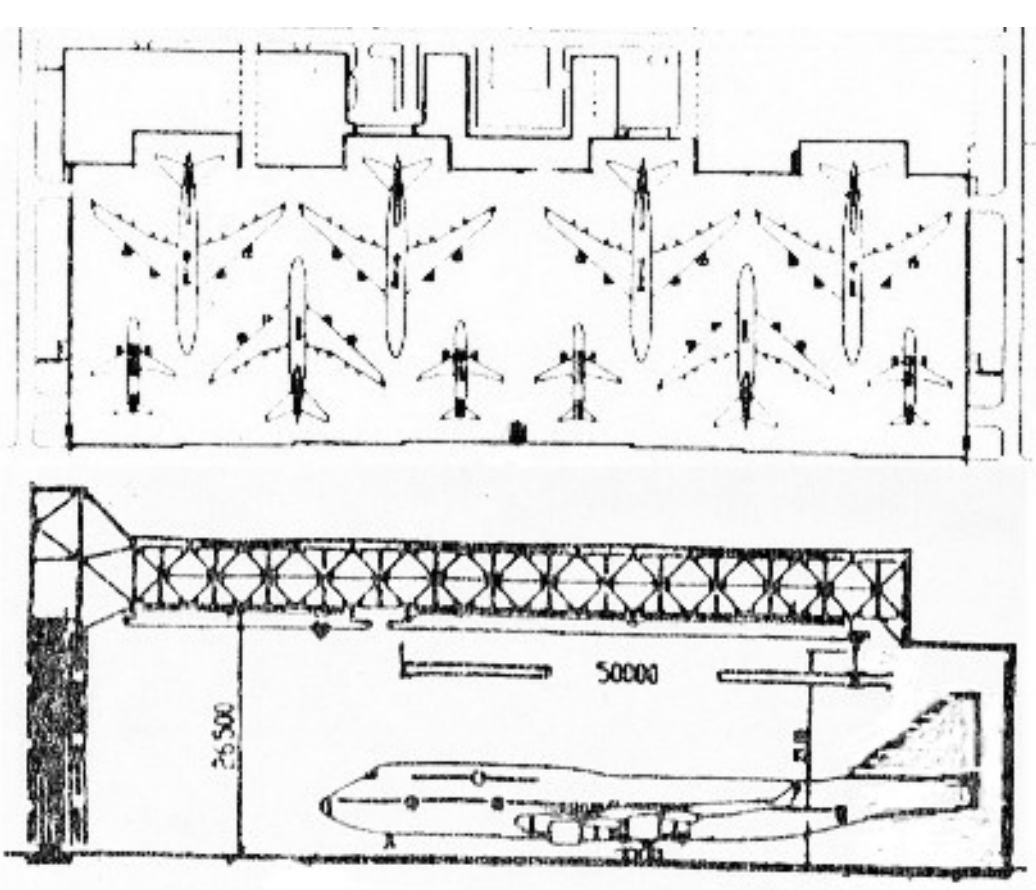

Figura 2.59 - Planta baixa e corte - Hangar de manutenção Beijing / China - Fonte: SHUTUN (1999) 


\subsubsection{CENTRO DE CONVENÇÕES ASSOCIAÇÃO ÁRVORE DA VIDA -} SUMARÉ / SP

Este auditório com capacidade para 10 mil pessoas destaca-se pela complexidade da geometria da treliça espacial de cobertura, que vence um vão livre de $75 \mathrm{~m}$, apoiada em 26 pórticos de concreto e com uma área desenvolvida de $7480 \mathrm{~m}^{2}$. A estrutura, construída em 1999, assemelha-se a uma concha, com curvaturas em diversas direções, o que resultou em um grande número de barras e nós diferentes.

O sistema de ligação é do tipo nó de aço com as extremidades dos perfis tubulares de aço estampadas ou na forma de ponteiras de chapas soldadas. Os fechamentos laterais são formados por treliças espaciais planas, também com nós de aço (Figuras 2.60 e 2.61).
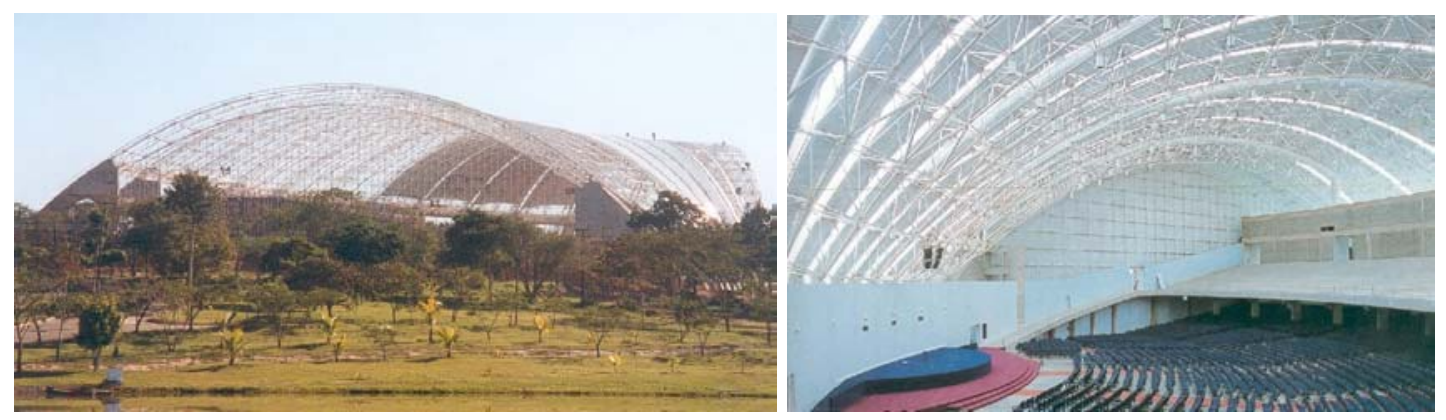

Figura 2.60 - Centro de Convenções Associação Árvore da Vida

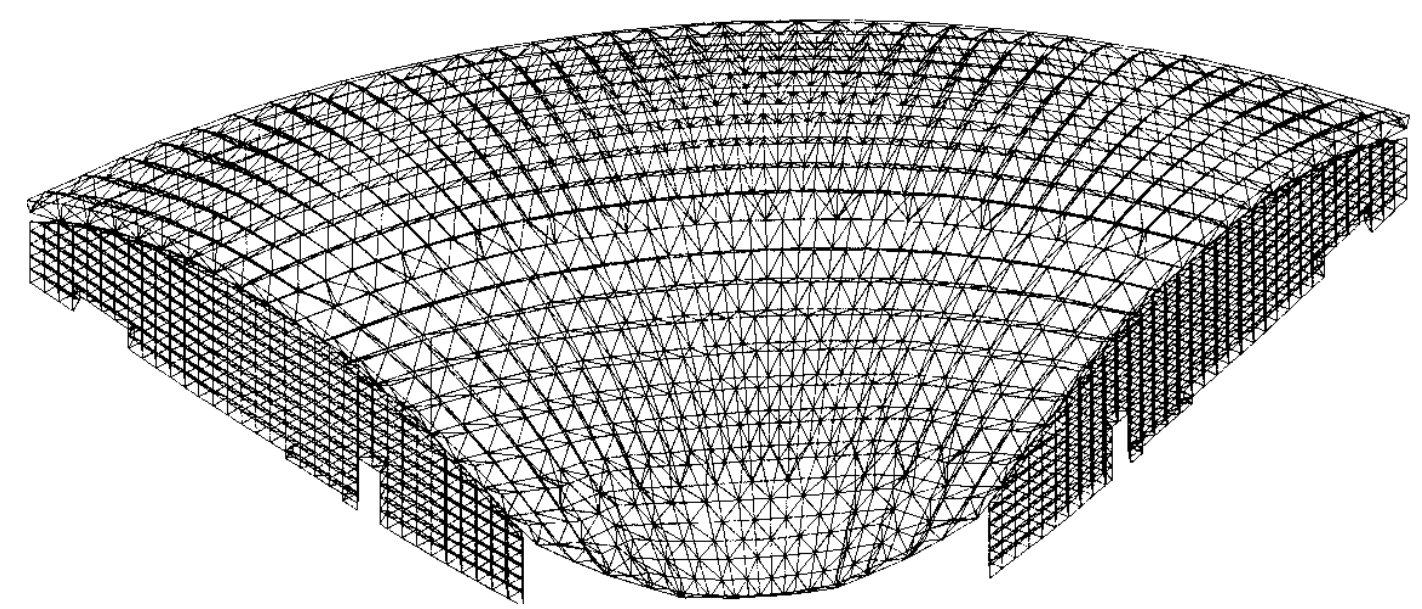

Figura 2.61 - Modelo tridimensional da estrutura - Centro de Convenções Associação Árvore da Vida 


\section{ANÁLISE NUMÉRICA DOS ARRANJOS ESTRUTURAIS PROPOSTOS}

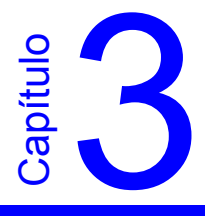

\subsection{ESQUEMA GERAL DAS EDIFICAÇÕES ANALISADAS}

Foram propostas quatro plantas de galpões, duas quadradas, e duas retangulares, mostradas nas Figuras 3.1, 3.2, 3.3 e 3.4.

Os apoios foram locados de maneira que formassem vãos internos de $60 \mathrm{~m}$, podendo os mesmos estar espaçados de $30 \mathrm{~m}$ ou $60 \mathrm{~m}$ nos alinhamentos do contorno. A escolha desta ordem de grandeza para o vão, deve-se ao fato de as estruturas espaciais tornarem-se mais viáveis na prática para vãos acima de $40 \mathrm{~m}$. Foi adotado um balanço de $3 \mathrm{~m}$ ao longo de todo perímetro.

Os pilares de apoio da estrutura de cobertura são perfis de aço de seção transversal tubular circular. O pé direito adotado foi de $10 \mathrm{~m}$ para todos os arranjos analisados.

Os fechamentos laterais dos galpões são independentes dos pilares e da treliça espacial de cobertura.

A cobertura apresenta linhas de calha a cada $30 \mathrm{~m}$, resultando em águas de $15 \mathrm{~m}$.

As plantas retangulares representam exemplos bastante utilizados de galpões para indústrias com linhas de produção de grande extensão. 


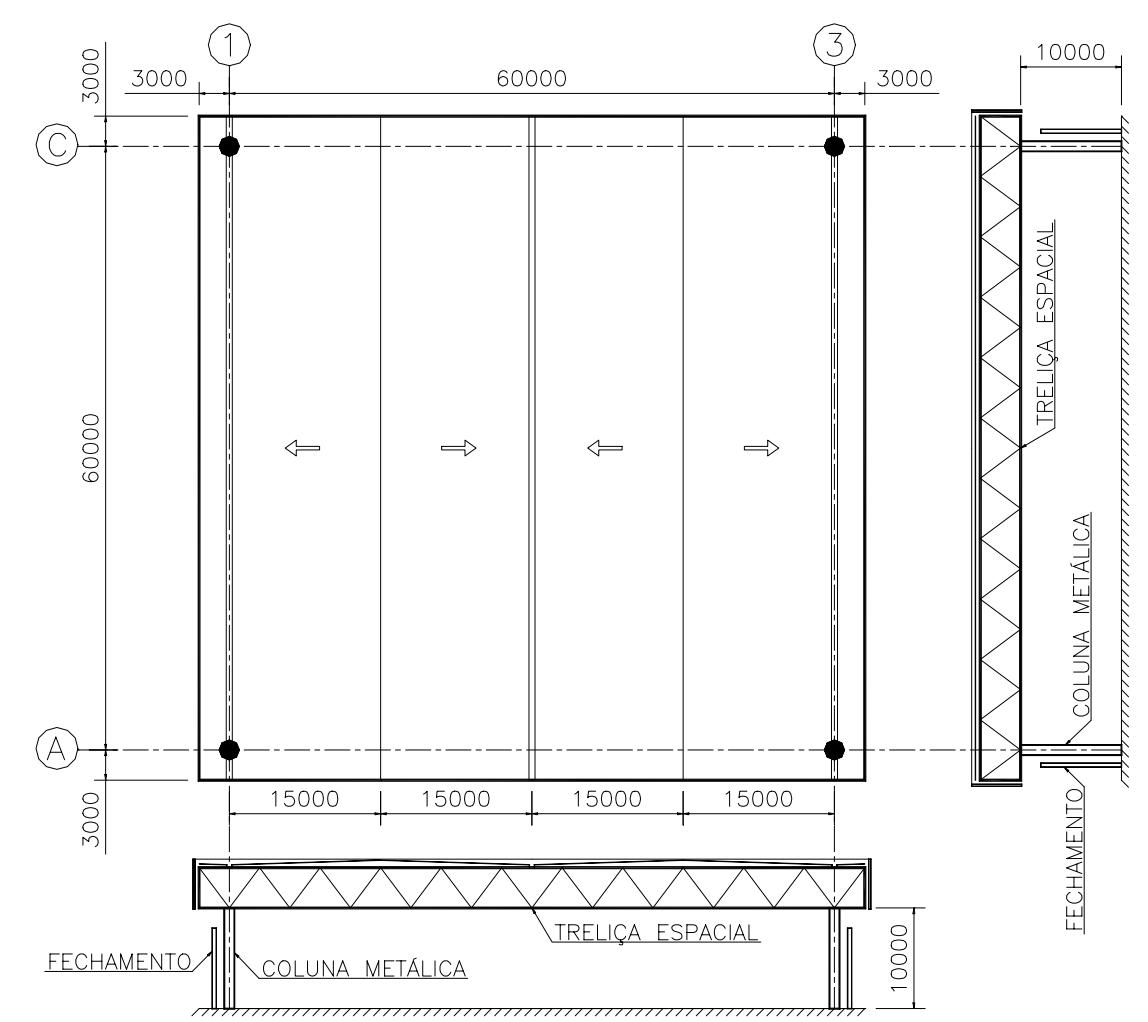

Figura 3.1 - Galpão com planta quadrada e pilares a cada $60 \mathrm{~m}$

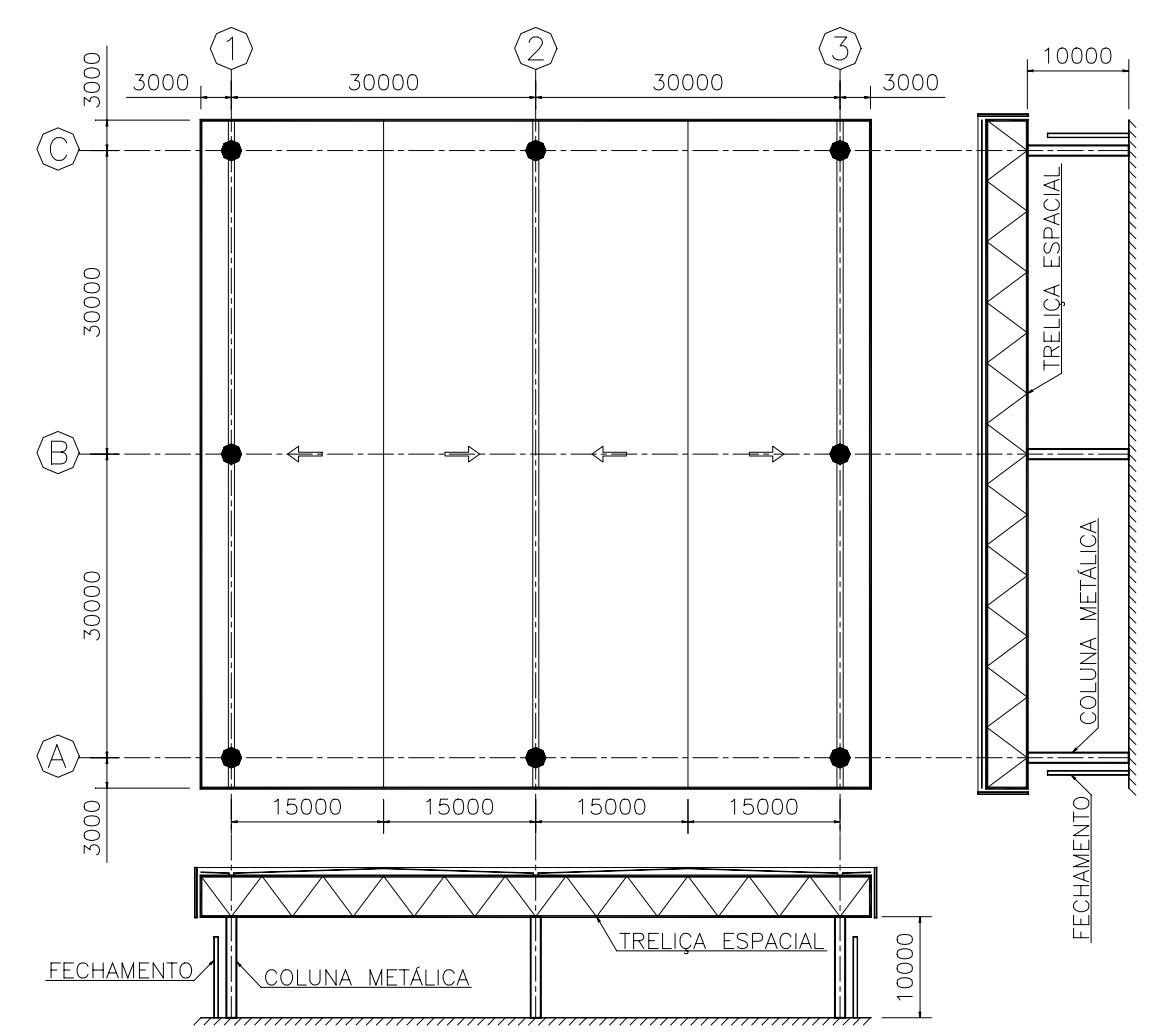

Figura 3.2 - Galpão com planta quadrada e pilares a cada $30 \mathrm{~m}$ 


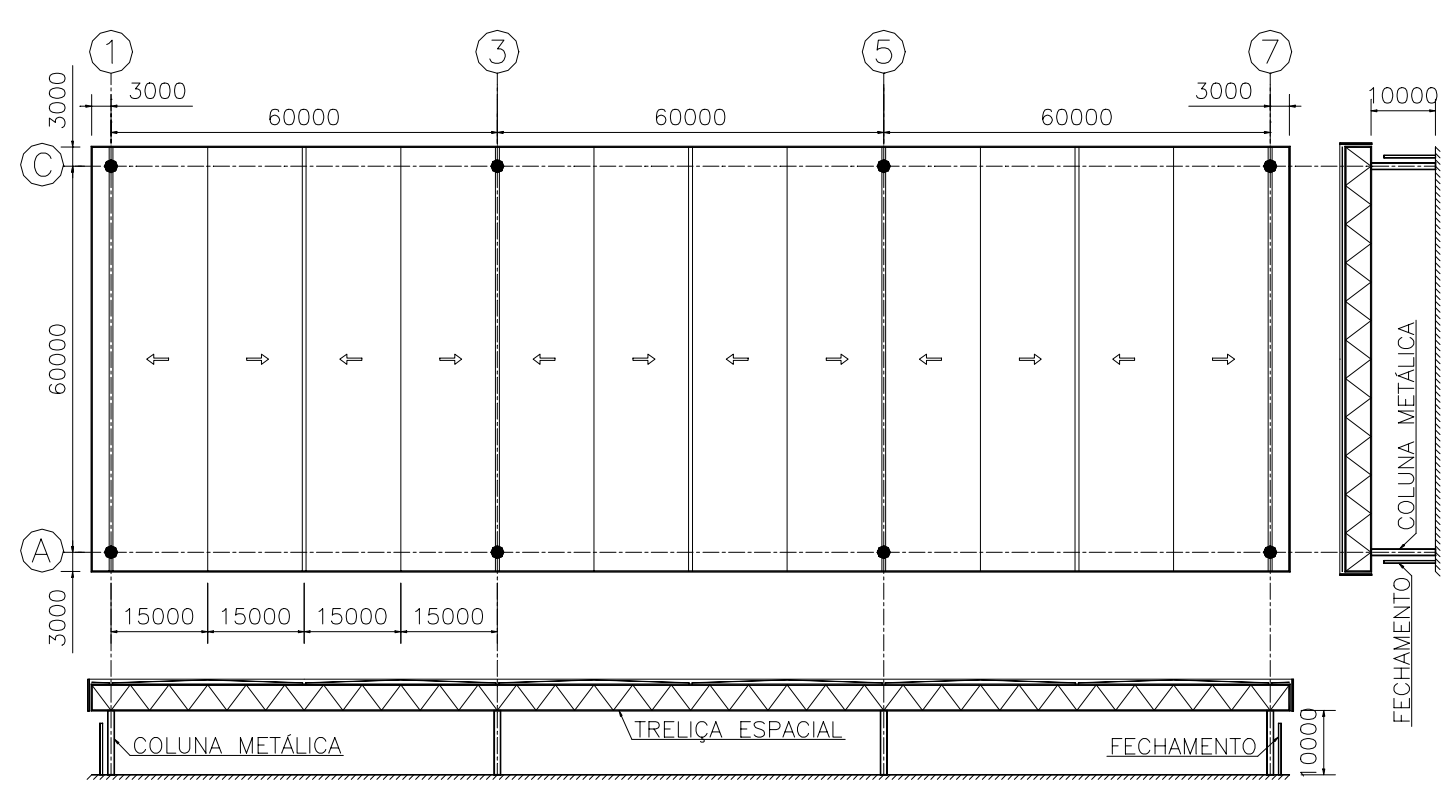

Figura 3.3 - Galpão com planta retangular e pilares a cada $60 \mathrm{~m}$

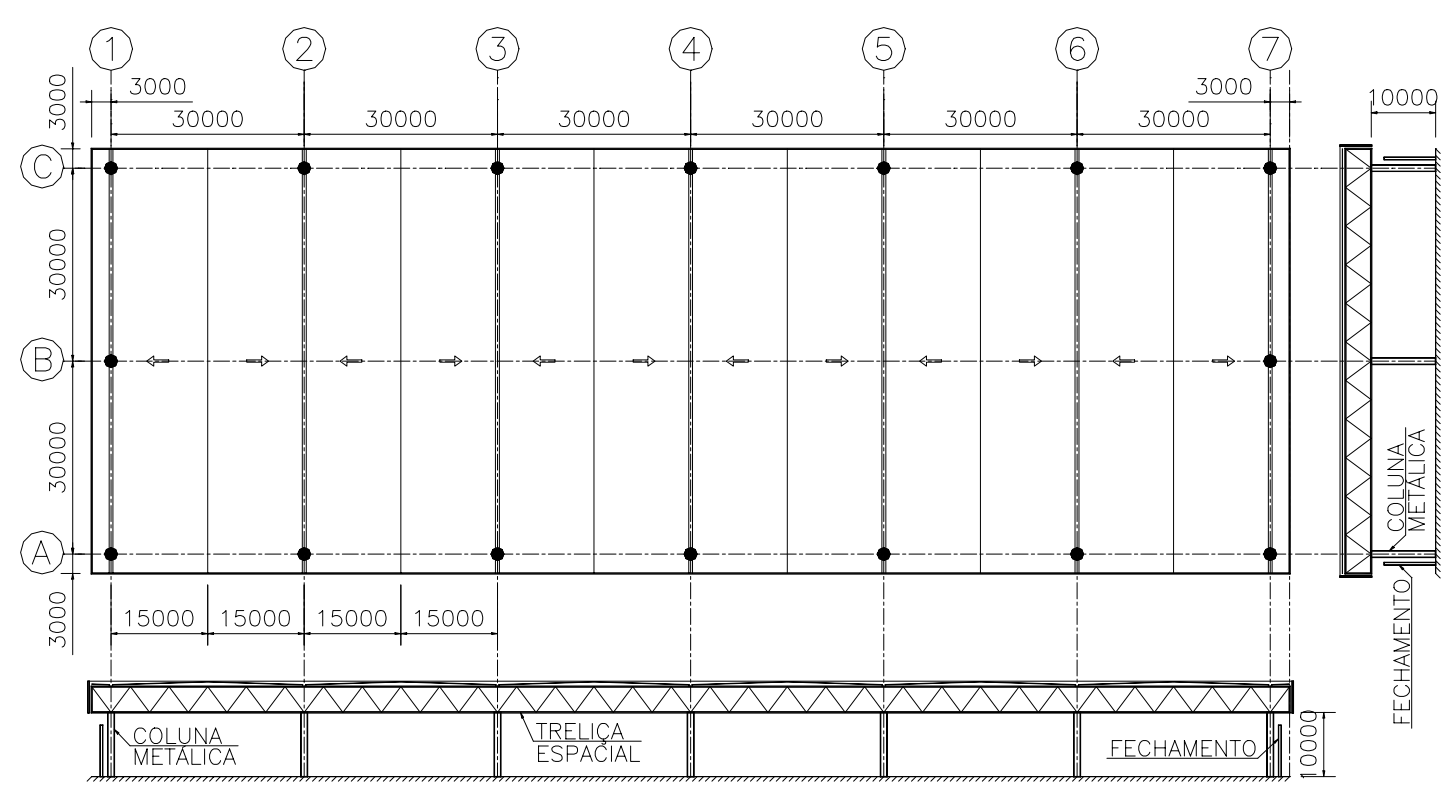

Figura 3.4 - Galpão com planta retangular e pilares a cada $30 \mathrm{~m}$ 


\subsection{DETERMINAÇÃO DAS AÇÕES}

\subsubsection{AÇÕES PERMANENTES}

Foram utilizadas as seguintes ações permanentes:

- Peso próprio de estrutura principal: gerado automaticamente pelo programa, baseado nos perfis das barras;

- Peso próprio da estrutura secundária em perfis de aço conformados a frio (terças, montantes, etc.) $=0,07 \mathrm{kN} / \mathrm{m}^{2}$;

- Peso próprio das telhas de cobertura (2 telhas de aço perfil trapezoidal, altura $40 \mathrm{~mm}$, espessura $0,50 \mathrm{~mm}$, com isolamento térmico de poliestireno expandido entre elas, com altura de $40 \mathrm{~mm})=0,13 \mathrm{kN} / \mathrm{m}^{2}$;

\subsubsection{AÇÕES VARIÁVEIS}

\subsubsection{SOBRECARGAS}

Foram utilizadas as seguintes sobrecargas:

- Sobrecarga mínima segundo a NBR $8800(1988)=0,25 \mathrm{kN} / \mathrm{m}^{2}$;

- Sobrecarga adicional de instalações e equipamentos nãopermanentes $=0,25 \mathrm{kN} / \mathrm{m}^{2}$;

\subsubsection{TEMPERATURA}

Por se tratarem de estruturas protegidas foi adotada uma variação de temperatura uniforme de $\pm 15^{\circ} \mathrm{C}$.

\subsubsection{VENTO}

O cálculo das ações do vento foi baseado nas recomendações da NBR 6123 (1988): 
Velocidade básica:

Localidade: São Carlos $/ \mathrm{SP} \Rightarrow \mathbf{V}_{\mathbf{0}}=\mathbf{4 0} \mathrm{m} / \mathrm{s}$;

Fator topográfico:

Terreno plano $\Rightarrow \mathbf{S}_{\mathbf{1}}=\mathbf{1 , 0}$

Fator de rugosidade do terreno e dimensões da edificação:

Categoria IV: área industrial parcialmente desenvolvida.

Classe C: maior dimensão horizontal da superfície frontal excede $50 \mathrm{~m}$.

Altura da edificação: $H=10,00 m$ (coluna) $+4,00 m$ (altura média das treliças analisadas) $+0,85 \mathrm{~m}$ (altura da estrutura secundária + telhas) $\Rightarrow \mathrm{H}=14,85 \mathrm{~m}$.

$S_{2}=b^{*} F_{r}^{*}\left(0,1^{*} Z\right)^{p}=0,84^{*} 0,95^{*}\left(0,1^{*} 14,85\right)^{0,135} \Rightarrow \mathbf{S}_{\mathbf{2}}=\mathbf{0 , 8 4}$

Fator estatístico:

Edifício industrial com alto fator de ocupação $\Rightarrow S_{3}=$ 1,0 ;

Velocidade característica:

$V_{K}=V_{0} * S_{1} * S_{2} * S_{3}=40 * 1,0 * 0,84 * 1,0 \Rightarrow V_{K}=33,6 \mathrm{~m} / \mathbf{s}$;

Pressão de obstrução:

$q=0,613 * V_{k}^{2}=0,613 *(33,6)^{2} \Rightarrow q=0,69 \mathrm{kN} / \mathrm{m}^{2}$

$>$ Coeficiente de pressão interna (Cpi):

Não existem aberturas dominantes e as quatro faces podem ser consideradas de igual permeabilidade $\Rightarrow \mathbf{C p i}=-\mathbf{0 , 3}$ ou $\mathbf{0}$;

Coeficiente de forma externo (Ce):

Os coeficientes de forma externos para as quatro direções do vento podem ser observados na Figura 3.5 (galpões com 
planta quadrada) e na Figura 3.6 (galpões com planta retangular). Os valores positivos indicam sobrepressão e os valores negativos sucção.

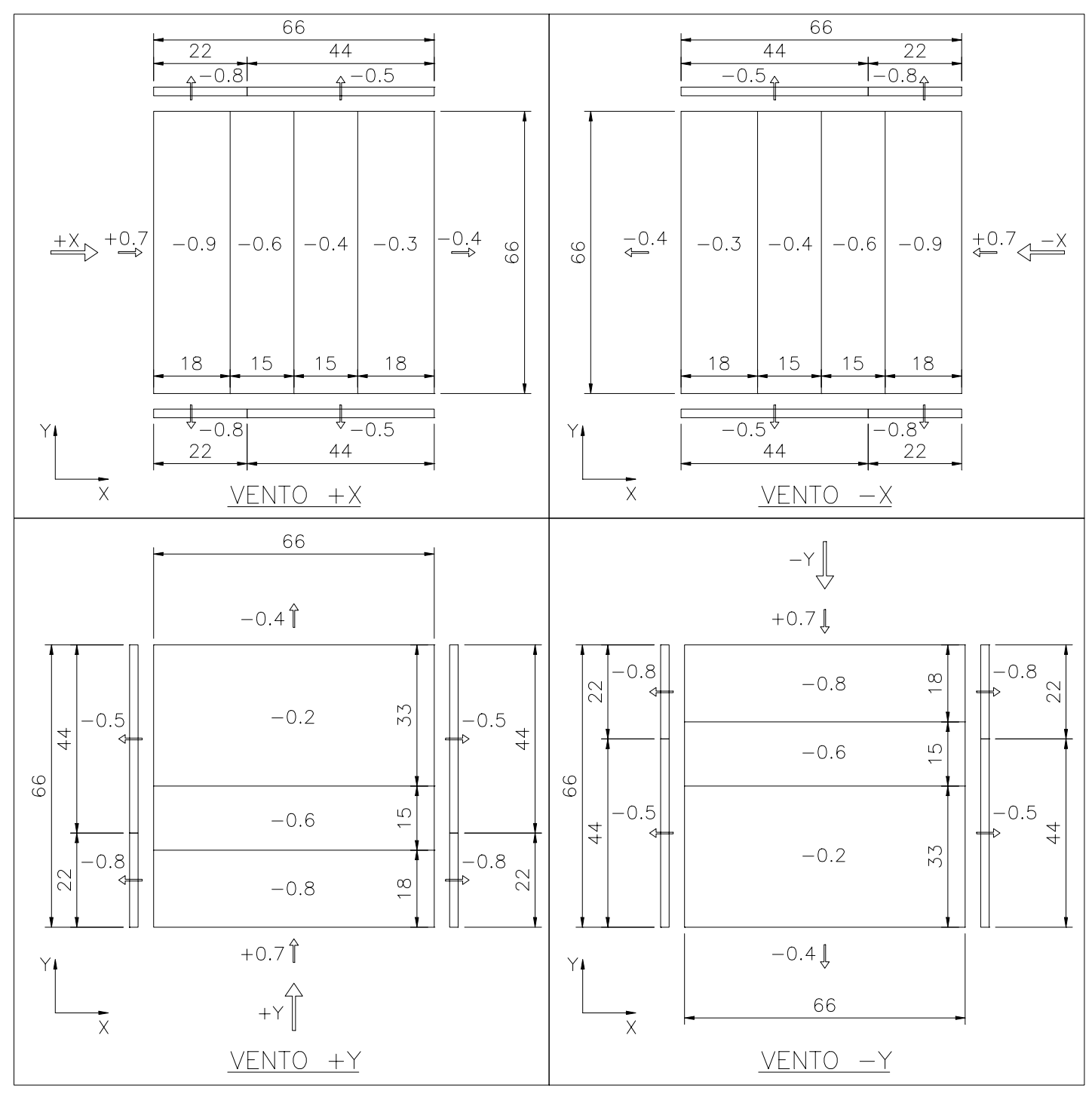

Figura 3.5 - Coeficientes de forma externos (Ce) Galpões com planta quadrada

As situações mais desfavoráveis de sucção ocorrem quando $\mathrm{Cpi}=0$. Para $\mathrm{Cpi}=-0,3$, existe sobrepressão muito baixa $(\Delta \mathrm{Cp}=+0,1)$ na metade da cobertura apenas para o vento na direção $Y$, para todas as outras situações existe sucção reduzida. Assim, para diminuir o número de combinações 
utilizadas no dimensionamento dos arranjos, foi adotado Cpi $=0$, ficando os coeficientes de forma representados pelos valores de Ce.

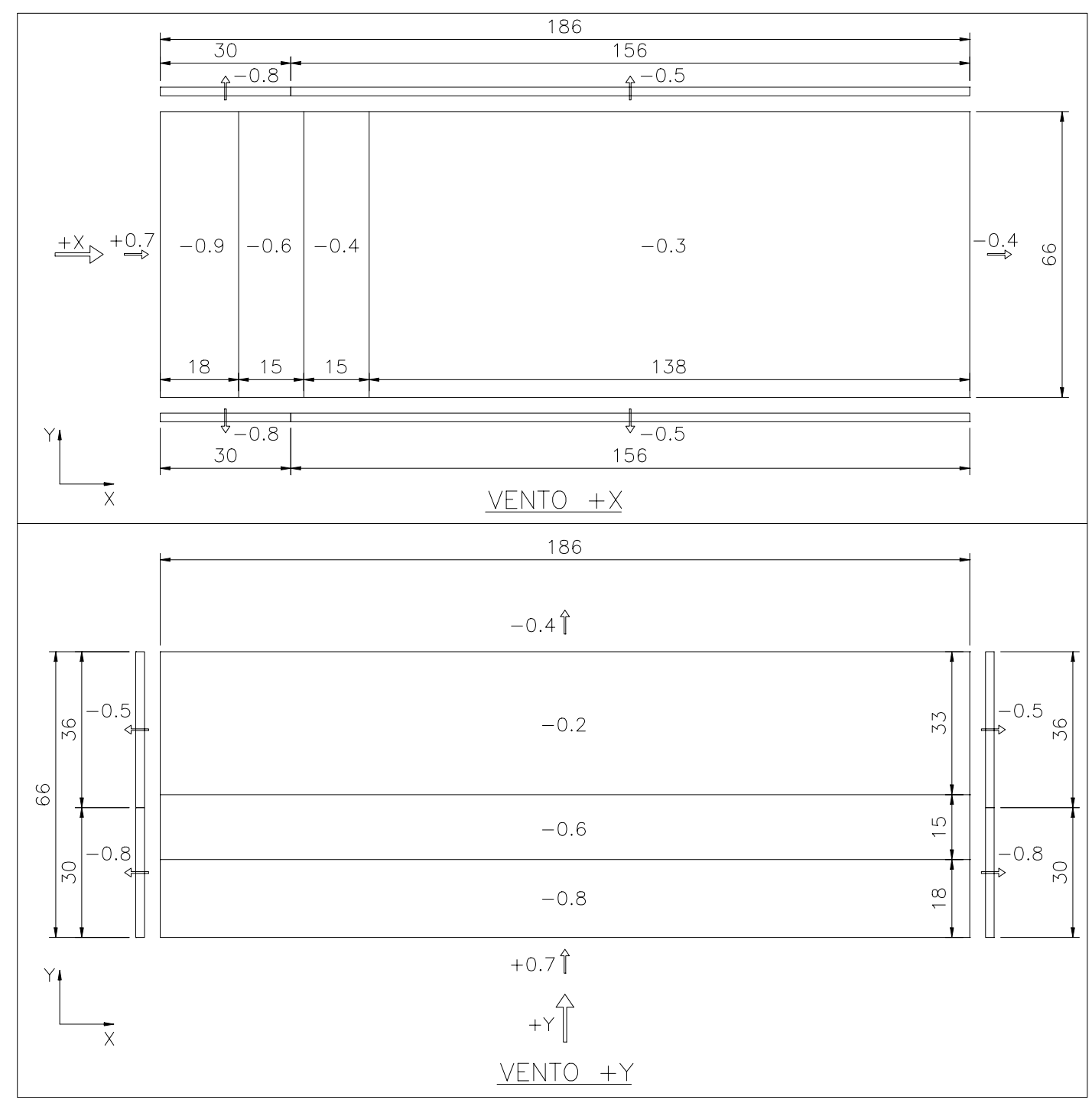

Figura 3.6 - Coeficientes de forma externos (Ce) Galpões com planta retangular

As ações de vento $-\mathrm{X}$ e $-\mathrm{Y}$ representam as ações do vento em sentidos opostos aos vento $+X$ e $+Y$, respectivamente. A adoção de dois sentidos opostos para a mesma direção do vento tem a função de promover a simetria do dimensionamento. Este procedimento é muito utilizado nos escritórios de cálculo, pois auxilia na uniformização da estrutura, dispensando a uniformização manual em relação aos eixos de simetria. 
Além disso, é uma importante ferramenta para conferência de dados de geometria e de carregamento de vento.

\subsection{ARRANJOS ESTRUTURAIS PROPOSTOS}

\subsubsection{ARRANJOS ESTRUTURAIS COM PLANTA QUADRADA}

Foram propostos 27 arranjos com planta quadrada:

- $18 \mathrm{com}$ pilares a cada $60 \mathrm{~m}$;

- 9 com pilares a cada $30 \mathrm{~m}$.

As alturas dos reticulados variam de vão/10 a vão/20, concentrandose nas alturas de 4,5m (vão/13), 4,0m (vão/15) e 3,5m (vão/17). Para o desenvolvimento da modulação mais adequada para estes 27 arranjos, procurou-se trabalhar com módulos que resultassem num ângulo para diagonais entre $40^{\circ}$ e $50^{\circ}$ em relação ao plano horizontal.

\subsubsection{ARRANJO ESTRUTURAL 1A}

Este arranjo apresenta reticulado quadrado sobre quadrado com defasagem de meio módulo (Figura 3.7).

- módulo $=6000 \mathrm{~mm} \times 6000 \mathrm{~mm}$;

- $\quad$ altura do reticulado $=4500 \mathrm{~mm}$ (vão/13);

- ângulo das diagonais $=46,7^{\circ}$;

- apoios no nível do banzo inferior;

- quantidade de pilares $=4$;

- $\quad$ altura dos pilares $=10 \mathrm{~m}$;

As dimensões das barras do arranjo $1 \mathrm{~A}$ foram tomadas como as dimensões máximas para tamanho de módulo, com barras de comprimento em torno de $6 \mathrm{~m}$. Barras com mais de $6 \mathrm{~m}$, e de diâmetros elevados, dificultam a fabricação, o transporte e a montagem, além de serem de difícil aquisição no mercado. 

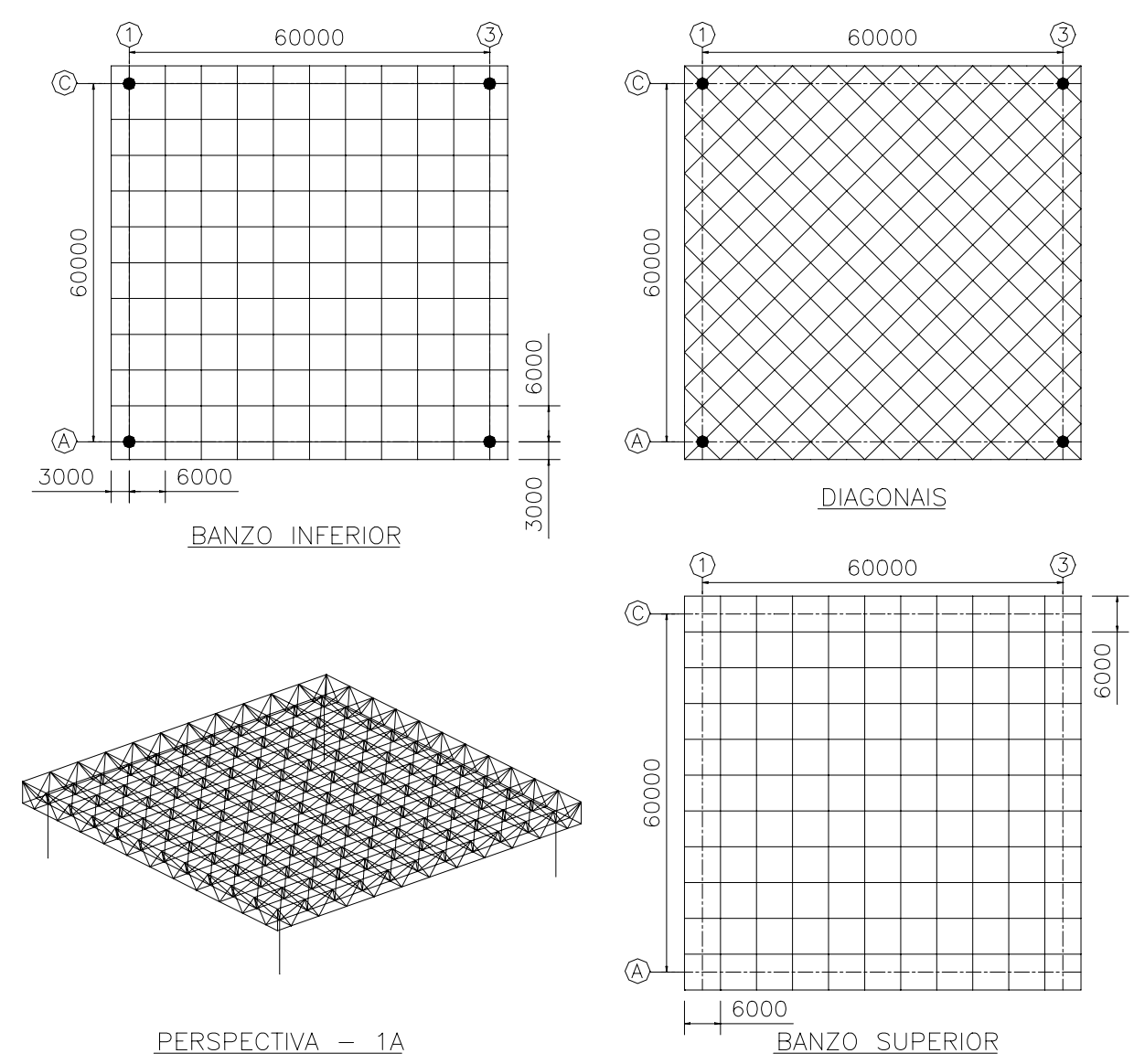

Figura 3.7 - Arranjo estrutural 1A

\subsubsection{ARRANJO ESTRUTURAL 1B}

Este arranjo é similar ao $1 \mathrm{~A}$, com alteração apenas na altura do reticulado.

- altura do reticulado $=4000 \mathrm{~mm}($ vão/15);

- ângulo das diagonais $=43,3^{\circ}$;

\subsubsection{ARRANJO ESTRUTURAL $1 \mathrm{C}$}

Este arranjo apresenta reticulado quadrado sobre quadrado com defasagem de meio módulo (Figura 3.8).

- $\quad$ módulo $=5000 \mathrm{~mm} \times 5000 \mathrm{~mm}$;

- $\quad$ altura do reticulado $=3500 \mathrm{~mm}($ vão/17); 
- ângulo das diagonais $=44,7^{\circ}$;

- apoios no nível do banzo inferior;

- quantidade de pilares $=4$;

- altura dos pilares $=10 \mathrm{~m}$;
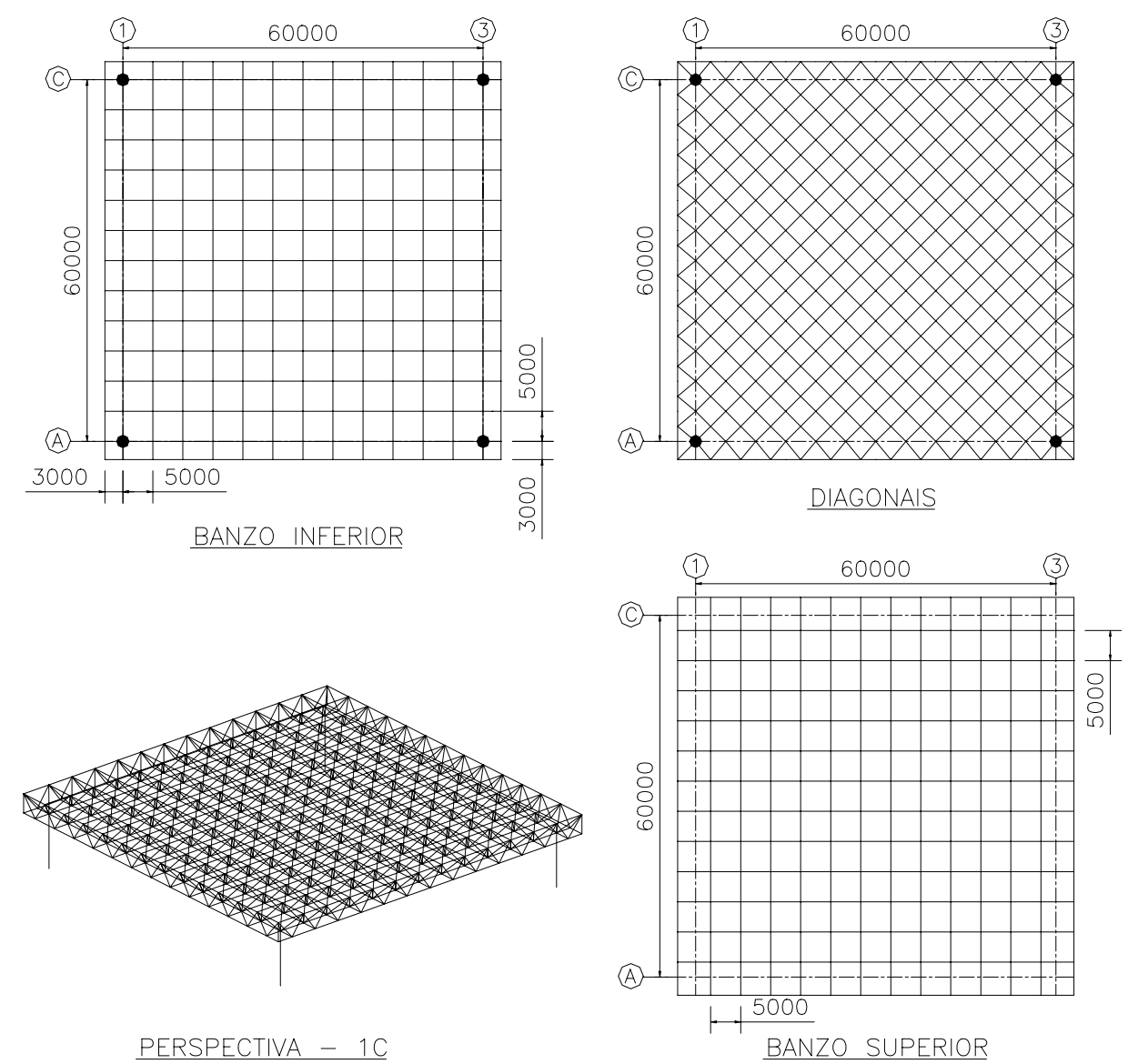

Figura 3.8 - Arranjo estrutural 1C

\subsubsection{ARRANJO ESTRUTURAL 1D}

Este arranjo apresenta reticulado quadrado sobre quadrado com defasagem de meio módulo (Figura 3.9).

- módulo $=4000 \mathrm{~mm} \times 4000 \mathrm{~mm}$;

- altura do reticulado $=3000 \mathrm{~mm}$ (vão/20);

- ângulo das diagonais $=46,7^{\circ}$;

- apoios no nível do banzo inferior; 
- $\quad$ quantidade de pilares $=4$;

- $\quad$ altura dos pilares $=10 \mathrm{~m}$;
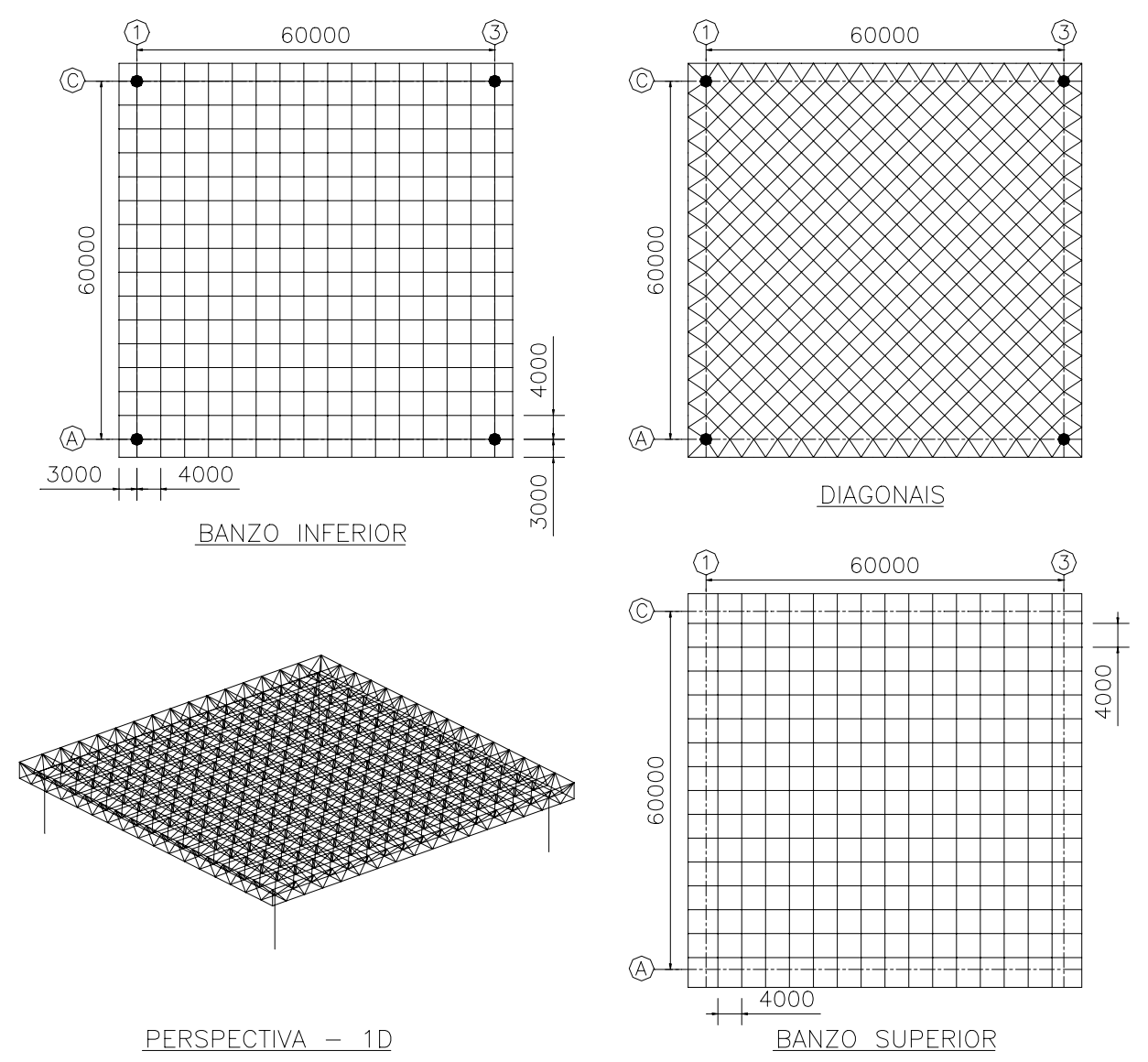

Figura 3.9 - Arranjo estrutural 1D

\subsubsection{ARRANJO ESTRUTURAL 2A}

Este arranjo apresenta reticulado quadrado diagonal sobre quadrado diagonal com defasagem de meio módulo (Figura 3.10).

- $\quad$ módulo = 6061 $\mathrm{mm} \times 6061 \mathrm{~mm}$;

- $\quad$ altura do reticulado $=4500 \mathrm{~mm}($ vão/13);

- ângulo das diagonais $=46,4^{\circ}$;

- apoios no nível do banzo inferior;

- $\quad$ quantidade de pilares $=4$;

- altura dos pilares $=10 \mathrm{~m}$; 

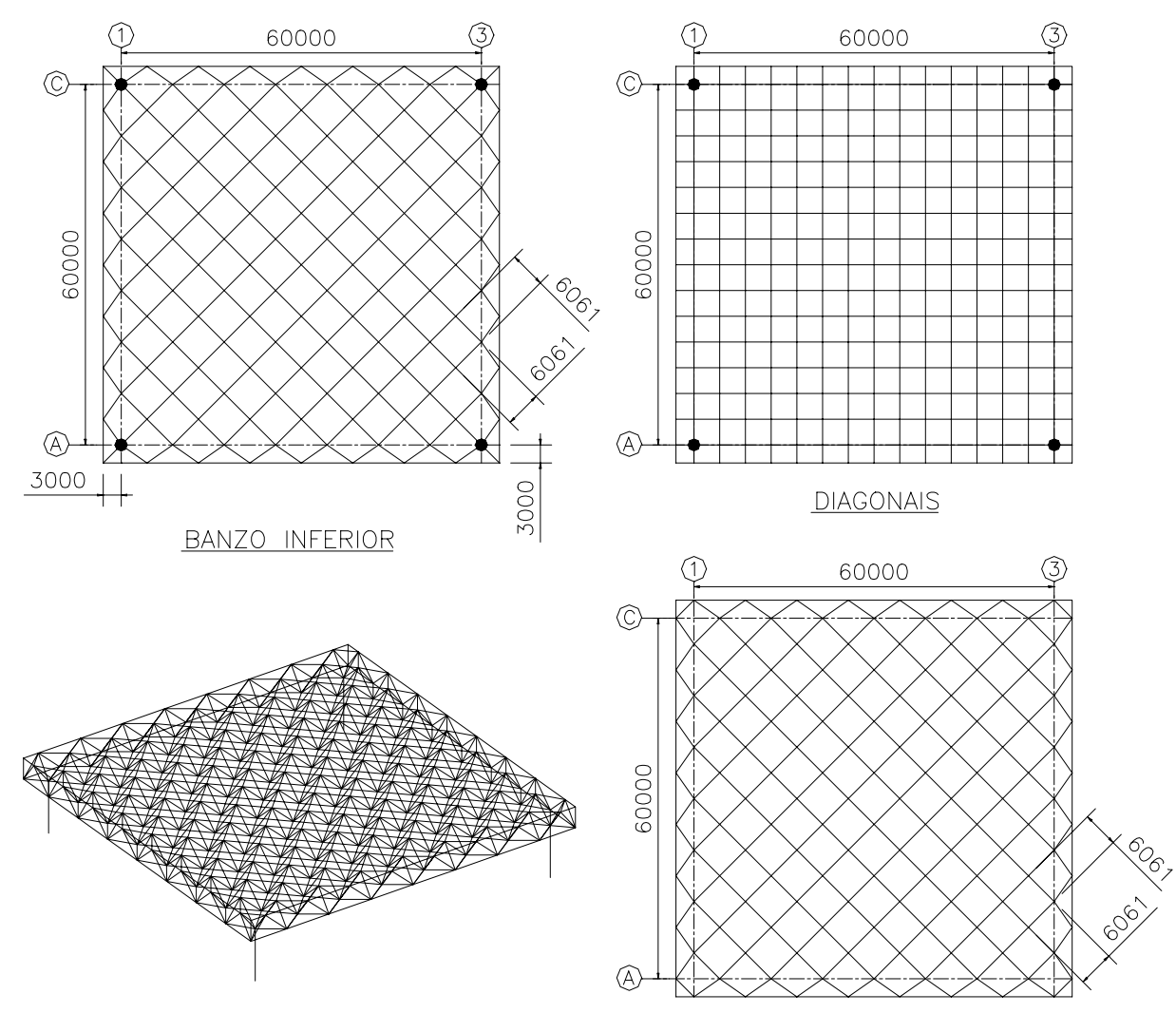

PERSPECTIVA - 2A

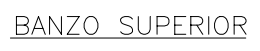

Figura 3.10 - Arranjo estrutural 2A

\subsubsection{ARRANJO ESTRUTURAL 2B}

Este arranjo é similar ao $2 \mathrm{~A}$, com alteração apenas na altura do reticulado.

- altura do reticulado $=4000 \mathrm{~mm}($ vão/15);

- ângulo das diagonais $=43,0^{\circ}$;

\subsubsection{ARRANJO ESTRUTURAL 2C}

Este arranjo apresenta reticulado quadrado diagonal sobre quadrado diagonal com defasagem de meio módulo (Figura 3.11).

- módulo $=4714 \mathrm{~mm} \times 4714 \mathrm{~mm}$;

- altura do reticulado $=3500 \mathrm{~mm}$ (vão/17); 
- ângulo das diagonais $=46,4^{\circ}$;

- apoios no nível do banzo inferior;

- quantidade de pilares $=4$;

- altura dos pilares $=10 \mathrm{~m}$;
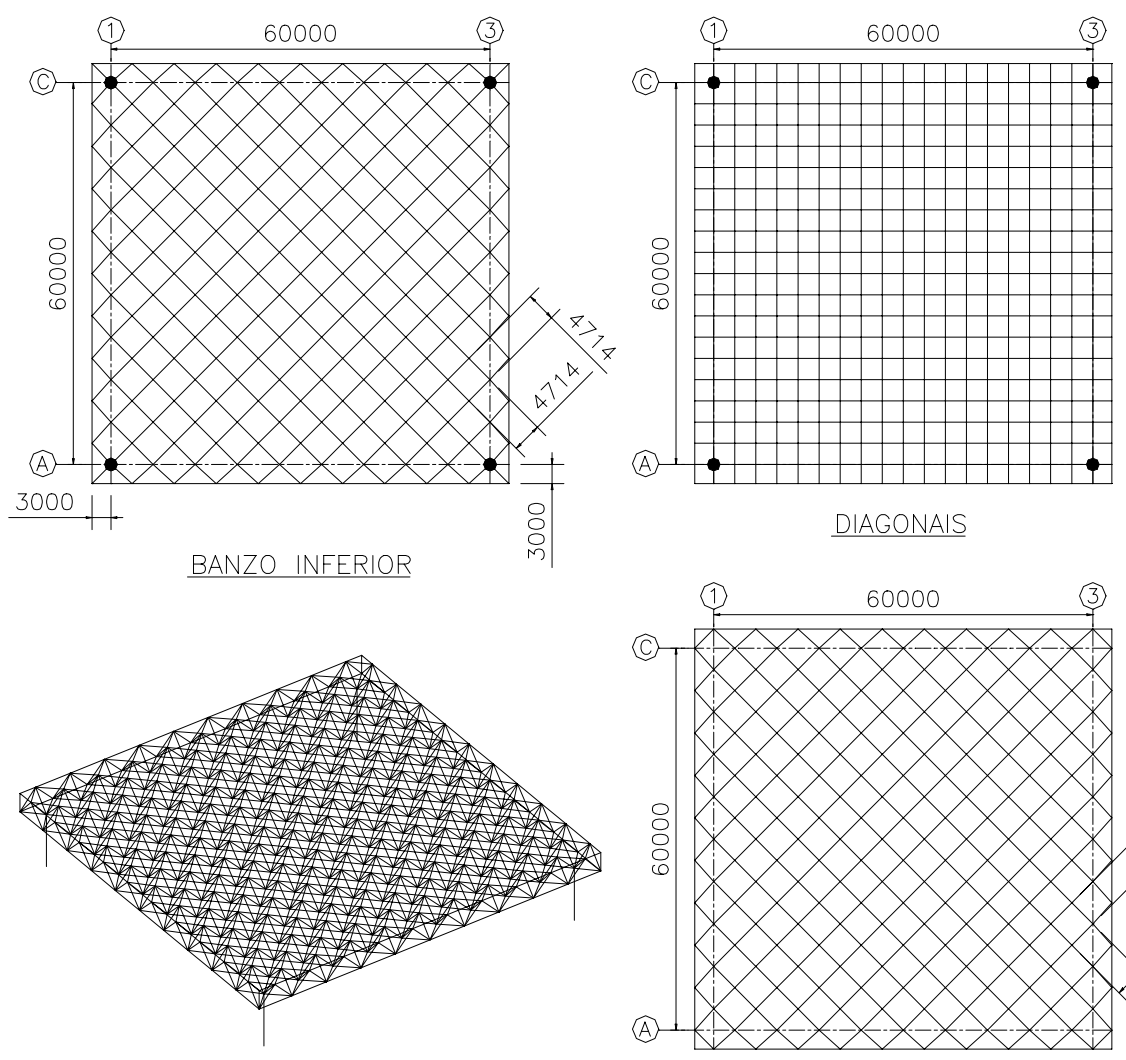

BANZO SUPERIOR

Figura 3.11 - Arranjo estrutural 2C

\subsubsection{ARRANJO ESTRUTURAL 3A}

Este arranjo apresenta reticulado quadrado reduzido sobre quadrado diagonal (Figura 3.12). Foi mantida a modulação do banzo inferior quadrado diagonal do arranjo 2A, sendo o banzo superior formado por quadrados inscritos nos quadrados diagonais do banzo inferior. Esta forma de concepção dos módulos, fez com que os ângulos das diagonais ficassem superiores a $50^{\circ} \mathrm{em}$ relação ao plano horizontal. Para tornar os ângulos das 
diagonais igual a $45^{\circ}$, seria preciso aumentar a dimensão do módulo do banzo inferior para $9 \mathrm{~m}$, mantendo-se fixa a altura do reticulado em 4,5m. Este tamanho de módulo torna-se inviável na prática. Assim, preferiu-se aumentar o ângulo das diagonais.

- módulo superior $=4285,8 \mathrm{~mm} \times 4285,8 \mathrm{~mm}$;

- módulo inferior $=6061 \mathrm{~mm} \times 6061 \mathrm{~mm}$;

- altura do reticulado $=4500 \mathrm{~mm}$ (vão/13);

- ângulo das diagonais $=56,0^{\circ}$;

- apoios no nível do banzo inferior;

- quantidade de pilares $=4$;

- altura dos pilares $=10 \mathrm{~m}$;
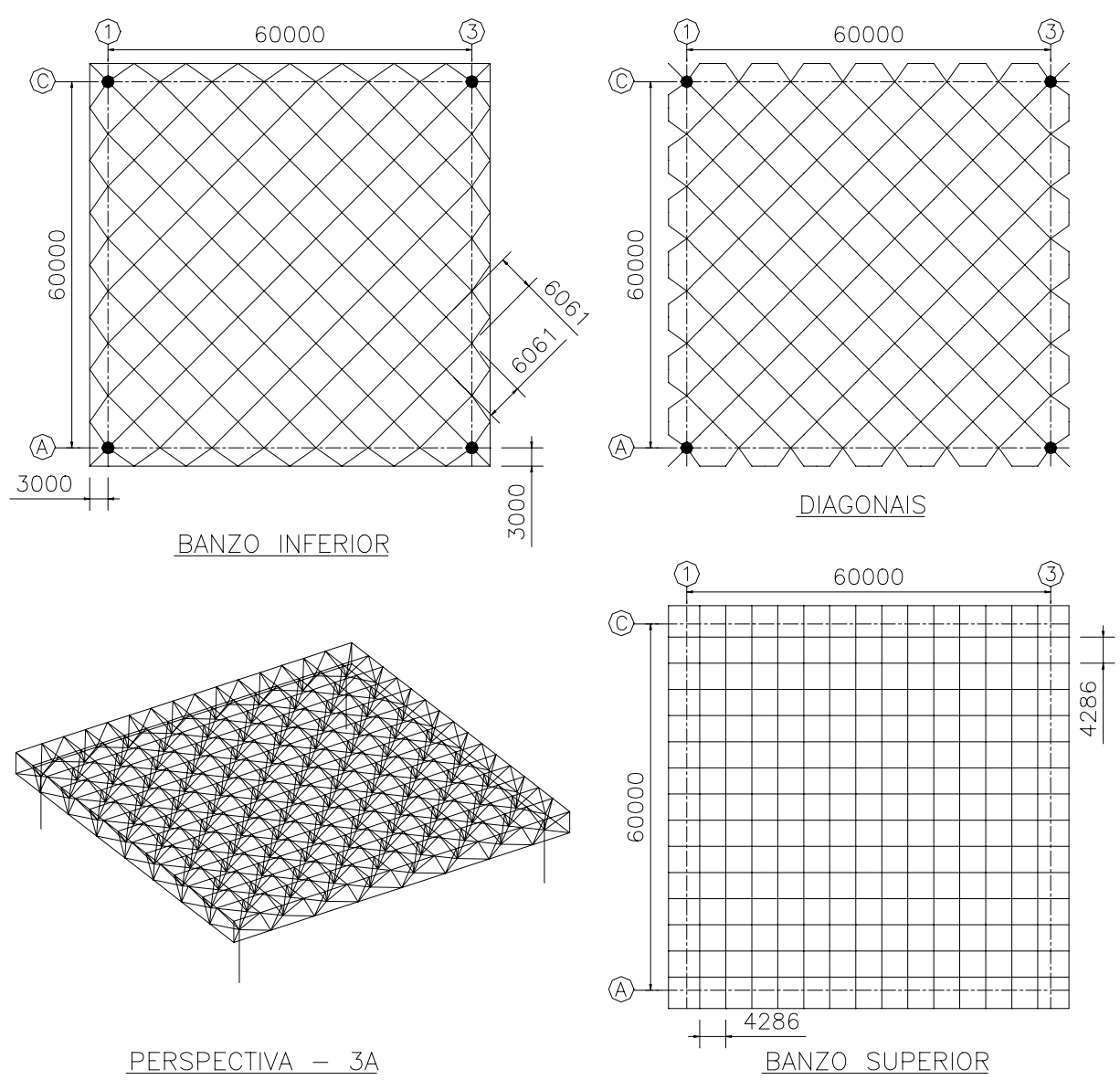

Figura 3.12 - Arranjo estrutural 3A 


\subsubsection{ARRANJO ESTRUTURAL 3B}

Este arranjo é similar ao 3A, com alteração apenas na altura do reticulado.

- $\quad$ altura do reticulado $=4000 \mathrm{~mm}($ vão/15);

- $\quad$ ângulo das diagonais $=52,9^{\circ}$;

\subsubsection{ARRANJO ESTRUTURAL 3C}

Este arranjo apresenta reticulado quadrado reduzido sobre quadrado diagonal (Figura 3.13).
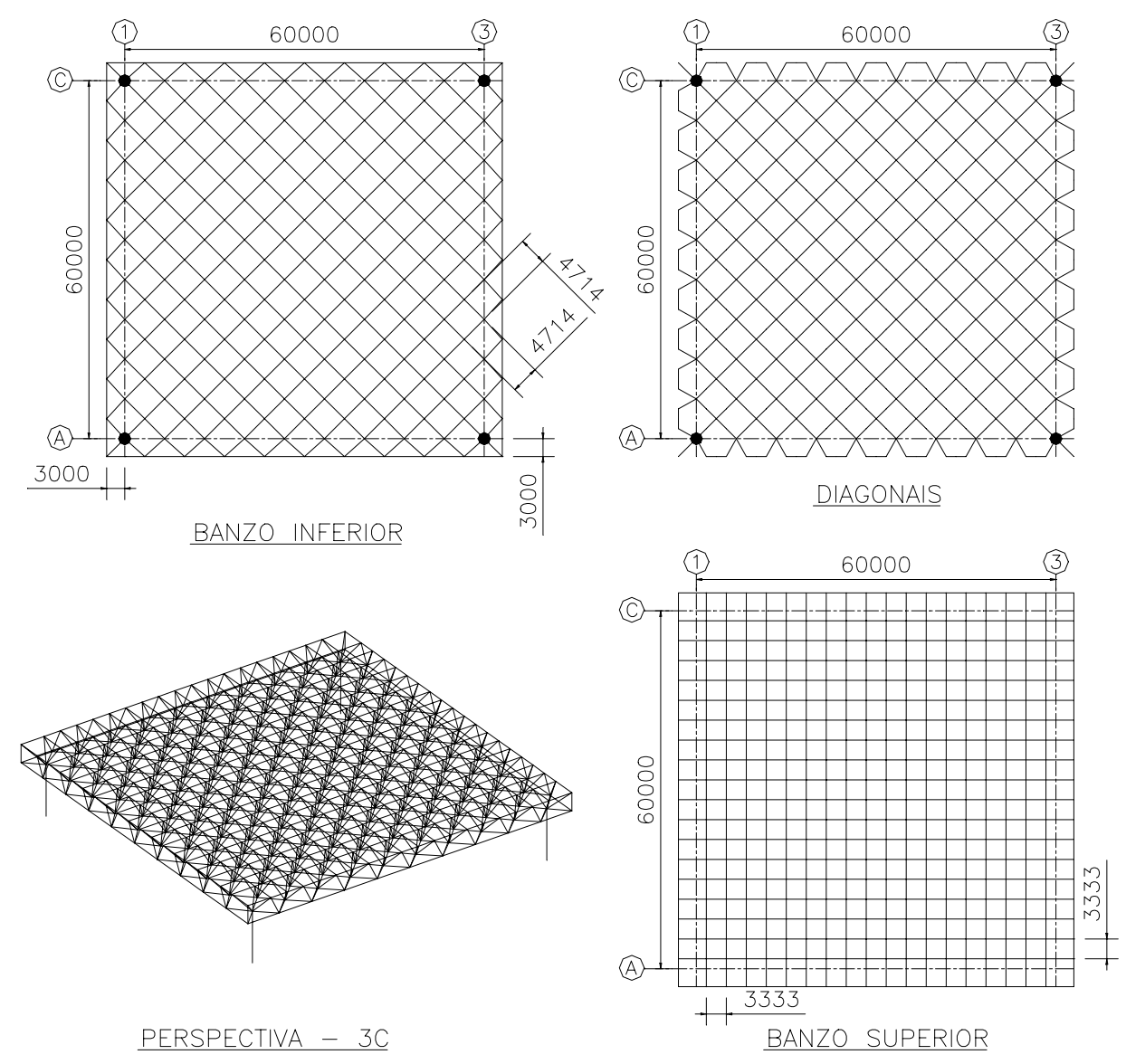

Figura 3.13 - Arranjo estrutural 3C 
Foi mantida a modulação do banzo inferior quadrado diagonal do arranjo $2 \mathrm{C}$, sendo o banzo superior formado por quadrados inscritos nos quadrados diagonais do banzo inferior.

- $\quad$ módulo superior $=3333,3 \mathrm{~mm} \times 3333,3 \mathrm{~mm}$;

- módulo inferior $=4714 \mathrm{~mm} \times 4714 \mathrm{~mm}$;

- altura do reticulado $=3500 \mathrm{~mm}$ (vão/17);

- ângulo das diagonais $=56,0^{\circ}$;

- apoios no nível do banzo inferior;

- quantidade de pilares $=4$;

- altura dos pilares $=10 \mathrm{~m}$;

\subsubsection{ARRANJO ESTRUTURAL 4A}

Este arranjo é similar ao $1 \mathrm{~A}$, porém com pilares a cada $30 \mathrm{~m}$ (Figura 3.14).

- quantidade de pilares $=8$;
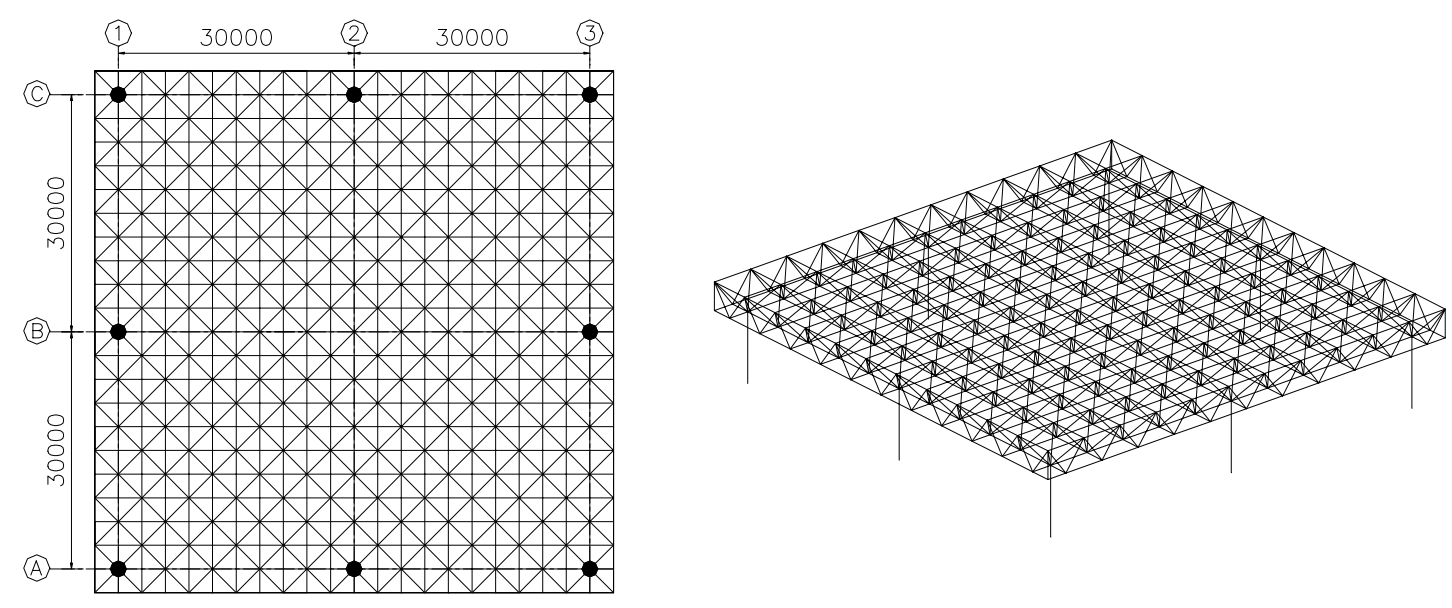

Figura 3.14 - Arranjo estrutural 4A 


\subsubsection{ARRANJO ESTRUTURAL 4B}

Este arranjo é similar ao 1B, porém com pilares a cada $30 \mathrm{~m}$.

- $\quad$ quantidade de pilares = 8;

\subsubsection{ARRANJO ESTRUTURAL 4C}

Este arranjo é similar ao 1C, porém com pilares a cada 30m (Figura 3.15).

- $\quad$ quantidade de pilares = 8;

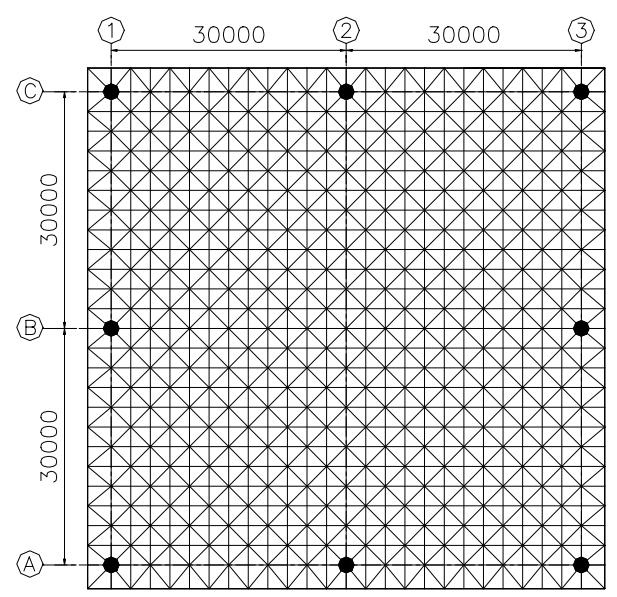

Figura 3.15 - Arranjo estrutural 4C

\subsubsection{ARRANJO ESTRUTURAL 5A}

Este arranjo é similar ao 2A, porém com pilares a cada 30m (Figura 3.16). Os apoios estão localizados no nível do banzo inferior para os pilares dos vértices, e no nível do banzo superior para os pilares intermediários. Isto ocorre pois os pilares intermediários não coincidem com o nó da modulação do banzo inferior, coincidindo apenas com o nó do banzo superior.

- apoios no nível do banzo inferior: eixos $1 \& A, 1 \& C, 3 \& A, 3 \& C$;

- apoios no nível do banzo superior: eixos $1 \& \mathrm{~B}, 2 \& \mathrm{~A}, 2 \& \mathrm{C}, 3 \& \mathrm{~B}$; 
- quantidade de pilares $=8$;

- altura dos pilares dos vértices $=10 \mathrm{~m}$;

- altura dos pilares intermediários $=14,5 \mathrm{~m}$;
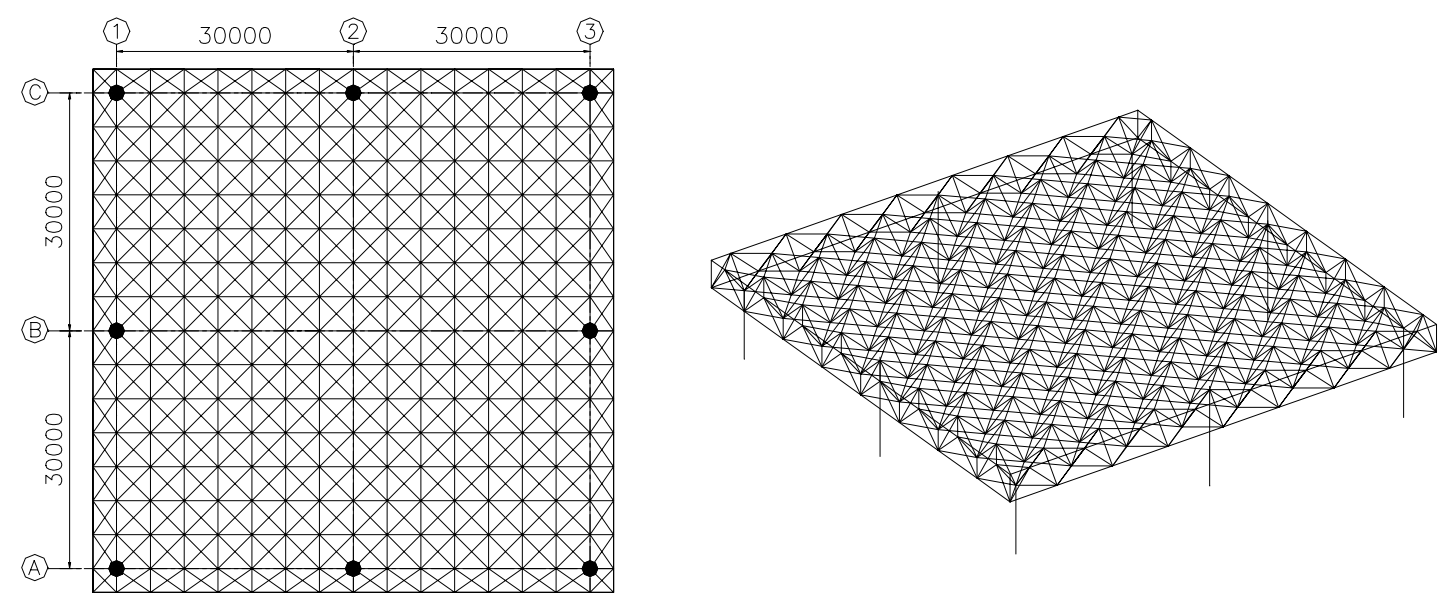

Figura 3.16 - Arranjo estrutural 5A

\subsubsection{ARRANJO ESTRUTURAL 5B}

Este arranjo é similar ao $2 \mathrm{~B}$, porém com pilares a cada $30 \mathrm{~m}$. Os apoios estão localizados no nível do banzo inferior para os pilares dos vértices, e no nível do banzo superior para os pilares intermediários.

- apoios no nível do banzo inferior: eixos 1\&A, 1\&C, 3\&A, 3\&C;

- apoios no nível do banzo superior: eixos 1\&B, 2\&A, 2\&C, 3\&B;

- quantidade de pilares $=8$;

- altura dos pilares dos vértices $=10 \mathrm{~m}$;

- altura dos pilares intermediários $=14 \mathrm{~m}$;

\subsubsection{ARRANJO ESTRUTURAL 5C}

Este arranjo é similar ao $2 \mathrm{C}$, porém com pilares a cada $30 \mathrm{~m}$ (Figura 3.17). Os apoios estão localizados no nível do banzo inferior para os pilares dos vértices, e no nível do banzo superior para os pilares intermediários. 
- apoios no nível do banzo inferior: eixos 1\&A, 1\&C, 3\&A, 3\&C;

- apoios no nível do banzo superior: eixos 1\&B, 2\&A, 2\&C, 3\&B;

- quantidade de pilares = 8;

- altura dos pilares dos vértices $=10 \mathrm{~m}$;

- altura dos pilares intermediários $=13,5 \mathrm{~m}$;
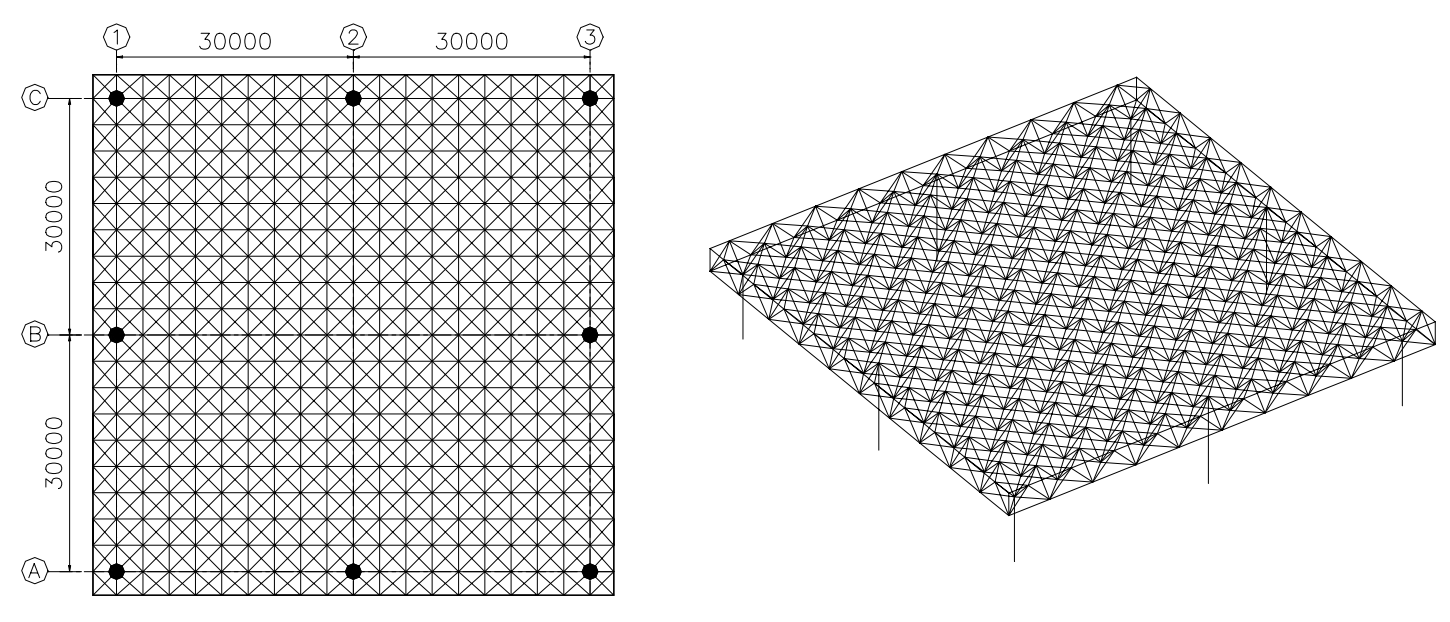

Figura 3.17 - Arranjo estrutural 5C

\subsubsection{ARRANJO ESTRUTURAL 6A}

Este arranjo é similar ao $3 \mathrm{~A}$, porém com pilares a cada 30m (Figura 3.18). Os apoios estão localizados no nível do banzo inferior para os pilares de vértice, e num nível abaixo do nível do banzo inferior para os pilares intermediários, formando apoios do tipo "pé-de-galinha" com a mesma altura da treliça. Isto ocorre pois os pilares intermediários não coincidem nem com o nó da modulação do banzo inferior, nem com o nó da modulação do banzo superior.

- altura do "pé-de-galinha" $=4500 \mathrm{~mm}$;

- apoios no nível do banzo inferior: eixos 1\&A, 1\&C, 3\&A, 3\&C;

- apoios do tipo "pé-de-galinha": eixos 1\&B, 2\&A, 2\&C, 3\&B;

- quantidade de pilares $=8$;

- altura dos pilares dos vértices $=10 \mathrm{~m}$; 
- altura dos pilares intermediários $=5,5 \mathrm{~m}$;
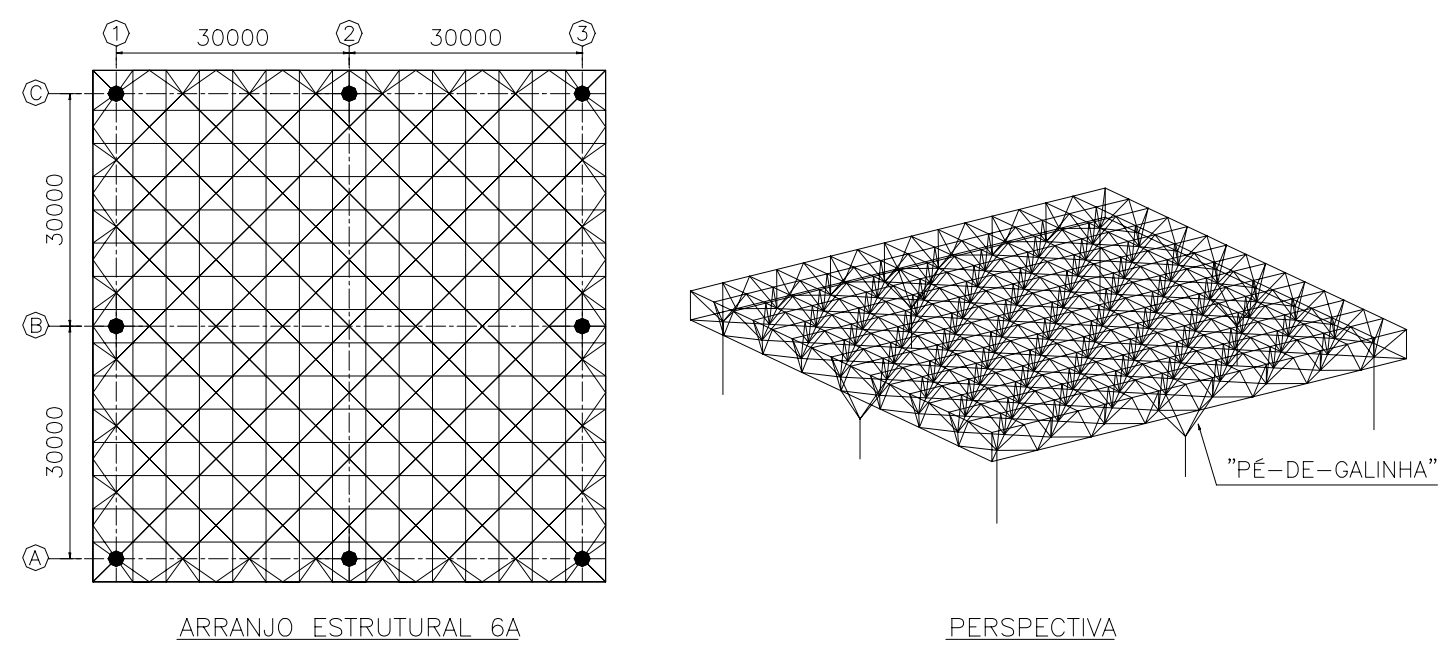

Figura 3.18 - Arranjo estrutural 6A

\subsubsection{ARRANJO ESTRUTURAL 6B}

Este arranjo é similar ao $3 \mathrm{~B}$, porém com pilares a cada $30 \mathrm{~m}$. Os apoios estão localizados no nível do banzo inferior para os pilares de vértice, e num nível abaixo do nível do banzo inferior para os pilares intermediários, formando apoios do tipo "pé-de-galinha" com a mesma altura do reticulado.

- altura do "pé-de-galinha" $=4000 \mathrm{~mm}$;

- apoios no nível do banzo inferior: eixos $1 \& \mathrm{~A}, 1 \& \mathrm{C}, 3 \& \mathrm{~A}, 3 \& \mathrm{C}$;

- apoios do tipo "pé-de-galinha": eixos 1\&B, 2\&A, 2\&C, 3\&B;

- quantidade de pilares $=8$;

- altura dos pilares dos vértices $=10 \mathrm{~m}$;

- altura dos pilares intermediários $=6 \mathrm{~m}$;

\subsubsection{ARRANJO ESTRUTURAL 6C}

Este arranjo é similar ao 3C, porém com pilares a cada 30m (Figura 3.19). Os apoios estão localizados no nível do banzo inferior para os pilares de vértice, e num nível abaixo do nível do banzo inferior para os pilares 
intermediários, formando apoios do tipo "pé-de-galinha" com a mesma altura da treliça.

- $\quad$ altura do "pé-de-galinha" = 3500mm;

- apoios no nível do banzo inferior: eixos 1\&A, 1\&C, 3\&A, 3\&C;

- apoios do tipo pé-de-galinha: eixos $1 \& B, 2 \& A, 2 \& C, 3 \& B$;

- quantidade de pilares = 8;

- $\quad$ altura dos pilares dos vértices $=10 \mathrm{~m}$;

- $\quad$ altura dos pilares intermediários $=6,5 \mathrm{~m}$;
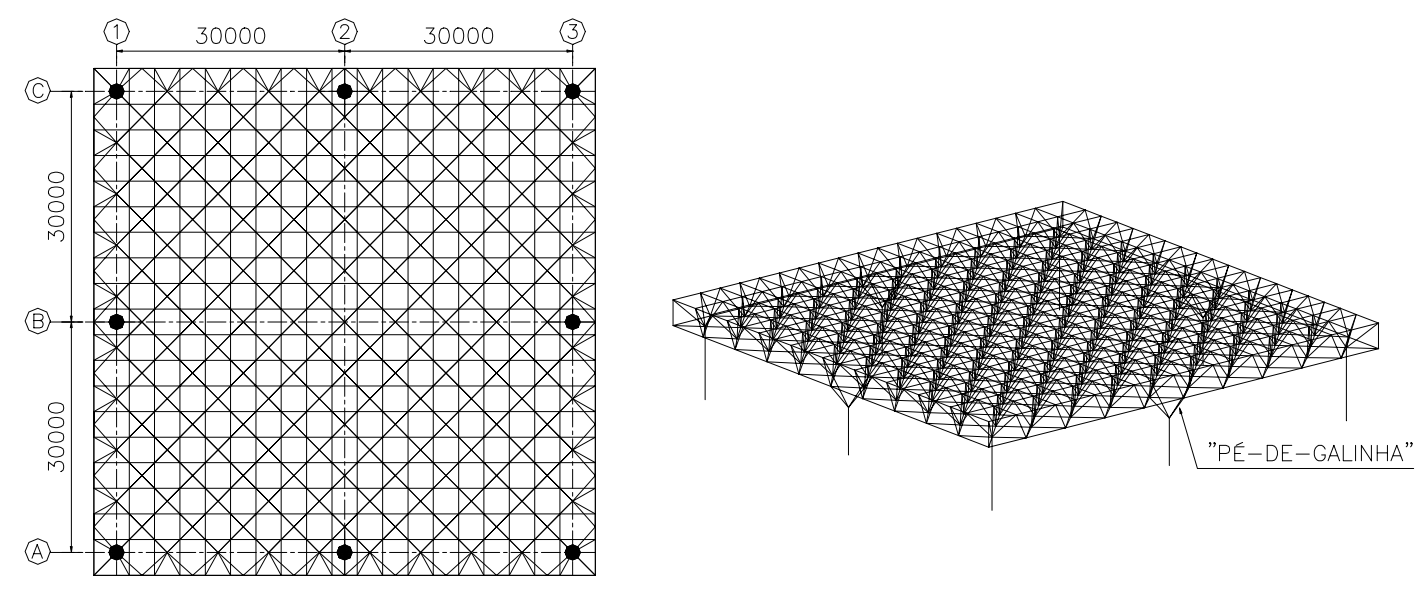

Figura 3.19 - Arranjo estrutural 6C

\subsubsection{ARRANJO ESTRUTURAL 7A}

Este arranjo, mostrado na Figura 3.20, apresenta reticulado quadrado sobre quadrado com defasagem de meio módulo, sendo que no alinhamento dos apoios, paralelo ao contorno, existe uma camada adicional de banzos, abaixo do nível do banzo inferior. A distância entre esta camada adicional de banzos e o banzo inferior é igual à altura do reticulado. Assim, nos alinhamentos dos apoios, o reticulado apresenta uma altura duas vezes maior que na região central, formando uma "viga de enrijecimento".

- módulo $=6000 \mathrm{~mm} \times 6000 \mathrm{~mm}$; 
- altura do reticulado $=4500 \mathrm{~mm}$ (vão/13) na região central e 9000 mm no alinhamento dos apoios paralelo ao contorno;

- $\quad$ ângulo das diagonais $=46,7^{\circ}$;

- apoios no nível da camada adicional de banzos;

- $\quad$ quantidade de pilares $=4$;

- $\quad$ altura dos pilares $=5,5 \mathrm{~m}$;
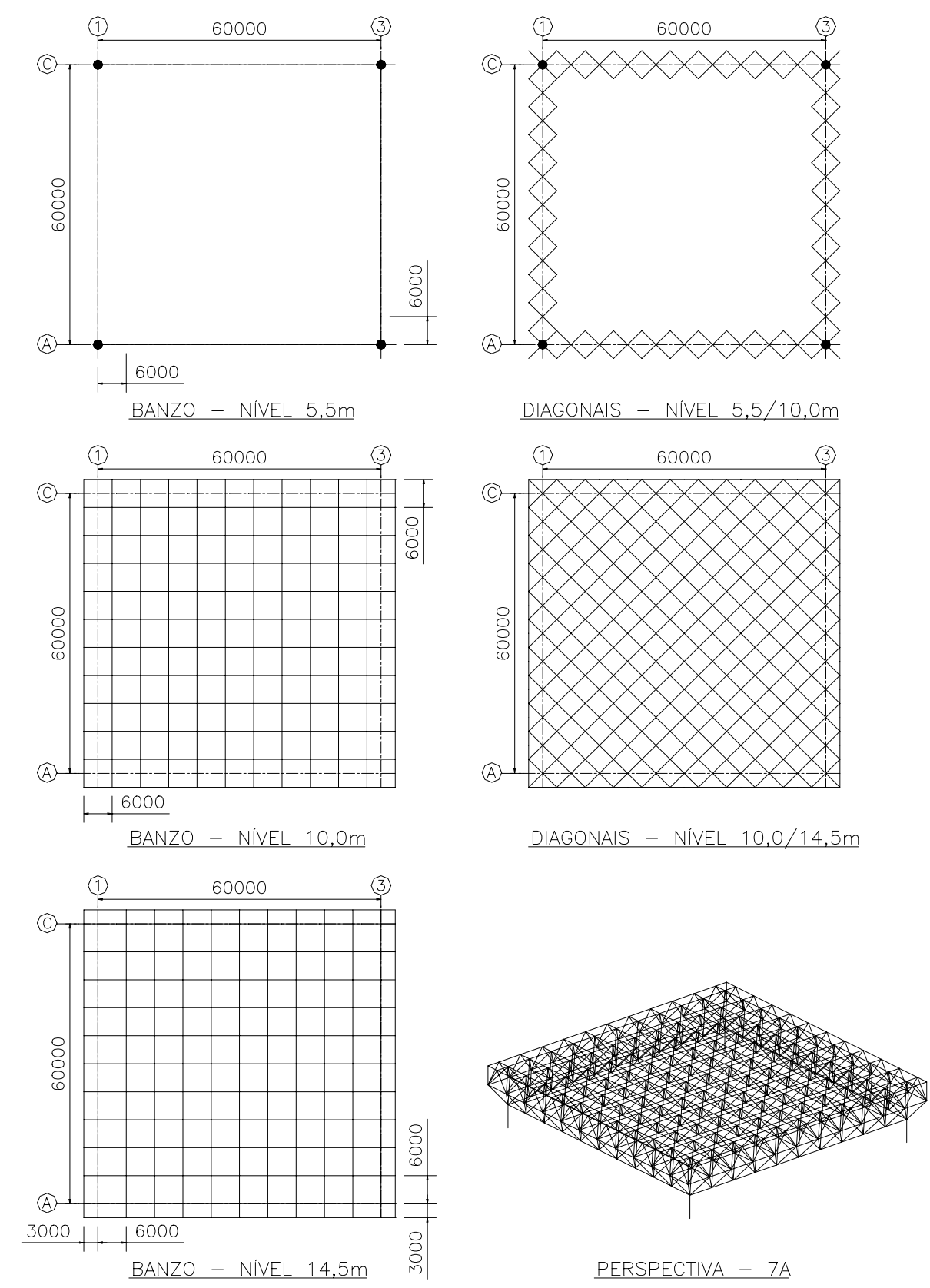

Figura 3.20 - Arranjo estrutural 7A 


\subsubsection{ARRANJO ESTRUTURAL 7B}

Este arranjo é similar ao 7A, com alteração apenas na altura do reticulado.

- altura do reticulado $=4000 \mathrm{~mm}($ vão/15) na região central $\mathrm{e}$ $8000 \mathrm{~mm}$ no alinhamento dos apoios paralelo ao contorno;

- ângulo das diagonais $=43,3^{\circ}$;

- $\quad$ altura dos pilares $=6 \mathrm{~m}$;

\subsubsection{ARRANJO ESTRUTURAL 7C}

Este arranjo é similar ao 7A, com alteração apenas no tipo de apoio. Os apoios são do tipo "engaste", ou seja, os pilares apoiam o reticulado nos três níveis de banzo. No nível de banzos intermediários foram adicionadas barras em " $X$ " que são conectadas aos pilares, conforme mostrado na Figura 3.21 .

- $\quad$ altura dos pilares $=14,5 \mathrm{~m}$;

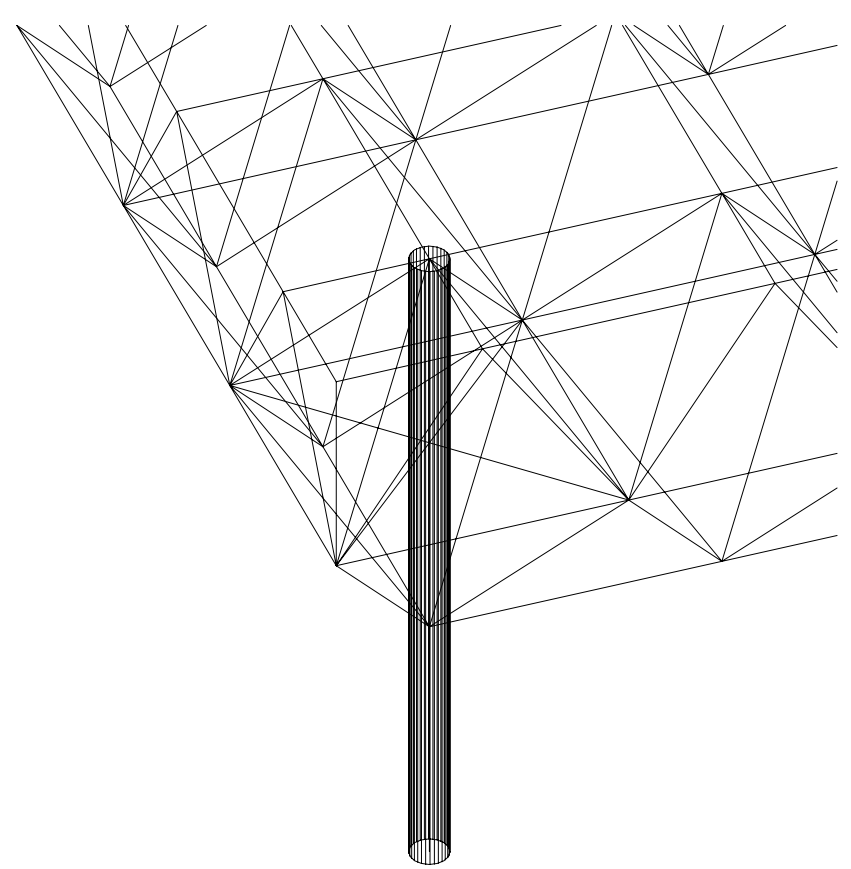

Figura 3.21 - Arranjo estrutural 7C - Apoio do tipo "engaste" 


\subsubsection{ARRANJO ESTRUTURAL 7D}

Este arranjo é similar ao 7B, com alteração apenas no tipo de apoio. Os apoios são do tipo "engaste".

- altura dos pilares $=14 \mathrm{~m}$;

\subsubsection{ARRANJO ESTRUTURAL 8A}

Este arranjo, mostrado na Figura 3.22, apresenta reticulado quadrado sobre quadrado com defasagem de meio módulo, e três camadas de banzo.

- módulo $=3000 \mathrm{~mm} \times 3000 \mathrm{~mm}$;

- altura do reticulado $=2 \times 3000=6000 \mathrm{~mm}$ (vão/10);

- ângulo das diagonais $=54,7^{\circ}$;

- apoios no nível do banzo inferior;

- quantidade de pilares $=4$;

- altura dos pilares $=10 \mathrm{~m}$;

\subsubsection{ARRANJO ESTRUTURAL 8B}

Este arranjo é similar ao 8A, com alteração apenas na altura do reticulado.

- altura do reticulado $=2 \times 2250=4500 \mathrm{~mm}$ (vão/13);

- ângulo das diagonais $=46,7^{\circ}$;

\subsubsection{ARRANJO ESTRUTURAL 8C}

Este arranjo é similar ao $8 \mathrm{~A}$, com alteração apenas na altura do reticulado.

- altura do reticulado $=2 \times 2000=4000 \mathrm{~mm}$ (vão/15);

- ângulo das diagonais $=43,3^{\circ}$; 
3.3.1.27. ARRANJO ESTRUTURAL 8D

Este arranjo é similar ao $8 \mathrm{~A}$, com alteração apenas na altura do reticulado.

- altura do reticulado $=2$ × $1500=3000 \mathrm{~mm}($ vão/20);

- $\quad$ ângulo das diagonais $=35,3^{\circ}$;
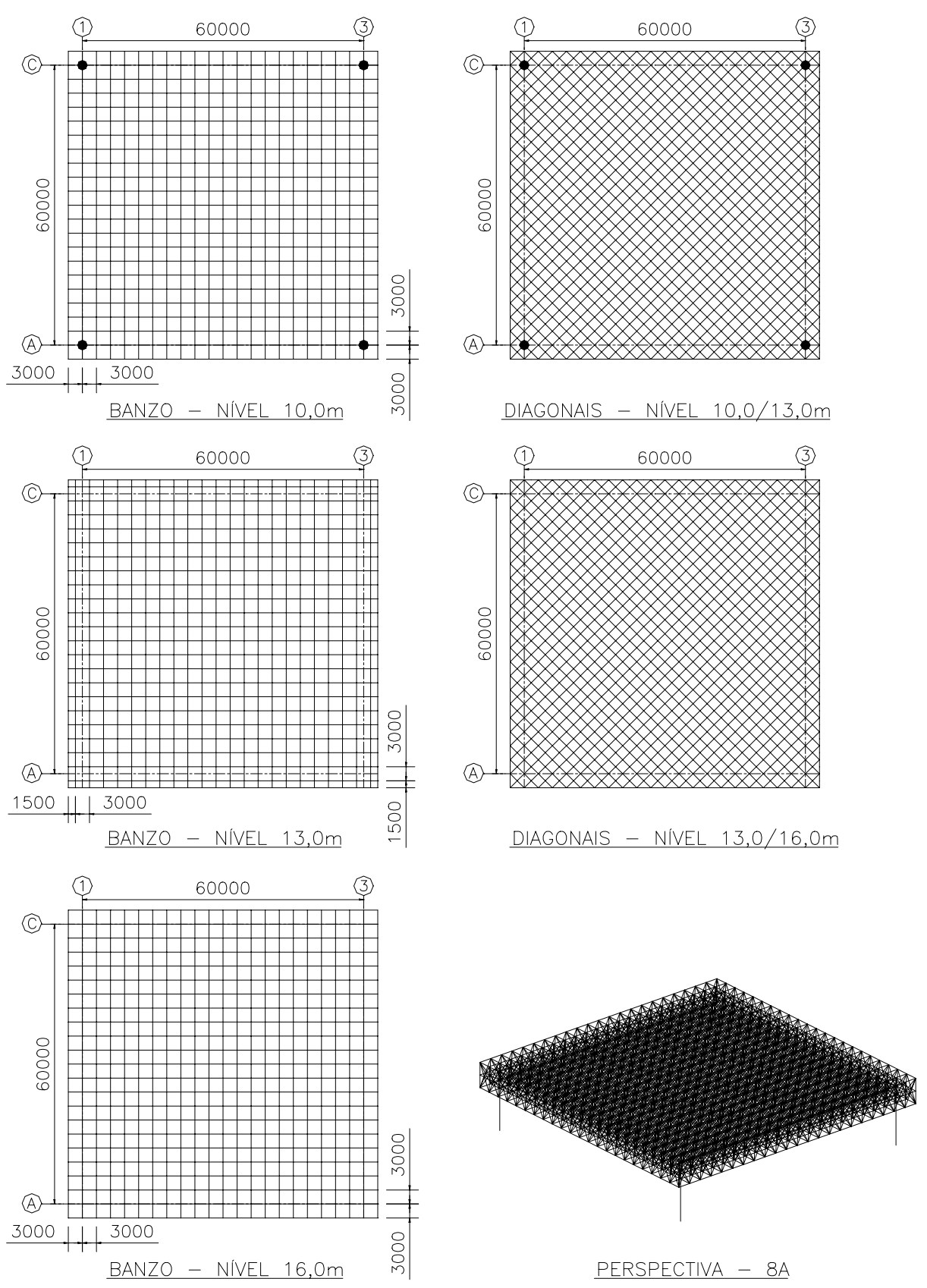

Figura 3.22 - Arranjo estrutural 8A 


\subsubsection{ARRANJOS ESTRUTURAIS COM PLANTA RETANGULAR}

Foram propostos 6 arranjos com planta retangular:

- 3 com pilares a cada $60 \mathrm{~m}$;

- 3 com pilares a cada $30 \mathrm{~m}$.

As alturas analisadas para os reticulados foram 4,5m (vão/13), 4,0m (vão/15) e 3,5m (vão/17), e as dimensões dos módulos são as mesmas adotadas para os arranjos 1A, 1B e 1C, respectivamente.

\subsubsection{ARRANJO ESTRUTURAL $9 A$}

Este arranjo apresenta reticulado quadrado sobre quadrado com defasagem de meio módulo (Figura 3.23).

- módulo $=6000 \mathrm{~mm} \times 6000 \mathrm{~mm}$;

- altura do reticulado $=4500 \mathrm{~mm}$ (vão/13);

- ângulo das diagonais $=46,7^{\circ}$;

- apoios no nível do banzo inferior;

- quantidade de pilares $=8$;

- altura dos pilares $=10 \mathrm{~m}$;

\subsubsection{ARRANJO ESTRUTURAL 9B}

Este arranjo é similar ao 9A, com alteração apenas na altura do reticulado.

- altura do reticulado $=4000 \mathrm{~mm}$ (vão/15);

- ângulo das diagonais $=43,3^{\circ}$; 

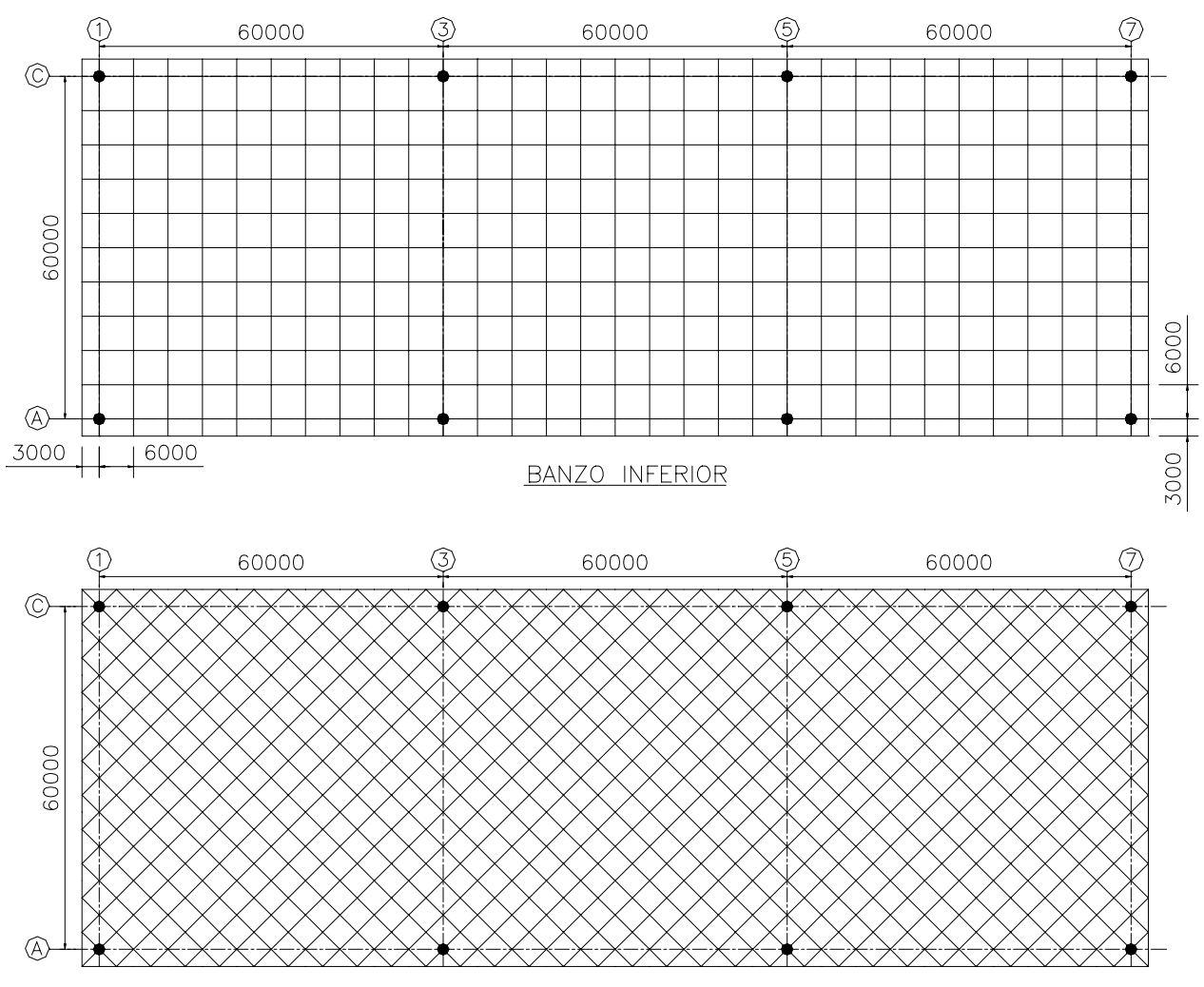

DIAGONAS

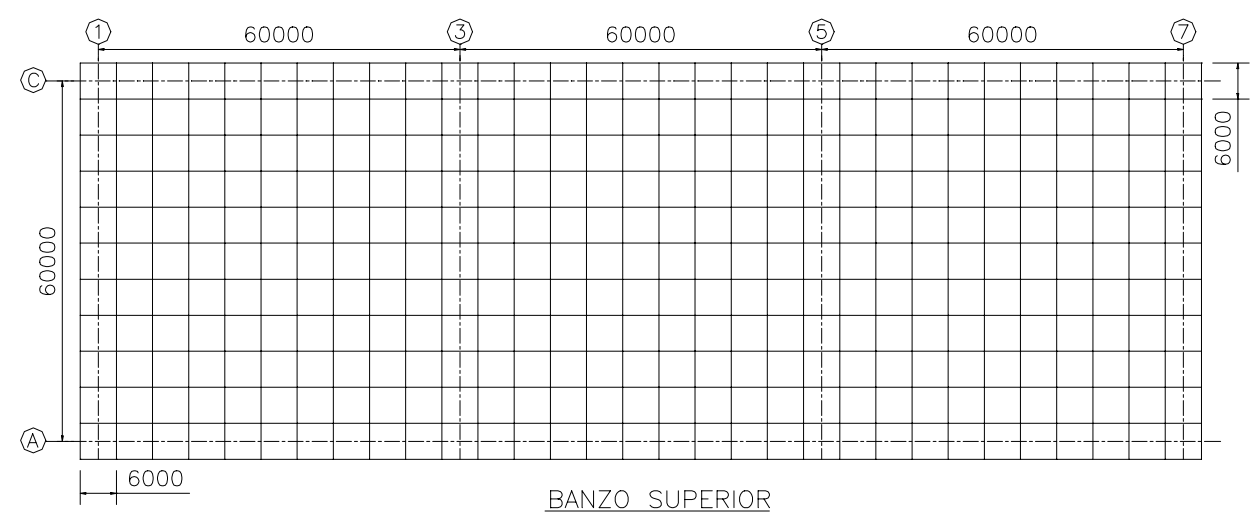

BANZO SUPERIOR

PERSPECTIVA - 9A

Figura 3.23 - Arranjo estrutural 9A 


\subsubsection{ARRANJO ESTRUTURAL 9C}

Este arranjo apresenta reticulado quadrado sobre quadrado com defasagem de meio módulo (Figura 3.24).

- módulo $=5000 \mathrm{~mm} \times 5000 \mathrm{~mm}$;

- altura do reticulado $=3500 \mathrm{~mm}$ (vão/17);

- ângulo das diagonais $=44,7^{\circ}$;

- apoios no nível do banzo inferior;

- quantidade de pilares = 8;

- altura dos pilares $=10 \mathrm{~m}$;

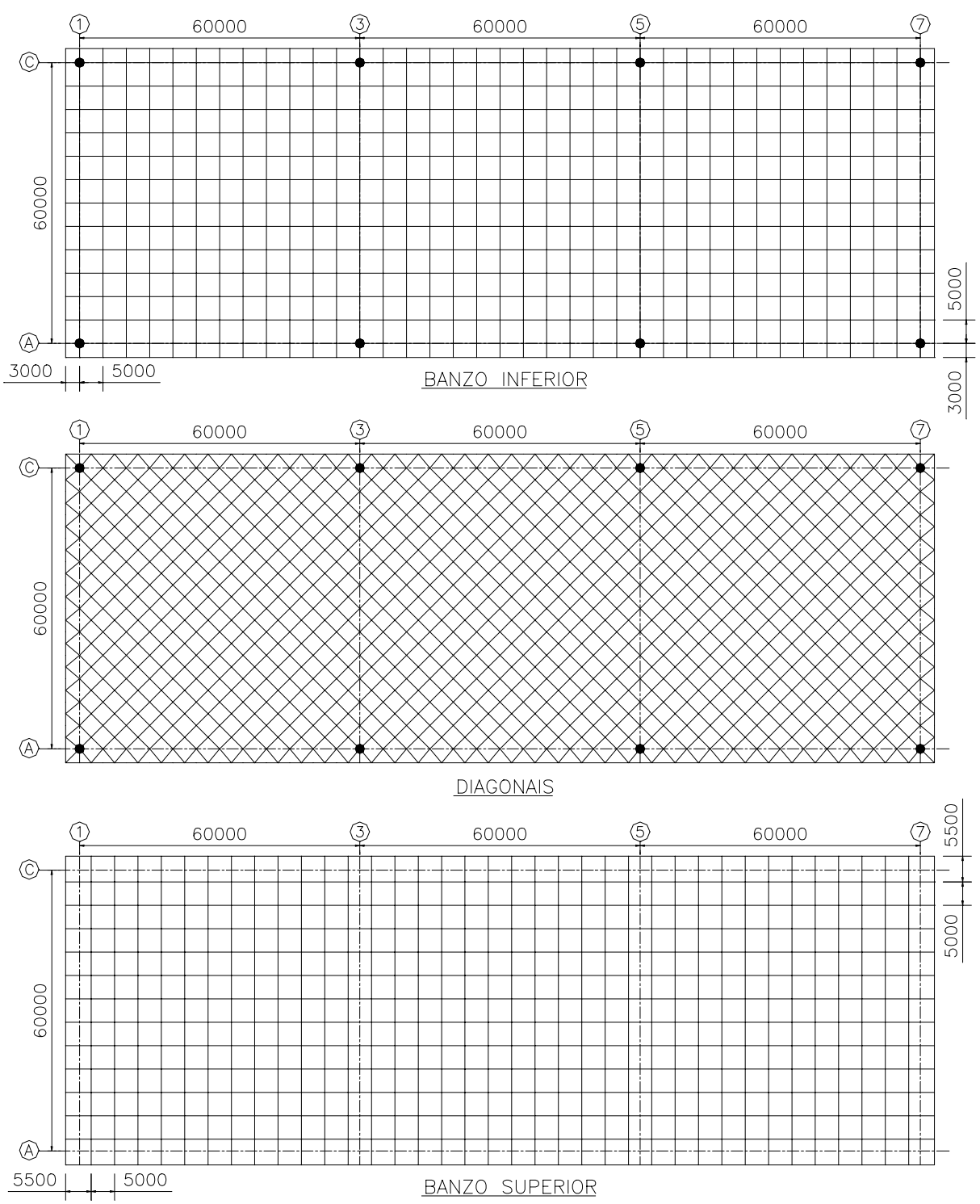

Figura 3.24 - Arranjo estrutural 9C 
3.3.2.5. ARRANJOS ESTRUTURAIS 10A, 10B E 10C

Os arranjos 10A, 10B e 10C são similares aos arranjos 9A, 9B e 9C, respectivamente, diferenciando-se apenas pela adição de pilares a cada $30 \mathrm{~m}$, conforme mostrado na Figura 3.25 para o arranjo $10 \mathrm{~A}$.

- quantidade de pilares = 16 ;
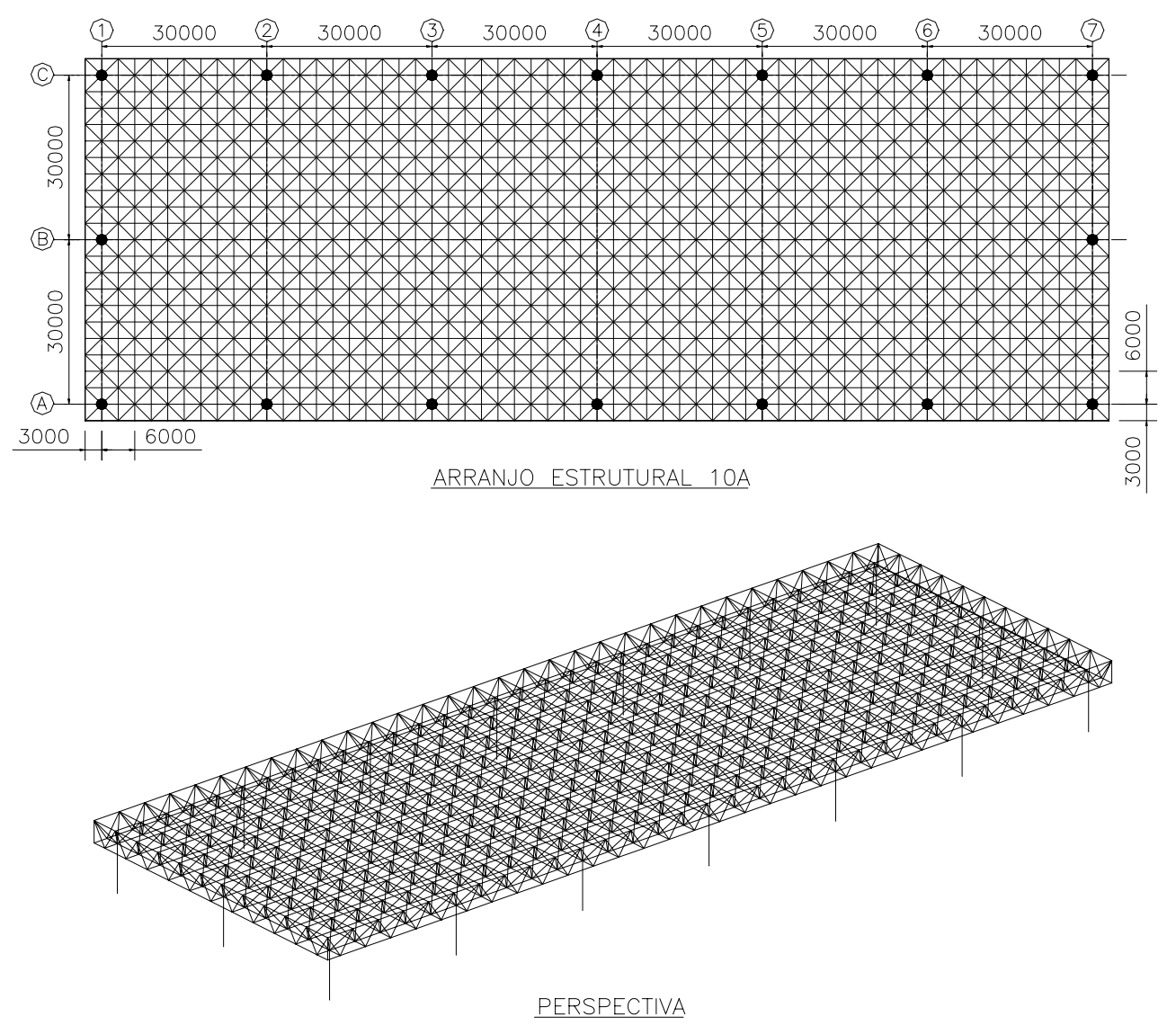

Figura 3.25 - Arranjo estrutural 10A

$\mathrm{Na}$ Tabela 3.1, apresenta-se um resumo das características principais dos arranjos estruturais analisados. 
Tabela 3.1 - Resumo dos arranjos estruturais propostos

\begin{tabular}{|c|c|c|c|c|c|}
\hline \multirow[t]{2}{*}{ Arranjo } & \multirow[t]{2}{*}{ Planta } & Apoios & Reticulado & \multirow{2}{*}{$\begin{array}{l}\text { Módulo } \\
\text { (mm) }\end{array}$} & \multirow{2}{*}{$\begin{array}{l}\text { Altura } \\
(\mathrm{mm})\end{array}$} \\
\hline & & $\begin{array}{c}\text { Quantidade } \\
\text { e posição }\end{array}$ & $\begin{array}{l}\text { Disposição de barras e } \\
\text { quantidade de camadas }\end{array}$ & & \\
\hline $1 \mathrm{~A}$ & quadrada & $\begin{array}{c}4 \\
\text { a cada } 60 \mathrm{~m}\end{array}$ & $\begin{array}{l}\text { quadrado sobre quadrado, } \\
\text { com } 2 \text { camadas de banzo }\end{array}$ & 6000 & $\begin{array}{l}4500 \\
\text { vão/13 }\end{array}$ \\
\hline $1 \mathrm{~B}$ & quadrada & $\begin{array}{c}4 \\
\text { a cada } 60 \mathrm{~m}\end{array}$ & $\begin{array}{l}\text { quadrado sobre quadrado, } \\
\text { com } 2 \text { camadas de banzo }\end{array}$ & 6000 & $\begin{array}{l}4000 \\
\text { vão/15 }\end{array}$ \\
\hline $1 \mathrm{C}$ & quadrada & $\begin{array}{c}4 \\
\text { a cada } 60 \mathrm{~m}\end{array}$ & $\begin{array}{l}\text { quadrado sobre quadrado, } \\
\text { com } 2 \text { camadas de banzo }\end{array}$ & 5000 & $\begin{array}{c}3500 \\
\text { vão/17 }\end{array}$ \\
\hline $1 \mathrm{D}$ & quadrada & $\begin{array}{c}4 \\
\text { a cada } 60 \mathrm{~m}\end{array}$ & $\begin{array}{l}\text { quadrado sobre quadrado, } \\
\text { com } 2 \text { camadas de banzo }\end{array}$ & 4000 & $\begin{array}{c}3000 \\
\text { vão/20 }\end{array}$ \\
\hline $2 A$ & quadrada & $\begin{array}{c}4 \\
\text { a cada } 60 \mathrm{~m}\end{array}$ & $\begin{array}{c}\text { quadrado diagonal sobre } \\
\text { quadrado diagonal, } \\
\text { com } 2 \text { camadas de banzo }\end{array}$ & 6061 & $\begin{array}{c}4500 \\
\text { vão/13 }\end{array}$ \\
\hline $2 B$ & quadrada & $\begin{array}{c}4 \\
\text { a cada } 60 \mathrm{~m}\end{array}$ & $\begin{array}{c}\text { quadrado diagonal sobre } \\
\text { quadrado diagonal, } \\
\text { com } 2 \text { camadas de banzo }\end{array}$ & 6061 & $\begin{array}{r}4000 \\
\text { vão/15 }\end{array}$ \\
\hline $2 \mathrm{C}$ & quadrada & $\begin{array}{c}4 \\
\text { a cada } 60 \mathrm{~m}\end{array}$ & $\begin{array}{c}\text { quadrado diagonal sobre } \\
\text { quadrado diagonal, } \\
\text { com } 2 \text { camadas de banzo }\end{array}$ & 4714 & $\begin{array}{c}3500 \\
\text { vão/17 }\end{array}$ \\
\hline $3 A$ & quadrada & $\begin{array}{c}4 \\
\text { a cada } 60 \mathrm{~m}\end{array}$ & $\begin{array}{c}\text { quadrado reduzido sobre } \\
\text { quadrado diagonal, } \\
\text { com } 2 \text { camadas de banzo }\end{array}$ & $\begin{array}{c}4285,8 \\
\text { sobre } \\
6061\end{array}$ & $\begin{array}{c}4500 \\
\text { vão/13 }\end{array}$ \\
\hline $3 B$ & quadrada & $\begin{array}{c}4 \\
\text { a cada } 60 \mathrm{~m}\end{array}$ & $\begin{array}{c}\text { quadrado reduzido sobre } \\
\text { quadrado diagonal, } \\
\text { com } 2 \text { camadas de banzo }\end{array}$ & $\begin{array}{c}4285,8 \\
\text { sobre } \\
6061\end{array}$ & $\begin{array}{l}4000 \\
\text { vão/15 }\end{array}$ \\
\hline $3 C$ & quadrada & $\begin{array}{c}4 \\
\text { a cada } 60 \mathrm{~m}\end{array}$ & $\begin{array}{c}\text { quadrado reduzido sobre } \\
\text { quadrado diagonal, } \\
\text { com } 2 \text { camadas de banzo }\end{array}$ & $\begin{array}{c}3333,3 \\
\text { sobre } \\
4714\end{array}$ & $\begin{array}{c}3500 \\
\text { vão/17 }\end{array}$ \\
\hline
\end{tabular}


Tabela 3.1 - Resumo dos arranjos estruturais propostos (continuação 1)

\begin{tabular}{|c|c|c|c|c|c|}
\hline $4 \mathrm{~A}$ & quadrada & $\begin{array}{c}8 \\
\text { a cada } 30 \mathrm{~m}\end{array}$ & $\begin{array}{l}\text { quadrado sobre quadrado, } \\
\text { com } 2 \text { camadas de banzo }\end{array}$ & 6000 & $\begin{array}{c}4500 \\
\text { vão/13 }\end{array}$ \\
\hline $4 \mathrm{~B}$ & quadrada & $\begin{array}{c}8 \\
\text { a cada } 30 \mathrm{~m}\end{array}$ & $\begin{array}{l}\text { quadrado sobre quadrado, } \\
\text { com } 2 \text { camadas de banzo }\end{array}$ & 6000 & $\begin{array}{c}4000 \\
\text { vão/15 }\end{array}$ \\
\hline $4 C$ & quadrada & $\begin{array}{c}8 \\
\text { a cada } 30 \mathrm{~m}\end{array}$ & $\begin{array}{l}\text { quadrado sobre quadrado, } \\
\text { com } 2 \text { camadas de banzo }\end{array}$ & 5000 & $\begin{array}{c}3500 \\
\text { vão/17 }\end{array}$ \\
\hline $5 A$ & quadrada & $\begin{array}{c}8 \\
\text { a cada } 30 \mathrm{~m}\end{array}$ & $\begin{array}{c}\text { quadrado diagonal sobre } \\
\text { quadrado diagonal, } \\
\text { com } 2 \text { camadas de banzo }\end{array}$ & 6061 & $\begin{array}{c}4500 \\
\text { vão/13 }\end{array}$ \\
\hline $5 B$ & quadrada & $\begin{array}{c}8 \\
\text { a cada } 30 \mathrm{~m}\end{array}$ & $\begin{array}{c}\text { quadrado diagonal sobre } \\
\text { quadrado diagonal, } \\
\text { com } 2 \text { camadas de banzo }\end{array}$ & 6061 & $\begin{array}{c}4000 \\
\text { vão/15 }\end{array}$ \\
\hline $5 C$ & quadrada & $\begin{array}{c}8 \\
\text { a cada } 30 \mathrm{~m}\end{array}$ & $\begin{array}{c}\text { quadrado diagonal sobre } \\
\text { quadrado diagonal, } \\
\text { com } 2 \text { camadas de banzo }\end{array}$ & 4714 & $\begin{array}{c}3500 \\
\text { vão/17 }\end{array}$ \\
\hline $6 \mathrm{~A}$ & quadrada & $\begin{array}{c}8 \\
\text { a cada } 30 \mathrm{~m}\end{array}$ & $\begin{array}{c}\text { quadrado reduzido sobre } \\
\text { quadrado diagonal, } \\
\text { com } 2 \text { camadas de banzo }\end{array}$ & $\begin{array}{c}4285,8 \\
\text { sobre } \\
6061\end{array}$ & $\begin{array}{c}4500 \\
\text { vão/13 }\end{array}$ \\
\hline $6 B$ & quadrada & $\begin{array}{c}8 \\
\text { a cada } 30 \mathrm{~m}\end{array}$ & $\begin{array}{c}\text { quadrado reduzido sobre } \\
\text { quadrado diagonal, } \\
\text { com } 2 \text { camadas de banzo }\end{array}$ & $\begin{array}{c}4285,8 \\
\text { sobre } \\
6061\end{array}$ & $\begin{array}{l}4000 \\
\text { vão/15 }\end{array}$ \\
\hline $6 C$ & quadrada & $\begin{array}{c}8 \\
\text { a cada } 30 \mathrm{~m}\end{array}$ & $\begin{array}{c}\text { quadrado reduzido sobre } \\
\text { quadrado diagonal, } \\
\text { com } 2 \text { camadas de banzo }\end{array}$ & $\begin{array}{r}3333,3 \\
\text { sobre } \\
4714\end{array}$ & $\begin{array}{c}3500 \\
\text { vão/17 }\end{array}$ \\
\hline $7 \mathrm{~A}$ & quadrada & $\begin{array}{c}4 \\
\text { a cada } 60 \mathrm{~m}\end{array}$ & $\begin{array}{l}\text { quadrado sobre quadrado, } \\
\text { com } 3 \text { camadas de banzo } \\
\text { (alinhamento dos apoios) }\end{array}$ & 6000 & $\begin{array}{c}4500 \\
\text { vão/13 }\end{array}$ \\
\hline $7 B$ & quadrada & $\begin{array}{c}4 \\
\text { a cada } 60 \mathrm{~m}\end{array}$ & $\begin{array}{l}\text { quadrado sobre quadrado, } \\
\text { com } 3 \text { camadas de banzo } \\
\text { (alinhamento dos apoios) }\end{array}$ & 6000 & $\begin{array}{c}4000 \\
\text { vão/15 }\end{array}$ \\
\hline
\end{tabular}


Tabela 3.1 - Resumo dos arranjos estruturais propostos (continuação 2)

\begin{tabular}{|c|c|c|c|c|c|}
\hline $7 \mathrm{C}$ & quadrada & $\begin{array}{c}4 \\
\text { a cada 60m } \\
\text { ("engaste") }\end{array}$ & $\begin{array}{l}\text { quadrado sobre quadrado, } \\
\text { com } 3 \text { camadas de banzo } \\
\text { (alinhamento dos apoios) }\end{array}$ & 6000 & $\begin{array}{l}4500 \\
\text { vão/13 }\end{array}$ \\
\hline $7 D$ & quadrada & $\begin{array}{c}4 \\
\text { a cada 60m } \\
\text { ("engaste") }\end{array}$ & $\begin{array}{l}\text { quadrado sobre quadrado, } \\
\text { com } 3 \text { camadas de banzo } \\
\text { (alinhamento dos apoios) }\end{array}$ & 6000 & $\begin{array}{l}4000 \\
\text { vão/15 }\end{array}$ \\
\hline $8 \mathrm{~A}$ & quadrada & $\begin{array}{c}4 \\
\text { a cada } 60 \mathrm{~m}\end{array}$ & $\begin{array}{l}\text { quadrado sobre quadrado, } \\
\text { com } 3 \text { camadas de banzo }\end{array}$ & 3000 & $\begin{array}{c}6000 \\
\text { vão/10 }\end{array}$ \\
\hline $8 B$ & quadrada & $\begin{array}{c}4 \\
\text { a cada } 60 \mathrm{~m}\end{array}$ & $\begin{array}{l}\text { quadrado sobre quadrado, } \\
\text { com } 3 \text { camadas de banzo }\end{array}$ & 3000 & $\begin{array}{l}4500 \\
\text { vão/13 }\end{array}$ \\
\hline $8 C$ & quadrada & $\begin{array}{c}4 \\
\text { a cada } 60 \mathrm{~m}\end{array}$ & $\begin{array}{l}\text { quadrado sobre quadrado, } \\
\text { com } 3 \text { camadas de banzo }\end{array}$ & 3000 & $\begin{array}{c}4000 \\
\text { vão/15 }\end{array}$ \\
\hline $8 \mathrm{D}$ & quadrada & $\begin{array}{c}4 \\
\text { a cada } 60 \mathrm{~m}\end{array}$ & $\begin{array}{l}\text { quadrado sobre quadrado, } \\
\text { com } 3 \text { camadas de banzo }\end{array}$ & 3000 & $\begin{array}{l}3000 \\
\text { vão/20 }\end{array}$ \\
\hline $9 \mathrm{~A}$ & $\begin{array}{l}\text { retangu- } \\
\text { lar }\end{array}$ & $\begin{array}{c}8 \\
\text { a cada } 60 \mathrm{~m}\end{array}$ & $\begin{array}{l}\text { quadrado sobre quadrado, } \\
\text { com } 2 \text { camadas de banzo }\end{array}$ & 6000 & $\begin{array}{l}4500 \\
\text { vão/13 }\end{array}$ \\
\hline $9 \mathrm{~B}$ & $\begin{array}{l}\text { retangu- } \\
\text { lar }\end{array}$ & $\begin{array}{c}8 \\
\text { a cada } 60 \mathrm{~m}\end{array}$ & $\begin{array}{l}\text { quadrado sobre quadrado, } \\
\text { com } 2 \text { camadas de banzo }\end{array}$ & 6000 & $\begin{array}{l}4000 \\
\text { vão/15 }\end{array}$ \\
\hline $9 \mathrm{C}$ & $\begin{array}{l}\text { retangu- } \\
\text { lar }\end{array}$ & $\begin{array}{c}8 \\
\text { a cada } 60 \mathrm{~m}\end{array}$ & $\begin{array}{l}\text { quadrado sobre quadrado, } \\
\text { com } 2 \text { camadas de banzo }\end{array}$ & 5000 & $\begin{array}{l}3500 \\
\text { vão/17 }\end{array}$ \\
\hline $10 \mathrm{~A}$ & $\begin{array}{l}\text { retangu- } \\
\text { lar }\end{array}$ & $\begin{array}{c}16 \\
\text { a cada } 30 \mathrm{~m}\end{array}$ & $\begin{array}{l}\text { quadrado sobre quadrado, } \\
\text { com } 2 \text { camadas de banzo }\end{array}$ & 6000 & $\begin{array}{r}4500 \\
\text { vão/13 }\end{array}$ \\
\hline 10B & $\begin{array}{l}\text { retangu- } \\
\text { lar }\end{array}$ & $\begin{array}{c}16 \\
\text { a cada } 30 \mathrm{~m}\end{array}$ & $\begin{array}{l}\text { quadrado sobre quadrado, } \\
\text { com } 2 \text { camadas de banzo }\end{array}$ & 6000 & $\begin{array}{l}4000 \\
\text { vão/15 }\end{array}$ \\
\hline $10 \mathrm{C}$ & $\begin{array}{l}\text { retangu- } \\
\quad \text { lar }\end{array}$ & $\begin{array}{c}16 \\
\text { a cada } 30 \mathrm{~m}\end{array}$ & $\begin{array}{l}\text { quadrado sobre quadrado, } \\
\text { com } 2 \text { camadas de banzo }\end{array}$ & 5000 & $\begin{array}{l}3500 \\
\text { vão/17 }\end{array}$ \\
\hline
\end{tabular}




\subsection{PROCESSAMENTO DAS ESTRUTURAS}

\subsubsection{COMBINAÇÕES DE AÇÕES}

Para as forças distribuídas atuando nos diversos planos de vedação da estrutura (abas laterais e telhado) determinou-se a resultante nos nós através da área de influência destes, admitindo as forças uniformemente distribuídas nas respectivas superfícies. As sobrecargas foram consideradas sendo aplicadas no banzo superior.

Por se tratar de um estudo comparativo entre arranjos e por conveniência devido a utilização do programa SAP $2000^{\circledR}$ para o processamento e pós-processamento (dimensionamento), foi adotada a norma americana do AMERICAN INSTITUTE OF STEEL CONSTRUCTION ASD - Allowable Stress Design (Ninth Edition -1989), baseada no método das tensões admissíveis.

Sendo:

- PP1: peso próprio da estrutura principal;

- PP2: peso próprio da estrutura secundária e elementos de vedação $=0,20 \mathrm{kN} / \mathrm{m}^{2}$;

- $S C 1$ : sobrecarga total $=0,50 \mathrm{kN} / \mathrm{m}^{2}$;

- VPX: vento na direção + X;

- VNX: vento na direção - X;

- VPY: vento na direção + Y;

- VNY: vento na direção - Y;

- TEMPP15: variação de temperatura de $+15^{\circ} \mathrm{C}$;

- TEMPN15: variação de temperatura de $-15^{\circ} \mathrm{C}$;

As seguintes combinações foram formadas:

1. $P P=P P 1+P P 2$

2. $P P S C=P P 1+P P 2+S C 1$

3. $P P V P X=P P 1+P P 2+V P X$

4. $P P V N X=P P 1+P P 2+V N X$

5. $P P V P Y=P P 1+P P 2+V P Y$ 
6. $P P V N Y=P P 1+P P 2+V N Y$

7. $\mathrm{PPTP}=\mathrm{PP} 1+\mathrm{PP} 2+\mathrm{TEMPP} 15$

8. $\mathrm{PPSCTP}=\mathrm{PP} 1+\mathrm{PP} 2+\mathrm{SC} 1+\mathrm{TEMPP} 15$

9. $P P V P X T P=P P 1+P P 2+V P X+T E M P P 15$

10. PPVNXTP $=$ PP1 + PP2 + VNX + TEMPP15

11. PPVPYTP = PP1 + PP2 + VPY + TEMPP15

12. $P P V N Y T P=P P 1+P P 2+V N Y+T E M P P 15$

13. $\mathrm{PPTN}=\mathrm{PP} 1+\mathrm{PP} 2+\mathrm{TEMPN} 15$

14. PPSCTN $=$ PP1 + PP2 + SC1 + TEMPN15

15. $P P V P X T N=P P 1+P P 2+V P X+T E M P N 15$

16. PPVNXTN $=$ PP1 + PP2 + VNX + TEMPN15

17. PPVPYTN = PP1 + PP2 + VPY + TEMPN15

18. PPVNYTN $=$ PP1 + PP2 + VNY + TEMPN15

\subsubsection{PERFIS UTILIZADOS}

Foram utilizados os perfis de aço de seção tubular circular comercialmente mais fáceis de serem encontrados, limitando-se como tubo mínimo o tubo $\varnothing 63,5 \times 2,00$.

Perfis para as barras da treliça espacial (diâmetro $x$ espessura):
1. $\varnothing 63,5 \times 2,00 \mathrm{~mm}$;
2. $\varnothing 76,2 \times 2,00 \mathrm{~mm}$;
3. $\varnothing 88,9 \times 2,65 \mathrm{~mm}$;
4. Ø 101,6 x 3,00 mm;
5. Ø 114,3 x 3,00 mm;
6. Ø 127,0 x 3,75 mm;
7. Ø 152,4 x 4,75 mm;
8. Ø 168,3 x 7,11 mm;
9. $\varnothing 219,1 \times 6,35 \mathrm{~mm}$;
10. $\varnothing 273,1$ x 6,35 mm;
11. $\varnothing 273,1 \times 12,7 \mathrm{~mm}$;
12. $\varnothing 323,8 \times 9,50 \mathrm{~mm}$;
13. $\varnothing 323,8 \times 12,7 \mathrm{~mm}$;
$14 . \varnothing 355,6$ × 9,50 mm;
15. $\varnothing 355,6 \times 12,7 \mathrm{~mm}$;
16. $\varnothing 355,6$ x 19,1 mm;
$17 . \varnothing 406,4$ x 12,7 mm; 
Perfis para os pilares (diâmetro $x$ espessura):

1. $\varnothing 323,85 \times 6,35 \mathrm{~mm}$;

2. $\varnothing 355,6 \times 6,35 \mathrm{~mm}$;

3. $\varnothing 355,6 \times 7,92 \mathrm{~mm}$;

4. $\varnothing 406,4 \times 6,35 \mathrm{~mm}$;

5. $\varnothing 406,4 \times 7,92 \mathrm{~mm}$;

6. $\varnothing 457,2 \times 6,35 \mathrm{~mm}$;

7. $\varnothing 457,2 \times 7,92 \mathrm{~mm}$;

8. $\varnothing 508,0 \times 6,35 \mathrm{~mm}$;

9. $\varnothing 508,0 \times 9,53 \mathrm{~mm}$; $10 . \varnothing 558,8 \times 6,35 \mathrm{~mm}$;

$11 . \varnothing 558,8 \times 9,53 \mathrm{~mm}$; 12. $\varnothing 609,6 \times 6,35 \mathrm{~mm}$;

13. $\varnothing 609,6 \times 9,53 \mathrm{~mm}$; 14. $\varnothing 660,4 \times 7,92 \mathrm{~mm}$;

$15 . \varnothing 660,4 \times 12,7 \mathrm{~mm}$; 16. $\varnothing 711,2 \times 7,92 \mathrm{~mm}$;

17. $\varnothing 711,2 \times 12,7 \mathrm{~mm}$; $18 . \varnothing 762,0 \times 12,7 \mathrm{~mm}$;

19. $\varnothing 812,8 \times 12,7 \mathrm{~mm}$; $20 . \varnothing 812,8 \times 15,88 \mathrm{~mm}$;

21. $\varnothing 914,4 \times 12,7 \mathrm{~mm}$; 22. $\varnothing 914,4 \times 15,88 \mathrm{~mm}$;

23. $\varnothing 914,4 \times 19,05 \mathrm{~mm}$; 24. $\varnothing 965,2 \times 12,7 \mathrm{~mm}$;

25. $\varnothing 965,2 \times 19,05 \mathrm{~mm}$; $26 . \varnothing 1016,0 \times 12,7 \mathrm{~mm}$;

$27 . \varnothing 1016,0 \times 19,05 \mathrm{~mm}$; $28 . \varnothing 1066,8 \times 12,7 \mathrm{~mm}$; $29 . \varnothing 1066,8 \times 19,05 \mathrm{~mm}$; $30 . \varnothing 1117,6 \times 12,7 \mathrm{~mm}$; 31. $\varnothing 1117,6$ x 19,05 mm; $32 . \varnothing 1168,4 \times 12,7 \mathrm{~mm}$; 33. $\varnothing 1168,4 \times 19,05 \mathrm{~mm}$; 35. $\varnothing 1219,2 \times 19,05 \mathrm{~mm}$; $34 . \varnothing 1219,2 \times 12,7 \mathrm{~mm}$; $36 . \varnothing 1320,8 \times 12,7 \mathrm{~mm}$; $37 . \varnothing 1320,8 \times 19,05 \mathrm{~mm}$; $38 . \varnothing 1371,6 \times 19,05 \mathrm{~mm}$; $39 . \varnothing 1524,0 \times 19,05 \mathrm{~mm}$; 40. $\varnothing 1524,0 \times 25,40 \mathrm{~mm}$; 41. $\varnothing 1828,8 \times 19,05 \mathrm{~mm}$; 42. $\varnothing 1828,8 \times 25,40 \mathrm{~mm}$; 43. $\varnothing 1930,4 \times 19,05 \mathrm{~mm}$; 44. Ø 1930,4 x 25,40 mm; 45. Ø 2032,0 x 19,05 mm; $47 . \varnothing 2133,6 \times 19,05 \mathrm{~mm}$; 49. $\varnothing 2235,2 \times 19,05 \mathrm{~mm}$; $51 . \varnothing 2336,8 \times 19,05 \mathrm{~mm}$; 46. Ø 2032,0 × 25,40 mm; 48. Ø 2133,6 × 25,40 mm; $50 . \varnothing 2235,2 \times 25,40 \mathrm{~mm}$; $52 . \varnothing 2336,8 \times 25,40 \mathrm{~mm}$;

\subsubsection{PROCEDIMENTOS}

Para o cálculo dos esforços nas barras da estrutura utilizou-se o programa computacional SAP $2000^{\circledR}$ Plus, versão 7.43 , assumindo-se um 
comportamento estrutural com linearidade física e geométrica (teoria de primeira ordem).

Como vinculação das barras, admitiram-se as extremidades de todas elas livres à rotação (portanto isentas de momentos fletores), com exceção feita às extremidades inferiores dos pilares, onde esta restrição torna-se indispensável. No dimensionamento dos pilares adotou-se um parâmetro efetivo de flambagem $(K)$ igual a 2, e para as barras da treliça igual a 1.

Inicialmente foi adotado o perfil de $\varnothing 63,5 \times 2,00 \mathrm{~mm}$ para todas as barras da treliça espacial e o perfil $\varnothing 323,85 \times 6,35 \mathrm{~mm}$ para todos os pilares. Após o primeiro processamento, os perfis foram redimensionados em função dos esforços obtidos. Com os novos perfis redimensionados a estrutura foi processada novamente. Esse ciclo de redimensionamento e processamento prosseguiu até que a estrutura estabilizasse e não houvesse mais alterações de perfis. Em média, essa estabilização ocorreu após 20 processamentos.

Ressalta-se que este dimensionamento não considera possíveis reduções nas resistências das barras em função da 'tipologia' das ligações empregadas. 


\section{RESULTADOS E DISCUSSÕES}

\subsection{QUANTIDADE DE NÓS E BARRAS}

A análise da quantidade de nós e barras, ou seja, da densidade do reticulado, é importante pois está diretamente relacionada com a fabricação e a montagem da estrutura. Quanto menor o número de elementos, mais rápida é a fabricação e a montagem.

Vale salientar que esta redução na quantidade de elementos tem um limite. Este limite está relacionado ao comprimento ou ao peso máximo que o elemento pode ter em função das tecnologias de fabricação e montagem. Treliças de alturas muito elevadas e com elementos muito longos, dificultam principalmente a montagem, que necessita de equipamentos especiais para a movimentação dos elementos.

Analisando a Tabela 4.1, que relaciona a quantidade de nós e barras das treliças espaciais dos arranjos estruturais quadrados 1 a 6 , percebe-se o aumento do número de elementos com a diminuição da altura da treliça. Treliças de altura reduzida exigem dimensões de módulo menores, para que os ângulos das diagonais fiquem próximos a $45^{\circ}$, em relação ao plano horizontal. Assim, o arranjo 1D apresenta quase o dobro de elementos dos arranjos $1 \mathrm{~A}$ e $1 \mathrm{~B}$. 
Tabela 4.1 - Quantidade de nós e barras - arranjos 1 a 6

\begin{tabular}{|c|c|c|c|c|c|c|}
\hline \multirow{2}{*}{} & \multicolumn{6}{|c|}{ ALTURA DA TRELIÇA } \\
\cline { 2 - 8 } & $\begin{array}{c}\text { A - vão/13 } \\
\mathrm{H}=4,5 \mathrm{~m}\end{array}$ & $\begin{array}{c}\text { B - vão/15 } \\
\mathrm{H}=4,0 \mathrm{~m}\end{array}$ & \multicolumn{2}{c|}{$\begin{array}{c}\text { C - vão/17 } \\
\mathrm{H}=3,5 \mathrm{~m}\end{array}$} & \multicolumn{2}{c|}{$\begin{array}{c}\text { D - vão/20 } \\
\mathrm{H}=3,0 \mathrm{~m}\end{array}$} \\
\hline ARRANJO & NÓS & BARRAS & NÓS & BARRAS & NÓS & BARRAS \\
\hline 1 & 313 & 1152 & 421 & 1568 & 613 & 2312 \\
\hline 2 & 293 & 1128 & 445 & 1728 & & \\
\hline 3 & 401 & 1280 & 621 & 2000 & & \\
\hline 4 & 313 & 1152 & 421 & 1568 & & \\
\hline 5 & 293 & 1128 & 445 & 1728 & & \\
\hline 6 & 405 & 1296 & 625 & 2016 & & \\
\hline
\end{tabular}

Com relação aos diferentes tipos de disposição de barras nos arranjos, percebe-se que os reticulados quadrado sobre quadrado (arranjos 1) e quadrado diagonal sobre quadrado diagonal (arranjos 2) apresentam densidades muito semelhantes, com variações inferiores a 10\%. Já o tipo quadrado reduzido sobre quadrado diagonal (arranjos 3) apresenta uma densidade um pouco maior que a dos dois anteriores, da ordem de $15 \%$ para as barras e de $38 \%$ para os nós. Essa diferença ocorre porque os comprimentos das barras do banzo superior são cerca de $30 \%$ menores que os comprimentos das barras do banzo inferior, resultando num reticulado mais denso.

Tabela 4.2 - Quantidade de nós e barras - arranjos 7

\begin{tabular}{|c|c|c|c|c|}
\hline \multirow{2}{*}{} & \multicolumn{4}{|c|}{ ALTURA DA TRELIÇA } \\
\cline { 2 - 5 } & $\begin{array}{c}\mathrm{A}-\text { vão/13 } \\
\mathrm{H}=4,5 \mathrm{~m}\end{array}$ & $\begin{array}{c}\mathrm{B}-\text { vão/15 } \\
\mathrm{H}=4,0 \mathrm{~m}\end{array}$ & $\begin{array}{c}\mathrm{C}-\text { vão/13 } \\
\mathrm{H}=4,5 \mathrm{~m}\end{array}$ & $\begin{array}{c}\mathrm{D}-\text { vão/15 } \\
\mathrm{H}=4,0 \mathrm{~m}\end{array}$ \\
\hline ARRANJO & NÓS & BARRAS & NÓS & BARRAS \\
\hline 7 & 353 & 1352 & 357 & 1368 \\
\hline
\end{tabular}

A adição de mais uma camada de banzos no alinhamento dos apoios (arranjos 7) resultou num aumento de $17 \%$ no número de barras em relação aos arranjos 1A e 1B (Tabela 4.2). As diferenças dos arranjos 7A e 7B em 
relação aos arranjos 7C e 7D, são devidas aos banzos em "X" ligados aos pilares no nível do banzo intermediário, para o apoio do tipo "engaste".

Os arranjos $8 \mathrm{~A}$ a $8 \mathrm{D}$, com três camadas de banzo, apresentam quantidades de nós e barras muito superiores aos arranjos com duas camadas (Tabela 4.3). O aumento da densidade é causado pela menor dimensão do módulo e pela adição de uma camada a mais de banzos e diagonais. Se comparados com os arranjos $1 \mathrm{~A}$ e $1 \mathrm{~B}$, os arranjos $8 \mathrm{~B}$ e $8 \mathrm{C}$ apresentam um aumento de cerca de 5 vezes na quantidade de nós, e de 6 vezes na quantidade de barras.

Tabela 4.3 - Quantidade de nós e barras - arranjos 8

\begin{tabular}{|c|c|c|c|c|}
\hline \multirow{2}{*}{} & \multicolumn{4}{|c|}{ ALTURA DA TRELIÇA } \\
\cline { 2 - 5 } & $\begin{array}{c}\mathrm{A}-\text { - vão/10 } \\
\mathrm{H}=2 \times 3,0 \mathrm{~m}\end{array}$ & $\begin{array}{c}\mathrm{B}-\text { vão/13 } \\
\mathrm{H}=2 \times 2,25 \mathrm{~m}\end{array}$ & $\begin{array}{c}\mathrm{C} \text { - vão/15 } \\
\mathrm{H}=2 \times 2,0 \mathrm{~m}\end{array}$ & $\begin{array}{c}\mathrm{D}-\text { vão/20 } \\
\mathrm{H}=2 \times 1,5 \mathrm{~m}\end{array}$ \\
\hline ARRANJO & \multicolumn{2}{|c|}{ NÓS } & \multicolumn{2}{c|}{ BARRAS } \\
\hline 8 & \multicolumn{2}{|c|}{1634} & \multicolumn{2}{c|}{7360} \\
\hline
\end{tabular}

Na Tabela 4.4 são mostradas as quantidades de nós e barras para os arranjos 9 e 10, os quais seguem o mesmo padrão de modulação e disposição de barras dos arranjos 1. Porém, estes arranjos apresentam quantidades maiores de nós e barras devido ao aumento das dimensões externas da edificação (contorno retangular).

Tabela 4.4 - Quantidade de nós e barras - arranjos 9 e 10

\begin{tabular}{|c|c|c|c|c|}
\hline \multirow{2}{*}{} & \multicolumn{3}{|c|}{ ALTURA DA TRELIÇA } \\
\cline { 2 - 5 } & $\begin{array}{c}\mathrm{A}-\text { vão/13 } \\
\mathrm{H}=4,5 \mathrm{~m}\end{array}$ & $\begin{array}{c}\text { B - vão/15 } \\
\mathrm{H}=4,0 \mathrm{~m}\end{array}$ & \multicolumn{2}{c|}{$\begin{array}{c}\mathrm{C} \text { - vão/17 } \\
\mathrm{H}=3,5 \mathrm{~m}\end{array}$} \\
\hline ARRANJO & NÓS & BARRAS & NÓS & BARRAS \\
\hline 9 & 813 & 3072 & 1117 & 4256 \\
\hline 10 & 813 & 3072 & 1117 & 4256 \\
\hline
\end{tabular}




\subsection{CONSUMO DE MATERIAL}

O consumo de material obtido nas análises, trata-se do valor teórico, no qual considera-se as barras com seu comprimento teórico, ou seja, a distância de centro a centro dos nós. $\mathrm{Na}$ realidade, as barras são interrompidas antes do nó, caso exista algum dispositivo especial de conexão (por exemplo, o "nó de aço"), ou são prolongadas para além do nó, caso não exista nenhum dispositivo especial de conexão (por exemplo, "nó típico"). Além disso, normalmente se realiza uma uniformização de perfis, visando diminuir o número de perfis diferentes e facilitar o detalhamento, a fabricação e a montagem. Esta uniformização é um processo empírico, variando de projetista para projetista. Na prática, a diferença entre o valor teórico e o valor final após a consideração dos sistemas de conexão e da uniformização é de no máximo de $10 \%$. Assim, os valores teóricos são bem representativos do peso final da estrutura e optou-se por trabalhar com estes valores.

O consumo de material é tratado pela maioria dos fabricantes como ponto principal de análise do custo de uma estrutura, visto que a maioria deles não conhece o custo individual de produção por elemento, realizando orçamentos que consideram apenas o peso total da estrutura. Para estruturas comuns, dependendo da experiência do fabricante, este tipo de análise pode ser válido. Porém, para estruturas de maior complexidade de nós e barras, com um grande número de elementos, este tipo de análise pode apresentar distorções.

A Tabela 4.5 relaciona o peso total (PT) e o peso por unidade de área (PM) para as treliças espaciais (T.E.), para os pilares (PILAR), e o total, dos arranjos estruturais 1 a 6 . 
Tabela 4.5 - Consumo de material - arranjos 1 a 6

\begin{tabular}{|c|c|c|c|c|c|c|c|c|}
\hline & \multicolumn{7}{|c|}{ ALTURA DA TRELIÇA } \\
\cline { 2 - 10 } & $\begin{array}{c}\mathrm{A}-\mathrm{vão} / 13 \\
\mathrm{H}=4,5 \mathrm{~m}\end{array}$ & \multicolumn{2}{|c|}{$\begin{array}{c}\mathrm{B}-\mathrm{vão} / 15 \\
\mathrm{H}=4,0 \mathrm{~m}\end{array}$} & \multicolumn{2}{c|}{$\begin{array}{c}\mathrm{C}-\mathrm{vão} / 17 \\
\mathrm{H}=3,5 \mathrm{~m}\end{array}$} & \multicolumn{2}{|c|}{$\begin{array}{c}\mathrm{D}-\mathrm{vão} / 20 \\
\mathrm{H}=3,0 \mathrm{~m}\end{array}$} \\
\hline ARRANJO & $\begin{array}{c}\mathrm{PT} \\
\mathrm{kg})\end{array}$ & $\begin{array}{c}\mathrm{PM} \\
\left(\mathrm{kg} / \mathrm{m}^{2}\right)\end{array}$ & $\begin{array}{c}\mathrm{PT} \\
(\mathrm{kg})\end{array}$ & $\begin{array}{c}\mathrm{PM} \\
\left(\mathrm{kg} / \mathrm{m}^{2}\right)\end{array}$ & $\begin{array}{c}\mathrm{PT} \\
(\mathrm{kg})\end{array}$ & $\begin{array}{c}\mathrm{PM} \\
\left(\mathrm{kg} / \mathrm{m}^{2}\right)\end{array}$ & $\begin{array}{c}\mathrm{PT} \\
(\mathrm{kg})\end{array}$ & $\begin{array}{c}\mathrm{PM} \\
\left(\mathrm{kg} / \mathrm{m}^{2}\right)\end{array}$ \\
\hline 1-T.E. & 118.940 & 27,3 & 126.526 & 29,0 & 134.281 & 30,8 & 147.754 & 33,9 \\
\hline 1-PILAR & 8.109 & 1,9 & 8.748 & 2,0 & 8.748 & 2,0 & 8.748 & 2,0 \\
\hline 1-TOTAL & 127.049 & 29,2 & 135.274 & 31,1 & 143.029 & 32,8 & 156.502 & 35,9 \\
\hline 2-T.E. & 126.280 & 29,0 & 141.796 & 32,6 & 139.277 & 32,0 & & \\
\hline 2-PILAR & 8.109 & 1,9 & 8.109 & 1,9 & 8.748 & 2,0 & & \\
\hline 2-TOTAL & 134.388 & 30,9 & 149.905 & 34,4 & 148.024 & 34,0 & & \\
\hline 3-T.E. & 114.283 & 26,2 & 124.590 & 28,6 & 136.633 & 31,4 & & \\
\hline 3-PILAR & 8.109 & 1,9 & 8.748 & 2,0 & 8.748 & 2,0 & & \\
\hline 3-TOTAL & 122.391 & 28,1 & 133.338 & 30,6 & 145.380 & 33,4 & & \\
\hline 4-T.E. & 65.774 & 15,1 & 69.163 & 15,9 & 67.301 & 15,5 & & \\
\hline 4-PILAR & 10.614 & 2,4 & 7.998 & 1,8 & 7.600 & 1,7 & & \\
\hline 4-TOTAL & 76.389 & 17,5 & 77.161 & 17,7 & 74.901 & 17,2 & & \\
\hline 5-T.E. & 68.807 & 15,8 & 68.365 & 15,7 & 62.620 & 14,4 & & \\
\hline 5-PILAR & 13.059 & 3,0 & 12.784 & 2,9 & 10.877 & 2,5 & & \\
\hline 5-TOTAL & 81.866 & 18,8 & 81.150 & 18,6 & 73.497 & 16,9 & & \\
\hline 6-T.E. & 54.723 & 12,6 & 52.387 & 12,0 & 52.048 & 11,9 & & \\
\hline 6-PILAR & 13.545 & 3,1 & 15.716 & 3,6 & 18.090 & 4,2 & & \\
\hline 6-TOTAL & 68.268 & 15,7 & 68.104 & 15,6 & 70.138 & 16,1 & & \\
\hline
\end{tabular}

No gráfico mostrado na Figura 4.1, que relaciona o PM das treliças espaciais e total, com as alturas das treliças, percebe-se como tendência o aumento do peso com a diminuição de altura da treliça. Comparando-se os três tipos de reticulados dos arranjos com pilares a cada $60 \mathrm{~m}$, o que apresentou menor consumo de material foi o reticulado quadrado reduzido 
sobre quadrado diagonal com altura igual a vão/13 (arranjo 3A), cerca de $26,2 \mathrm{~kg} / \mathrm{m}^{2}$ para as treliças e $28,1 \mathrm{~kg} / \mathrm{m}^{2}$ considerando os pilares. Já o que apresentou maior consumo foi o reticulado quadrado sobre quadrado com altura igual a vão/20 (arranjo 1D), cerca de $33,9 \mathrm{~kg} / \mathrm{m}^{2}$ para as treliças e 35,9 $\mathrm{kg} / \mathrm{m}^{2}$ considerando os pilares. Salienta-se, que apesar do arranjo 1D ter apresentado o maior consumo de material entre os arranjos analisados, os reticulados do tipo quadrado diagonal sobre quadrado diagonal (arranjos 2) apresentaram maior consumo para as outras três relações de altura das treliças.

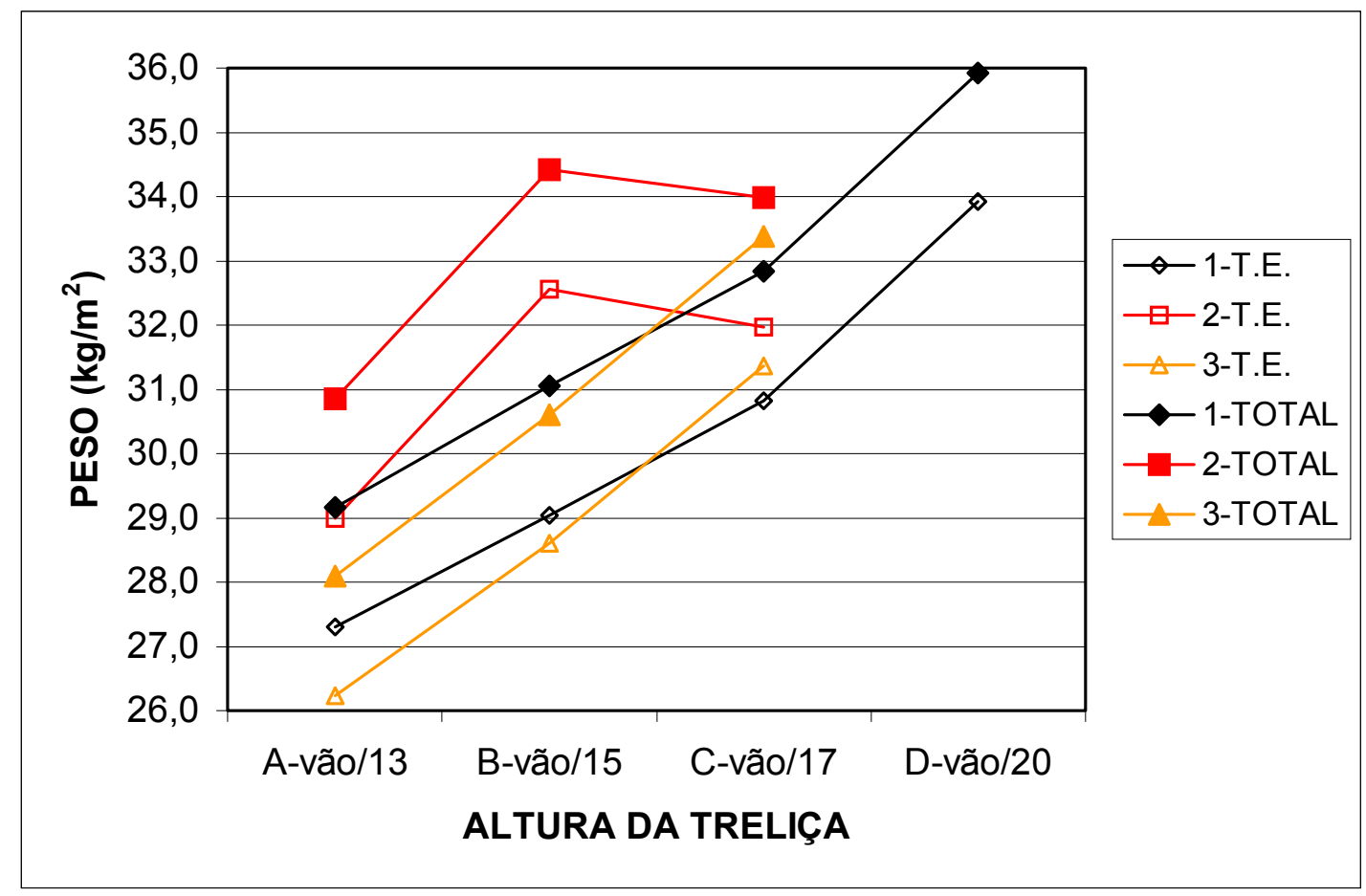

Figura 4.1 - Consumo de material por unidade de área - arranjos 1 a 3

Analisando o gráfico mostrado na Figura 4.2, dos arranjos com pilares a cada $30 \mathrm{~m}$, nota-se um consumo muito inferior de material quando comparado com o consumo dos arranjos com pilares a cada $60 \mathrm{~m}$, uma redução de cerca de $55 \%$ quando comparados os pesos mínimos das treliças. Considerando o peso dos pilares, esta redução é de cerca de $43 \%$.

Nestes arranjos não se verifica a tendência de aumento de peso com a diminuição da altura do reticulado como verificado nos arranjos anteriores. 
No caso dos arranjos 5 e 6 , houve uma redução no peso da treliça com a diminuição da altura do reticulado. O reticulado que apresentou menor consumo de material foi o quadrado reduzido sobre quadrado diagonal (arranjos 6), com peso de $11,9 \mathrm{~kg} / \mathrm{m}^{2}$ para a treliça espacial com altura igual a vão/17. Os pilares dos arranjos $6 \mathrm{~A}, 6 \mathrm{~B}$ e $6 \mathrm{C}$ resultaram mais pesados que os dos arranjos 4 e 5 , apesar de apresentarem menor altura. Isto ocorreu devido às elevadas forças horizontais nos topos dos pilares intermediários com apoios do tipo "pé-de-galinha".

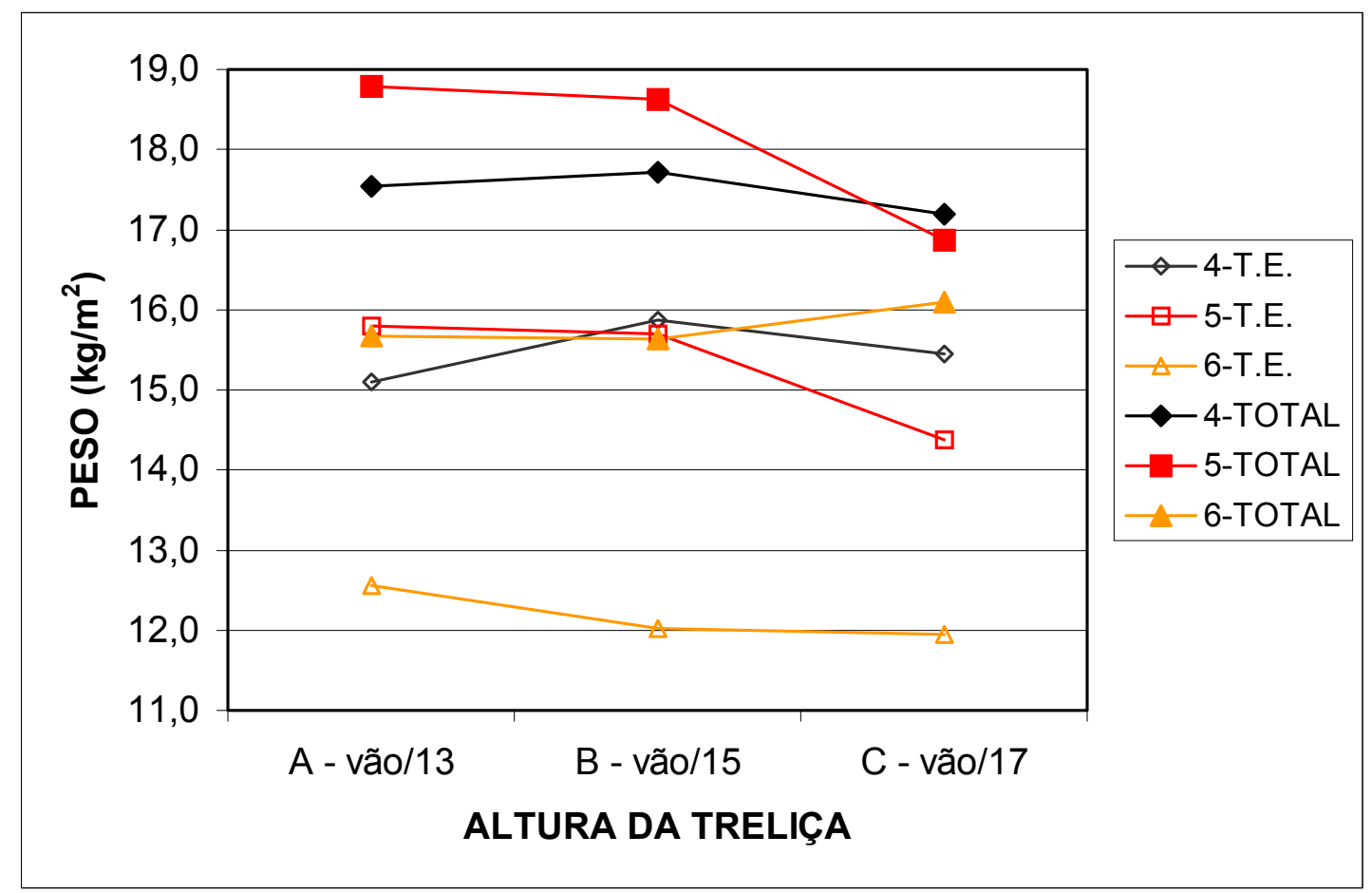

Figura 4.2 - Consumo de material por unidade de área - arranjos 4, 5 e 6

Os arranjos 7C e 7D, com apoios do tipo engaste, apresentaram menor consumo de material para a treliça espacial quando comparados com os arranjos com apoios no banzo inferior (7A e 7B). Porém, devido ao maior comprimento dos pilares que atingem o nível do banzo superior para promover o "engaste", o peso total para os arranjos 7C e 7D resultou superior (Tabela 4.6). 
Tabela 4.6 - Consumo de material - arranjos 7

\begin{tabular}{|c|c|c|c|c|c|c|c|c|}
\hline & \multicolumn{8}{|c|}{ ALTURA DO TRELIÇA } \\
\hline & \multicolumn{2}{|c|}{$\begin{array}{l}\text { A - vão/13 } \\
\mathrm{H}=4,5 \mathrm{~m}\end{array}$} & \multicolumn{2}{|c|}{$\begin{array}{l}\mathrm{B} \text { - vão/15 } \\
\mathrm{H}=4,0 \mathrm{~m}\end{array}$} & \multicolumn{2}{|c|}{$\begin{array}{l}\mathrm{C} \text { - vão/13 } \\
\mathrm{H}=4,5 \mathrm{~m}\end{array}$} & \multicolumn{2}{|c|}{$\begin{array}{l}\mathrm{D} \text { - vão/15 } \\
\mathrm{H}=4,0 \mathrm{~m}\end{array}$} \\
\hline ARRANJO & $\begin{array}{l}\text { PT } \\
(\mathrm{kg})\end{array}$ & $\begin{array}{c}\mathrm{PM} \\
\left(\mathrm{kg} / \mathrm{m}^{2}\right)\end{array}$ & $\begin{array}{l}\text { PT } \\
(\mathrm{kg})\end{array}$ & $\begin{array}{c}\mathrm{PM} \\
\left(\mathrm{kg} / \mathrm{m}^{2}\right)\end{array}$ & $\begin{array}{l}\text { PT } \\
(\mathrm{kg})\end{array}$ & $\begin{array}{c}\mathrm{PM} \\
\left(\mathrm{kg} / \mathrm{m}^{2}\right)\end{array}$ & $\begin{array}{l}\text { PT } \\
(\mathrm{kg})\end{array}$ & $\begin{array}{c}\mathrm{PM} \\
\left(\mathrm{kg} / \mathrm{m}^{2}\right)\end{array}$ \\
\hline 7-T.E. & 93.077 & 21,4 & 94.291 & 21,6 & 88.220 & 20,3 & 85.275 & 19,6 \\
\hline 7-PILAR & 19.750 & 4,5 & 21.858 & 5,0 & 35.474 & 8,1 & 34.251 & 7,9 \\
\hline 7-TOTAL & 112.826 & 25,9 & 116.149 & 26,7 & 123.694 & 28,4 & 119.526 & 27,4 \\
\hline
\end{tabular}

Os arranjos com três camadas completas de banzo (arranjos 8), apresentaram a tendência vista anteriormente de aumento de peso com a diminuição da altura da treliça (Tabela 4.7). A relação de altura da treliça de vão/20 levou ao maior consumo de material.

Tabela 4.7 - Consumo de material - arranjos 8

\begin{tabular}{|c|c|c|c|c|c|c|c|c|}
\hline & \multicolumn{7}{|c|}{ ALTURA DA TRELIÇA } \\
\cline { 2 - 9 } & $\begin{array}{c}\text { A - vão/10 } \\
\mathrm{H}=2 \times 3,0 \mathrm{~m}\end{array}$ & \multicolumn{2}{c|}{$\begin{array}{c}\mathrm{B} \text { - vão/13 } \\
\mathrm{H}=2 \times 2,25 \mathrm{~m}\end{array}$} & $\begin{array}{c}\text { C - vão/15 } \\
\mathrm{H}=2 \times 2,0 \mathrm{~m}\end{array}$ & \multicolumn{2}{c|}{$\begin{array}{c}\text { D - vão/20 } \\
\mathrm{H}=2 \times 1,5 \mathrm{~m}\end{array}$} \\
\hline ARRANJO & $\begin{array}{c}\mathrm{PT} \\
(\mathrm{kg})\end{array}$ & $\begin{array}{c}\mathrm{PM} \\
\left(\mathrm{kg} / \mathrm{m}^{2}\right)\end{array}$ & $\begin{array}{c}\mathrm{PT} \\
(\mathrm{kg})\end{array}$ & $\begin{array}{c}\mathrm{PM} \\
\left(\mathrm{kg} / \mathrm{m}^{2}\right)\end{array}$ & $\begin{array}{c}\mathrm{PT} \\
(\mathrm{kg})\end{array}$ & $\begin{array}{c}\mathrm{PM} \\
\left(\mathrm{kg} / \mathrm{m}^{2}\right)\end{array}$ & $\begin{array}{c}\mathrm{PT} \\
(\mathrm{kg})\end{array}$ & $\begin{array}{c}\mathrm{PM} \\
\left(\mathrm{kg} / \mathrm{m}^{2}\right)\end{array}$ \\
\hline 8-T.E. & 124.515 & 28,6 & 128.133 & 29,4 & 132.083 & 30,3 & 160.334 & 36,8 \\
\hline 8-PILAR & 9.387 & 2,2 & 8.748 & 2,0 & 9.387 & 2,2 & 8.748 & 2,0 \\
\hline 8-TOTAL & 133.902 & 30,7 & 136.880 & 31,4 & 141.470 & 32,5 & 169.082 & 38,8 \\
\hline
\end{tabular}

Os arranjos com planta retangular (arranjos 9 e 10) apresentaram a mesma tendência de aumento de peso com a diminuição da altura da treliça (Tabela 4.8). O posicionamento de pilares a cada $30 \mathrm{~m}$ (arranjos 10) provocou uma redução de cerca de $25 \%$ no consumo de material em relação aos arranjos com pilares a cada 60m (arranjos 9). A adição de mais pilares 
reduziu significativamente o peso de cada pilar, resultando num peso total de pilares muito próximo para os arranjos 9 e 10.

Tabela 4.8 - Consumo de material - arranjos 9 e 10

\begin{tabular}{|c|c|c|c|c|c|c|}
\hline \multirow{2}{*}{} & \multicolumn{6}{|c|}{ ALTURA DA TRELIÇA } \\
\cline { 2 - 7 } & $\begin{array}{c}\text { A - vão/13 } \\
\mathrm{H}=4,5 \mathrm{~m}\end{array}$ & \multicolumn{2}{c|}{$\begin{array}{c}\mathrm{B} \text { - vão/15 } \\
\mathrm{H}=4,0 \mathrm{~m}\end{array}$} & \multicolumn{2}{c|}{$\begin{array}{c}\text { C - vão/17 } \\
\mathrm{H}=3,5 \mathrm{~m}\end{array}$} \\
\hline ARRANJO & $\begin{array}{c}\mathrm{PT} \\
(\mathrm{kg})\end{array}$ & $\begin{array}{c}\mathrm{PM} \\
\left(\mathrm{kg} / \mathrm{m}^{2}\right)\end{array}$ & $\begin{array}{c}\mathrm{PT} \\
(\mathrm{kg})\end{array}$ & $\begin{array}{c}\mathrm{PM} \\
\left(\mathrm{kg} / \mathrm{m}^{2}\right)\end{array}$ & $\begin{array}{c}\mathrm{PT} \\
(\mathrm{kg})\end{array}$ & $\begin{array}{c}\mathrm{PM} \\
\left(\mathrm{kg} / \mathrm{m}^{2}\right)\end{array}$ \\
\hline 9-T.E. & 289.321 & 23,6 & 291.072 & 23,7 & 316.135 & 25,8 \\
\hline 9-PILAR & 24.498 & 2,0 & 25.137 & 2,0 & 35.756 & 2,9 \\
\hline 9-TOTAL & 313.819 & 25,6 & 316.209 & 25,8 & 351.891 & 28,7 \\
\hline 10-T.E. & 213.691 & 17,4 & 217.032 & 17,7 & 223.379 & 18,2 \\
\hline 10-PILAR & 24.334 & 2,0 & 24.334 & 2,0 & 24.334 & 2,0 \\
\hline 10-TOTAL & 238.025 & 19,4 & 241.366 & 19,7 & 247.713 & 20,2 \\
\hline
\end{tabular}

Os arranjos 1, 7 e 9 apresentam o mesmo padrão de modulação e espaçamento de pilares. Comparando-se os pesos das treliças obtidos para estes três arranjos, conforme mostrado na Figura 4.3, percebe-se o efeito favorável da terceira camada de banzos no alinhamento dos apoios ("viga de enrijecimento") dos arranjos 7. O efeito da continuidade existente nos arranjos retangulares (arranjos 9) mostrou também ser favorável, quando se compara com os arranjos quadrados apoiados nos quatro vértices (arranjos 1). Os arranjos com três camadas completas de banzo (arranjos 8) apresentaram o maior consumo de material entre os arranjos analisados.

Comparando-se os arranjos 4 e 10, percebe-se que o efeito da continuidade não foi suficiente para diminuir o consumo de material das treliças dos arranjos quadrados com pilares a cada 30m (Figura 4.4). 


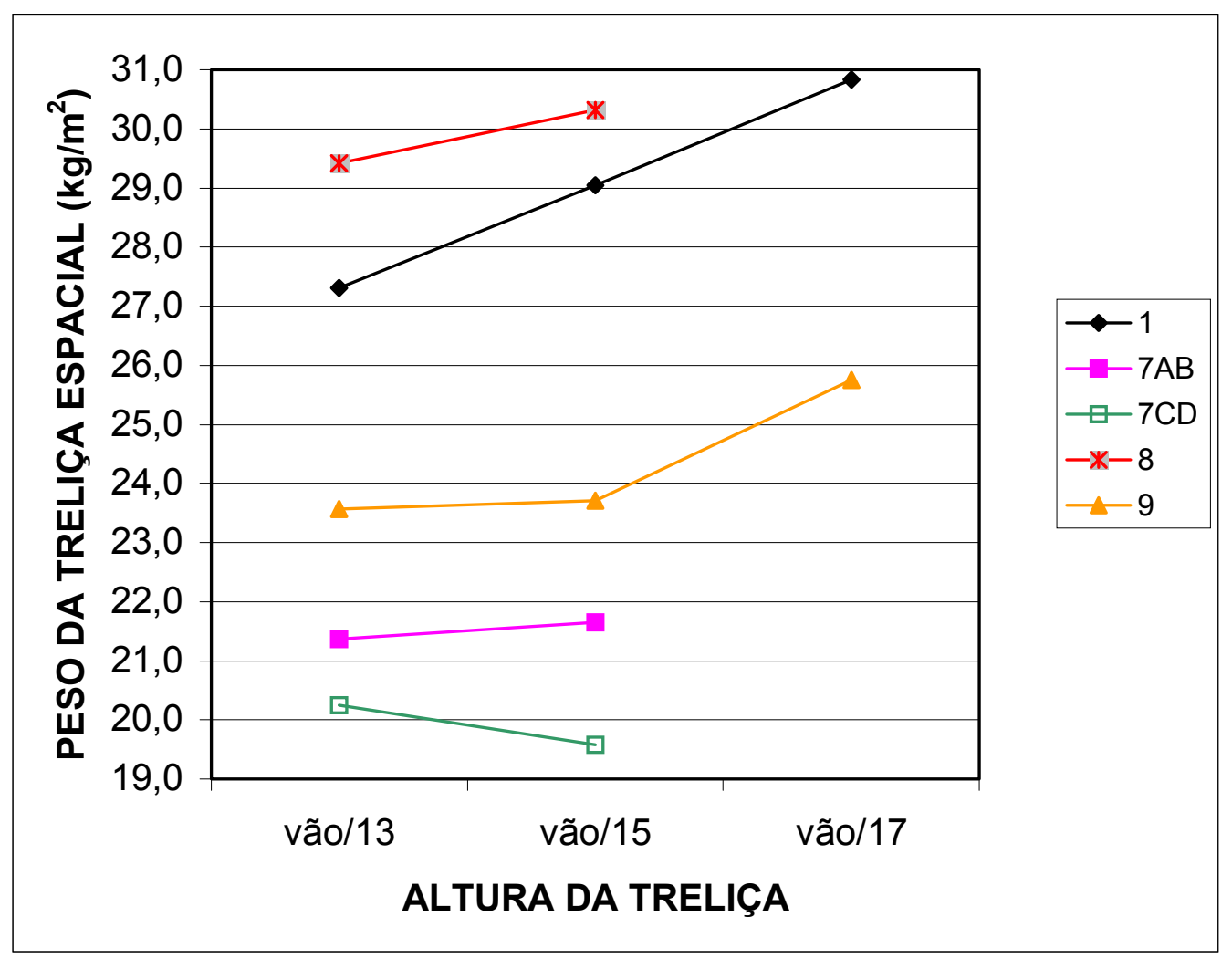

Figura 4.3 - Consumo de material por unidade de área - arranjos 1, 7, 8 e 9

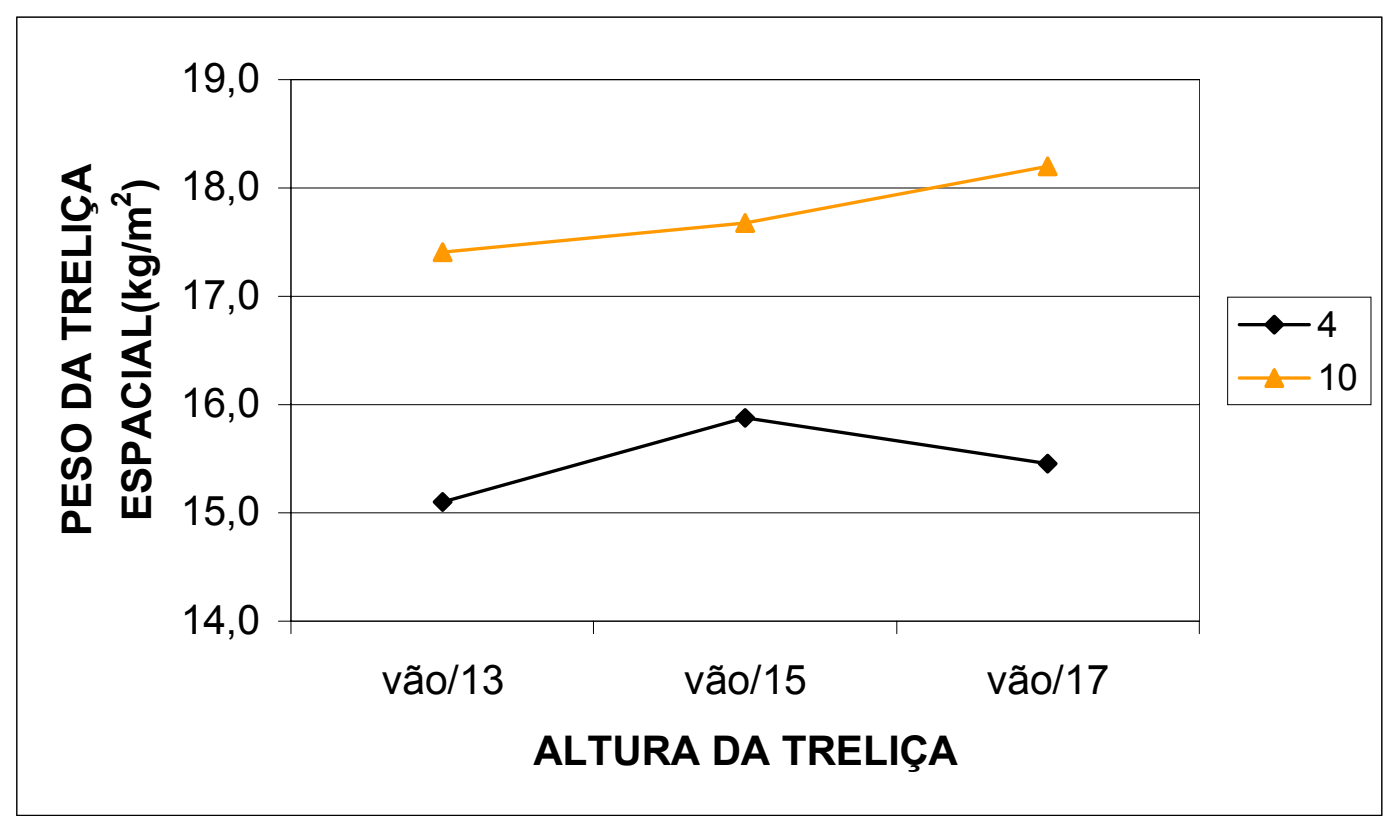

Figura 4.4 - Consumo de material por unidade de área - arranjos 4 e 10 


\subsection{DESLOCAMENTOS}

Os máximos deslocamentos verticais ocorreram na região central das treliças. A combinação de ações que provocou este máximo deslocamento vertical envolvia o peso próprio, a sobrecarga e a variação de temperatura.

Os máximos deslocamentos horizontais ocorreram nos nós da borda nas posições centrais, para as combinações de ações que envolviam peso próprio, vento e variação de temperatura.

Na Tabela 4.9 são mostrados os máximos deslocamentos horizontais ( $\triangle$ HOR.) e verticais ( $\triangle$ VER.), dos arranjos estruturais 1 a 6.

Tabela 4.9 - Deslocamentos máximos - arranjos 1 a 6

\begin{tabular}{|c|c|c|c|c|c|c|c|c|}
\hline & \multicolumn{8}{|c|}{ ALTURA DA TRELIÇA } \\
\hline & \multicolumn{2}{|c|}{$\begin{array}{c}\text { A - vão/13 } \\
\mathrm{H}=4,5 \mathrm{~m}\end{array}$} & \multicolumn{2}{|c|}{$\begin{array}{l}\text { B - vão/15 } \\
\mathrm{H}=4,0 \mathrm{~m}\end{array}$} & \multicolumn{2}{|c|}{$\begin{array}{l}\mathrm{C} \text { - vão/17 } \\
\mathrm{H}=3,5 \mathrm{~m}\end{array}$} & \multicolumn{2}{|c|}{$\begin{array}{l}\mathrm{D} \text { - vão/20 } \\
\mathrm{H}=3,0 \mathrm{~m}\end{array}$} \\
\hline ARRANJO & $\begin{array}{l}\Delta \mathrm{HOR} . \\
(\mathrm{mm})\end{array}$ & $\begin{array}{l}\Delta \text { VER. } \\
(\mathrm{mm})\end{array}$ & $\begin{array}{c}\Delta \mathrm{HOR} . \\
(\mathrm{mm})\end{array}$ & $\begin{array}{r}\Delta \text { VER } \\
(\mathrm{mm})\end{array}$ & $\begin{array}{r}\Delta \mathrm{HOR} \\
(\mathrm{mm})\end{array}$ & $\begin{array}{l}\Delta \text { VER } \\
(\mathrm{mm})\end{array}$ & $\begin{array}{r}\Delta \mathrm{HOR} \\
(\mathrm{mm})\end{array}$ & $\begin{array}{r}\Delta \text { VER } \\
(\mathrm{mm})\end{array}$ \\
\hline 1 & 97 & -219 & 72 & -247 & 66 & -289 & 59 & -350 \\
\hline 2 & 99 & -236 & 90 & -255 & 68 & -316 & & \\
\hline 3 & 105 & -245 & 82 & -266 & 77 & -317 & & \\
\hline 4 & 85 & -126 & 94 & -142 & 101 & -171 & & \\
\hline 5 & 106 & -98 & 93 & -111 & 120 & -135 & & \\
\hline 6 & 17 & -98 & 16 & -115 & 17 & -139 & & \\
\hline
\end{tabular}

No gráfico mostrado na Figura 4.5, que relaciona o deslocamento em função do vão com a altura da treliça para os arranjos 1,2 e 3, verifica-se o aumento do deslocamento com a diminuição da altura da malha, sendo que os reticulados que apresentam menor deslocamento são os do tipo quadrado sobre quadrado (arranjos 1), e os que apresentam maior deslocamento são os do tipo quadrado reduzido sobre quadrado diagonal (arranjos 3). A NBR-8800 (1986) sugere para edifícios não industriais, um limite máximo de deslocamento, provocado por sobrecarga, em barras biapoioadas de pisos e coberturas, suportando construções e acabamentos não sujeitos à fissuração, de 1/300 do vão. Adotando-se esta recomendação para as treliças espaciais, percebemos que nenhum dos arranjos atende 
esta recomendação, e o que chega mais próximo é o arranjo $1 \mathrm{~A}$, com uma relação de vão/276. Vale salientar, que o peso próprio da treliça espacial corresponde a cerca de $40 \%$ da carga que provoca este deslocamento máximo, ou seja, prevendo-se uma contra-flecha na estrutura para anular os deslocamentos causados pelo peso próprio, os arranjos estruturais analisados atenderiam às recomendações da norma.

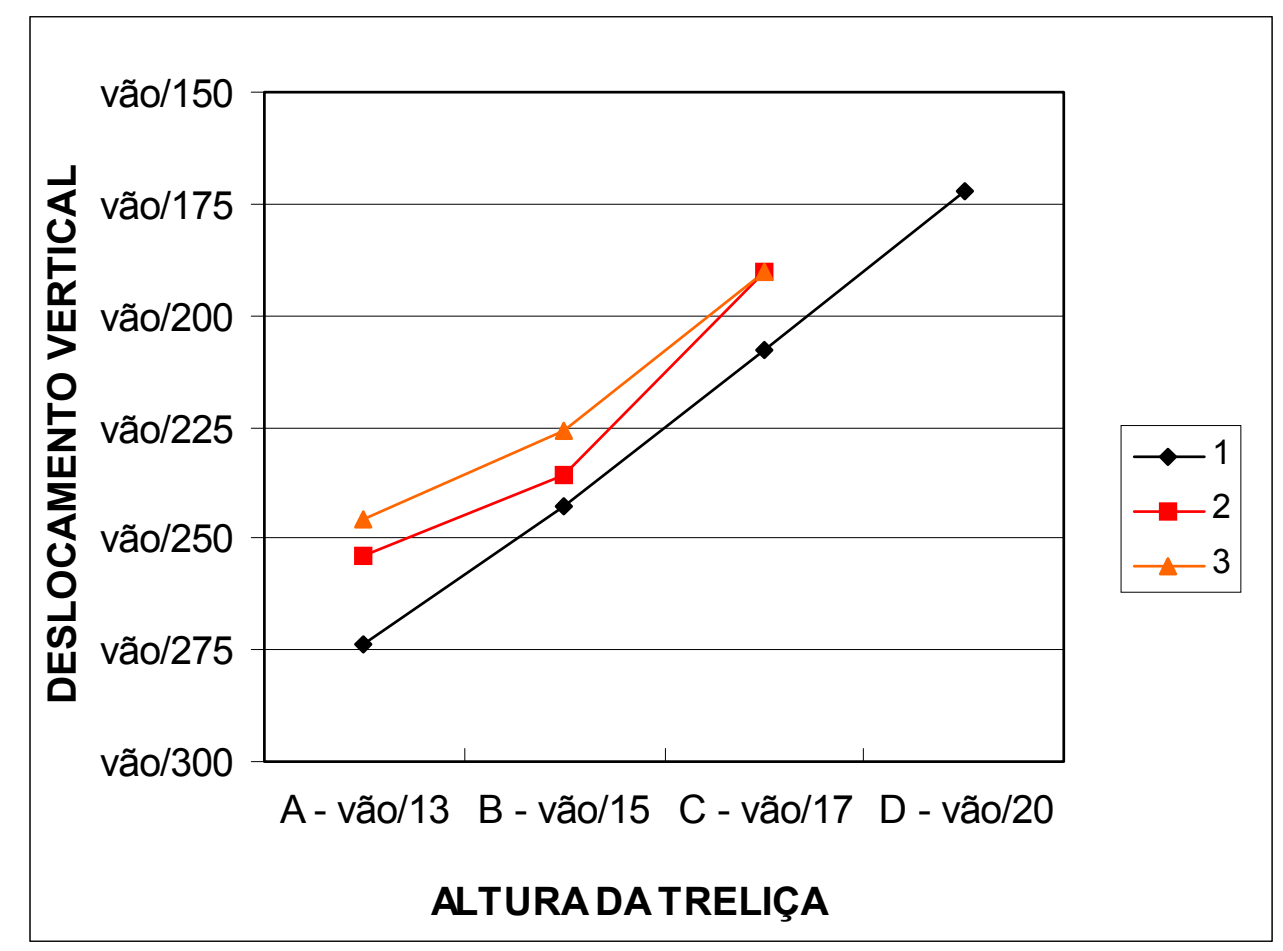

Figura 4.5 - Deslocamento vertical - arranjos 1, 2 e 3

Os arranjos 4, 5 e 6 atendem à recomendação da norma para todas as alturas analisadas, mesmo sem considerar uma eventual contra-flecha para anular os deslocamentos causados pelo peso próprio (Figura 4.6). Para estes arranjos, com pilares a cada $30 \mathrm{~m}$, os reticulados quadrado diagonal sobre quadrado diagonal e quadrado reduzido sobre quadrado diagonal (arranjos 4 e 5) foram os que apresentaram os menores deslocamentos, com comportamentos bastante semelhantes. 


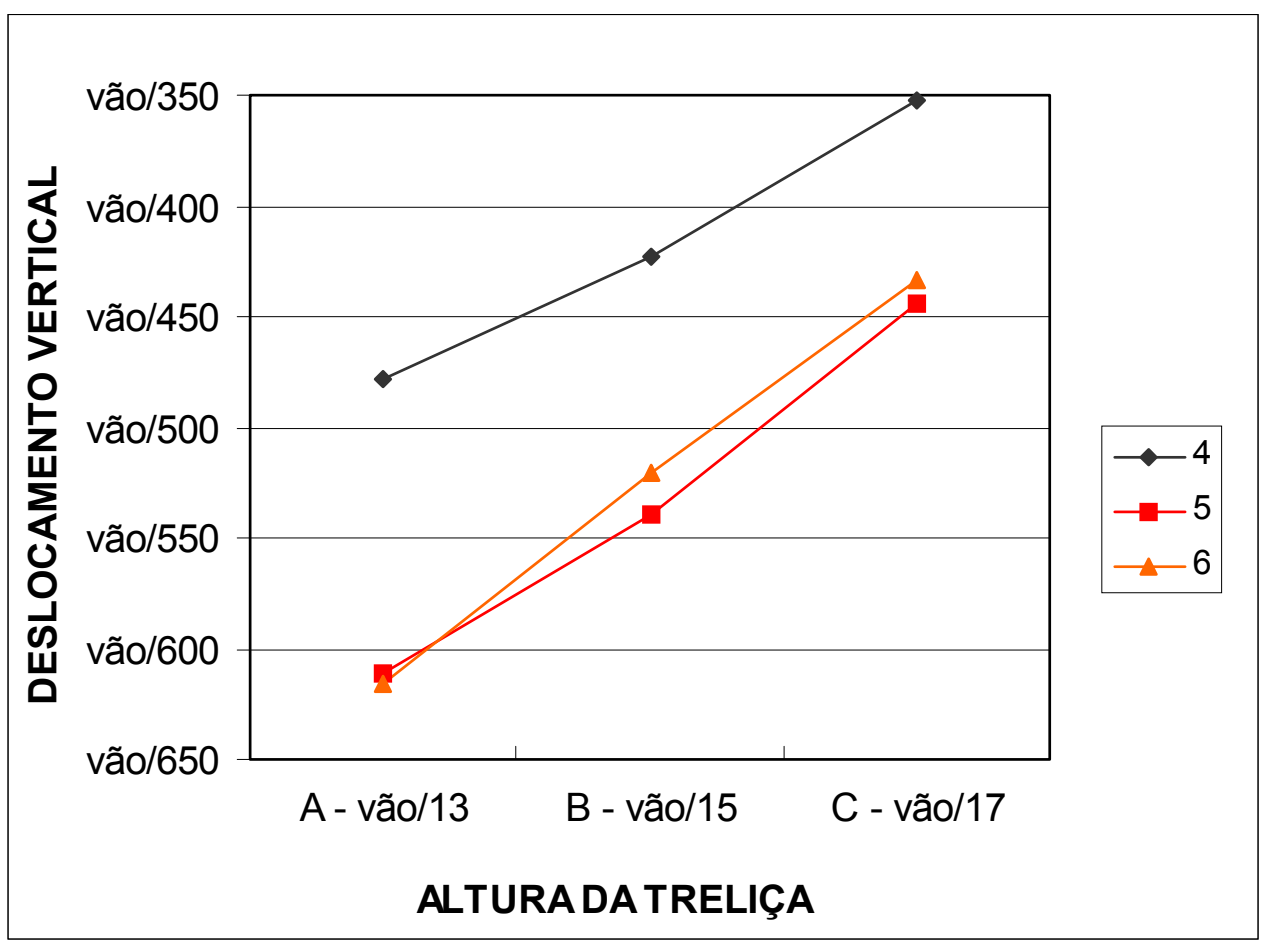

Figura 4.6 - Deslocamento vertical - arranjos 4, 5 e 6

Nas Tabelas 4.10, 4.11 e 4.12 são mostrados os máximos deslocamentos horizontais e verticais, dos arranjos estruturais 7 a 10 .

Tabela 4.10 - Deslocamentos máximos - arranjos 7

\begin{tabular}{|c|c|c|c|c|c|c|c|c|}
\hline & \multicolumn{8}{|c|}{ ALTURA DA TRELIÇA } \\
\hline & \multicolumn{2}{|c|}{$\begin{array}{l}\mathrm{A} \text { - vão/13 } \\
\mathrm{H}=4,5 \mathrm{~m}\end{array}$} & \multicolumn{2}{|c|}{$\begin{array}{l}\mathrm{B}-\text { vão/15 } \\
\mathrm{H}=4,0 \mathrm{~m}\end{array}$} & \multicolumn{2}{|c|}{$\begin{array}{l}\text { C - vão/13 } \\
\mathrm{H}=4,5 \mathrm{~m}\end{array}$} & \multicolumn{2}{|c|}{$\begin{array}{l}\mathrm{D} \text { - vão/15 } \\
\mathrm{H}=4,0 \mathrm{~m}\end{array}$} \\
\hline ARRANJO & $\begin{array}{c}\Delta \mathrm{HOR} . \\
(\mathrm{mm})\end{array}$ & $\begin{array}{c}\Delta \text { VER. } \\
(\mathrm{mm})\end{array}$ & $\begin{array}{c}\Delta \mathrm{HOR} . \\
(\mathrm{mm})\end{array}$ & $\begin{array}{c}\Delta \text { VER. } \\
(\mathrm{mm})\end{array}$ & $\begin{array}{c}\Delta \mathrm{HOR} . \\
(\mathrm{mm})\end{array}$ & $\begin{array}{c}\Delta \text { VER. } \\
(\mathrm{mm})\end{array}$ & $\begin{array}{c}\Delta \mathrm{HOR} . \\
(\mathrm{mm})\end{array}$ & $\begin{array}{c}\Delta \text { VER. } \\
(\mathrm{mm})\end{array}$ \\
\hline 7 & 35 & -149 & 36 & -174 & 34 & -141 & 35 & -165 \\
\hline
\end{tabular}

Tabela 4.11 - Deslocamentos máximos - arranjos 8

\begin{tabular}{|c|c|c|c|c|c|c|c|c|}
\hline & \multicolumn{8}{|c|}{ ALTURA DA TRELIÇA } \\
\hline & \multicolumn{2}{|c|}{$\begin{array}{c}\text { A - vão/10 } \\
\mathrm{H}=2 \times 3,0 \mathrm{~m}\end{array}$} & \multicolumn{2}{|c|}{$\begin{array}{c}\text { B - vão/13 } \\
H=2 \times 2,25 \text { m }\end{array}$} & \multicolumn{2}{|c|}{$\begin{array}{c}\text { C - vão/15 } \\
\mathrm{H}=2 \times 2,0 \mathrm{~m}\end{array}$} & \multicolumn{2}{|c|}{$\begin{array}{c}D \text { - vão/20 } \\
H=2 \times 1,5 \mathrm{~m}\end{array}$} \\
\hline ARRANJO & $\begin{array}{r}\Delta \mathrm{HOR} \\
(\mathrm{mm}) \\
\end{array}$ & $\begin{array}{c}\Delta \text { VER. } \\
(\mathrm{mm})\end{array}$ & $\begin{array}{c}\Delta \mathrm{HOR} . \\
(\mathrm{mm})\end{array}$ & $\begin{array}{c}\Delta \text { VER. } \\
(\mathrm{mm})\end{array}$ & $\begin{array}{c}\Delta \mathrm{HOR} . \\
(\mathrm{mm})\end{array}$ & $\begin{array}{c}\triangle \text { VER. } \\
(\mathrm{mm})\end{array}$ & $\begin{array}{c}\Delta \mathrm{HOR} . \\
(\mathrm{mm})\end{array}$ & $\begin{array}{r}\Delta \text { VER. } \\
(\mathrm{mm})\end{array}$ \\
\hline 8 & 84 & -183 & 79 & -249 & 60 & -285 & 59 & -382 \\
\hline
\end{tabular}


Tabela 4.12 - Deslocamentos máximos - arranjos 9 e 10

\begin{tabular}{|c|c|c|c|c|c|c|}
\hline \multirow{2}{*}{} & \multicolumn{4}{|c|}{ ALTURA DA TRELIÇA } \\
\cline { 2 - 7 } & \multicolumn{2}{|c|}{$\begin{array}{c}\mathrm{A}-\text { vão/13 } \\
\mathrm{H}=4,5 \mathrm{~m}\end{array}$} & \multicolumn{2}{c|}{$\begin{array}{c}\mathrm{B}-\text { vão/15 } \\
\mathrm{H}=4,0 \mathrm{~m}\end{array}$} & \multicolumn{2}{c|}{$\begin{array}{c}\mathrm{C}-\text { vão/17 } \\
\mathrm{H}=3,5 \mathrm{~m}\end{array}$} \\
\hline ARRANJO & $\begin{array}{c}\Delta \mathrm{HOR} . \\
(\mathrm{mm})\end{array}$ & $\begin{array}{c}\Delta \text { VER. } \\
(\mathrm{mm})\end{array}$ & $\begin{array}{c}\Delta \text { HOR. } \\
(\mathrm{mm})\end{array}$ & $\begin{array}{c}\Delta \text { VER. } \\
(\mathrm{mm})\end{array}$ & $\begin{array}{c}\Delta \mathrm{HOR} . \\
(\mathrm{mm})\end{array}$ & $\begin{array}{c}\Delta \text { VER. } \\
(\mathrm{mm})\end{array}$ \\
\hline 9 & 56 & -198 & 49 & -234 & 40 & -262 \\
\hline 10 & 93 & -142 & 86 & -161 & 78 & -181 \\
\hline
\end{tabular}

Os arranjos 7 apresentaram deslocamentos inferiores a vão/300. Os arranjos 9 apresentaram deslocamentos inferiores aos arranjos 1, sendo que para a relação de altura da treliça de vão/13 este deslocamento ficou abaixo do limite recomendado para norma. Os arranjos com três camadas de banzo (arranjos 8) apresentaram os maiores deslocamentos, sendo que apenas para a relação de altura da treliça de vão/10 o descolamento foi inferior a vão/300 (Figura 4.7). Os arranjos retangulares com pilares a cada $30 \mathrm{~m}$ (arranjos 10) apresentaram deslocamentos superiores aos arranjos quadrados com pilares a cada $30 \mathrm{~m}$ (arranjos 4 ).

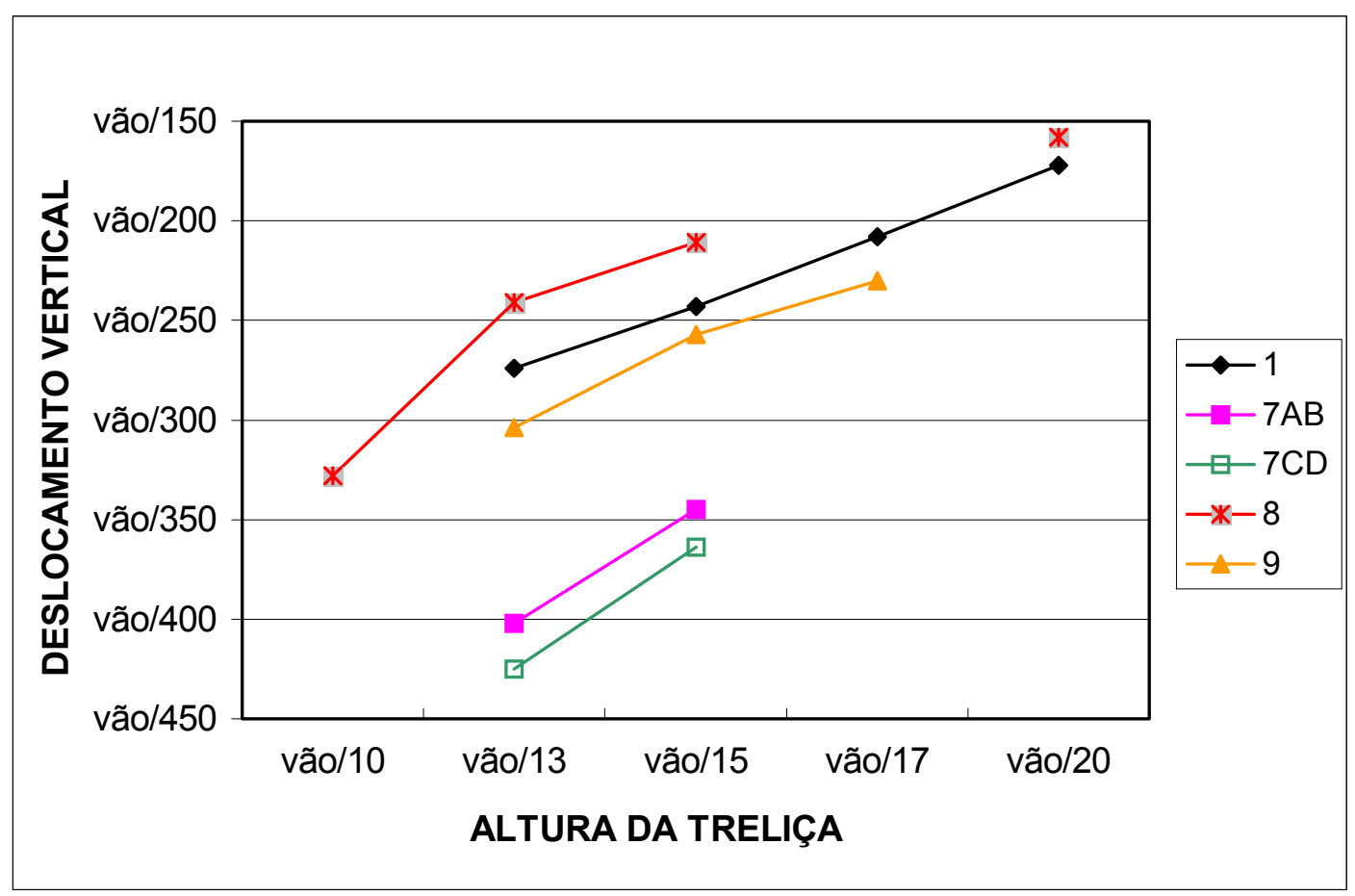

Figura 4.7 - Deslocamento vertical - arranjos 1, 7, 8 e 9 
$\mathrm{Na}$ Figura 4.8 são mostradas as configurações deslocadas dos arranjos 1B, 4B, 7B, 8C, 9B e 10B, com os deslocamentos dos nós ampliados 30 vezes para a combinação PPSCTN.

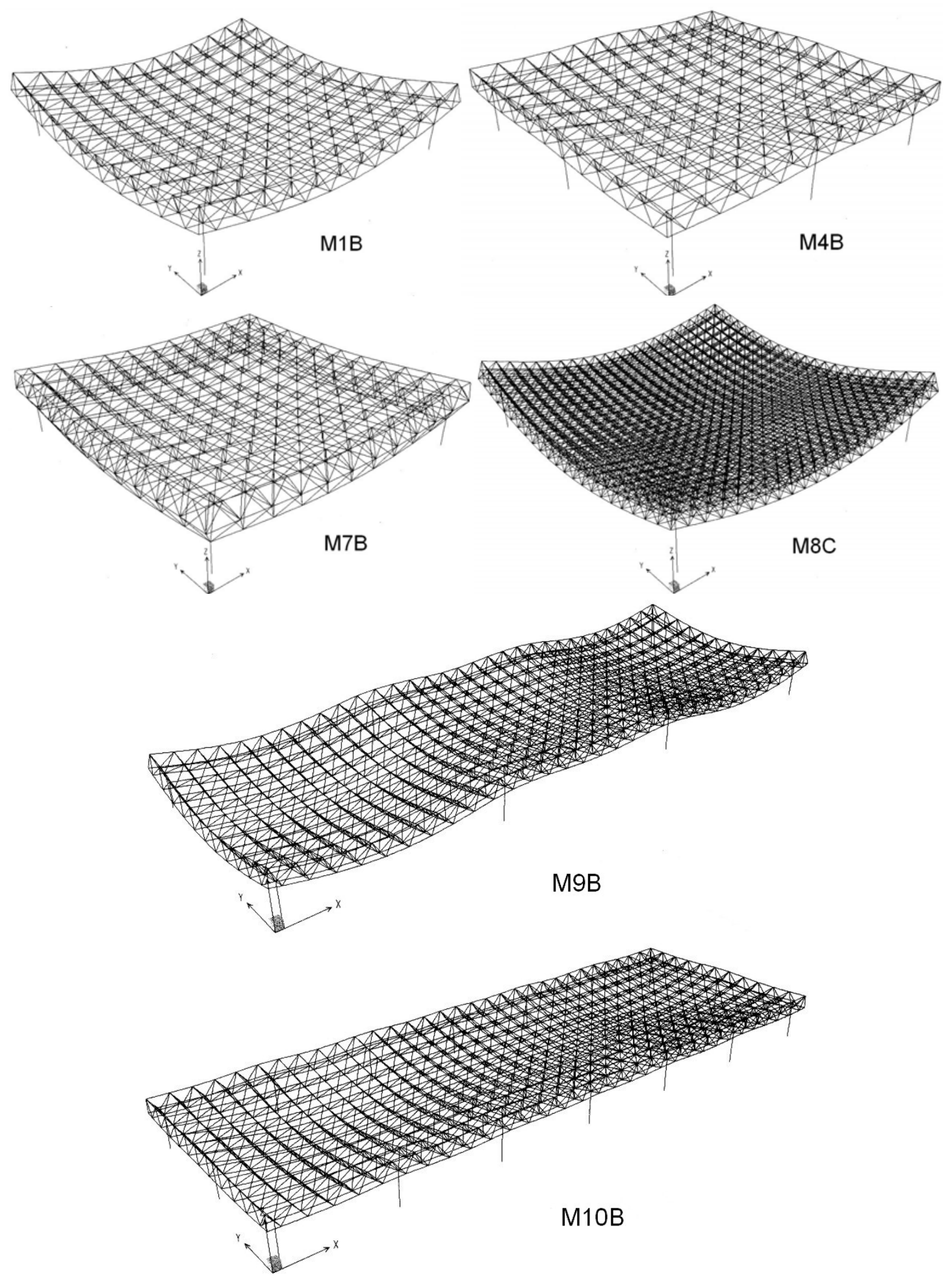

Figura 4.8 - Configurações deslocadas - arranjos 1B, 4B, 7B, 8C, 9B e 10B 


\subsection{REAÇÕES DE APOIO}

Foram analisadas as máximas reações de apoio horizontais, verticais e de momentos fletores. Estas reações máximas, não obrigatoriamente simultâneas, são mostradas na Tabela 4.13.

Tabela 4.13 - Reações de apoio máximas

\begin{tabular}{|c|c|c|c|c|c|}
\hline & \multicolumn{5}{|c|}{ REAÇÕES DE APOIO MÁXIMAS } \\
\hline ARRANJO & $\begin{array}{c}\text { R-FX } \\
(\mathrm{kN})\end{array}$ & $\begin{array}{c}\text { R-FY } \\
(\mathrm{kN})\end{array}$ & $\begin{array}{c}\text { R-FZ } \\
(\mathrm{kN})\end{array}$ & $\begin{array}{c}\text { R-MX } \\
(\mathrm{kN} \cdot \mathrm{m})\end{array}$ & $\begin{array}{c}\text { R-MY } \\
(\mathrm{kN} \cdot \mathrm{m})\end{array}$ \\
\hline 1A & 74 & 75 & 1080 & 746 & 738 \\
\hline 1B & 69 & 70 & 1100 & 703 & 691 \\
\hline 1C & 63 & 64 & 1120 & 643 & 631 \\
\hline 1D & 57 & 59 & 1154 & 586 & 574 \\
\hline 2A & 74 & 74 & 1098 & 743 & 735 \\
\hline 2B & 68 & 69 & 1137 & 686 & 677 \\
\hline 2C & 63 & 64 & 1132 & 642 & 630 \\
\hline 3A & 74 & 74 & 1068 & 740 & 743 \\
\hline 3B & 69 & 70 & 1096 & 699 & 691 \\
\hline 3C & 63 & 64 & 1126 & 643 & 631 \\
\hline 4A & 68 & 67 & 739 & 673 & 681 \\
\hline 4B & 60 & 59 & 740 & 592 & 596 \\
\hline 4C & 52 & 51 & 746 & 513 & 516 \\
\hline 5A & 52 & 51 & 837 & 513 & 515 \\
\hline 5B & 46 & 45 & 843 & 455 & 457 \\
\hline 5C & 30 & 30 & 846 & 410 & 409 \\
\hline 6A & 462 & 463 & 770 & 2547 & 2543 \\
\hline 6B & 519 & 519 & 773 & 3112 & 3117 \\
\hline 6C & 554 & 554 & 782 & 3601 & 3603 \\
\hline 7A & 904 & 907 & 1044 & 4988 & 4973 \\
\hline 7B & 1010 & 1018 & 1053 & 6105 & 6060 \\
\hline 7C & 719 & 720 & 1072 & 2329 & 2316 \\
\hline 7D & 740 & 744 & 1061 & 2535 & 2513 \\
\hline 8A & 96 & 97 & 1097 & 971 & 956 \\
\hline 8B & 76 & 77 & 1105 & 769 & 756 \\
\hline 8C & 71 & 73 & 1116 & 729 & 713 \\
\hline 8D & 58 & 59 & 1185 & 588 & 577 \\
\hline 9A & 119 & 122 & 2065 & 1224 & 1186 \\
\hline 9B & 142 & 122 & 2069 & 1216 & 1415 \\
\hline 9C & 284 & 203 & 2111 & 2032 & 2845 \\
\hline & & & & & \\
\hline
\end{tabular}


Tabela 4.13 - Reações de apoio máximas (continuação)

\begin{tabular}{|c|c|c|c|c|c|}
\hline & \multicolumn{5}{|c|}{ REAÇÕES DE APOIO MÁXIMAS } \\
\hline ARRANJO & $\begin{array}{c}\text { R-FX } \\
(\mathrm{kN})\end{array}$ & $\begin{array}{c}\text { R-FY } \\
(\mathrm{kN})\end{array}$ & $\begin{array}{c}\text { R-FZ } \\
(\mathrm{kN})\end{array}$ & $\begin{array}{c}\text { R-MX } \\
(\mathrm{kN} . \mathrm{m})\end{array}$ & $\begin{array}{c}\text { R-MY } \\
(\mathrm{kN} . \mathrm{m})\end{array}$ \\
\hline 10A & 32 & 73 & 1047 & 732 & 319 \\
\hline 10B & 30 & 67 & 1005 & 672 & 300 \\
\hline 10C & 28 & 61 & 1017 & 612 & 280 \\
\hline Notas: \\
R-FX: Máxima reação de apoio na direção horizontal X. \\
R-FY: Máxima reação de apoio na direção horizontal \\
R-FZ: Máxima reação de apoio na direção vertical Z. \\
R-MX: Máxima reação de momentos fletores em torno do eixo X. \\
R-MY: Máxima reação de momentos fletores em torno do eixo Y. \\
Obs: ver esquema geral de orientação dos eixos na Figura 4.8.
\end{tabular}

Para os arranjos 1, 2, 3, 4, 5, 8 e 10 as máximas reações horizontais e de momentos fletores ocorreram para as combinações que envolviam peso próprio, vento e variação de temperatura, e as máximas reações verticais para combinações que envolviam peso próprio, sobrecarga e variação de temperatura. Nestes arranjos houve uma redução das reações horizontais e de momentos fletores com a diminuição da altura da treliça.

Nos arranjos 1, 2, 3 e 8 não ocorreram alterações significativas nas reações de apoio em função da disposição de barras dos reticulados, para uma mesma altura de treliça. Os arranjos 4, 5 e 10, devido ao aumento do número de pilares, apresentaram reações de apoio inferiores às dos arranjos 1, 2 e 9, respectivamente.

Para os arranjos 6 e 7, todas as reações de apoios máximas ocorreram para as combinações que envolviam peso próprio, sobrecarga e variação de temperatura. Estes arranjos apresentaram reações horizontais e de momentos fletores muito superiores às dos outros arranjos. Nos arranjos 6 os apoios intermediários são do tipo "pé-de-galinha", apoiando a estrutura num nível abaixo do banzo inferior, com diagonais interligando o topo dos pilares aos nós do banzo inferior. Como nos pontos de apoio chegam apenas diagonais, tem-se uma elevada resultante horizontal, muito superior às resultantes dos outros tipos de apoio, e que resulta em elevadas reações 
de apoio nas bases dos pilares. O aumento destas reações com a diminuição da altura do reticulado, deve-se ao fato de que a distância entre o topo dos pilares e o nível do banzo inferior é igual à altura do reticulado. Assim, com a diminuição da altura do reticulado, aumenta-se a altura dos pilares e conseqüentemente o momento nas bases. Os arranjos 7 por apresentarem a terceira camada de banzos incompleta, com banzos apenas nos alinhamentos dos apoios, paralelos ao contorno, apresentaram também reações de apoio elevadas. Os apoios do tipo engaste, nos arranjos 7C e 7D, reduziram as reações de apoio horizontais e de momentos fletores, sendo que para os momentos fletores a redução foi superior a $50 \% \mathrm{em}$ relação aos valores obtidos para os arranjos 7A e 7B.

Os arranjos 9 apresentaram reações de apoios máximas para as combinações que envolviam peso próprio, sobrecarga e variação de temperatura, com exceção da reação horizontal na direção $Y$ para os arranjos 9A e 9B que ocorreu para as combinações que envolviam peso próprio, vento e variação de temperatura. Nestes arranjos ocorreu um aumento das reações de apoio em relação aos arranjos 1, devido ao aumento da área de influência de cada pilar.

Nos gráficos das Figuras 4.9 e 4.10 são mostradas as máximas reações de apoio verticais (R-FZ) e de momentos fletores (R-MX).

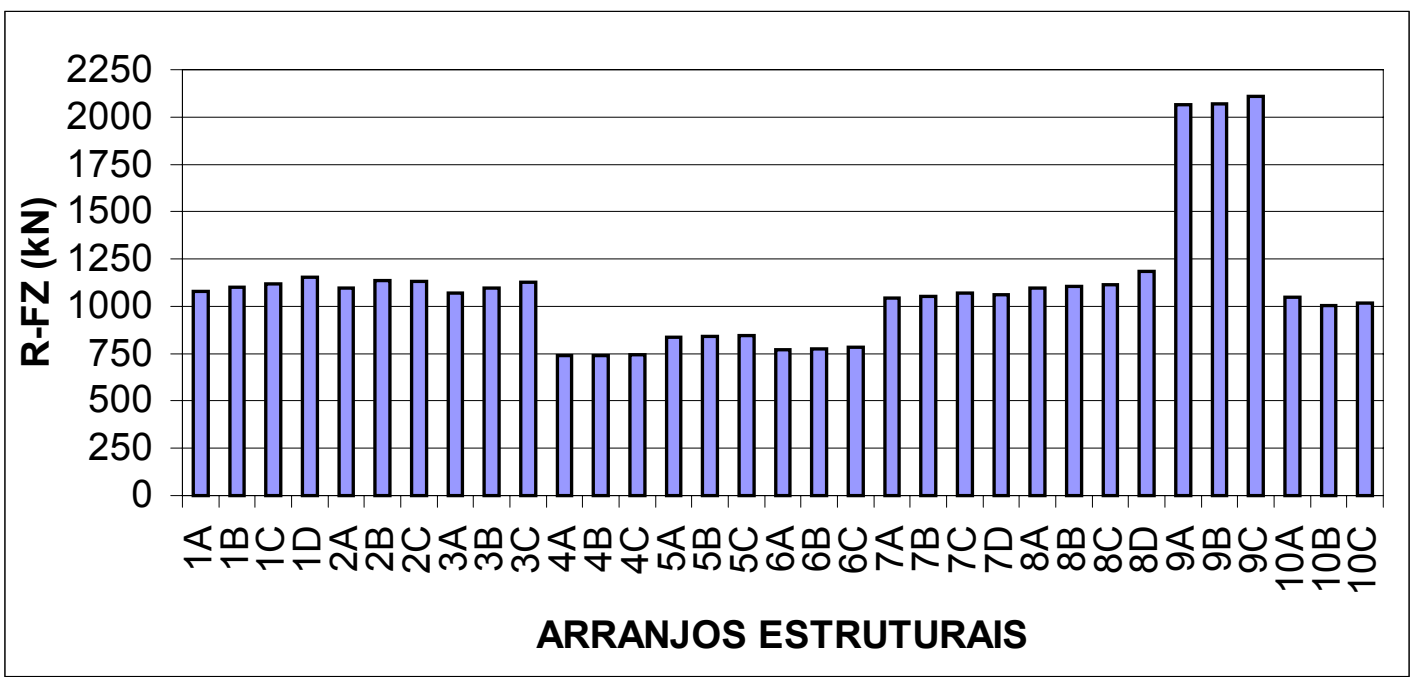

Figura 4.9 - Máximas reações de apoio verticais - R-FZ 


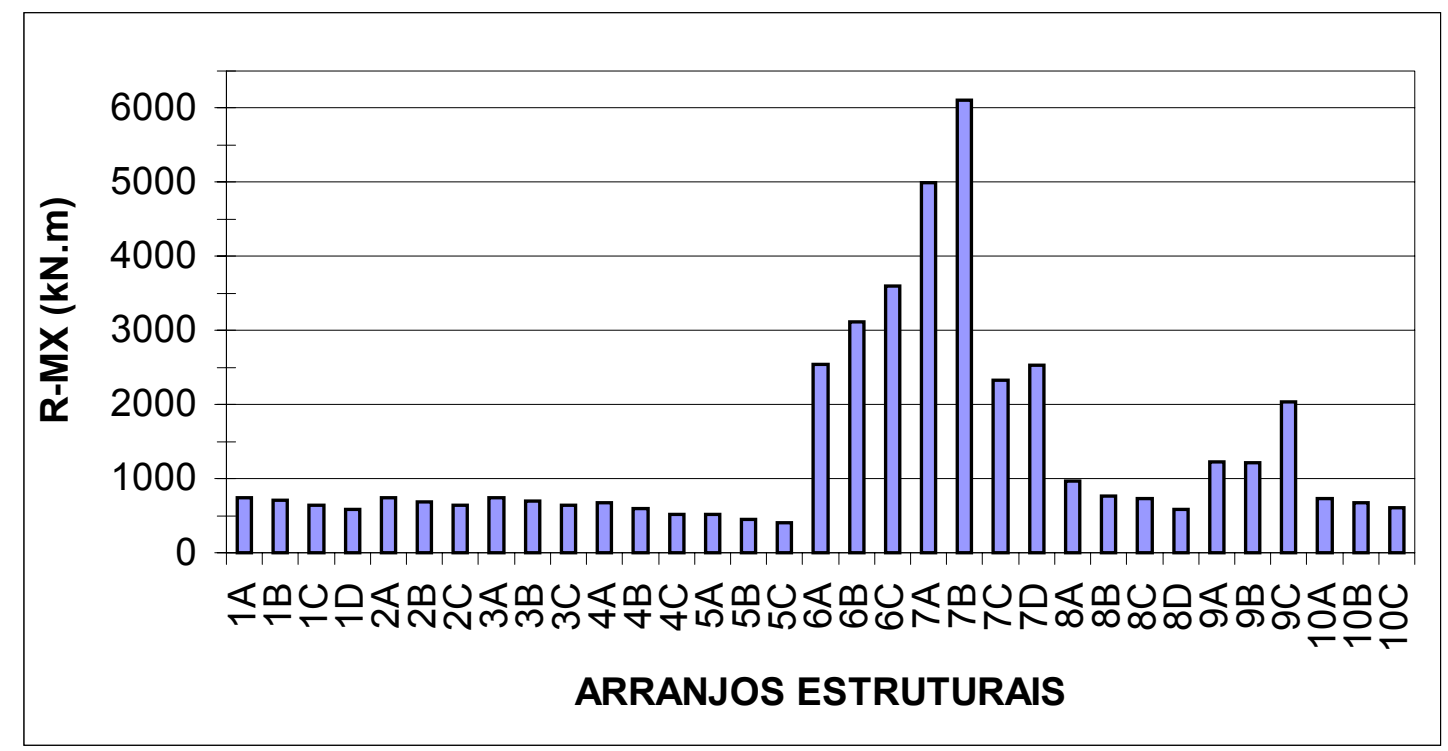

Figura 4.10 - Máximas reações de apoio de momentos fletores - R-MX

\subsection{ESFORÇOS INTERNOS}

Foram analisados os esforços máximos nas barras dos banzos e das diagonais dos arranjos.

Analisando a Tabela 4.14, o banzo inferior caracteriza-se como tendo esforços máximos predominantemente de tração, causados pelas combinações de ações que envolviam sobrecarga. Para pilares a cada $60 \mathrm{~m}$, os reticulados do tipo quadrado sobre quadrado (arranjos 1) apresentaram os menores esforços de tração. Porém, para pilares a cada $30 \mathrm{~m}$, esta situação se inverteu e estes reticulados (arranjos 4) apresentaram os maiores esforços de tração. Ocorreu uma redução na tração máxima, variando de $50 \%$ a $90 \%$, com a colocação de pilares intermediários a cada trinta metros nos arranjos 4, 5 e 6. Para os arranjos 6, os esforços máximos no banzo inferior foram os de compressão. Nos arranjos 9 e 10 os valores máximos de tração foram semelhantes aos obtidos nos arranjos 1, apesar dos arranjos 10 apresentarem pilares a cada $30 \mathrm{~m}$. 
Tabela 4.14 - Esforços máximos - banzo inferior

\begin{tabular}{|c|c|c|c|c|c|c|c|c|}
\hline & \multicolumn{7}{|c|}{ ALTURA DA TRELIÇA } \\
\cline { 2 - 10 } & $\mathrm{A}-$ vão/13 & \multicolumn{2}{c|}{$\mathrm{B}-$ vão/15 } & \multicolumn{2}{c|}{$\mathrm{C}-$ vão/17 } & \multicolumn{2}{c|}{$\mathrm{D}-$ vão/20 } \\
\cline { 2 - 10 } & $\mathrm{H}=4,5 \mathrm{~m}$ & $\mathrm{H}=4,0 \mathrm{~m}$ & $\mathrm{H}=3,5 \mathrm{~m}$ & $\mathrm{H}=3,0 \mathrm{~m}$ \\
\hline ARRANJOS & $\mathrm{T}$ & $\mathrm{C}$ & $\mathrm{T}$ & $\mathrm{C}$ & $\mathrm{T}$ & $\mathrm{C}$ & $\mathrm{T}$ & $\mathrm{C}$ \\
\hline & $\mathrm{kN})$ & $(\mathrm{kN})$ & $(\mathrm{kN})$ & $(\mathrm{kN})$ & $(\mathrm{kN})$ & $(\mathrm{kN})$ & $(\mathrm{kN})$ & $(\mathrm{kN})$ \\
\hline 1 & 1084 & -65 & 943 & -46 & 1006 & -26 & 1069 & -10 \\
\hline 2 & 1262 & -43 & 1267 & -78 & 1548 & -76 & & \\
\hline 3 & 1196 & -224 & 1159 & -231 & 1208 & -259 & & \\
\hline 4 & 445 & -83 & 479 & -94 & 488 & -131 & & \\
\hline 5 & 293 & -135 & 372 & -171 & 315 & -186 & & \\
\hline 6 & 110 & -179 & 119 & -204 & 153 & -241 & & \\
\hline 9 & 1081 & -625 & 1185 & -686 & 1111 & -778 & & \\
\hline 10 & 1007 & -139 & 1097 & -155 & 1100 & -209 & & \\
\hline
\end{tabular}

Tabela 4.15 - Esforços máximos - banzo superior

\begin{tabular}{|c|c|c|c|c|c|c|c|c|}
\hline & \multicolumn{7}{|c|}{ ALTURA DA TRELIÇA } \\
\cline { 2 - 10 } & $\mathrm{A}-$ vão/13 & \multicolumn{2}{c|}{$\mathrm{B}-$ vão/15 } & \multicolumn{2}{c|}{$\mathrm{C}-$ vão/17 } & \multicolumn{2}{c|}{$\mathrm{D}-$ vão/20 } \\
\cline { 2 - 10 } & $\mathrm{H}=4,5 \mathrm{~m}$ & $\mathrm{H}=4,0 \mathrm{~m}$ & \multicolumn{2}{c|}{$\mathrm{H}=3,5 \mathrm{~m}$} & \multicolumn{2}{c|}{$\mathrm{H}=3,0 \mathrm{~m}$} \\
\hline ARRANJOS & $\mathrm{T}$ & $\mathrm{C}$ & $\mathrm{T}$ & $\mathrm{C}$ & $\mathrm{T}$ & $\mathrm{C}$ & $\mathrm{T}$ & $\mathrm{C}$ \\
\hline & $(\mathrm{kN})$ & $(\mathrm{kN})$ & $(\mathrm{kN})$ & $(\mathrm{kN})$ & $(\mathrm{kN})$ & $(\mathrm{kN})$ & $(\mathrm{kN})$ & $(\mathrm{kN})$ \\
\hline 1 & 109 & -985 & 123 & -1125 & 137 & -1144 & 172 & -1254 \\
\hline 2 & 273 & -1112 & 290 & -1190 & 305 & -1388 & & \\
\hline 3 & 210 & -1083 & 231 & -1146 & 260 & -1160 & & \\
\hline 4 & 221 & -408 & 250 & -467 & 269 & -459 & & \\
\hline 5 & 79 & -267 & 91 & -303 & 171 & -291 & & \\
\hline 6 & 220 & -301 & 244 & -334 & 271 & -357 & & \\
\hline 9 & 1011 & -1011 & 1100 & -1145 & 1293 & -1099 & & \\
\hline 10 & 325 & -880 & 359 & -932 & 372 & -991 & & \\
\hline
\end{tabular}

$\mathrm{Na}$ Tabela 4.15 são mostrados os esforços máximos no banzo superior, os quais são de compressão, causados pelas combinações de ações que envolviam sobrecarga. Ocorreu, na maioria dos arranjos, um 
aumento dos valores compressão máxima com a diminuição da altura do reticulado. Os reticulados quadrado sobre quadrado apresentaram os menores valores máximos de compressão para pilares a cada 60m (arranjos 1), e os maiores valores máximos de compressão para pilares a cada $30 \mathrm{~m}$ (arranjos 4). Nos arranjos 9 e 10 os valores máximos de compressão também foram semelhantes aos obtidos nos arranjos 1.

Na Tabela 4.16 são mostrados os esforços máximos nas diagonais, os quais são na maioria de compressão, causados pelas combinações de ações que envolviam sobrecarga. Os arranjos 5 apresentam esforços máximos de tração, causados pelo apoio dos pilares no banzo superior da treliça. Para os arranjos 6, as diagonais dos apoios tipo "pé-de-galinha" apresentaram valores de compressão elevados, muito próximos daqueles obtidos para as situações com pilares a cada $60 \mathrm{~m}$.

Tabela 4.16 - Esforços máximos - diagonais

\begin{tabular}{|c|c|c|c|c|c|c|c|c|}
\hline \multirow[b]{4}{*}{ ARRANJOS } & \multicolumn{8}{|c|}{ ALTURA DA TRELIÇA } \\
\hline & \multicolumn{2}{|c|}{$A-v a ̃ o / 13$} & \multicolumn{2}{|c|}{ B - vão/15 } & \multicolumn{2}{|c|}{ C - vão/17 } & \multicolumn{2}{|c|}{ D - vão/20 } \\
\hline & \multicolumn{2}{|c|}{$\mathrm{H}=4,5 \mathrm{~m}$} & \multicolumn{2}{|c|}{$\mathrm{H}=4,0 \mathrm{~m}$} & \multicolumn{2}{|c|}{$\mathrm{H}=3,5 \mathrm{~m}$} & \multicolumn{2}{|c|}{$\mathrm{H}=3,0 \mathrm{~m}$} \\
\hline & $\mathrm{T}$ & $\mathrm{C}$ & $\mathrm{T}$ & C & $\mathrm{T}$ & C & $T$ & $\mathrm{C}$ \\
\hline & $(\mathrm{kN})$ & $(\mathrm{kN})$ & $(\mathrm{kN})$ & $(\mathrm{kN})$ & $(\mathrm{kN})$ & $(\mathrm{kN})$ & $(\mathrm{kN})$ & $(\mathrm{kN})$ \\
\hline 1 & 239 & -666 & 264 & -737 & 282 & -831 & 280 & -814 \\
\hline 2 & 414 & -447 & 430 & -460 & 415 & -444 & & \\
\hline 3 & 474 & -498 & 543 & -568 & 578 & -595 & & \\
\hline 4 & 115 & -300 & 123 & -320 & 126 & -320 & & \\
\hline 5 & 334 & -192 & 329 & -212 & 327 & -193 & & \\
\hline 6 & 228 & -247 & 236 & -255 & 264 & -276 & & \\
\hline 6-PDG & 239 & -675 & 235 & -714 & 232 & -775 & & \\
\hline 9 & 401 & -873 & 449 & -957 & 393 & -928 & & \\
\hline 10 & 263 & -509 & 274 & -532 & 278 & -525 & & \\
\hline $\begin{array}{l}\text { Notas: } \\
\text { T: Máximo } \\
\text { C: Máximo } \\
\text { PDG: Diagc }\end{array}$ & $\begin{array}{l}\text { sforço } \\
\text { sforço } \\
\text { lais de }\end{array}$ & e trac & ressâ & & & & & \\
\hline
\end{tabular}

Os arranjos 7 apresentaram valores de esforços máximos, nos banzos, inferiores aos dos outros arranjos com pilares espaçados a cada 
60m (Tabela 4.17). Estes arranjos apresentam os máximos valores de compressão nas diagonais de chegada aos apoios. Os apoios do tipo "engaste" provocaram um aumento nos valores máximos de tração para os banzos intermediários e um aumento nos valores máximos de compressão para os banzos inferiores, nas barras ligadas aos pilares.

Tabela 4.17 - Esforços máximos - Arranjos 7

\begin{tabular}{|c|c|c|c|c|c|c|c|c|}
\hline & \multicolumn{9}{|c|}{ ALTURA DA TRELIÇA } \\
\cline { 2 - 10 } & $\mathrm{A}-$ vão/13 & \multicolumn{2}{|c|}{$\mathrm{B}-$ vão/15 } & \multicolumn{2}{c|}{$\mathrm{C}-$ vão/13 } & \multicolumn{2}{c|}{$\mathrm{D}$ - vão/15 } \\
\cline { 2 - 10 } & $\mathrm{H}=4,5 \mathrm{~m}$ & $\mathrm{H}=4,0 \mathrm{~m}$ & $\mathrm{H}=4,5 \mathrm{~m}$ & $\mathrm{H}=4,0 \mathrm{~m}$ \\
\hline ARRANJOS & $\mathrm{T}$ & $\mathrm{C}$ & $\mathrm{T}$ & $\mathrm{C}$ & $\mathrm{T}$ & $\mathrm{C}$ & $\mathrm{T}$ & $\mathrm{C}$ \\
\hline 7 & $(\mathrm{kN})$ & $(\mathrm{kN})$ & $(\mathrm{kN})$ & $(\mathrm{kN})$ & $(\mathrm{kN})$ & $(\mathrm{kN})$ & $(\mathrm{kN})$ & $(\mathrm{kN})$ \\
\hline $\mathrm{BN} 1$ & 456 & -379 & 515 & -407 & 393 & -505 & 443 & -546 \\
\hline $\mathrm{BN} 2$ & 167 & -130 & 180 & -170 & 370 & -90 & 384 & -87 \\
\hline $\mathrm{BN} 3$ & 85 & -491 & 90 & -536 & 78 & -415 & 82 & -441 \\
\hline D12 & 279 & -1082 & 301 & -1174 & 392 & -1072 & 421 & -1102 \\
\hline D23 & 247 & -509 & 271 & -544 & 134 & -301 & 200 & -304 \\
\hline Notas: & \multicolumn{10}{|c|}{} \\
T: Máximo esforço de tração \\
C: Máximo esforço de compressão \\
BN1: Banzos inferiores \\
BN2: Banzos intermediários \\
BN3: Banzos superiores \\
D12: Diagonais entre BN1 e BN2 \\
D23: Diagonais entre BN2 e BN3
\end{tabular}

Os arranjos 8 apresentaram um significativo aumento dos valores de esforços máximos com a diminuição da altura da treliça (Tabela 4.18). Porém, estes arranjos apresentaram valores máximos de esforços inferiores aos obtidos para os outros arranjos com pilares a cada $60 \mathrm{~m}$ e duas camadas de banzo. 
Tabela 4.18 - Esforços máximos - Arranjos 8

\begin{tabular}{|c|c|c|c|c|c|c|c|c|}
\hline & \multicolumn{7}{|c|}{ ALTURA DA TRELIÇA } \\
\cline { 2 - 9 } & $\mathrm{A}-$ vão/10 & \multicolumn{2}{c|}{$\mathrm{B}-\mathrm{vão} / 13$} & $\mathrm{C}-$ vão/15 & \multicolumn{2}{c|}{$\mathrm{D}$ - vão/20 } \\
\cline { 2 - 9 } & $\mathrm{H}=2 \times 3,0 \mathrm{~m}$ & $\mathrm{H}=2 \times 2,25 \mathrm{~m}$ & $\mathrm{H}=2 \times 2,0 \mathrm{~m}$ & \multicolumn{2}{c|}{$\mathrm{H}=2 \times 1,5 \mathrm{~m}$} \\
\hline ARRANJOS & $\mathrm{T}$ & $\mathrm{C}$ & $\mathrm{T}$ & $\mathrm{C}$ & $\mathrm{T}$ & $\mathrm{C}$ & $\mathrm{T}$ & $\mathrm{C}$ \\
\hline 8 & $(\mathrm{kN})$ & $(\mathrm{kN})$ & $(\mathrm{kN})$ & $(\mathrm{kN})$ & $(\mathrm{kN})$ & $(\mathrm{kN})$ & $(\mathrm{kN})$ & $(\mathrm{kN})$ \\
\hline BN1 & 444 & -36 & 604 & -23 & 706 & -17 & 1143 & -19 \\
\hline BN2 & 115 & -16 & 144 & -22 & 170 & -24 & 254 & -39 \\
\hline BN3 & 30 & -419 & 43 & -584 & 48 & -682 & 89 & -1206 \\
\hline D12 & 112 & -447 & 121 & -519 & 145 & -532 & 162 & -689 \\
\hline D23 & 86 & -235 & 129 & -306 & 127 & -305 & 161 & -377 \\
\hline
\end{tabular}

Os valores de esforços máximos ocorreram nas seguintes barras:

- Arranjos estruturais 1A, 1B, 1C e 1D:

- Banzo inferior: barras tracionadas no meio do vão no alinhamento dos pilares, paralelas ao contorno (Fig. 4.11);

○ Diagonais: barras comprimidas ligadas aos pilares;

- Banzo superior: barras comprimidas no meio do vão no alinhamento dos pilares, paralelas ao contorno (Fig. 4.11);
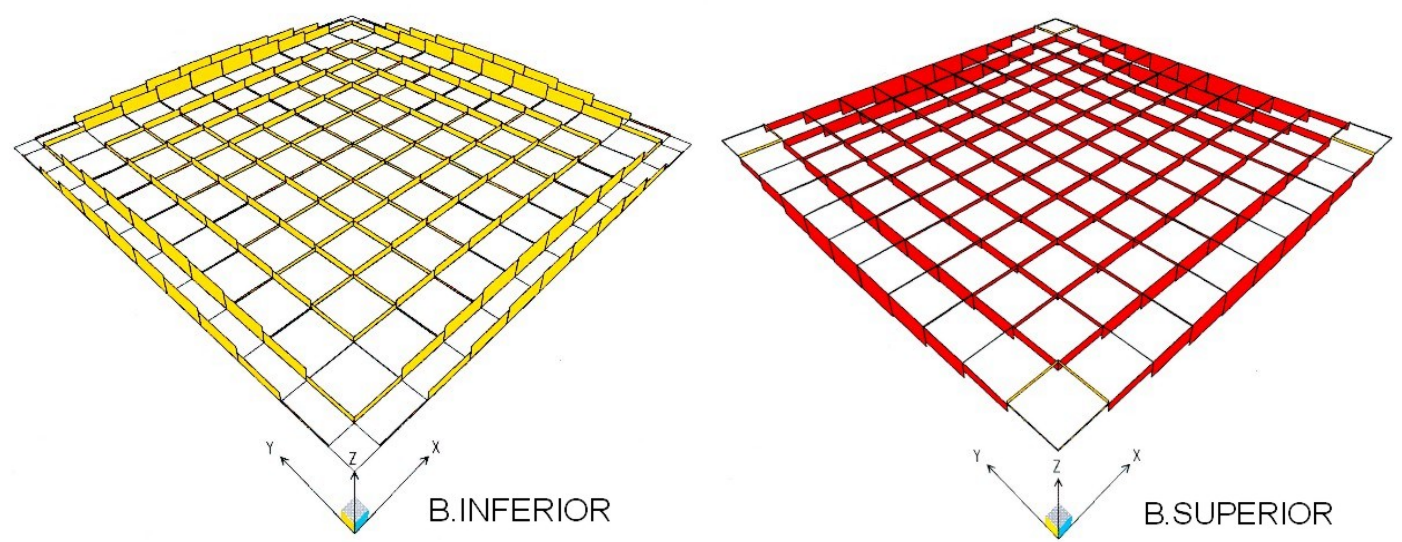

Figura 4.11 - Diagramas de esforços normais - Arranjo 1B Combinação PPSC (amarelo: tração e vermelho: compressão) 
- Arranjos estruturais $2 \mathrm{~A}, 2 \mathrm{~B}$ e $2 \mathrm{C}$ :

- Banzo inferior: barras tracionadas no meio do vão no alinhamento dos pilares, paralelas e diagonais ao contorno (Fig. 4.12);

- Diagonais: barras comprimidas ligadas aos pilares;

- Banzo superior: barras comprimidas no meio do vão no alinhamento dos pilares, paralelas e diagonais ao contorno (Fig. 4.12);
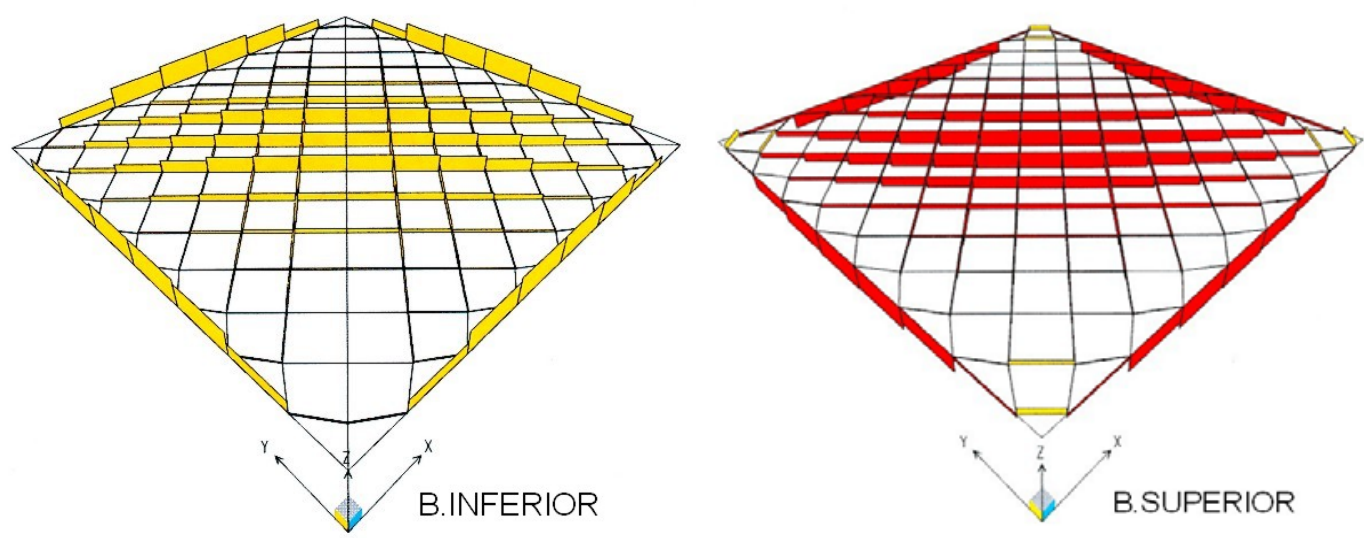

Figura 4.12 - Diagramas de esforços normais - Arranjo 2B Combinação PPSC (amarelo: tração e vermelho: compressão)

- Arranjos estruturais 3A, 3B e 3C:

- Banzo inferior: barras tracionadas no meio do vão no alinhamento dos pilares, paralelas e diagonais ao contorno (Fig. 4.13);

- Diagonais: barras comprimidas ligadas aos pilares;

- Banzo superior: barras comprimidas no meio do vão no alinhamento dos pilares, paralelas ao contorno (Fig. 4.13); 

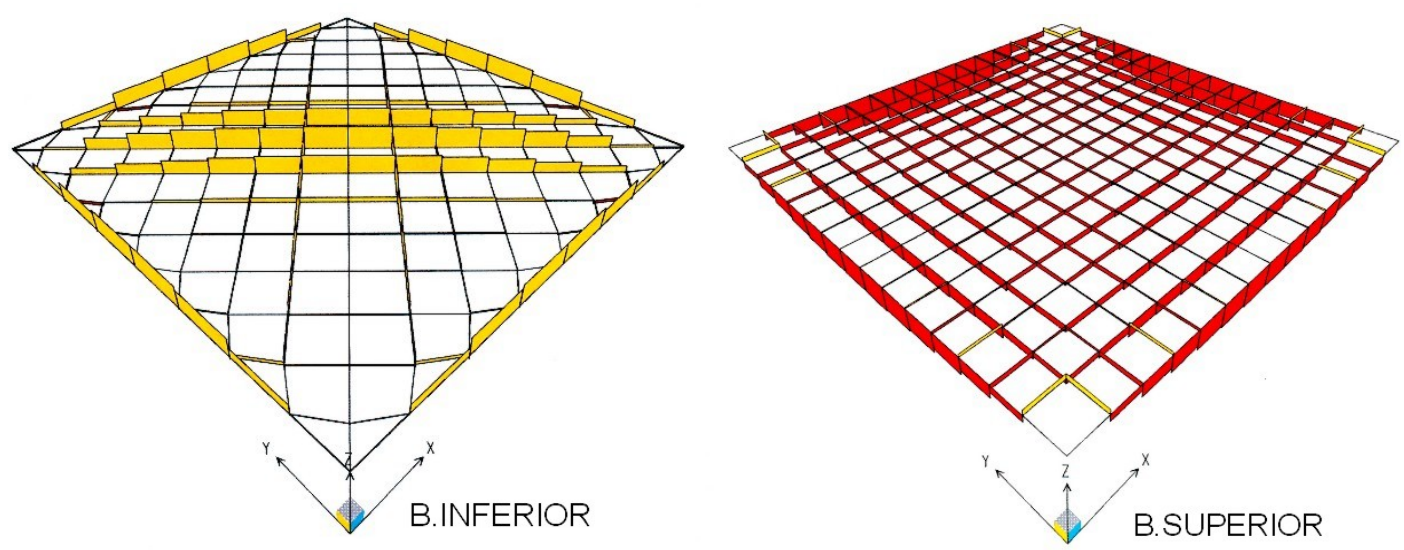

Figura 4.13 - Diagramas de esforços normais - Arranjo 3B

Combinação PPSC (amarelo: tração e vermelho: compressão)

- Arranjos estruturais 4A, 4B e 4C:

- Banzo inferior: barras tracionadas no meio do vão no alinhamento dos pilares intermediários, paralelas ao contorno (Fig. 4.14);

- Diagonais: barras comprimidas ligadas aos pilares;

- Banzo superior: barras comprimidas no meio do vão no alinhamento dos pilares intermediários, paralelas ao contorno (Fig. 4.14);
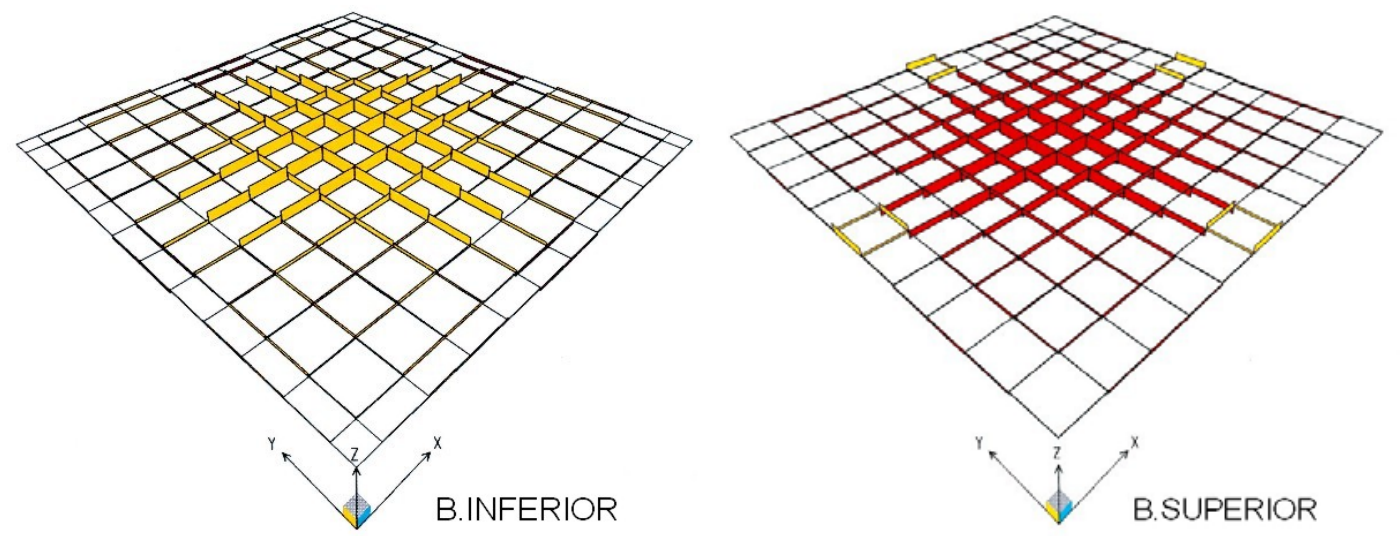

Figura 4.14 - Diagramas de esforços normais - Arranjo 4B

Combinação PPSC (amarelo: tração e vermelho: compressão) 
- Arranjos estruturais 5A, 5B e 5C:

- Banzo inferior: barras tracionadas no meio do vão no alinhamento dos pilares intermediários, diagonais ao contorno (Fig. 4.15);

- Diagonais: barras tracionadas ligadas aos pilares intermediários;

- Banzo superior: barras comprimidas no meio do vão no alinhamento dos pilares intermediários, diagonais ao contorno (Fig. 4.15);
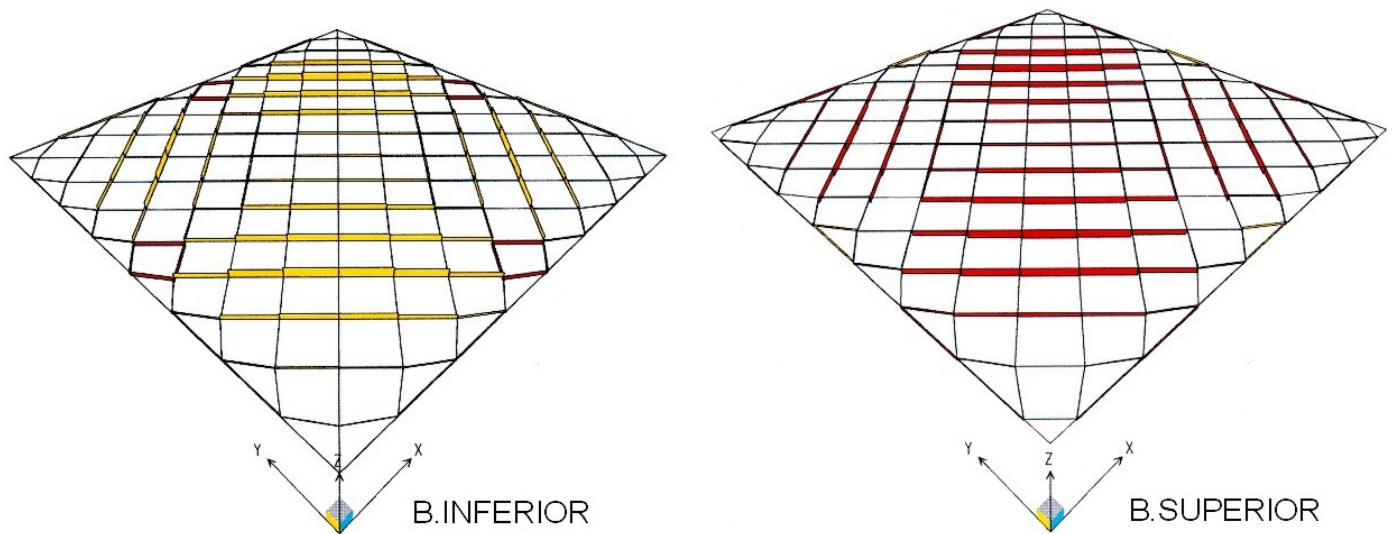

Figura 4.15 - Diagramas de esforços normais - Arranjo 5B

Combinação PPSC (amarelo: tração e vermelho: compressão)

- Arranjos estruturais 6A, 6B e 6C:

- Banzo inferior: barras comprimidas ligadas aos nós que recebem as diagonais dos apoios tipo "pé-de-galinha", diagonais ao contorno (Fig. 4.16);

- Diagonais: diagonais comprimidas ligadas aos pilares intermediários, formando os apoios tipo "pé-de-galinha";

- Banzo superior: barras comprimidas no meio do vão no alinhamento dos pilares intermediários, paralelas ao contorno (Fig. 4.16); 

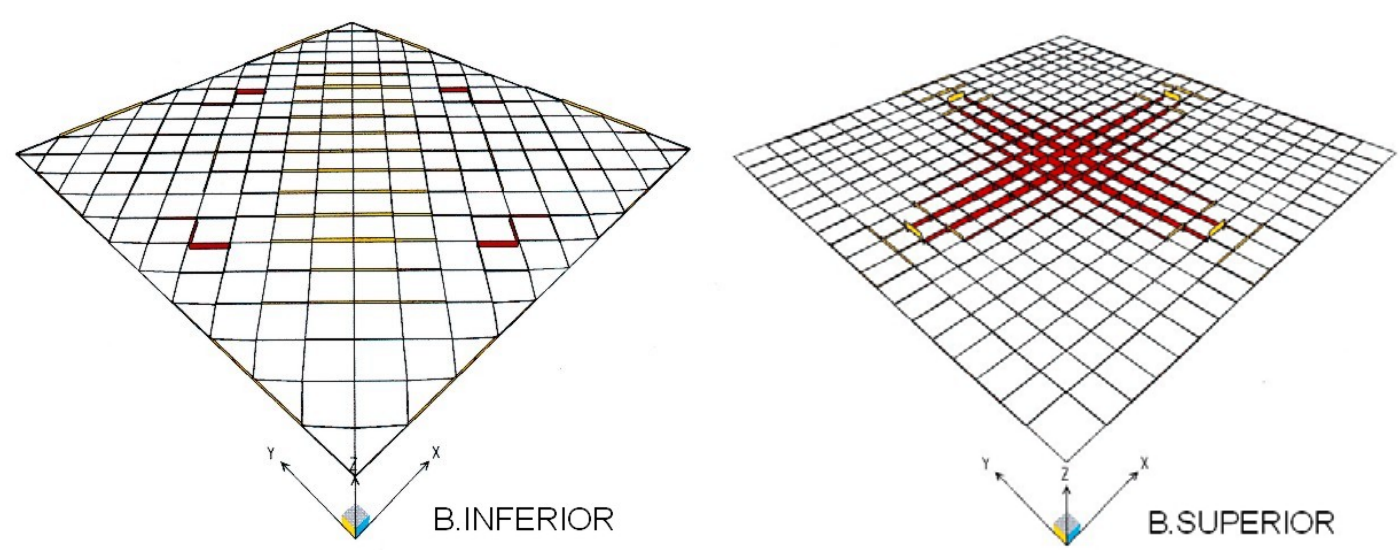

Figura 4.16 - Diagramas de esforços normais - Arranjo 6B Combinação PPSC (amarelo: tração e vermelho: compressão)

- Arranjos estruturais 7A, 7B, 7C e 7D:

- Banzo inferior - BN1: barras tracionadas no meio do vão e barras comprimidas ligadas aos pilares, ambas no alinhamento dos pilares, paralelas ao contorno (Figura 4.17);

- Diagonais D12: barras comprimidas ligadas aos pilares (Figura 4.17);

- Banzo intermediário - BN2:

- Modelos M7A e M7B: barras tracionadas no meio do vão no alinhamento dos pilares, paralelas ao contorno;

- Modelos M7C e M7D: barras tracionadas ligadas aos pilares (Figura 4.17);

- Diagonais D23: barras comprimidas ligadas às diagonais D12;

- Banzo superior - BN3: barras comprimidas do meio do vão no alinhamento dos pilares e na região central dos arranjos (Figura 4.17); 


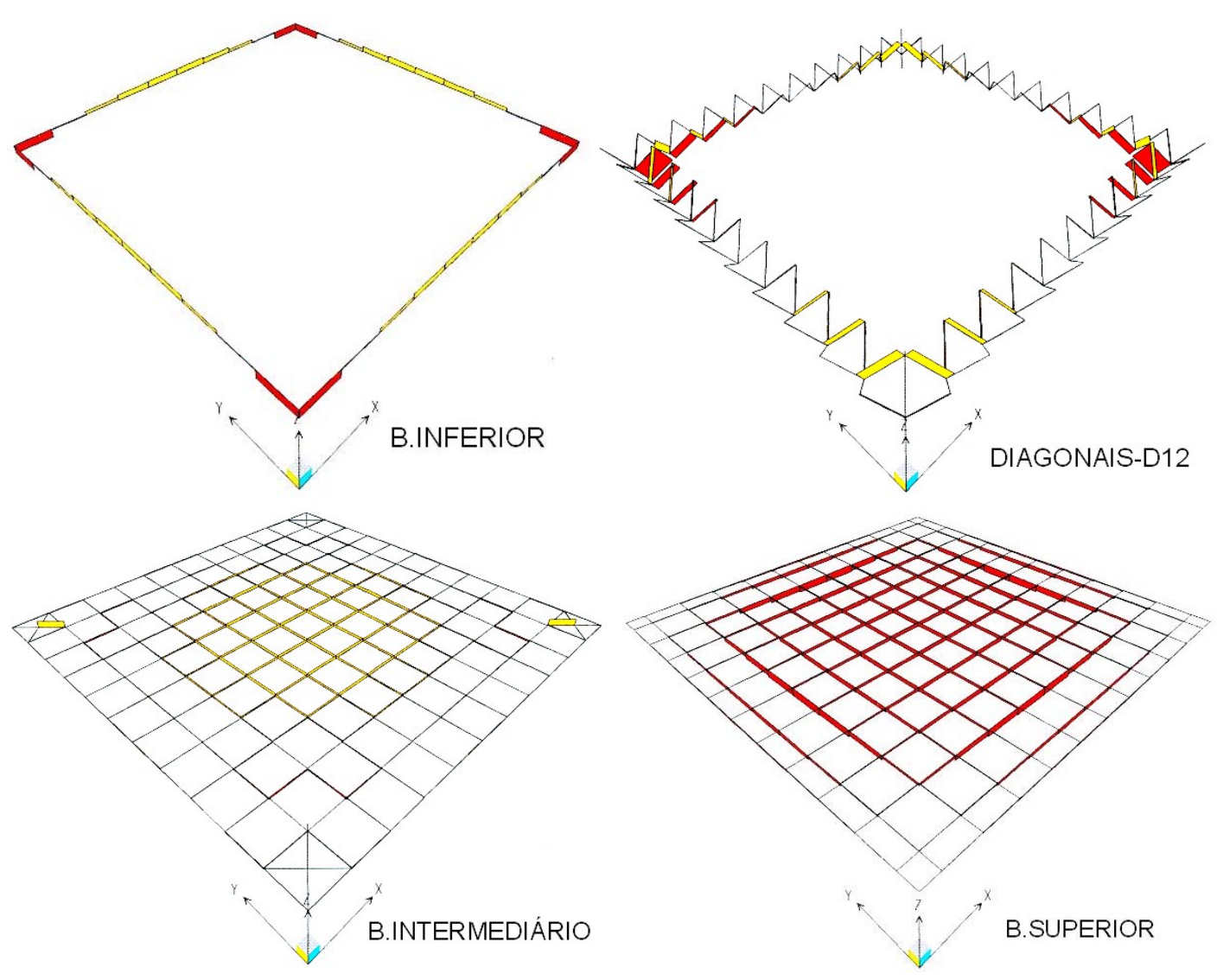

Figura 4.17 - Diagramas de esforços normais - Arranjo 7D

Combinação PPSC (amarelo: tração e vermelho: compressão)

- Arranjos estruturais 8A, 8B, 8C e 8D:

- Banzo superior - BN1: barras tracionadas no meio do vão no alinhamento dos pilares, paralelas ao contorno;

- Diagonais D12: barras comprimidas ligadas aos pilares;

- Banzo intermediário - BN2: barras tracionadas próximas aos pilares;

- Diagonais D23: barras comprimidas ligadas às diagonais D12;

- Banzo superior - BN3: barras comprimidas no meio do vão no alinhamento dos pilares, paralelas ao contorno; 
- Arranjos estruturais 9A, 9B, 9C, 10A, 10B e 10C:

- Banzo inferior: barras tracionadas no meio do vão no alinhamento dos pilares intermediários e barras comprimidas ligadas aos pilares intermediários na direção longitudinal dos arranjos (Fig. 4.18);

- Diagonais: barras comprimidas ligadas aos pilares intermediários;

- Banzo superior: barras comprimidas no meio do vão no alinhamento dos pilares intermediários e barras tracionadas sobre os pilares intermediários na direção longitudinal dos arranjos (Fig. 4.18);
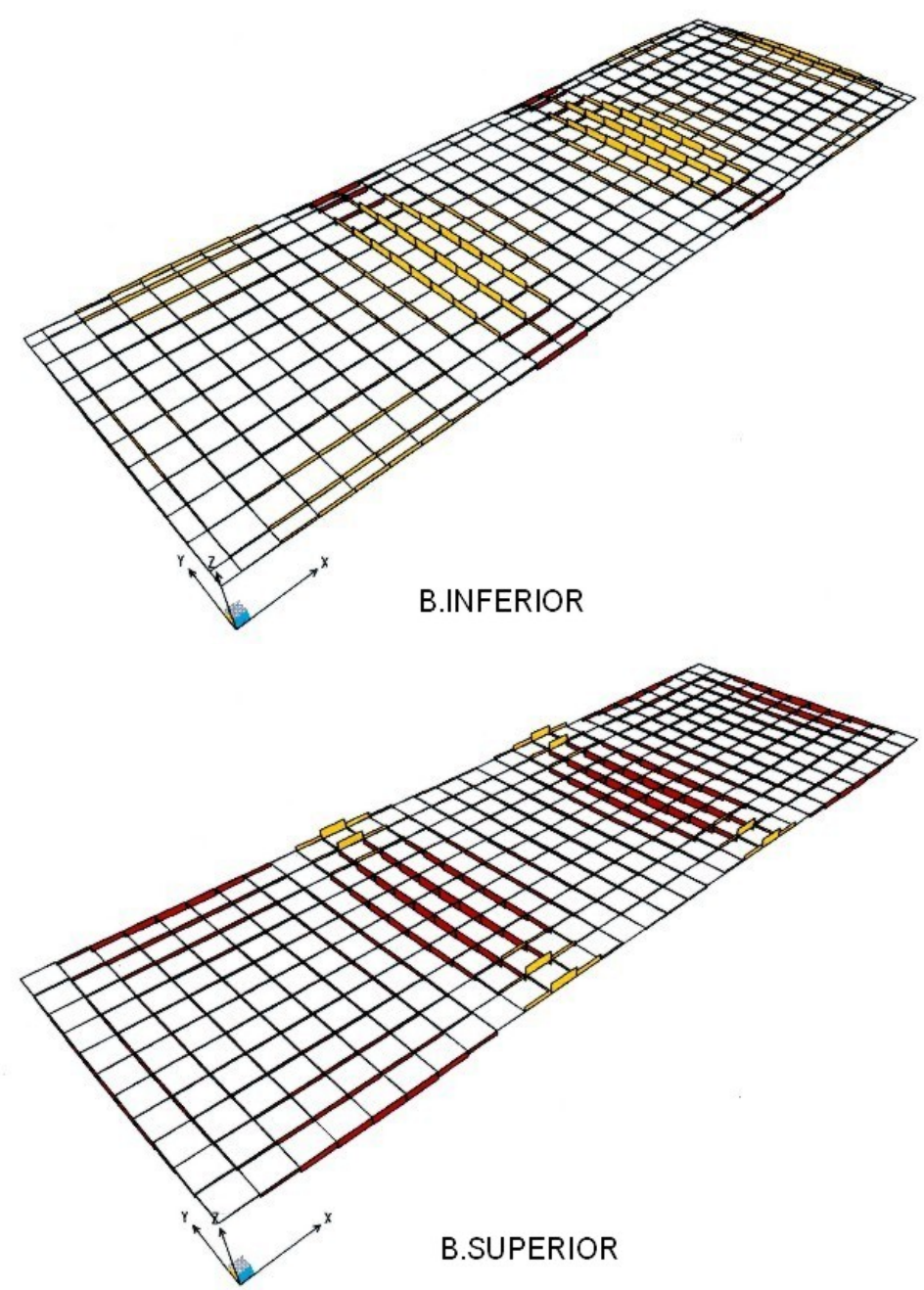

Figura 4.18 - Diagramas de esforços normais - Arranjo 9B Combinação PPSC (amarelo: tração e vermelho: compressão) 
As treliças espaciais de cobertura apresentam aspectos particulares de concepção de projeto. O arranjo tridimensional de barras, a elevada hiperestaticidade, os grandes vãos, e a complexidade das conexões são alguns dos fatores que tornam os projetos das estruturas espaciais diferenciados.

Os sistemas de conexões exercem grande influência na confiabilidade, no comportamento e no custo final da treliça espacial. Existem diversos sistemas de conexão, alguns de confiabilidade já consagrada, como o sistema MERO, e outros que necessitam de mais estudos devido às incertezas sobre o comportamento e a confiabilidade.

A maioria dos sistemas utilizados no Brasil emprega barras de seção tubular circular com as extremidades estampadas, tal como o sistema de "nó típico", muito utilizado devido ao baixo custo de fabricação e montagem. Porém, estes sistemas com barras de extremidades estampadas apresentam limitações estruturais, e vários estudos têm sido realizados no Departamento de Engenharia de Estruturas da EESC-USP para avaliação da eficiência desses tipos de conexão.

Para a análise estrutural das treliças espaciais, os projetistas têm utilizado o modelo teórico de treliça ideal em análise elástica linear (teoria de primeira ordem). Os nós são supostos perfeitamente articulados e as barras sem imperfeições ou variações de inércia. Porém, as imperfeições geométricas das barras, geradas na fabricação ou na montagem, e as 
particularidades ou deficiências dos sistemas de conexão, podem levar a uma distribuição de esforços que difere da ideal, levando algumas barras a receberem esforços superiores aos previstos. Além disso, alguns pesquisadores chamam a atenção para a necessidade de uma análise não linear para melhor avaliação do comportamento dessas estruturas.

A escolha do arranjo geométrico para uma treliça espacial de cobertura está muito ligada à quantidade e ao posicionamento dos apoios da edificação, além das técnicas disponíveis de fabricação e montagem. $O$ arranjo geométrico do reticulado determina a quantidade de elementos a serem fabricados e montados, o consumo de material, os deslocamentos da estrutura, as reações de apoio e a distribuição de esforços na estrutura.

No Brasil, a grande maioria das treliças espaciais de cobertura utiliza arranjos geométricos do tipo quadrado sobre quadrado com defasagem de meio módulo. Geralmente, a altura da treliça varia de vão/10 a vão/20, e a dimensão do módulo é tal que resulta em ângulos para as diagonais em torno de $45^{\circ}$ em relação ao plano horizontal. A predominância da utilização deste tipo de reticulado, deve-se a padrões e conceitos já estabelecidos de arquitetura, análise estrutural, detalhamento, fabricação e montagem. Para determinadas situações outros tipos de arranjos podem ser mais eficientes, tanto do ponto de vista estrutural como do ponto de vista econômico.

Foi realizada uma análise numérica com 33 arranjos geométricos diferentes de treliças espaciais planas de cobertura, com vãos internos de $60 \mathrm{~m}$. Estes arranjos geométricos apresentavam variações na quantidade e posicionamento dos apoios, na disposição das barras do reticulado, na altura da treliça e nas dimensões dos módulos.

O fator que causou maior influência no comportamento das treliças espaciais analisadas foi a disposição dos apoios. Os arranjos com planta quadrada e pilares no contorno a cada $30 \mathrm{~m}$ apresentaram consumo de material variando de $48 \%$ a $60 \%$ do consumo de material dos arranjos com planta quadrada e pilares no contorno a cada $60 \mathrm{~m}$. Os deslocamentos máximos e os esforços máximos de tração e compressão nos banzos, também apresentaram redução significativa com o aumento da quantidade 
de pilares, superior a $40 \%$ para os deslocamentos e superior a $60 \%$ para os esforços máximos. Para os arranjos com planta retangular também ocorreu redução no consumo de material, cerca de $25 \%$, e nos deslocamentos máximos, cerca de $30 \%$, com o aumento da quantidade de pilares no contorno.

Os três tipos de disposição de barras nos reticulados analisados, quadrado sobre quadrado, quadrado diagonal sobre quadrado diagonal e quadrado reduzido sobre quadrado diagonal, apresentaram resultados próximos em relação ao consumo de material, aos deslocamentos máximos, às reações de apoio máximas e aos esforços máximos. Os reticulados quadrado reduzido sobre quadrado diagonal apresentaram consumo de material um pouco inferior ao consumo dos outros reticulados. Os reticulados quadrado sobre quadrado apresentaram os menores deslocamentos máximos para pilares no contorno a cada $60 \mathrm{~m}$ e os maiores para pilares a cada $30 \mathrm{~m}$.

As alturas das treliças influenciaram todos os aspectos analisados, principalmente para pilares no contorno a cada $60 \mathrm{~m}$. De maneira geral, os melhores resultados foram obtidos para as treliças de maior altura (vão/13). Porém, as maiores alturas também causaram maiores reações de apoio horizontais e momentos fletores nas bases dos pilares, devido ao aumento da área lateral sujeita à ação do vento.

A utilização de três camadas de banzos apenas no alinhamento dos apoios, formando uma "viga de enrijecimento", provocou uma redução de cerca de $12 \%$ no consumo de material e $30 \%$ nos deslocamentos máximos, quando comparados com os arranjos de duas camadas de banzo. Porém, as reações de apoio horizontais e de momentos fletores, para os arranjos com "viga de enrijecimento", foram muito superiores aos dos outros arranjos. Estas reações de apoio foram reduzidas com a utilização de apoios do tipo "engaste".

Os arranjos com três camadas completas de banzo apresentaram uma quantidade de elementos cerca de cinco vezes maior que os arranjos com duas camadas. Além disso, a utilização das três camadas completas 
apenas mostrou bons resultados para alturas elevadas de treliça, no caso, superiores a vão/10.

A continuidade existente nos arranjos com planta retangular, causou uma redução no consumo de material superior a $12 \%$, em relação aos arranjos com planta quadrada. Já os deslocamentos máximos sofreram uma redução que variou de $5 \%$ a $10 \%$, e os esforços máximos de tração e compressão sofreram alterações mínimas.

Devido a grande quantidade de variáveis envolvidas nos projetos das treliças espaciais, torna-se difícil generalizar procedimentos de concepção estrutural através dos resultados obtidos neste trabalho. Porém, com os resultados aqui obtidos, tem-se diretrizes para concepção de projetos de treliças espaciais de cobertura com plantas arquitetônicas semelhantes às analisadas.

Em continuidade a esse trabalho, sugere-se a análise de uma maior variedade de arranjos, com diferentes plantas e disposições de apoios, o que contribuirá muito para aumentar 0 conhecimento sobre 0 comportamento das treliças espaciais e auxiliar projetistas e fabricantes na concepção destas estruturas especiais. 


\section{REFERÊNCIAS BIBLIOGRÁFICAS}

AFFAN, A.; CALLADINE, C.R. (1986). Structural mechanics of double-layer space grids. In: IASS SYMPOSIUM ON SHELLS, MEMBRANES AND SPACE FRAMES, Osaka, v.3, p.41-48.

AGERSKOV, H. (1986). Optimum geometry design of double-layer space structure. Journal of Structural Engineering, v. 112, n.6, p.1454-1463.

AMERICAN INSTITUTE OF STEEL CONSTRUCTION (1989). ASD Allowable Stress Design (Ninth Edition). AISC, Chicago.

AMERICAN INSTITUTE OF STEEL CONSTRUCTION (2001). LRFD - Load and Resistance Factor Design (Third Edition). AISC, Chicago.

AMERICAN IRON AND STEEL INSTITUTE (1996). LRFD - Load and resistance factor design specification for cold-formed steel manual. Washington, DC.

AMERICAN SOCIETY OF CIVIL ENGINEERS (1972). Bibliography on latticed structures. Journal of the Structural Division, v.98, n.7, p.15451566.

AMERICAN SOCIETY OF CIVIL ENGINEERS (1976). Latticed structures: state-of-the-art report. Journal of the Structural Division, v.102, n.11, p.2197-2230.

ASSOCIAÇÃO BRASILEIRA DE NORMAS TÉCNICAS (1988). NBR 6123 Forças Devidas ao Vento em Edificações: Procedimento. Rio de Janeiro. 
ASSOCIAÇÃO BRASILEIRA DE NORMAS TÉCNICAS (1986). NBR 8800 Projeto e Execução de Estruturas de Aço de Edifícios: Método dos Estados Limites. Rio de Janeiro.

BALUT, N.; GIONCU, V. (2000). The influence of geometrical tolerances on the behaviour of space structures. International Journal of Space Structures, v.15, n.3\&4, p.189-194.

BUTTERWORTH, J.W. (1981). Analysis of double-layer grids. In: MAKOWSKI, Z.S., ed. Analysis, design and construction of Doublelayer grids, Applied Science, p.57-91.

CHAPMAN, J.C.; BUHAGIER, D.; DOWLING, P.J. (1993). Developments in cold-formed space structures. In: INTERNATIONAL CONFERENCE ON SPACE STRUCTURES, 4, Guildford, UK, 1993, London, Thomas Telford, v.2, p.1604-1612.

CODD, E.T. (1984). Low technology space frames. In: INTERNATIONAL CONFERENCE ON SPACE STRUCTURES, 3, Guildford, UK, 1984, London/New York, Elsevier Applied Science, p.955-960.

CROOKER, J.; BUCHERT, K. (1970). Reticulated space structures. Journal of the Structural Division, v.96, n.ST3, p.687-700.

DEHDASHTI, G.; SCHMIDT, L.C. (1995). Barrel-vault space trusses shaped by posttensioning. Journal of the Structural Engineering, v.121, n.12, p.1758-1764.

D'ESTE, A.V. (1998). Comportamento de estruturas espaciais tubulares padronizadas. Rio de Janeiro. Dissertação (Mestrado) - Pontifícia Universidade Católica do Rio de Janeiro. 
DU CHATEAU, S. (1984). Structures spatiales. In: INTERNATIONAL CONFERENCE ON SPACE STRUCTURES, 3, Guildford, UK, 1984, London/New York, Elsevier Applied Science, p.1058-1067.

EL-SHEIKH, A.I.; EL-BAKRY, H. (1996). Experimental study of behaviour of new space truss system. Journal of Structural Engineering, v.122, n.8, p.845-853.

EL-SHEIKH, A.I. (1996). Development of a new space truss system. Journal of Constructional Steel Research, v.37, n.3 , p.205-227.

EL-SHEIKH, A.I. (1999). Design of web members in space trusses. International Journal of Space Structures, v.14, n.1, p.25-34.

FLOWER, W.; SCHMIDT, L.C. (1971). Analysis of space truss as equivalent plate. Journal of the Structural Division, v.97, n.12, p.2777-2789

HANAOR, A.; MARSH, C.; PARKE, G.A.R. (1989). Modification of behavior of double-layer grids: overview. Journal of the Structural Engineering, v.115, n.5, p.1021-1037.

HILL, C.D.; BLANDFORD, G.E.; WANG, S.T. (1989). Post-buckling analysis of steel space trusses. Journal of the Structural Engineering, v.115, n.4, p.900-919.

IFFLAND, J. (1982). Preliminary planning of steel roof space trusses. Journal of the Structural Division, v.108, n.11, p.2578-2589.

JOGLEKAR, S.G.; KHANRA, K.K.; NAVANI, K.P.; DADLANI, N.S. (1999). Long span space frame hangar with suspended docking system and cranes for heavy maintenance of 747-400 aircraft for Air India at 
Mumbai, India. International Journal of Space Structures, v.14, n.3, p.197-209.

KOO, B. (1984). Analysis of compression members in spatial roof structures. In: INTERNATIONAL CONFERENCE ON SPACE STRUCTURES, 3, Guildford, UK, 1984, London/New York, Elsevier Applied Science, p.442-445.

LAN, T.T. (1994). Structural failure and quality assurance of space frames. In: IASS-ASCE INTERNATIONAL SYMPOSIUM ON SPATIAL, LATTICE AND TENSION STRUCTURES, Atlanta, USA, 1994, p.123132.

LAN, T.T.; QIAN, R. (1986). A study on the optimum design of space trusses - optimal geometrical configuration and selection of type. In: IASS SYMPOSIUM ON SHELLS, MEMBRANES AND SPACE FRAMES, Osaka, v.3, p.191-198.

LANDOLFO, R.; MAZZOLANI, F. (1993). Qualification analysis of a new structural system. In: INTERNATIONAL CONFERENCE ON SPACE STRUCTURES, 4, Guildford, UK, 1993, London, Thomas Telford.

MADI, U.R. ; EL-TAYEM, A. (1991). On the effective length of compression members in double-layer grids. International Journal of Space Structures, v.6, n.1, p.33-39.

MADI, U.R. ; EL-TAYEM, A. (1993). Collapse patterns for double-layer grids. In: INTERNATIONAL CONFERENCE ON SPACE STRUCTURES, 4, Guildford, UK, 1993, London, Thomas Telford, v.1, p.631-639. 
MAGALHÃES, J.R.M. (1996). Sobre o projeto e a construção de estruturas metálicas espaciais. São Carlos. Dissertação (Mestrado) - Escola de Engenharia de São Carlos, Universidade de São Paulo.

MAIOLA, C. H. (1999). Análise teórica e experimental de treliças espaciais constituídas por barras com extremidades estampadas. São Carlos. Dissertação (Mestrado) - Escola de Engenharia de São Carlos, Universidade de São Paulo.

MAKOWSKI, Z.S. (1984). Space structures of today and tomorrow. In: INTERNATIONAL CONFERENCE ON SPACE STRUCTURES, 3, Guildford, UK, 1984, London/New York, Elsevier Applied Science, p.18.

MAKOWSKI, Z.S. (1987). A worldwide review of space structures in sports buildings. In: INTERNATINAL COLLOQUIUM ON SPACE STRUCTURES FOR SPORTS BUILDINGS, Beijing, 1987, London, Elsevier Applied Publishers.

MAKOWSKI, Z.S. (1993). Space structures - a review of the developments within the last decade. In: INTERNATIONAL CONFERENCE ON SPACE STRUCTURES, 4, Guildford, UK, 1993, London, Thomas Telford, p.1623-1630.

MALLA, R.B.; SERRETTE, R.L. (1996a). Double-layer grids: review of static and thermal analysis methods and special topics. Journal of the Structural Engineering, v.122, n.8, p.873-881.

MALLA, R.B.; SERRETTE, R.L. (1996b). Double-layer grids: review of dynamic analysis methods and special topics. Journal of the Structural Engineering, v.122, n.8, p.882-889. 
MALITE, M.; et al. (1997). Barras de aço comprimidas de seção tubular com extremidades estampadas - análise teórica e experimental. In: JORNADAS SUDAMERICANAS DE INGENIERIA ESTRUCTURAL, 28, São Carlos, Brasil, 1997, v.1, p.417-426.

MALITE, M.; et al. (1998). Space structures in brazil. In: WORLD CONFERENCE ON STEEL IN CONSTRUCTION, 2, San Sebastian, Spain, 1998, Oxford, Elsevier Science.

MALITE, M.; et al. (2001). Experimental Analysis of the Structural Performance of Space Trusses Commonly Used in Brazil. International Journal of Space Structures, v.16, n. 4, p.253-260.

MARSH, C. (1986). Improving space truss performance by member removal. In: IASS SYMPOSIUM ON SHELLS, MEMBRANES AND SPACE FRAMES, Osaka, v.3, p.215-220.

MARSH, C. (2000). Some observations on designing double layer grids. International Journal of Space Structures, v.15, n.3\&4, p.225-231.

MURTHA-SMITH, E. (1988). Alternate path analysis of space trusses for progressive colapse. Journal of Structural Engineering, v.114, n.9, p.1978-1999.

MURTHA-SMITH, E.; LEARY, S.F. (1993). Space truss structural integrity. In: INTERNATIONAL CONFERENCE ON SPACE STRUCTURES, 4, Guildford, UK, 1993, London, Thomas Telford, v.1, p.640-648.

MURTHA-SMITH, E. (1994). Compression-member models for space trusses: review. Journal of Structural Engineering, v.120, n.8, p.23992407. 
OLIVEIRA, N.C.; et al. (1969). Estrutura de alumínio: Pavilhão de Exposições terá a maior estrutura de alumínio do mundo. O Dirigente Construtor, v.5, n.9, p.31-36.

SCHMIDT, L.C. ; MORGAN, P.R. (1982). Ultimate load of testing of space trusses. Journal of the Structural Division, v.118, n.6, p.1324-1335.

SCHMIDT, L.C. ; HANAOR, A. (1979). Force limiting device in space trusses. Journal of the Structural Division, v.105, n.5, p.939-951.

SCHMIDT, L.C. (2000). Some design aspects peculiar to space trusses. International Journal of Space Structures, v.15, n.3\&4, p.215-223.

SHU-T'IEN LI, F. (1962). Metallic dome-structures systems. Journal of the Structural Division, v.88, n.6, p.201-226.

SHUTUN, L. (1999). Design and construction of 306m span hangar roof at Capital Airport. International Journal of Space Structures, v.14, n.3, p.185-190.

SMITH, E.A. (1984). Space truss nonlinear analysis. Journal of Structural Engineering, v.110, n.4, p.688-705.

SOUZA, A.S.C. (1998). Contribuição ao estudo das estruturas metálicas espaciais. São Carlos. Dissertação (Mestrado) - Escola de Engenharia de São Carlos, Universidade de São Paulo.

VENDRAME. M.A. (1999). Contribuição ao estudo das cúpulas treliçadas utilizando elementos tubulares em aço. São Carlos. Dissertação (Mestrado) - Escola de Engenharia de São Carlos, Universidade de São Paulo. 